Prepared for the U.S. Department of Energy

Under Contract DE-AC05-76RL01830

\title{
Model Documentation for the MiniCAM
}

AL Brenkert

AJ Smith
SH Kim

HM Pitcher

July 2003

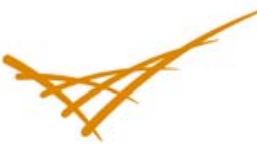

Pacific Northwest

NATIONAL LABORATORY 


\title{
DISCLAIMER
}

This report was prepared as an account of work sponsored by an agency of the United States Government. Neither the United States Government nor any agency thereof, nor Battelle Memorial Institute, nor any of their employees, makes any warranty, express or implied, or assumes any legal liability or responsibility for the accuracy, completeness, or usefulness of any information, apparatus, product, or process disclosed, or represents that its use would not infringe privately owned rights. Reference herein to any specific commercial product, process, or service by trade name, trademark, manufacturer, or otherwise does not necessarily constitute or imply its endorsement, recommendation, or favoring by the United States Government or any agency thereof, or Battelle Memorial Institute. The views and opinions of authors expressed herein do not necessarily state or reflect those of the United States Government or any agency thereof.

\author{
PACIFIC NORTHWEST NATIONAL LABORATORY \\ operated by \\ BATTELLE \\ for the \\ UNITED STATES DEPARTMENT OF ENERGY \\ under Contract DE-AC05-76RL01830
}

Printed in the United States of America
Available to DOE and DOE contractors from the Office of Scientific and Technical Information,
P.O. Box 62, Oak Ridge, TN 37831-0062;
ph: (865) 576-8401
fax: $(865)$ 576-5728
email: reports@adonis.osti.gov

\begin{abstract}
Available to the public from the National Technical Information Service, U.S. Department of Commerce, 5285 Port Royal Rd., Springfield, VA 22161 ph: (800) 553-6847 fax: $(703) 605-6900$ email: orders@ntis.fedworld.gov online ordering: http://www.ntis.gov/ordering.htm
\end{abstract}

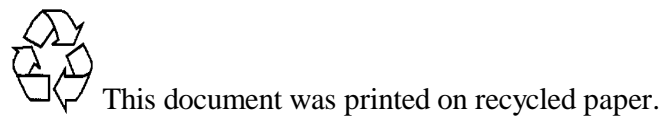


PNNL-14337

\section{Model Documentation for the MiniCAM}
AL Brenkert
SH Kim
AJ Smith
HM Pitcher

July 2003

Prepared for the United States Environmental Protection Agency under Contracts AGRDW89939464-01 and AGRDW89939645-01

for the U.S. Department of Energy

under Contract DE-AC05-76RL01830

Pacific Northwest National Laboratory

Richland, Washington 99352 


\section{Acknowledgments}

We want to thank Elizabeth L. Malone for steadfast support.

We want to thank Marshall Wise for his review.

We want to thank the Environmental Protection Agency's Clean Air Markets Division

(Office of Atmospheric Programs) for making this documentation become reality. 


\section{Summary}

The MiniCAM, short for the Mini-Climate Assessment Model, is an integrated assessment model of moderate complexity focused on energy and agriculture sectors. The model produces emissions of greenhouse gases (carbon dioxide, methane and nitrous oxide) and other radiatively important substances such as sulfur dioxide. Through incorporation of the simple climate model MAGICC, the consequences of these emissions for climate change and sea-level rise can be examined. The MiniCAM is designed to be fast and flexible.

The MiniCAM is a long-term, partial-equilibrium model designed to examine long-term, largescale changes in global and regional energy system where the characteristics of existing capital stocks are not the dominant factor in determining the dynamics of the energy system. Markets are defined for oil (conventional and unconventional), gas, coal, biomass, carbon, and agricultural products. The MiniCAM has no markets for labor and capital. It is specifically designed to address issues associated with global change, including (1) projecting baseline carbon dioxide emissions over time for a country or group of countries; (2) projecting various other radiatively important gases (e.g., methane, nitrous oxide, sulfur dioxide, reactive gases); (3) evaluating the energy-system, emissions, and other consequences of various technological options; (4) evaluating some aspects of potential climate change, e.g., temperature change, sea-level rise; (5) providing a measure of the carbon price, in dollars per metric ton for an emissions target; and (6) providing a measure of the overall cost of meeting an emissions target.

The MiniCAM model can be conceptualized as consisting of four modules (see Figure below).

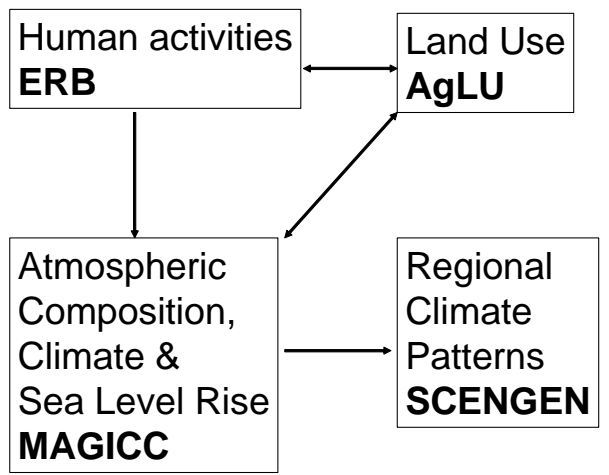

These modules can be described as simulating

- energy supply and demand using an updated version of the Edmonds-Reilly-Barnes model (ERB) (Edmonds and Reilly 1985; Edmonds, Reilly, Gardner and Brenkert 1986; Edmonds, Wise, Pitcher, Wigley and MacCracken 1997);

- agriculture and land-use using the Agriculture and Land Use model (AgLU) (Edmonds et al. 1996; Sands and Leimbach 2001; Gillingham et al. 2002; Sands and Edmonds 2002);

- atmospheric composition and global-mean climate changes using the Model for the Assessment of Greenhouse-gas Induced Climate Change (MAGICC) (Hulme and Raper 1993; Wigley 1994a,b; Wigley and Raper 1987, 1992, 1993, 2001); and 
- regional patterns of climate change using the Regional Climate Change Scenario Generator (SCENGEN) (Hulme, Jiang, and Wigley 1995).

The MiniCAM projects economic activity, energy consumption, and emissions in 15-year time steps from 1990 through 2095. The MiniCAM has global coverage in the form of 14 distinct regions (United States, Canada, Western Europe, Japan, Australia \& New Zealand, Former Soviet Union, Eastern Europe, Latin America, Africa, Middle East, China [\& Asian Reforming Economies], India, South Korea, Rest of South \& East Asia).

The MiniCAM has a strong focus on energy supply technologies. A wide range of technologies, fuels, and energy carriers can be used to supply end-use energy demands. Transformation losses are accounted for throughout the supply system. Technologies include electricity generation (from coal, oil, gas, biomass, hydro power, fuel cells, nuclear energy, wind energy, solar PV, solar-wind storage, and space solar PV), hydrogen production (from coal, oil, gas, biomass, and electrolysis), synthetic fuel production (synthetic liquids from coal, gas, and biomass; synthetic gas from coal, and biomass), geologic carbon sequestration from fossil fuels (during electricity generation, hydrogen production, and synthetic fuel production). Biomass supply includes "waste" biomass streams and commercial biomass produced regionally by the AgLU module. End-use fuels include those currently in widespread use (coal, oil, gas, biomass, electricity), and future options such as synthetic liquids, synthetic gases and hydrogen. Carbon sequestration is an option for all conversion technologies, particularly electric generation and hydrogen production.

The MiniCAM contains a large set of parameters to simulate technical change over time. These parameters include the rate of change in efficiency of inputs to any particular production sector in the model (e.g., primary energy transformation to secondary energy; secondary energy transformation to tertiary energy). These rates of change in input efficiency can be varied at each 15 -year time step.

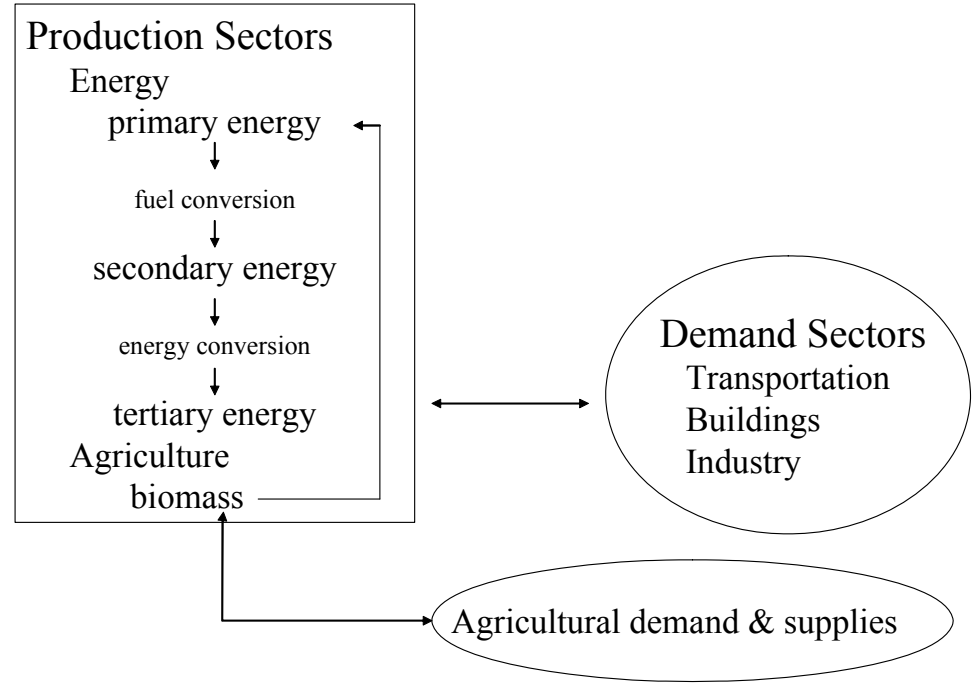

The conceptual framework of the ERB and AgLU modules is shown in the figure above. Each production process is represented by a fixed-coefficient (Leontief) production function requiring three parameters: fuel input, efficiency, and non-fuel costs. During the transformation processes 
from raw fuel to refined fuels and to fuels to be consumed by end-users, fuels compete based on their prices. This competition is simulated by means of a share equation (the logit share equation) which is based on fuel prices and their elasticities. The price of each of the fuels is assumed to fall within a fuel-price range based on the cost of fuel and various costs like transportation costs, taxes, non-fuel costs, and structural factors. This variance of each fuel price is captured in an energy price exponent or elasticity coefficient. Through the logit methodology all fuels that compete can contribute in the generation of the supply of a secondary fuel or an energy service, with shares changing in a smooth manner as prices or policies change with time.

The demand for energy is determined by regional population levels, levels of economic activity and the price of energy services. The demand by the end-use sectors for energy services is simulated as a demand for the least costly energy service fuel mode through a combination of the constant elasticity and logit share equations. The constant elasticity equation includes price elasticities and income elasticities.

End-use energy services can be supplied by refined fossil-fuels, biomass (traditional and from dedicated biomass farms), electricity, hydrogen, and synthetic fuels. The three end-use sectors are buildings, industry, and transportation.

Regional populations determine regional economic activity and end-use demands. Technological change impacts energy demand, while regional taxes and tariffs (and climate policies which influence the price of greenhouse gas emissions) determine regional energy prices, which affect, in turn, regional energy demands. Regional energy resources and prices determine regional energy supplies, which impact global supply and demand, which in turn affect world prices that feed back to the regional energy prices, which then impact regional supply and demands. Through this iterative process, global supply and demand of the primary fuels are balanced. Emissions are calculated simultaneously with the balancing process, so as to efficiently solve for any carbon constraint.

When equilibrium occurs, the markets are said to "clear." The mechanism for clearing the markets is through the solution algorithm, which adjusts market prices (e.g., primary fuel prices) until the excess demand - the difference between demand and supply - is less than the solution criteria, typically a small number (less than one but greater than zero).

The MiniCAM is most often used to examine one or more baseline (no climate policy) scenarios in combination with possible climate policies that are intended to alter the baseline emissions trajectory. In the present version of the MiniCAM, the SRES scenarios are generally used for analysis. In order to facilitate this analysis and make comparisons with other models, the MiniCAM is able to exactly calibrate to any specified scenario in terms of population, GDP, and/or final energy use. It is these parameters that are the primary determinants of energy demands in each region.

When a baseline scenario is generated, the function of the model in non-policy cases is to determine the least-cost method of supplying the energy services demanded. In a policy (i.e., GHG emissions control) case, GDP and energy are generally allowed to freely respond to any changes in energy prices. The model can then be used to determine the cost of meeting a specified policy goal. The change in the shares of energy technologies that occurs as a result of meeting some policy goal is also an important output of the model. 


\section{TABLE OF CONTENTS}

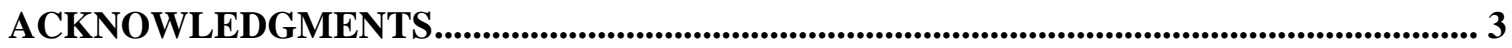

SUMMARY .............................................................................................................................................. 4

INTRODUCTION ................................................................................................................................ 11

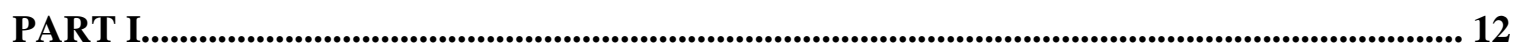

1. AN OVERVIEW OF THE MINICAM MODEL .................................................................... 12

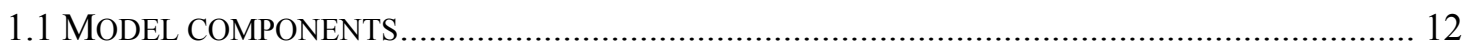

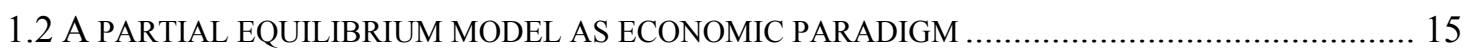

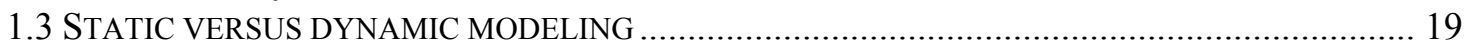

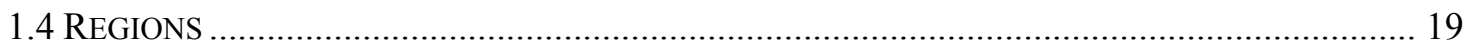

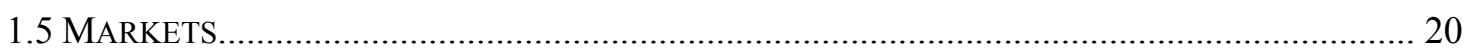

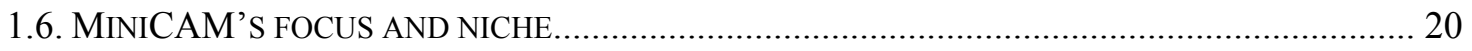

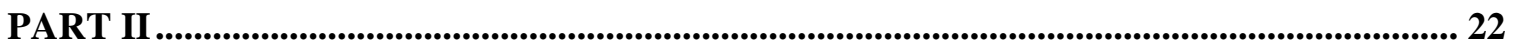

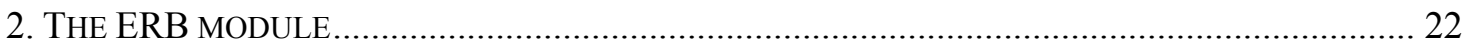

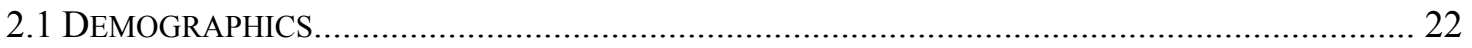

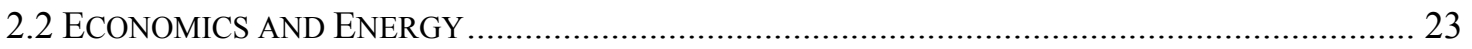

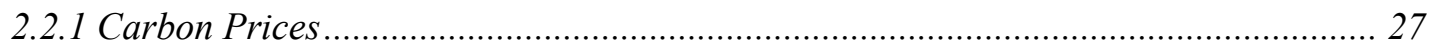

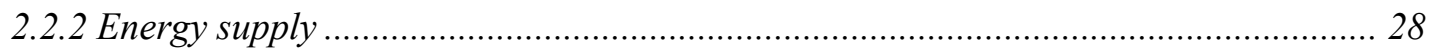

Supply (resources) of crude oil, natural gas, and coal and uranium............................... 29

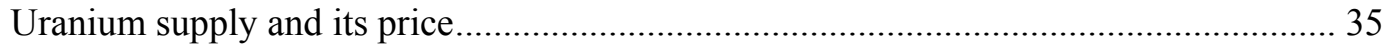

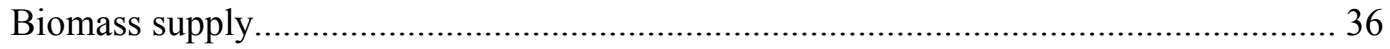

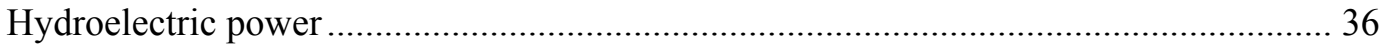

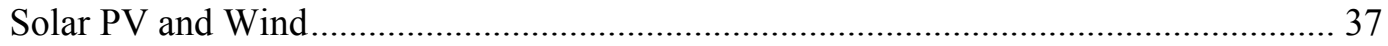

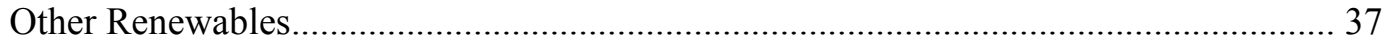

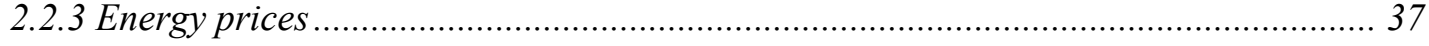

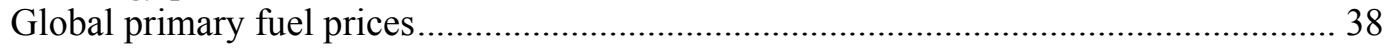

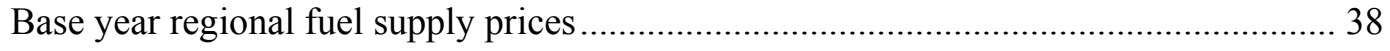

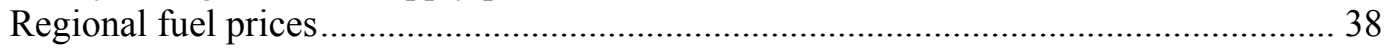

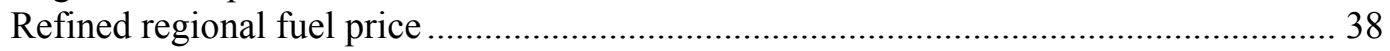

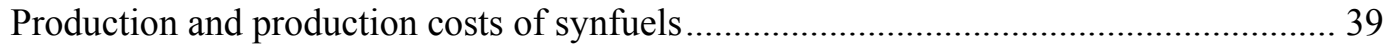

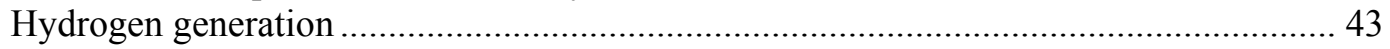

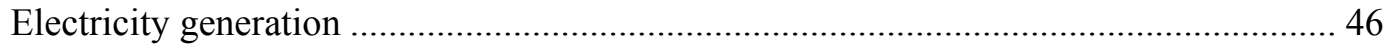

The costs of energy services in the form of fuel mode prices ......................................... 49

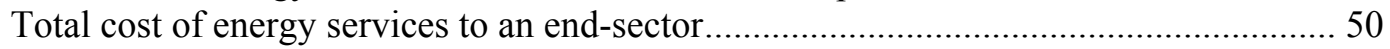

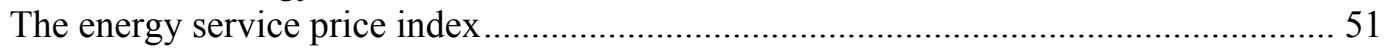

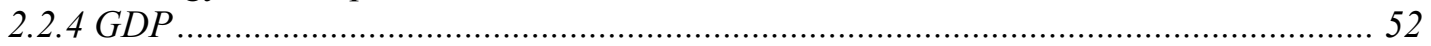

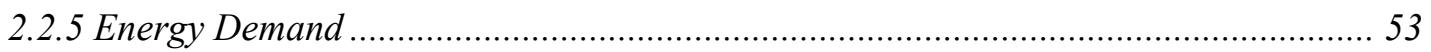

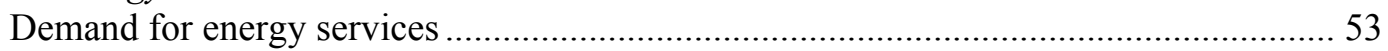

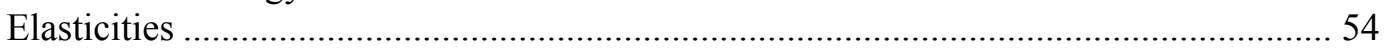

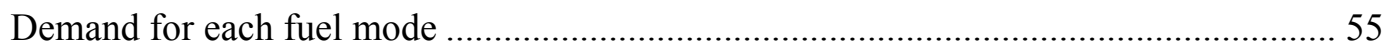

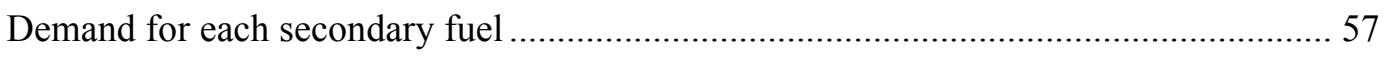

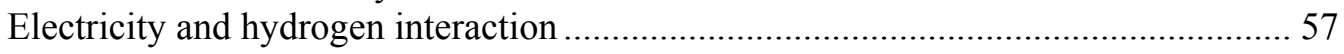

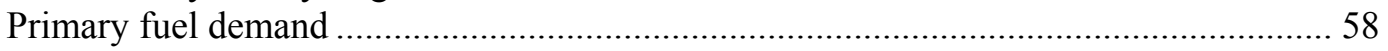

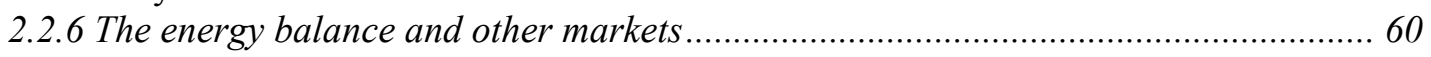

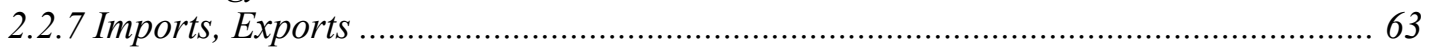




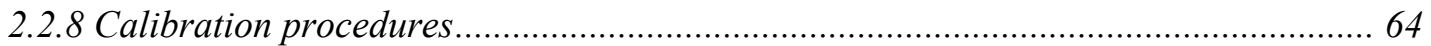

2.3 CALCUlating GREENHOUSE AND NON-GREENHOUSE GAS EMISSION................................ 65

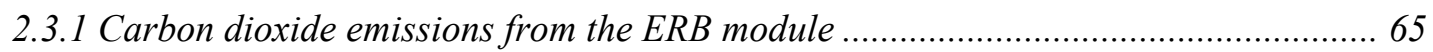

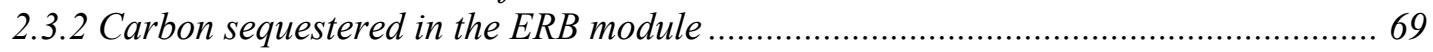

2.3.3 Non-CO $\mathrm{C}_{2}$ Greenhouse Gas and Reactive Gas Emissions from the ERB module ......... 70

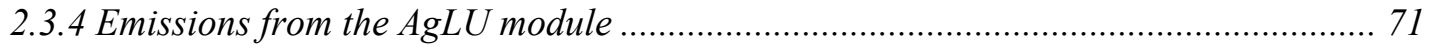

2.3.5 Non- $\mathrm{CO}_{2}$ greenhouse gas emissions from the $\mathrm{AgLU}$ module …............................... 72

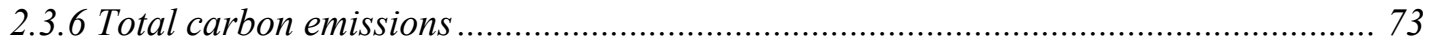

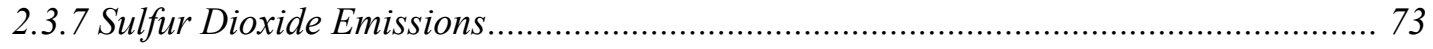

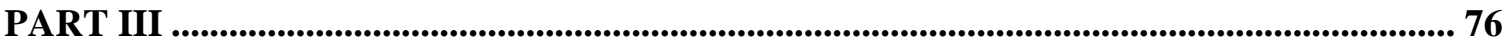

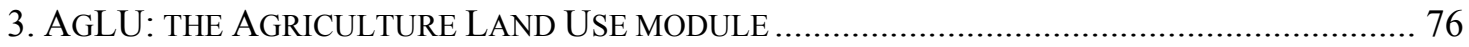

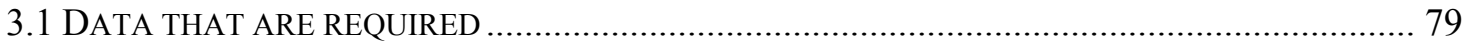

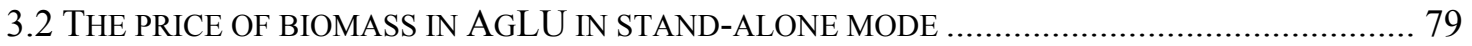

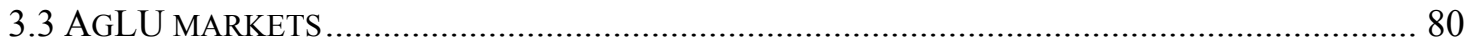

3.2.1 Demand

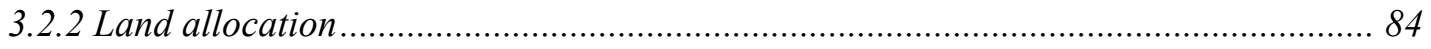

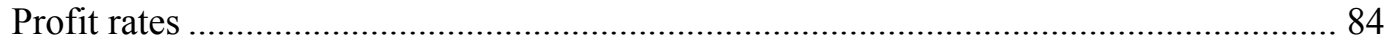

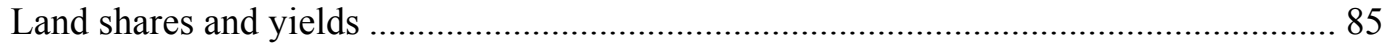

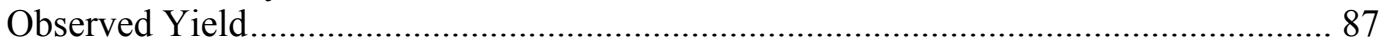

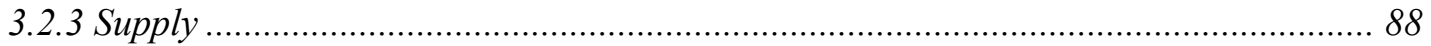

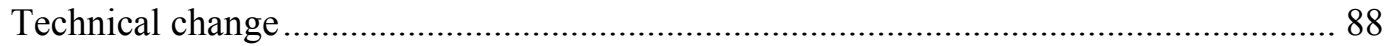

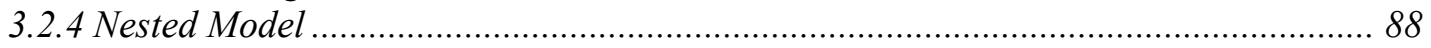

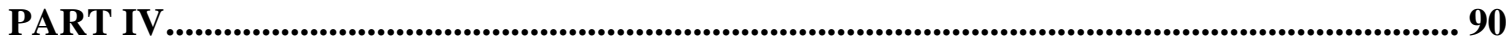

4. MAGICC: MODEL FOR THE ASSESSMENT OF GREENHOUSE-GAS INDUCED CLIMATE

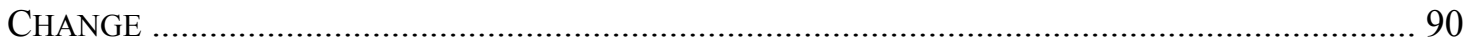

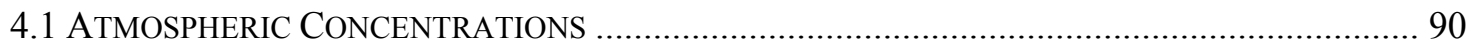

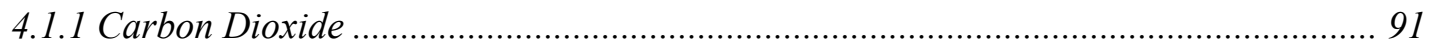

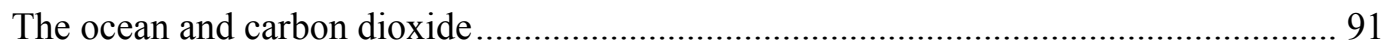

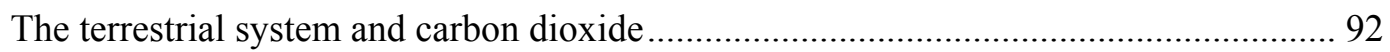

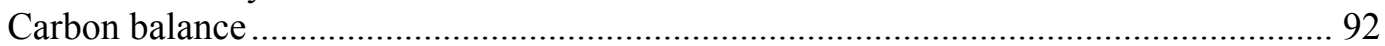

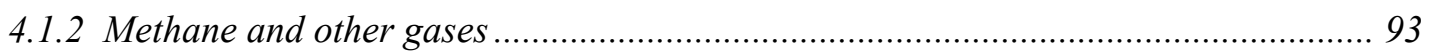

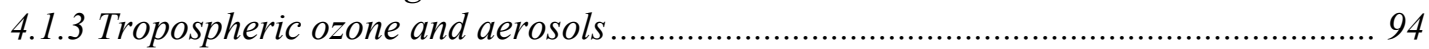

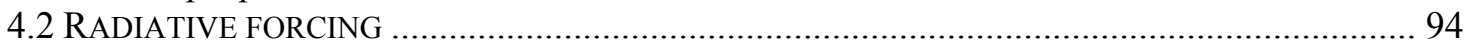

4.3 TEMPERATURE CHANGE: TERRESTRIAL, ATMOSPHERIC AND IN THE OCEAN ..................... 95

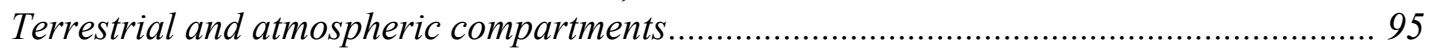

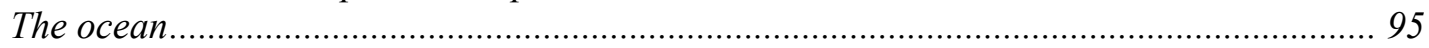

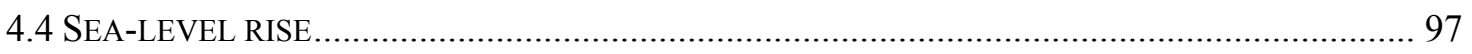

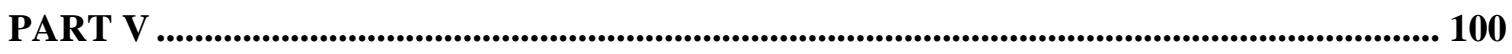

5. SCENGEN: REgIONAL CLIMATE CHANGE SCENARIO GENERATOR .................................. 100

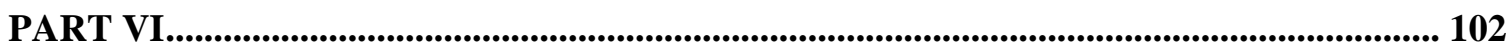

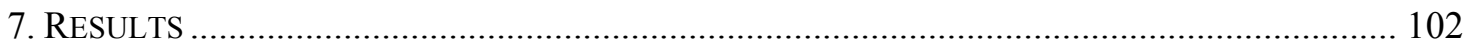

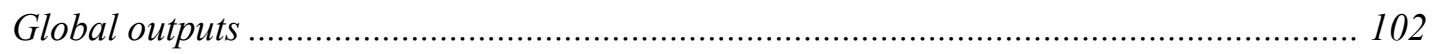

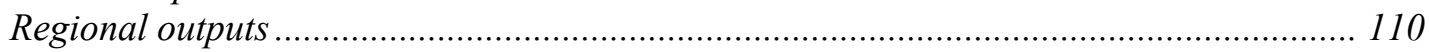

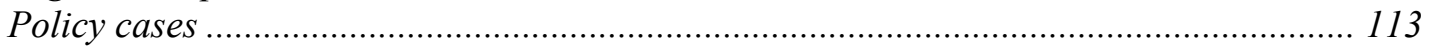

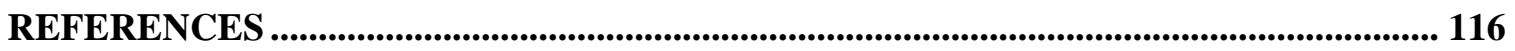




\section{TABLE OF FIGURES}

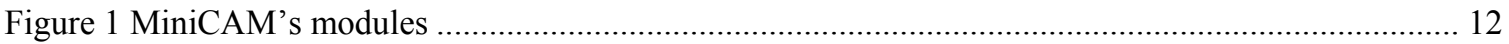

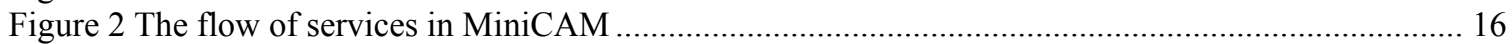

Figure 3 An energy-economics-emissions model (based on Edmonds and Reilly, 1985 p17 \& p247)........ 18

Figure 4 Energy flow processes in the ERB and AgLU modules of MiniCAM (Adapted from Edmonds and

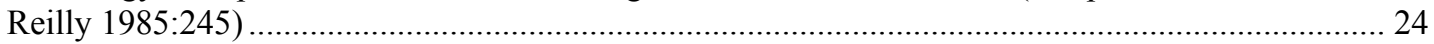

Figure 5 Schematic cost distributions for three different energy options (Adapted from............................. 26

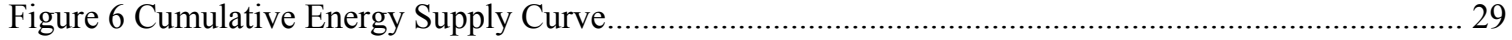

Figure 7 Nesting of cost calculations of hydrogen generation ............................................................... 45

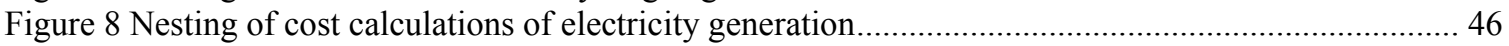

Figure 9 Cost curve example relating carbon prices to emission reductions ............................................ 71

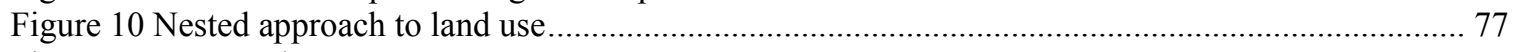

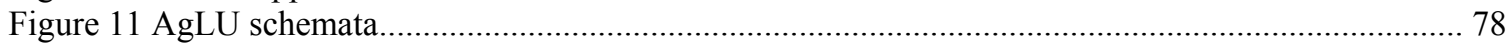

Figure 12 Food consumption in 11 regions in 1990 (from Sands and Leimbach 2001).............................. 82

Figure 13 Average incomes, globally, in the four SRES scenarios .........................................................103

Figure 14 Total global electricity generation in the four SRES scenarios showing divergence in the A1 scenario due to various assumptions with regard to fossil fuel use and technological change. ...........104

Figure 15 Average diets in the four SRES scenarios with divergence in the A1 scenario. .........................105

Figure 16 Global anthropogenic carbon-equivalent emissions in the four SRES scenarios ........................106

Figure 17 Carbon dioxide concentrations in the four SRES scenarios .....................................................106

Figure 18 Sulfur emissions in the four SRES scenarios with divergence in the A1 scenarios. ...................107

Figure 19 Nitrous oxide emissions in the four SRES scenarios with divergence in the A1 scenarios. .......108

Figure 20 Methane emissions in the four SRES scenarios with divergence in the A1 scenarios. ...............108

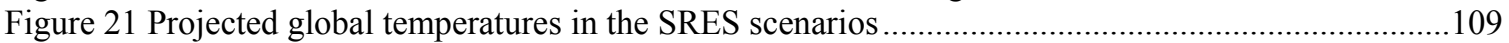

Figure 22 Projected sea-level rise in the SRES scenarios......................................................................109

Figure 23 Regional differences in income over time in IPCC's B2 scenario ............................................110

Figure 24 Regional differences in caloric intake in IPCC's B2 scenario ...............................................111

Figure 25 Regional differences in electricity consumption per capita in IPCC's B2 scenario .....................112

Figure 26 Regional differences in anthropogenic emissions in IPCC's B2 scenario..................................112

Figure 27 An example of anthropogenic carbon-equivalent emissions under carbon policy implementations

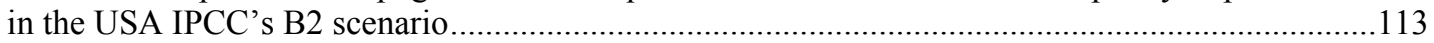

Figure 28 Carbon sequestered in the USA IPCC's B2 carbon policy scenarios........................................114

Figure 29 Sulfur emissions in the USA in IPCC's B2 carbon policy scenarios ........................................115

Figure 30 Carbon prices in the USA in IPCC's B2 carbon policy scenarios............................................115 


\section{TABLE OF TABLES}

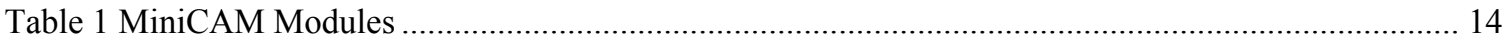

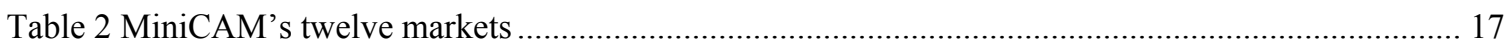

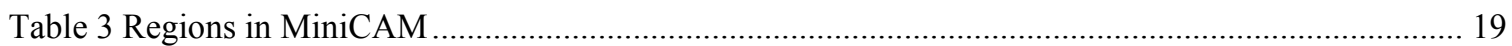

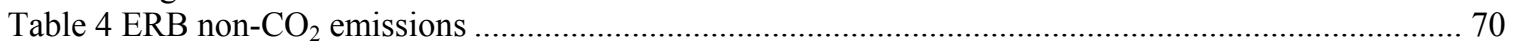

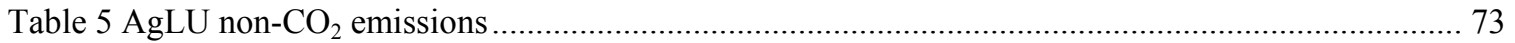

Table 6 FAO production and demand example (from Sands and Leimbach 2001)..................................... 83 


\section{Introduction}

This documentation consists of six parts. Part I provides for an overview of the MiniCAM model (the Mini-Climate Assessment Model), its model components, how the model solves for market prices of fossil fuels, biomass and carbon or carbon equivalents, its regional divisions and its niche in the energy and economics modeling context.

Part II describes the detailed processes of the energy and economics module, an updated Edmonds-Reilly-Barnes module (ERB) that calculates energy supply and demand and resulting emissions. Part III describes the processes simulated in agriculture and land-use using the Agriculture and Land Use model (AgLU). In the AgLU module the amount of land used for crops, animal grazing, forest products, and energy crops and the emissions associated with the production of food and fiber and with land-use changes is determined.

Part IV describes MAGICC (the Model for the Assessment of Greenhouse-gas induced climate change). This description contains less detail than the ERB and AgLU modules given that MAGICC was not developed at JGCRI and that its component parts are documented in numerous journal articles. Similarly, SCENGEN (the Regional Climate Change Scenario Generator) is described only in general terms in Part V for the same reasons. MAGICC calculates global aspects of climate change such as of atmospheric concentrations of greenhouse gases, radiative forcing, temperature, and sea-level rise, while SCENGEN simulates the regional pattern of climate change.

Part VI provides for data tables that support and illustrate the model processes described in Parts II and III. Part VII shows some results of model runs. Part VIII attempts to put both model results and modeling approach in perspective.

Part VI shows some results of model runs to illustrate the model processes described.

The Appendices provide for data tables and a table of the equations

Much of the MiniCAM, including updates to the ERB, and the AgLU module, and all non-CO2 emissions code is based on original work by the modeling team at the Joint Global Change Research Institute (JGCRI), a collaboration between Pacific Northwest National Laboratory and the University of Maryland, operated by Battelle. The MiniCAM is maintained and further developed at JGCRI. Verification of the MiniCAM's modules ERB and AgLU has been achieved through this documentation process. 


\section{PART I}

\section{An Overview of the MiniCAM Model}

\subsection{Model components}

The MiniCAM, short for the Mini-Climate Assessment Model, is a highly aggregated integrated assessment model that focuses on the world's energy and agriculture systems, atmospheric concentrations of greenhouse gases $\left(\mathrm{CO}_{2}\right.$ and non- $\left.\mathrm{CO}_{2}\right)$ and sulfur dioxide, and consequences regarding climate change and sea-level rise. It has been updated many times since the early Eighties to include additional technology options. The MiniCAM is capable of incorporating a shadow price for carbon and carbon constraints in conjunction with numerous technology options including carbon capture and sequestration. The model has been exercised extensively to explore how the technology gap can be filled between a business-as-usual emissions future and an atmospheric stabilization scenario.

The MiniCAM model is designed to assess various climate change policies and technology strategies for the globe over long time scales. It is configured as a partial equilibrium model that balances supply and demand for commodities such as oil, gas, coal, biomass and agricultural products. The MiniCAM does not contain explicit markets for labor and capital, and there are no constraints such as balance of payments. It is therefore considered a partial equilibrium model of the economy. The model runs in 15-year time steps from 1990 to 2095 and includes (presently) 14 geographic regions (see Appendix 3) and is composed of four modules (see Figure 1) that can be run separately or linked.

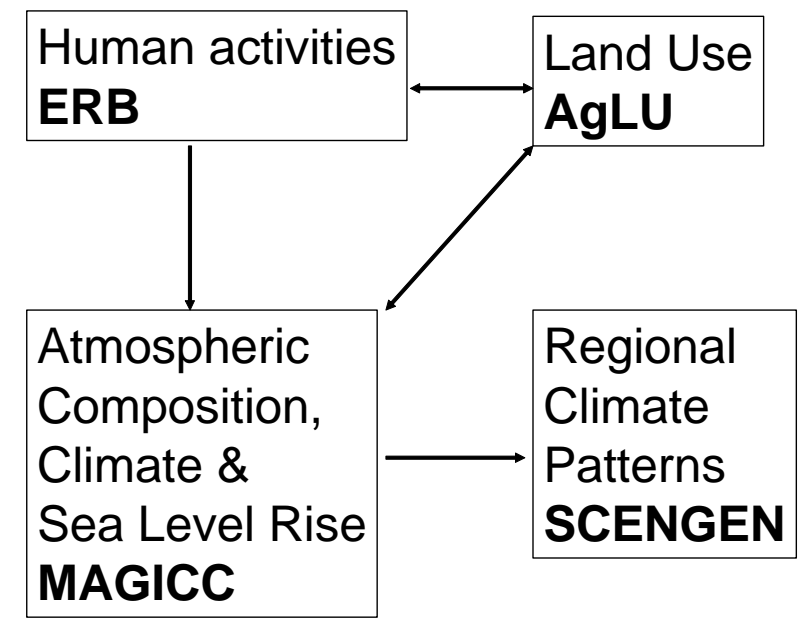

Figure 1 MiniCAM's modules 
The MiniCAM model (Figure 1) includes modules simulating:

- $\quad$ energy supply and demand using an updated Edmonds-Reilly-Barnes module (ERB) (Edmonds and Reilly 1985; Edmonds, Reilly, Gardner and Brenkert 1986; Edmonds, Wise, Pitcher, Wigley and MacCracken 1997);

- agriculture and land-use using the Agriculture and Land Use model (AgLU) (Edmonds et al. 1996; Sands and Leimbach 2001; Gillingham et al. 2002; Sands and Edmonds 2002);

- atmospheric composition and global-mean climate changes using the Model for the Assessment of Greenhouse-gas Induced Climate Change (MAGICC) (Hulme and Raper 1993; Wigley 1994a,b; Wigley and Raper 1987, 1992, 1993, 2001); and

- regional patterns of climate change using the Regional Climate Change Scenario Generator (SCENGEN) (Hulme, Jiang, and Wigley 1995).

The precursor of one of the modules of the MiniCAM model, the Edmonds-Reilly-Barns (ERB) module, was documented by Edmonds and Reilly (1985). ERB was based on a long history of energy-economic research at the Institute for Energy Analysis (IEA). ERB was developed such that "at every decision juncture the simplest possible representation of policy interactions of energy, economics, and demographics have been sought" (Edmonds and Reilly 1985:242). Since then the model has been modified but the essential premise and fundamental structure has been retained. The ERB module includes energy-producing activities, and industrial and waste management processes and their associated emissions. The demand for energy services, as well as the efficiency of fuel conversion to energy are the major factors determining total emissions. Demographics characteristics can be included as a set of exogenous parameters or modeled by an age-cohort method.

In this documentation, we will describe the MiniCAM model and refer, when comparisons are relevant, to the Second Generation Model (SGM), which is a process-level version of the ERB formulated as a general-equilibrium energy-economy model ${ }^{1}$. The MiniCAM is concerned with the supply and demand of energy, of agricultural production and land use, interactions between emissions of various greenhouse gases and other substances (e.g., sulfur dioxide, reactive gases), and links with climate change and sea-level rise. In contrast, the SGM tracks many more aspects of the economy but does not extend its calculations to atmospheric greenhouse gas concentrations, climate change and sea-level rise. The MiniCAM results represent long-term scenario projections based on various views on how economics and energy use may develop in the future. The SGM results can be evaluated for short(er) term mitigation and cost alternatives.

The Agriculture and Land-Use module (AgLU) of the MiniCAM simulates land use based upon available land and competing demands for that land. AgLU simulates the supply and demand for food and fiber products using a market mechanism to balance supply and demand, which includes international trade. This becomes the basis for determining (1) the amount of land used for crops, animal grazing, forest products, and energy crops and (2) the emissions associated with the production of food and fiber and with land-use changes. The production of biomass energy crops is, however, assumed to be carbon-neutral; biomass production sequesters and releases the same carbon when used for energy.

\footnotetext{
${ }^{1}$ Brenkert et al. 2003. SGM model documentation.
} 
MAGICC (Model for the Assessment of Greenhouse-gas Induced Climate Change; http://sedac.ciesin.org/mva/magicc/MAGICC.html) is a reduced form climate model that simulates the causal chain from emissions to atmospheric concentrations, to radiative forcing, to global-mean climate change. The ERB and AgLU MiniCAM modules supply projections of emissions for greenhouse gases, sulfur dioxide, and reactive gases which MAGICC uses to produce atmospheric concentrations and global-mean temperature and sea-level rise projections by using a combined set of gas-cycle, climate, and ice-melt models.

Climate impact analysis generally requires regional climate changes, not global-mean values. Regional temperature and precipitation changes can be provided using SCENGEN (SCENario GENerator). SCENGEN produces regional patterns of future climate change by scaling General Circulation Model (GCM) simulation outputs to match the output of MAGICC.

Table 1 MiniCAM Modules

\begin{tabular}{|c|c|c|c|c|}
\hline $\begin{array}{l}\overline{0} \\
\frac{0}{0}\end{array}$ & . & Description & Inputs and Outputs & References \\
\hline$\frac{m}{a}$ & 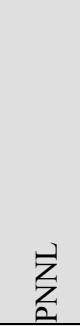 & $\begin{array}{l}\text { The Edmonds-Reilly- } \\
\text { Barnes (ERB) model is a } \\
\text { market equilibrium model } \\
\text { of the energy and } \\
\text { economic systems. }\end{array}$ & $\begin{array}{l}\text { Inputs: labor productivity growth; } \\
\text { population, fossil and non-fossil fuel } \\
\text { resources, energy technologies (69) and } \\
\text { productivity growth rates; } \\
\text { Outputs: Energy supplies and demands by } \\
\text { fuel (4 primary + renewables, } 6 \text { final) and } \\
\text { region (14), emissions }\left(\mathrm{CO}_{2}, \mathrm{CH}_{4}, \mathrm{~N}_{2} \mathrm{O}, \mathrm{SO}_{2} \text {, }\right. \\
\text { others), and economic activity. } \\
\text { Temporal Resolution: } 15 \text {-year time step. }\end{array}$ & $\begin{array}{l}\text { Edmonds and Reilly (1985); } \\
\text { Edmonds, Reilly, Gardner and } \\
\text { Brenkert (1986); Edmonds, } \\
\text { Wise, Pitcher, Wigley and } \\
\text { MacCracken (1997) }\end{array}$ \\
\hline ?. & Z & $\begin{array}{l}\text { The Agriculture-Land-use } \\
\text { Model (AgLU) is a market } \\
\text { equilibrium model of the } \\
\text { land use. }\end{array}$ & $\begin{array}{l}\text { Inputs: Income, population, regional climate, } \\
\text { initial land-use allocation, productivity } \\
\text { growth rates, and biomass energy price. } \\
\text { Outputs: Agriculture and forestry production; } \\
\text { greenhouse emissions; land-use and land-use } \\
\text { emissions, and agricultural prices } \\
\text { Temporal Resolution: } 15 \text {-year time step. }\end{array}$ & $\begin{array}{l}\text { Edmonds, Wise, Sands, Brown, } \\
\text { and Kheshgi (1996); Sands and } \\
\text { Leimbach (2001); Sands and } \\
\text { Edmonds } 2002\end{array}$ \\
\hline 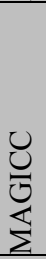 & $\begin{array}{l}\text { 妾 } \\
\text { 乙 }\end{array}$ & $\begin{array}{l}\text { MAGICC is an integrated } \\
\text { model of the carbon cycle, } \\
\text { atmospheric chemistry, } \\
\text { radiative forcing, sea- } \\
\text { level, and global mean } \\
\text { climate change. }\end{array}$ & $\begin{array}{l}\text { Inputs: Emissions of greenhouse gases; } \\
\text { historic atmospheric composition, climate } \\
\text { feedback parameters, ocean inertia; } \\
\text { Outputs: Concentration of greenhouse gases; } \\
\text { radiative forcing; global mean temperature; } \\
\text { sea-level } \\
\text { Temporal Resolution: 1-year time step. }\end{array}$ & $\begin{array}{l}\text { Hulme and Raper (1993); } \\
\text { Wigley (1994a,b); Wigley and } \\
\text { Raper (1987, 1992, 1993, } \\
\text { 2001) }\end{array}$ \\
\hline \begin{tabular}{l}
$Z$ \\
Z1 \\
0 \\
Z1 \\
U \\
\hdashline
\end{tabular} & 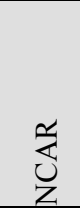 & $\begin{array}{l}\text { SCENGEN models the } \\
\text { regional pattern of climate } \\
\text { change. }\end{array}$ & $\begin{array}{l}\text { Inputs: Global mean temperature; sulfur- } \\
\text { dioxide emissions; } \\
\text { Outputs: Geographic patterns of temperature } \\
\text { and precipitation change. } \\
\text { Temporal Resolution: NA (steady-state) }\end{array}$ & $\begin{array}{l}\text { Hulme, Jiang, and Wigley } \\
\text { (1995) }\end{array}$ \\
\hline
\end{tabular}

Table 1 provides summaries of the modules. Part II of this documentation describes MiniCAM's ERB module; Part III decribes the AgLU module. Both these modules were developed by researchers at Pacific Northwest National Laboratory (PNNL). In Parts IV and V we will describe 
MAGICC and SCENGEN, respectively, but in much less detail. Part VI shows reference case results. The Appendix 6 deals with input data and Appendix 7 provides a list of the equations described.

\subsection{A partial equilibrium model as economic paradigm}

MiniCAM's ERB and AgLU modules form a partial equilibrium model that balances supply and demand of energy commodities and agricultural products. The ERB module handles the energy balancing; the AgLU module simulates the supply and demand of food and fiber products using the same market mechanism, which includes international trade.

The objectives of the ERB and AgLU modules are to determine greenhouse gas emissions based on supply of and demand for energy services, food and fiber products, and the efficiency of converting fossil fuels into energy. The efficiency of fuels conversion to energy is based upon the fuels themselves and the technologies used to combust them. An important additional objective is the evaluation and quantification of how much the level of emissions can be affected by policies aimed at reducing emissions.

The version of the ERB used in the MiniCAM has three major components not present in the original version:

- links to agricultural and land-use activities through the AgLU, which includes biomass production,

- quantification of emissions of sulfur dioxide and additional greenhouse gases, e.g., methane and nitrous oxide, and

- additional technologies such as carbon capture and sequestration, hydrogen-fuel production and consumption (e.g., fuel cells), and energy production from biomass.

Numerous other enhancements to the original ERB have been implemented such as calibration, and a multi-gas emissions market for the evaluation of generalized emission reduction policies. 


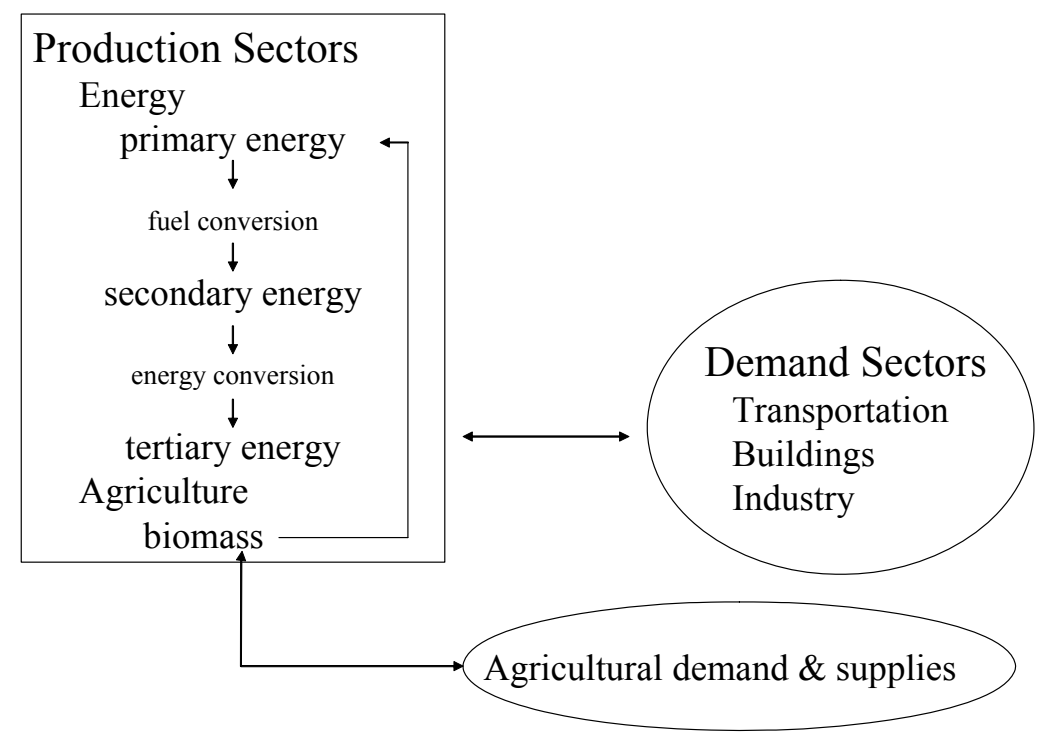

Figure 2 The flow of services in MiniCAM

At the onset of the model development it was recognized that "at the very least, an assessment tool must provide a global energy balance to enable consistent $\mathrm{CO}_{2}$ release scenarios to be generated" (Edmonds and Reilly1985:244). This requirement has been expanded to account for other radiatively important gases. Secondly, it was deemed important to differentiate between primary or raw fuels, and secondary forms of energy (see Figure 2 and the more detailed Figure 4) - secondary fuels being usable energy - and to be able to distinguish between fuels that are combusted and fuels for non-combustion uses (e.g., petrochemical feedstock, asphalt). Primary energy is comprised of the raw fuels, graded based on extraction costs, traded and ultimately balanced, based on prices. These raw fuels are:

- Conventional oil

- Unconventional oil

- Coal

- Biomass \& waste

- Natural gas

- Uranium.

The six secondary fuel and energy carriers are:

- Liquids (which include refined liquids, and synthetic liquids from coal, natural gas or biomass)

- Coal

- Biomass (from commercial biomass and/or waste)

- Gases (which include natural gas and synthetic gas from coal or biomass)

- Electricity (from oil, coal, biomass, natural gas, hydrogen, nuclear power, fusion hydro power or renewables like solar PV, wind, and space satellite solar)

- Hydrogen (from oil, coal, biomass, gas or electrolysis). 
The secondary fuels are consumed to produce energy services. Conceptually, energy services are provided to the demand or end-use sectors. Energy services include heating, cooling, transportation, etc. The energy used to supply these services is sometimes called tertiary energy.

The demand, or end-use, sectors in the MiniCAM are:

- Transportation

- Buildings (residential/commercial)

- Industry

Balancing the energy, carbon, and agricultural products at each time step ensures global equilibrium in each of the global primary energy fuel markets, the greenhouse gas (GHG) market, and each of the agricultural product markets. This balancing is achieved by pooling the regional demands for and supplies of each of the fuels (conventional and unconventional fossil oil, natural gas, coal, and waste and commercial biomass), total carbon or greenhouse gas emissions (accounting for any carbon sequestration), and each of the agricultural products, which are current and forward market wood products, food grains, oil crops, miscellaneous crops, and pasture products. The pooling results in 12 markets to be cleared, as shown in Table 2 . Note that the global markets can be re-configured by the user into regional blocks as needed - the markets shown in Table 2 are most commonly used in the global context.

Table 2 MiniCAM's twelve markets

\begin{tabular}{|l|l|l|}
\hline Fuel markets & Agricultural product markets & \\
\hline $1=$ Oil & $6=$ Wood & \\
\hline $2=$ Gas & $7=$ Forward Wood & \\
\hline $3=$ Coal & $8=$ Food Grains & which includes wheat and rice, \\
\hline $4=$ Biomass & $9=$ Coarse Grains & which includes all other cereals \\
\hline GHG market & $10=$ Oil Crops & \\
\hline $\begin{array}{l}5=\text { Carbon Dioxide or Carbon- } \\
\text { Equivalents }\end{array}$ & $11=$ Miscellaneous Crops & $\begin{array}{l}\text { which includes fruits, vegetables, starchy } \\
\text { roots and pulses }\end{array}$ \\
\hline & $12=$ Pasture Products & which includes beef and mutton \\
\hline
\end{tabular}

Supply and demand is made to balance in each time period by adjusting the prices of the traded (pooled) commodities. As the price of a commodity increases, supply increases and demand decreases. Similarly, as the price of a commodity decreases, supply decreases and demand increases. The different regions produce the demanded fuels and agricultural products when their production costs are competitive. Trade is therefore implicitly simulated. Animal product supply is balanced with demand at the regional level. Trade in animal products between regions is fixed at 1990 levels given the relatively small amount of trade between regions. Uranium is implicitly traded by pooling regional supplies. Price response to demand can be determined from supply curves but no explicit market is established. Electricity and hydrogen are not traded, since they are not primary energy fuels. Moreover, sufficient electricity and hydrogen is assumed to be generated, regionally, to meet demand. The MiniCAM does not contain an explicit backstop technology, which is often included in modeling as a generic unlimited electricity source available at a fixed price. While nuclear and some other non-fossil-fuel technologies can, in principle, provide unlimited amounts of electricity, the cost of these sources are not necessarily constant in the MiniCAM. 
Figure 3 illustrates the conceptual framework of the ERB module in a different way from Figure 2. Regional populations determine regional economic activity and energy demands.

Technological change impacts energy demand, while regional taxes and tariffs (and climate policies which influence the price of greenhouse gas emissions) determine regional energy prices, which affect, in turn, regional energy demands. Regional energy resources and prices determine regional energy supplies, which impact global supply and demand, which in turn affect world prices that feed back to the regional energy prices, which then impact regional supply and demands. Through an iterative process, global supply and demand of the primary fuels are balanced. Emissions are calculated simultaneously with the balancing process, so as to efficiently solve for any carbon constraint.

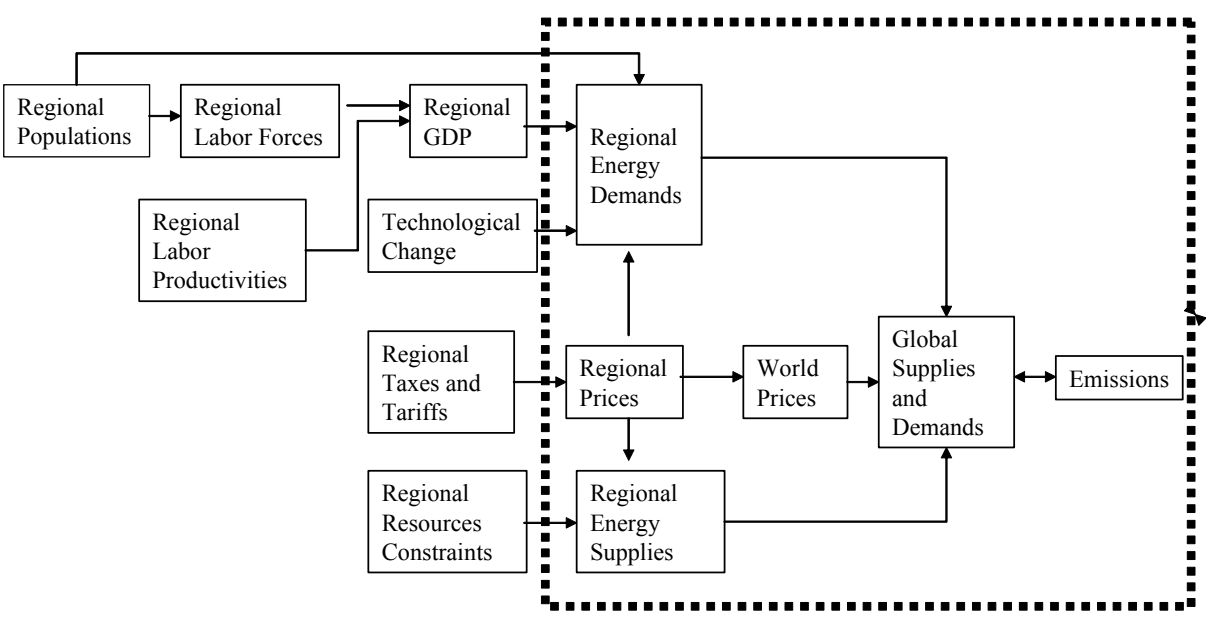

Figure 3 An energy-economics-emissions model (based on Edmonds and Reilly, 1985 p17 \& p247)

When equilibrium occurs, the markets are said to "clear." The mechanism for clearing the markets is through the solution algorithm, which adjusts market prices (e.g., primary fuel prices) until excess demand - the difference between demand and supply - is less than a specified solution criteria, typically a small number (less than one but greater than zero). The solution algorithm needs only to access information on the price, supply, and demand to operate. The solution algorithm adjusts prices until supplies and demands are balanced to within the solution criteria. Prices adjusted by the solution algorithm affect technology costs, demand for inputs and sector outputs.

It has been our experience that the use of multiple solution algorithms ensures that a solution (all the markets are cleared) is found quickly and that the solution is robust. Routines that are commonly used for economic modeling are the bisection and Newton-Raphson routines. These routines are used in the MiniCAM (and the SGM). The bisection and Newton-Raphson routines are called independently. (See Appendix 3 for a further description of the routines.) 


\subsection{Static versus dynamic modeling}

Dynamic modeling means that a solution in one time step has impacts on the next time step. The ERB and AgLU are dynamic in some aspects but not in others. The ways in which the ERB and AgLU are static rather than dynamic are as follows:

- The solution in each time period is largely separate from those of the prior periods because ERB (unlike the SGM) does not take into account capital stock lifetimes. The assumption is that over one to two of the 15-year periods considered by the model, relatively large changes in the energy system are possible.

- In the AgLU module the primary drivers of land use are population and GDP-levels over time. Both parameter sets are identical for the ERB and AgLU modules and are exogenous.

- Technical change and changes in labor productivity are dependent on values in the previous time-period, but these are all specified exogenously.

The limited effects of a solution in a previous time period on a subsequent time period in the MiniCAM are:

- Physical stocks of depletable resources, such as fossil fuels, are modeled explicitly. Therefore, production rates and resulting prices of depletable fuels are dependent on production occurring in the previous time-periods. When easily accessible (or processable) fossil resources are extracted, remaining resources will be more difficult to exploit and require higher extraction costs. The same applies to uranium, if a limited supply is assumed.

- In cases where the GDP is not exogenous but allowed to vary (i.e., not calibrated to exogenously set data) changes in GDP through the energy-price feedback will carry through to subsequent periods.

\subsection{Regions}

MiniCAM's global coverage is comprised of fourteen regions. The regions are determined by economic criteria and do not necessarily follow political divisions. Seven of the regions represent countries listed in Annex I of the Framework Convention on Climate Change (FCCC). Models of these regions are especially useful for simulating international trade in carbon emissions rights.

Table 3 Regions in MiniCAM ${ }^{2}$

\begin{tabular}{|l|l|}
\hline Annex I & Non-Annex I \\
\hline United States & China/Asia Reforming \\
\hline Canada & India \\
\hline Western Europe (OECD90) & South Korea \\
\hline Japan & Middle East \\
\hline
\end{tabular}

${ }^{2}$ See Appendix 2 for the list of countries in the regions.

Annex I regions are the same in the MiniCAM and SGM; Non-Annex I regions differ 


\begin{tabular}{|l|l|}
\hline Australia \& New Zealand & Latin America \\
\hline Former Soviet Union & Africa \\
\hline Eastern Europe & (rest of) S\&E Asia \\
\hline
\end{tabular}

\subsection{Markets}

The energy markets are the core of the MiniCAM model. Markets are defined for oil (conventional and unconventional are traded together), gas, coal, biomass, carbon, and agricultural products (see Table 2). Through a market definition procedure the MiniCAM regions can be fully integrated and trade is implicit for all commodities brought to market. Alternatively, through the market definition procedure some regions may trade while others remain independent representing a partial market clearing. A third alternative is that regions are completely independent.

Note that the MiniCAM is a partial equilibrium model: the MiniCAM has no explicit markets for labor and capital and there are no constraints such as balance of payments. The MiniCAM does balance supply and demand of energy commodities and agricultural products, while the GHG market is used through the implementation of a carbon fee to either limit carbon dioxide or all greenhouse gas emissions. Carbon revenue is not recycled.

The GHG market operates using the same mechanism as each of the energy and agricultural markets. Implementation of a carbon market can be achieved by (1) imposing an emission limit or target or 2) imposing a global or regional carbon price. In either case the impacts on energy production, consumption and sector-specific emission levels can be analyzed.

In its simplest form, a carbon dioxide constraint is specified as a global carbon emissions target for each time period. The global carbon price is adjusted until global carbon dioxide emissions are below the specified target value. Alternatively, emissions constraints can be in the form of total greenhouse gas emissions, which are the sum of the carbon-equivalent emissions for all greenhouse gases. Note that carbon fees are not applied to biomass production or consumption.

If a carbon price is specified, fees can be added to all fossil fuels within the specified market region at a value proportional to their carbon content. If the user has specified that non- $\mathrm{CO}_{2}$ greenhouse gases are part of the market, then a carbon fee is translated to a carbon-equivalent value appropriate for that gas using a user-specified Global Warming Potential (GWP) weighting factor (see Table 5). For non- $\mathrm{CO}_{2}$ greenhouse gases a marginal abatement curve approach is used to determine the amount of emissions reductions obtained for a given carbon price (see section 2.3). Under a configuration with one global carbon market, there is implicit global trading of carbon permits. Alternatively, regional carbon markets remain independent and there is no trading of carbon permits.

\subsection{MiniCAM's focus and niche}

Implementing the MiniCAM provides for the ability to understand the impact of technologies and policies related to GHG emissions in a national and global context. Secondly, it provides for the ability to quickly evaluate technologies including carbon sequestration. Thirdly, it provides for an 
evaluation of land use given that biomass land competes with food and fiber uses in the agriculture/land-use model. And finally, MAGICC allows for the calculation of GHG concentrations, radiative forcing, and climate change in the form of changes in temperature and sea level rise which can be regionalized through the use of SCENGEN.

PNNL's modeling team has been an active participant in the Intergovernmental Panel of Climate Change (IPCC) SRES scenario development (Nakicenovic et al. (2000). Part VI of this documentation provides an overview of some of the results.

Outputs of the MiniCAM have allowed for evaluations of sustainability (Pitcher 1993) and country-based vulnerabilities (Moss, Brenkert, and Malone, 2001). 


\section{PART II}

\section{The ERB module}

MiniCAM's ERB and AgLU modules are run as mutually dependent modules. AgLU can be run separately. We describe the ERB module in PART II and the AgLU module in PART III. Commercial biomass, along with the shared driving forces of GDP and population, provide the link between the energy structure of ERB and land use in AgLU. The AgLU module adds markets for composite crops, animal products, and forest products to the ERB world markets for oil, gas, coal, and biomass (see Table 2 for a list of the final 12 markets).

The fundamental problem the ERB model must address is finding global energy supply consistent with demand for each market. If supply and demand of the primary fuels is equal, the market clears. If not, then, within each time period, prices are re-iterated until supply and demands for each fuel are equal. A given model scenario requires, for each region, primary fuel resource supply curves, the prices of fuels and other inputs such as land, transformation costs, technology options, technological change parameters, population levels, and labor productivity rates.

The three major exogenous inputs determining energy demands over time are

- Regional population changes

- Regional economic activity changes, which are determined primarily by the rate of labor productivity increase and

- Regional

0 technological change in energy transformation ${ }^{3}$, and

0 autonomous end-use energy intensity improvements ${ }^{4}$, which are improvements in the amount of energy needed to provide a given level of service.

Changes in regional energy prices, based on global prices, also impact energy demands over time.

Three end-use sectors for energy services are simulated (see Figures 2 and 4), which are

- Transportation

- Buildings (residential/commercial)

- Industry.

Changes over time in the population affect economic activity and energy demands. The population and labor force parameters can be specified in a number of ways, as described in the demographics section below (Section 2.1). The simulated interactions of energy supply, energy prices, energy demand and technological change is described in sections thereafter.

\subsection{Demographics}

\footnotetext{
${ }^{3}$ Autonomous, given that technological changes are input parameters which are independent of price.

${ }^{4}$ Autonomous energy intensity improvement (AEII): the AEII specifies how the amount of energy required to produce a given level of output would decline over time as a result of technical change, independent of energy prices (Edmonds, Roop and Scott 2000)
} 
The MiniCAM can use a number of methods for specifying demographic variables. There are two primary demographic inputs that are needed in MiniCAM: total population (ZLM, where $L$ stands for region and $M$ for time-period) and the fraction of the population in the labor force (RLFP: unitless; a regional time-dependent input). Total population levels are used to drive energy and agricultural demands. The size of the labor force, together with labor productivity (PROLM: unitless rate; a regional time-dependent input parameter), determines the level of economic output (for data examples see Appendix 6).

The simplest demographic method is to obtain the regional total populations (population data may be read in, using the projections from either the World Bank or United Nations) and regional labor force fractions (representing the number of people between the ages of 15 and 65) for each region at each point in time. Note that the labor force fraction tends to be relatively stable over time, given that a decrease in mortality rates and increases in female participation in the formal work force tends to be offset by increased time spent in school.

As an alternative, the MiniCAM contains an internal demographics module that uses an agecohort method of calculating population by age and gender for each region. The required input variables are fertility, migration, and mortality rates. The demographics module keeps track of population within each region by gender and five-year age cohort. Base year populations may evolve by applying assumptions with regard to survival rates, fertility rates, and migration rates (Appendix 4 provides the equations).

\subsection{Economics and Energy}

The MiniCAM model has three general equation structures that recur. These are the Leontief or constant input-output coefficient equation for the description of energy transformation technologies, the logit structure determining fuel sharing and the constant elasticity equation determining demand. Figure 4 illustrates fully the energy transformation processes. Details of the transformation processes are described in the sections below.

MiniCAM can be described as follows: each region has a unique set of primary energy prices, which are derived from world prices (market prices, determined when solving the model for supply and demand in the energy and other markets) and region-specific taxes, tariffs and subsidies. Primary energy is transformed at a certain efficiency and cost to secondary energy and is then converted, again at a certain efficiency and cost, such that end-use sector-specific energy services can be met in the form of tertiary fuels or energy carriers, that is, of end-use sectorspecific fuel modes. The demand for secondary energy depends not only on the overall demand for energy and the relative cost of that particular energy modality, but also on the non-energy costs of transforming that modality into a useful energy service (see also Edmonds and Reilly 1985:244). Supply prices are, however, not only determined by demand, but also by the fact that easily obtained abundant resources tend to be cheaper than more limited, higher grade resources. Raw fuel supplies are cost based resources; carbon prices can be levied on production, and/or consumption. Implicit trade of raw fuels takes place when regional supplies do not meet demand. 


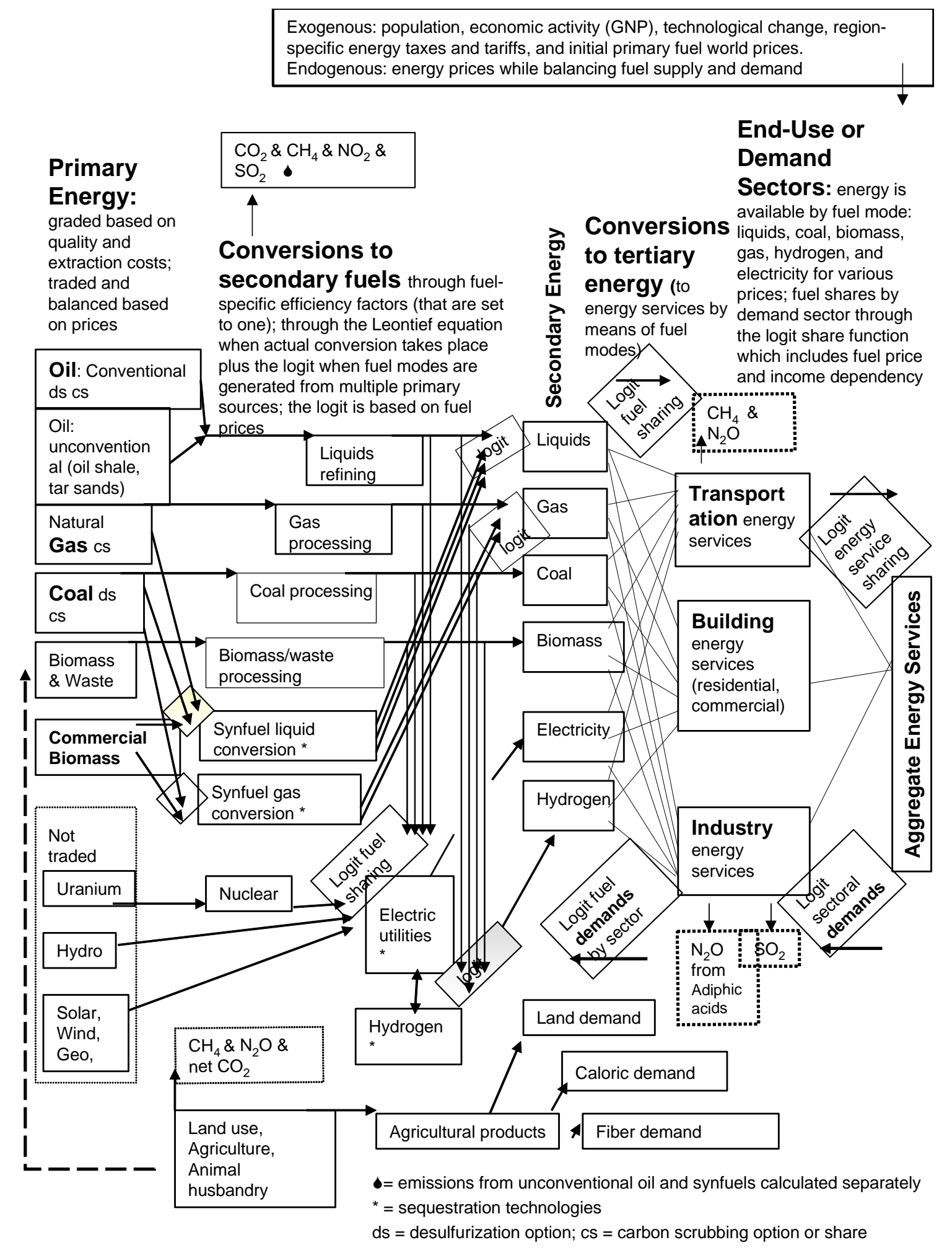

Figure 4 Energy flow processes in the ERB and AgLU modules of MiniCAM (Adapted from Edmonds and Reilly 1985:245) 
The basic energy transformation process costs are captured by the Leontief equation

Pr ice $=\mathrm{P} \bullet \mathrm{g}+\mathrm{h} \quad$ (\$/energy unit) Eq. 1

where

Price is the cost of energy (or an energy service) which is determined by

$P$ the costs of energy input,

$\mathrm{g}$ a conversion coefficient representing the relationship between the input of one unit of energy to one unit of transformed fuel, and

$\mathrm{h}$, which represents the levelized non-energy costs associated with one unit of transformed fuel.

Some of the secondary fuels (electricity, hydrogen, synfuels) can be provided in a number of different ways (see Figure 4). Electricity as a secondary fuel, can, for example, be generated by coal-fired power plants and by nuclear energy. Analogously, different fuel modes can provide an energy service, e.g., residential energy services such as heating can be generated by electricity, gas, and/or fuel oil.

The different primary fuels or fuel modes will compete for generating a secondary fuel or energy service. The price of each of the fuels is assumed to fall within a fuel-price range which is based on the cost of fuel and various other costs such as transportation costs, taxes, non-fuel costs, and structural factors. This variance of each fuel price is captured in an energy price exponent (Edmonds and Reilly 1985:259). The share each competing fuel will capture will depend on both its price and its variance and how those compare with competing fuels. Figure 5 illustrates the basic premise that in the case of providing a transformed energy, the cost distributions show alternative costs of providing this energy (Edmonds and Reilly 1985:250, 259). Shares of the fuels providing the transformed energy are calculated by means of the McFadden's (1981) logit share equation. In that formulation the shares of the competing fuels add to one, are dependent on an assumed base share value for each of the competing fuels and are dependent on the elasticities of their prices. Thus, the share $S_{j}$ of a fuel $j$ allocated to a demand or market where the fuels compete is given by

Share $_{j}=\frac{\mathrm{b}_{\mathrm{j}} \bullet \mathrm{P}_{\text {fuel } \mathrm{j}}{ }^{\mathrm{r}_{\mathrm{p}}}}{\sum_{\mathrm{j}}\left(\mathrm{b}_{\mathrm{j}} \bullet \mathrm{P}_{\text {fuel } \mathrm{j}}{ }^{\mathrm{r}_{\mathrm{p}}}\right)}$

(unitless) Eq. 2

where

$\mathrm{P}_{\text {fuelj }}$ is the cost of fuel $j$ (or the cost of providing an energy service),

$r_{p}$ is the price exponent, that is the parameter that determines the variance of the price distribution; $r_{p}$ is the parameter that determines the rate that the use of this fuel will change in response to a change in the cost of this fuel (mode); this exponent has also been called the elasticity,

$\mathrm{b}_{\mathrm{j}}$ is the base share or weight of fuel $j$, sometimes called scale parameter, and the denominator is the sum over all possible shares. 


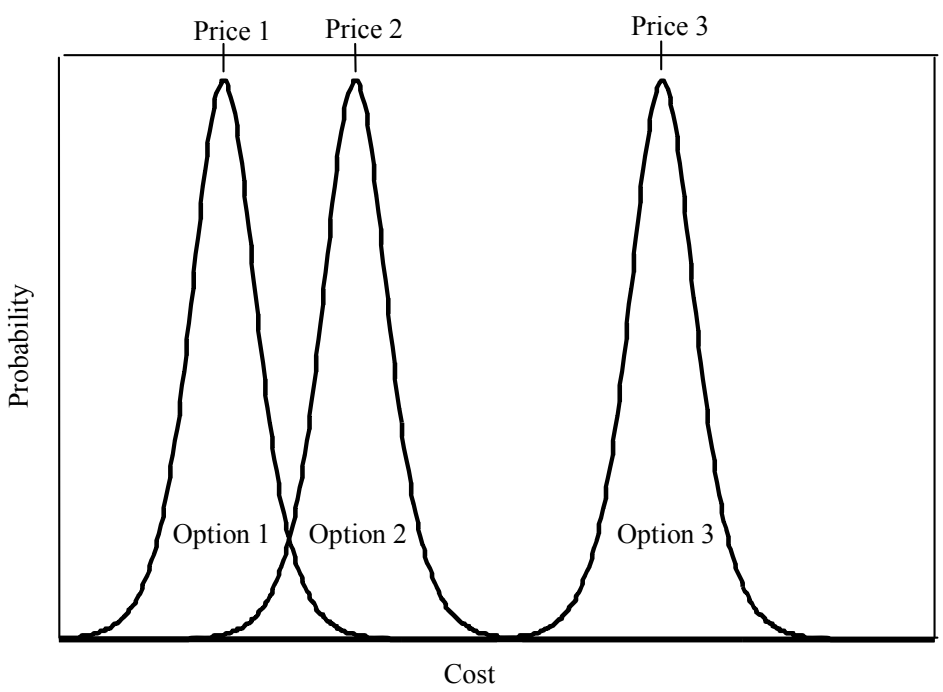

Figure 5 Schematic cost distributions for three different energy options (Adapted from Edmonds and Reilly 1985:251). Options 1 and 2 will compete for market share. The price distribution for option three does not overlap and will not have a significant share for the market shown. For a further theoretical discussion of the logit sharing mechanism see Clarke and Edmonds (1993).

Synfuel generation is based on the share equation as is the competition between scrub and nonscrub technologies in the production of electricity and hydrogen (see Figure 4 for various other share equation implementations).

The aggregate demand for energy services is determined for each region by a constant elasticity equation where the aggregate demand is a function of population, income, the aggregate price of the energy services and the income and price elasticities. The aggregate price for energy services is based on the average price of energy services in that demand sector. This prices is derived, ultimately, from the market prices of primary energy, adjusted step-wise from market prices of primary fuels, to regional prices for secondary fuels, and, finally, to prices or costs of energy services. An energy price elasticity measures the relationship between energy service price and energy demand for the given sector. An economic activity elasticity represents the elasticity of economic activity either based on GDP or income. Thus, the demand for fuel $j$ in sector $k$ is given by

Demand $=\mathrm{b} \bullet \mathrm{P}^{\mathrm{rpk}} \bullet \mathrm{X}^{\mathrm{rxk}}$

(energy/year) Eq. 3

where

$\mathrm{P}$ is the energy service price,

$\mathrm{X}$ may be income or a GDP index,

$\mathrm{b}$ is a base scale parameter or weight,

$r_{p k}$ is the energy price elasticity of demand which equals

$d \ln$ Demand $/ d \ln \mathrm{P}$ representing the percentage change in demand resulting from a one percent change in price and

$\mathrm{r}_{\mathrm{xk}}$ is the income elasticity of demand which equals

$d \ln$ Demand $/ d \ln \mathrm{X}$ representing the percentage change in demand resulting from a one percent change in $\mathrm{X}$. 
In the MiniCAM a variety of climate policy options have been explored and they will be discussed next (Section 2.2.1). Then we will discuss how energy supplies are simulated (Section 2.2.2). This will be followed by a detailed description of energy prices (Section 2.2.3) and energy demands (Section 2.2.5) and how they interrelate (Section 2.2.6).

\subsubsection{Carbon Prices}

As was described before, the GHG market operates using the same mechanism as each of the energy and agricultural markets. Implementation of a carbon market can be achieved by (1) imposing an emission limit or target or (2) imposing a global or regional carbon price. In either case the impacts on energy production, consumption and sector-specific emission levels. GHG fees can be added to

1) the raw fuel extraction processes (as $P f i s_{i s, l, m}{ }^{5}$ ); these fees are regional time-dependent severance costs that can be imposed when prices of resource supplies of regional primary fuels are determined (see Equation 5),

2) the production of regional primary fuels (as $\left.P f i_{i, l, m}\right)$ (see Equation 24),

3 ) the consumption of fossil fuels (as $\left.P f u_{u i, l, m}\right)^{6}$; by raising the prices of the to be consumed refined oil, processed gas and $\mathrm{coal}^{7}$ when meeting the liquids and gas energy service demands (see Equations 31, 32, 33, and 35), the fractions (or shares) of the total demand of each of the secondary (processed/refined) fuels will change resulting in a change in emissions,

4) the consumption of fossil fuels (as $P f u_{u i l, m}$ ) by electricity and hydrogen production (see Equations 37, 38, 44 and 45), and/or

5) the transformation of secondary to sector-specific tertiary energy (fuel modes) (as $P f j k_{j, k, l, m}$ ), that is on the consumption of liquids, gas, and coal; not on biomass (see Equations 36 and 56).

The implementation of fees may vary; e.g., (case 1) both the $P f u_{u i, l, m}$ and the $P f j k_{j, k, l, m}$ fees are applied, while the $P f i_{i s, l, m}$ fees are set to zero; (case 2) the $P f u_{u i, l, m}, P f j k_{j, k, l, m}$, and $P f i s_{i s, l, m}$ fees are all applied but halved; or (case 3 ) only the $P f i s_{i s, l, m}$ fees are levied. Numerous variations can be

\footnotetext{
${ }^{5}$ To aid the reading of the parameter names in this document (see also Appendix 1) one has to keep in mind that

'is' stands for raw fuel,

'ig' stands for grades of primary fuel,

' $\mathrm{i}$ ' stands for primary fuel, except in the synfuel calculations where $i$ refers to synliquid and syngas produced

'ui' stands for electric utilities,

'hi' indicates hydrogen fuel production

' $\mathrm{j}$ ' indicates secondary fuel, except in the synfuel calculations where $j$ refers to the feedstocks

' $\mathrm{k}$ ' indicates end-use sector,

' 1 ' indicates region,

' $\mathrm{m}$ ' indicates time period,

'es' indicates energy supply,

'ed' indicates energy demand.

${ }^{6}$ Although the MiniCAM has this $P f u_{u i, l, m}$ carbon fee option, in practice, carbon fees are imposed during the tranformation of secondary fuels to fuel modes for energy services, $P f j k_{j, k, l, m}$

${ }^{7}$ in the determination of the SynShares
} 
envisioned with some regions not applying fees to some fuels, some regions applying fees only when emissions exceed a certain amount, etc.

(1) The severance fee of regional extraction processes $\left(P f i s_{i s, l, m}\right)$ may be applied when extraction costs are determined. This fee is an exogenous or endogenous regional time-period specific (input) parameter for conventional and unconventional oil, conventional gas, and coal and set to zero for biomass and uranium (units: \$/EJ). The parameter has an exogenously set or endogenously determined value depending on the type of constraints assumed in a simulation.

(2) The regional price increases $\left(P f i_{i, l, m}\right)$ on oil, gas, coal, and biomass production costs are regional and time-period specific (through 2050) input parameters. These multipliers can also be interpreted as trade barriers or as scale factors to regionalize the global fuel prices; the coefficients range from 1.8 to 0.75 ; for biomass they equal one.

( $3 \& 4)$ The energy consumption $\left(P f u_{u i l, m}\right)$ fees can be fixed (exogenously set and changing over time) or may function as constraints such that, for example, exogenously set greenhouse gas emissions standards can be met.

$>$ If the $P f u_{u i, l, m}$ fees are not directly related to carbon emissions, the fees on the consumption of energy sources generating electricity (which includes nuclear, hydro, solar and other renewables), hydrogen fuels and synfuels may be exogenously determined input.

$>$ If the $P f u_{u i, l, m}$ fees are intended to impact carbon emission levels then the fossil fuelspecific fees are based on the fuel-specific carbon content. The fuel-specific carbon content $\left(\mathrm{CO}_{i}\right.$ : tons $\mathrm{C} / \mathrm{Joule}$ energy combusted) is recalculated by means of a conversion factor $\left(C V R T 90^{8}\right)$ and the resulting parameter is called $P f 0_{u i, l, m}$. This parameter $\left(P f 0_{u i l, l, m}\right)$ has units of tons $\mathrm{C} / \mathrm{J} *$ dollar conversion ratio $\left(C O_{i}\right.$ divided by $\left.C V R T\right)$ such that when it is multiplied with the $1990 \$$ carbon price-costs $\left(P R C_{l, m}\right.$ in $\$$ /million tons $\left.C\right)$ the resulting $P f u_{u i, l, m}$ price increases are in units of $\$ / \mathrm{GJ}$. Thus, $P f 0_{u i l, m}$ is a conversion factor that accounts for the carbon content of the fuel and incorporates a conversion of 1975 to $1990 \$$.

(5) The carbon fees, $P f j k_{j, k, l, m}$, are added to the costs of the transformation of secondary fuels to fuel modes (see Equation 56 where this fee is implemented for coal and Equation 36 where it is implemented for liquids and gas when synfuel liquids and syngas are shared with oil and gas, respectively); they are global; they are the same for each of the three end-use sectors and they are the same for refined oil, processed gas and coal and can be obtained from exogenously set input or can be set identical to the $P f u_{u i, l, m}$ values.

Note that a global or regional carbon price $\left(P R C_{l, m}\right)$ can be exogenously set; emissions are then dependent on this price; or, when emission limits are set exogenously the carbon price is determined in the GHG market.

\subsubsection{Energy supply}

\footnotetext{
${ }^{8}$ The GDP deflator from $1975 \$$ to $1990 \$$ is hardwired in the code and its use is for accounting purposes only: CVRT90 $=2.212$
} 
Energy supplies in the MiniCAM fall in a number of categories. Oil, gas, coal and uranium supplies of raw resources are determined by cumulative supply curves. These supply curves reflect that easily obtained resources tend to be cheaper than more difficult to extract resources.

Uranium production is based on a long-term production schedule which depends on the previous period's annual production rate.

Biomass comes, first of all, from waste, which for most regions supplies all of the present biomass demands. Secondly, biomass may be obtained from dedicated biomass farms which produce biomass on an economic basis under competition with food crops and other land uses.

Hydroelectric power is a resource constrained renewable technology. Geothermal power is not modeled separately, but is (assumed) included in the hydropower category.

Generation of electricity by solar PV (photovoltaic) and wind turbines are considered unrestrained renewable resources (apart from capacity limits, see below).

Space solar power (SSP) is implemented as a source of electricity with no capacity constraints.

Solar-wind storage is implemented as a means of storing and then delivering solar PV or wind energy. With this technology, solar PV and wind energy is generated and then stored for delivery into the electric grid as needed.

Details of the different aspects of the different supplies of energy are described below.

\section{Supply (resources) of crude oil, natural gas, and coal and uranium}

Supplies of crude oil, gas, coal, and uranium are governed by cumulative supply curves. Energy resources with similar extraction costs are grouped into grades where each grade has a range of extraction costs. A representative cumulative supply curve is shown in Figure 6 with extraction costs $\left(\mathrm{C}_{\mathrm{ig}, \mathrm{is}}\right)$ on the vertical axis and cumulative supply $\left(\mathrm{R}_{\mathrm{ig}, \mathrm{is}, \mathrm{l}}\right)$ on the horizontal axis. Note that the model does not use a static resource curve as shown, however, since technological change is included (see below).

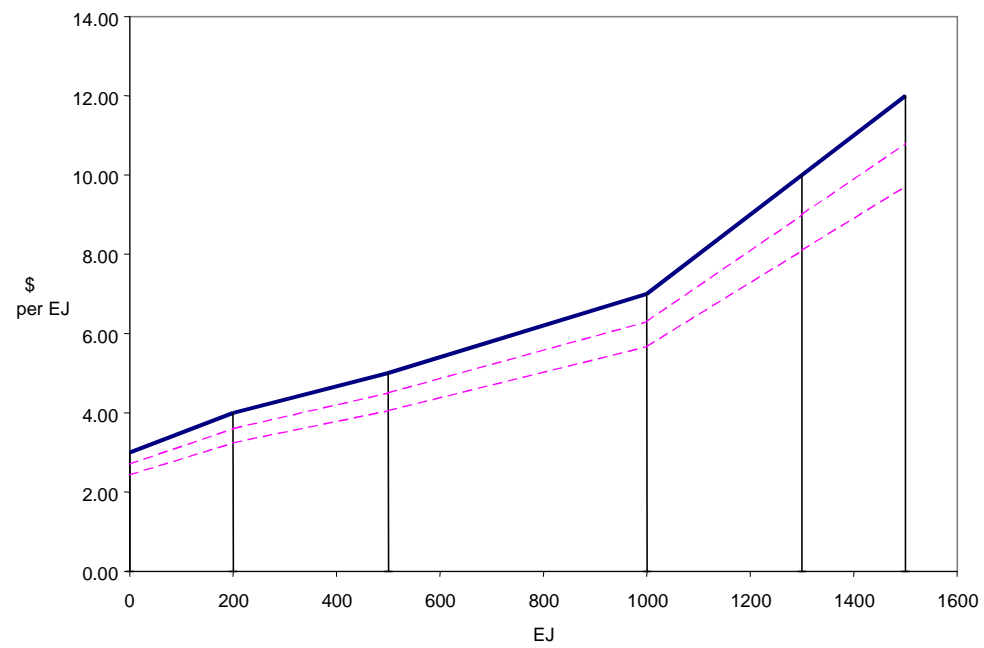

Figure 6 Cumulative Energy Supply Curve 
Note also that resource grade definitions are somewhat arbitrary and grades may be defined in any way convenient to the modeler. Grades may represent different types of oil, say proven reserves compared to speculative resources, or may simply be breakpoints needed to define a cumulative supply curve. In the MiniCAM unconventional oil is a separate category because of its greater carbon content. Unconventional natural gas resources are treated as more expensive grades of natural gas. Nuclear fission is resource limited if light-water reactors are the dominant technology. Use of breeder reactors results in an essentially unlimited source of energy at a higher cost.

Figure 6 illustrates that easily obtained resources tend to be cheaper than more limited, highergrade resources. Regional resource prices determine how much energy needs to be supplied by other regions; moreover, the regional resources determine the final balance of global supply and demand. Regional resource $\operatorname{costs}^{9}$ are simulated by the following sets of parameters and processes:

Extraction costs $\left(C_{i g, i s} C I G I S: \$ / G J\right)$ determine the minimum cost of a global primary fuel by grade; they are global grade- and fuel-specific sets of input parameters relating energy resources $\left(R_{\text {igis, }}\right.$ in Joules) and prices $(\$ / \mathrm{EJ})$.

Each regional supply $\left(R_{i g, i s, l} R I G I S \mathrm{~L}: \mathrm{EJ}\right)$ of conventional oil, unconventional oil, natural gas, coal, and uranium is determined by combinations of (6) grade levels and amounts of energy (Joules) assumed available at that grade level-specific extraction costs.

The by-grade determined extraction costs relate to the regional primary fuel supply curves through regional environmental costs and taxes, and global time-dependent technological change in production costs:

Environmental costs $\left(V_{i s, l, m}:\right.$ VISLM: $\left.\$ / G J\right)$ are exogenous regional time- and primary fuelspecific input parameter. The environmental costs are added to the production (extraction) cost for each fuel. Like other parameters in the MiniCAM, environmental costs can be considered a parameter that is scenario-dependent. Dependent on the analysis to be made impacts of environmental costs can be evaluated. For the reference case the environmental costs are low for gas extraction and highest for coal extraction. Note, that if environmental costs are kept constant the effective cost may, in effect, decrease significantly in the future.

A global primary fuel-specific rate of technological change ( $T e c h_{m}$ unitless) is calculated from the exogenous unitless time-dependent technological change parameter $S T_{i s, m}(S T I S M)$. The rate of technological change determines the rate at which the sum of the extraction and environmental costs decline with time. This is a key variable that affects the future price of fossil fuels. The cumulative supply curve shifts downward over time as technical change causes extraction costs to decline. Technical change is calculated as follows:

$\operatorname{Tech}_{\mathrm{m}}=\operatorname{Tech}_{\mathrm{m}-1} \bullet\left(1+\mathrm{ST}_{\mathrm{is}, \mathrm{m}}\right)^{\text {Nstep }} \quad$ (unitless) Eq. 4 where

Tech $_{\mathrm{m}}$ is the global primary fuel-specific rate of technological change, set to one in the base year,

\footnotetext{
${ }^{9}$ Prices and costs of energy are calculated in $\$ /$ GJ, while physical energy quatities are calculated in EJ.
} 
$\mathrm{ST}_{\mathrm{is}, \mathrm{m}}$ is the technology change parameter used in calculating the rate of technological change over time (unitless: exogenous global time- and fuel-specific for conventional and unconventional oil, coal, gas, and uranium), and

Nstep is the time span from one time period to the next (15 years in MiniCAM)

A severance fee of regional extraction processes (Pfis is,,$m_{m} ;$ TXISLM: $\left.\$ / G J\right)$ may be applied when extraction costs are determined.

Thus, over time, global primary fuel prices (extraction costs of conventional oil, unconventional oil, coal, gas, and uranium) in units of $\$ / G J$ are in part determined by the regional fuel-specific supply curves, environmental and other costs as follows:

ExtrCost $_{\mathrm{is}, 1, \mathrm{~m}}=\frac{\left(\mathrm{C}_{\mathrm{ig}, \mathrm{is}}+\mathrm{V}_{\mathrm{is}, 1, \mathrm{~m}}\right)}{\text { Tech }_{\mathrm{m}}}+$ Pfis $_{\mathrm{is}, 1, \mathrm{~m}}$

for oil, gas, coal and unconventional oil $\quad(\$ / G J) \quad$ Eq. 5

where

the extraction cost $\mathrm{C}_{\mathrm{ig}, \mathrm{is}}$ is the exogenous global raw fuel-specific minimum cost of a next grade in a supply curve (CIGIS: $\$ / E J$ ),

the environmental costs $\mathrm{V}_{\mathrm{is}, 1, \mathrm{~m}}$ is a regional, exogenous time-specific input parameter (VISLM: \$/EJ),

$\mathrm{Tech}_{\mathrm{m}}$ is calculated from input $\mathrm{ST}_{\mathrm{is}, \mathrm{m}}$ which represents a global, exogenous fuel-specific technological change coefficient (STISM: unitless), and

Pfis $_{\text {is, }, 1, \mathrm{~m}}$, which is a regional time-dependent severance fee that can be imposed when extraction costs are calculated (TXISLM: $\$ / G J$ ); this fee is an exogenous or endogenous regional time-period specific (input) parameter. The parameter has an exogenously set or endogenously determined value depending on the type of constraints assumed in a simulation. The parameter may have values for conventional and unconventional oil, conventional gas, and coal extraction but is set to zero for uranium and biomass.

If this fee is considered a carbon severance fee, the fee for unconventional oil is a modified conventional oil fee through multiplication with a carbon emission coefficient ratio:

$$
\begin{aligned}
& \text { Pfis }_{\text {is }, 1, \mathrm{~m}}=\mathrm{Pfis}_{\mathrm{is}=\text { conventionaloil, }, \mathrm{m}} \bullet \mathrm{CO}_{\mathrm{i}=\text { unconventionaloil }} / \mathrm{CO}_{\mathrm{i}=\text { conventionaloil }} \\
& \text { for unconventional oil (\$/GJ) Eq. } 6
\end{aligned}
$$

Once the regional extraction costs are determined, the amount of fuel (ESILM $M_{i, l . m}$ : Energy Supply of primary fuel $i$ in region $l$ : EJ/year) that can be produced for that price is determined by determining the location of the calculated regional extraction costs on the vertical axis of the regional supply curves by interpolation between grades from the $C_{i g, i s}$ data and calculating the related energy from the $R_{i g, i s, l}$ data. We are concerned in these calculations about the amounts of energy available for a certain price; the demand equations will ultimately determine, in an iterative process with prices, how much fuel needs to be extracted when markets need to be cleared. ${ }^{10}$

\footnotetext{
${ }^{10}$ We therefore do not calculate specific fuel prices at this stage, but only set up equation structures that can be activated when prices of energy have been determined through its transformation processes from global primary fuels to energy services, such that when demands are determined, the primary fuel supply can be calculated when markets need to be cleared.
} 
Determining the location of the calculated regional extraction costs on the vertical axis of the regional supply curves and determining from that point the amount of each of the fossil fuel supplies available is calculated in steps.

The annual production rate is calculated from the cumulative production, which is based on the resource amounts and short-term capacity limits. Thus, the cumulative production over time is calculated first.

Total resource available at time $t\left(Q_{i s, l, m}\right)$ would be

$$
\mathrm{Q}_{\mathrm{is}, 1, \mathrm{~m}}=\sum_{\mathrm{ig}=1}^{\mathrm{n}} \mathrm{R}_{\mathrm{ig}, \mathrm{is}, 1}
$$

where $n$ is the grade level below which extraction has to take place for demands to be met at the market price. Thus, when the extraction costs for a grade level (ExtrCost $t_{i s, l, m}$ : see Equation 5, which is modified for unconventional oil based on Equation 6) become larger than this market price $\left(P_{i, l, m}\right)$, extraction costs have to be scaled back and the exact allowable fuel-specific extraction costs have to be determined that meet the fuel-specific market price. The final extraction costs will be located somewhere between grade level $n-1$ and grade level $n$. To determine that price point the following calculation is made

$$
\text { slope }=\frac{\mathrm{R}_{\mathrm{ig}-1, \mathrm{is}, 1}}{\left(\mathrm{C}_{\mathrm{ig}, \mathrm{is}}-\mathrm{C}_{\mathrm{ig}-1, \mathrm{is}}\right)} / \operatorname{Tech}_{\mathrm{m}}
$$

which determines the location on the resource curve. Next, the supply required for production is calculated:

$$
\mathrm{Q}_{\mathrm{is}, 1, \mathrm{~m}}=\sum_{\mathrm{ig}=1}^{\mathrm{n}-1} \mathrm{R}_{\mathrm{ig}, \mathrm{s}, \mathrm{l}}+\left(\mathrm{P}_{\mathrm{i}, \mathrm{l}, \mathrm{m}}-\text { ExtrCost }_{\mathrm{is}, 1, \mathrm{~m}}\right) \bullet \text { slope }
$$

where the calculated potential supply (EJ) is reduced by one grade level and added to by the difference between the market price and the extraction costs of the next grade (Equation 5) multiplied by the 'slope' location.

For the base year, the amount of fossil fuel available at the onset of the simulation is set exogenously, based on annual production $\left(E S I L M_{i l, m}\right.$ : Energy Supply of primary fuel $i$ in region $l$ is set equal to $E S F I L_{i s, l}:$ EJ/year)

$\mathrm{ESILM}_{\mathrm{i}, 1, \mathrm{~m}=1}=\mathrm{ESFIL}_{\mathrm{is}, 1}$ for oil, gas, coal and unconventional oil in base year (EJ/year) Eq. 10

For the projections, annual supply equals double the annualized difference between the supply required for the production at the present and previous point in time divided by the time step minus the previous time period's annual supply:

$\operatorname{ESILM}_{\mathrm{i}, 1, \mathrm{~m}}=2 \bullet \frac{\mathrm{Q}_{\mathrm{is}, 1, \mathrm{~m}}-\mathrm{Q}_{\mathrm{is}, 1, \mathrm{~m}-1}}{\text { Nstep }}-\operatorname{ESILM}_{\mathrm{i}, 1, \mathrm{~m}-1}$

for oil, gas, coal and unconventional oil in projections

(EJ/year) Eq. 11 
This calculation of supply is subject to a short term capacity constraint. This constraint represents the notion that production can only increase by so much from one period to the next. This maximum rate, in EJ/year, is called the short-term supply limit. The short-term supply limit is assumed to be a function of GDP, fuel price, and technological change. The GDP and technological change factors represent, albeit crudely, potential increases in expansion capability due to technological change and the ability of an expanding economy to foster new investment. The price dependence represents a further expansion drive by price increases. Thus, supply can always expand, but this expansion may need to be driven by price increases.

The short-term capacity limit is determined by the production in the previous period time (in $\mathrm{EJ} / \mathrm{yr}$ ) multiplied by the change in $G D P$ and a price factor as

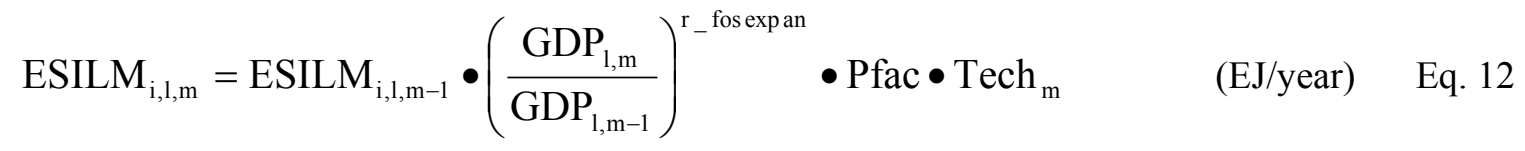

where

ESILM $_{\mathrm{i}, 1, \mathrm{~m}}$ is the regional annual energy production from the previous period; this production rate is exogenously set in the base year (ESFIL: EJ/year) and calculated thereafter,

$\mathrm{Tech}_{\mathrm{m}}$ is the rate of technological change defined above,

$\mathrm{GDP}_{1, \mathrm{~m}}$ is either an exogenously set parameter or calculated and re-iterated in the model (see Section 2.3),

r_fosexpan is an input parameter that controls how fast the short term capacity limit can expand as GDP grows, and

Pfac is a regional primary fuel-specific multiplier (price factor) determined by the ratio of the current to previous price and an elasticity parameter of that ratio. The fuel prices are adjusted to be the extraction costs only, so that the environmental costs are not included. Thus,

$$
\operatorname{Pfac}=\left(\frac{\mathrm{P}_{\mathrm{i}, 1, \mathrm{~m}}-\mathrm{V}_{\mathrm{is}, 1, \mathrm{~m}} / \text { Tech }_{\mathrm{m}}}{\mathrm{P}_{\mathrm{i}, 1, \mathrm{~m}-1}-\mathrm{V}_{\mathrm{is}, 1, \mathrm{~m}-1} \bullet \operatorname{Tech}_{\mathrm{m}-1} / \text { Tech }_{\mathrm{m}}}\right)^{\mathrm{r}_{\mathrm{i}, \mathrm{l}}}
$$

where

$\mathrm{P}_{\mathrm{i}, 1, \mathrm{~m}}$ is the global (market) primary fuel price $(\$ / \mathrm{GJ})^{11}$ at time $\mathrm{t}(\mathrm{m})$, and

$r_{i l}$ is a regional, exogenous primary time period- and fuel-specific extraction cost elasticity parameter $^{12}$ (RIL: unitless).

Note that the GDP factor in the above equation is only applied if GDP is expanding $\left(\mathrm{GDP}_{1, \mathrm{~m}} \bullet \mathrm{Tech}_{\mathrm{m}}>\mathrm{GDP}_{1, \mathrm{~m}-1}\right)$ so that regions with contracting GDPs do not suffer a production penalty.

\footnotetext{
${ }_{11}^{11} \mathrm{P}_{\mathrm{i}, \mathrm{l}, \mathrm{m}}$ gets updated in the solution routines

${ }^{12}$ Representing that a one percent change in the $\mathrm{P}_{\text {fac }}$ at time $t$ results from a one percent $1 \%$ change in the PS ratio; the PS ratio represents the change in the sum of the cost of energy services in each service sector weighted by that sector's share of all energy services at time $t$ divided by the weighted sum calculated during the previous point in time.
} 
The short-term capacity limit thus calculated is compared to an exogenous value (by fuel and region) for a minimum short-term capacity limit. If the capacity limit is smaller than this value, the short-term capacity limit is set to this minimum value. This feature allows production of a fuel to be "re-started" in case production falls to very low levels in any period. Given the dependence of the short-term supply rate on previous production, production of a fuel could be quite small if minimum short-term supply is insufficient. The minimum short-term supplies for conventional oil and gas equal one EJ; for coal they are set equal to the production of coal in 1990; and for unconventional oil they are set to regional-specific values to enable that fuel to always play a role.

The supply of depletable resources is, therefore, determined by a cost curve calculation, adjusted downward if the resulting production exceeds the short-term capacity limit.

Gas lost in gas production (which implicitly includes non-commercial gas use) due to flaring is calculated from flaring coefficients. The equation that determines gas flaring $\left(F L R_{l, m}\right)$ is illustrated in Equation 14 where Flr 1 is the initial proportion of flared gas lost, FLr2 is the ultimate fraction that is lost at time $m$ and Flr3 is the number of years losing FLr2.

$\mathrm{FLR}_{1, \mathrm{~m}}=\mathrm{Flr}_{1} \frac{\left(1-(\mathrm{m}-1)^{*} \mathrm{~N} \text { step }\right)}{\mathrm{Fl} l_{3}} \bullet \mathrm{Flr}_{2} \frac{(\mathrm{m}-1)^{*} \mathrm{~N} \text { step }}{\mathrm{Fl} l_{3}}$ (unitless) Eq. 14

where

Nstep equals 15 and $m$ is the number of time periods since the base year, and Flr11, Flr12, and Flrl3 are regional gas flare parameters.

Gas supply correction is simply

$$
\mathrm{ESILM}_{\mathrm{i}=\mathrm{gas}, 1, \mathrm{~m}}=\mathrm{ESILM}_{\mathrm{i}=\mathrm{gas}, 1, \mathrm{~m}} \bullet\left(1-\mathrm{FLR}_{1, \mathrm{~m}}\right) \quad \quad \text { (EJ/year) } \quad \text { Eq. } 15
$$

If regional production rates are larger than the production capacity limit, the amount of fuel that is regionally produced $\left(\operatorname{ESILM}_{i, l, m}\right)$ is reduced accordingly (Equations 11 and 12) as are the resources that are left (as starting points for a new period)

$$
\mathrm{Q}_{\mathrm{is}, 1, \mathrm{~m}}=\mathrm{Q}_{\mathrm{is}, 1, \mathrm{~m}-1}+\mathrm{Nstep} \bullet \frac{\mathrm{ESILM}_{\mathrm{i}, \mathrm{l}, \mathrm{m}}+\mathrm{ESILM}_{\mathrm{i}, \mathrm{l}, \mathrm{m}-1}}{2} \quad \quad \text { (EJ/year) } \quad \text { Eq. } 16
$$

If regional supply is less than regional demand, additional demands are met through trade. The concept of trade in the MinCAM thus involves finding regions where production of fuels can meet global demand. This is achieved by (1) pooling all regional demands and pooling all regional supplies, and (2) balancing the global supplies and demands of the primary fuels. Trade in primary fuels includes not only crude oil, natural gas, and coal, but also biomass. In practice this is done globally, although regional trading blocks can be constructed for any fuel. No electricity generation sources (nuclear, hydropower, wind, etc.) are traded.

Appendix 6 lists values for parameters described above. Note that market prices for fuels are ultimately determined by the market solution algorithms. 


\section{Uranium supply and its price}

There are no explicit markets for uranium. Therefore the price of uranium is not market dependent and can be determined directly from extraction costs, regional supplies and environmental costs. Uranium supply is based on a long-term supply schedule defined in the same manner as for the other depletable resources. For the first period $(m=1)$ the regional cumulative production $\left(Q_{\text {is=uranium,l, } m}\right)$ is zero. At and after the second period, $(m \geq 2)$ the regional cumulative production is updated by means of the last period's annual production rate

$$
\mathrm{Q}_{\text {is }=\text { nuclear }, 1, \mathrm{~m}}=\mathrm{Q}_{\mathrm{is}, 1, \mathrm{~m}-1}+\text { Nstep } \bullet \mathrm{ESU}_{\text {ui, }, 1, \mathrm{~m}-1} \quad \text { (EJ/year) Eq. } 17
$$

where

$\mathrm{ESU}_{\mathrm{ui}, 1, \mathrm{~m}-1}$ is the demanded (yearly) electricity supply (secondary energy in Joules) generated by nuclear energy in the previous time period.

Global production and the global resource of uranium are used in determining the nuclear fuel price

$$
\begin{aligned}
& \mathrm{Q}=\sum_{\mathrm{l}=1}^{\mathrm{nreg}} \mathrm{Q}_{\mathrm{is}, 1, \mathrm{~m}} \\
& \mathrm{~W}=\sum_{\mathrm{ig}=1}^{\mathrm{n}}\left(\sum_{\mathrm{l}=1}^{\text {nreg }} \mathrm{R}_{\mathrm{ig}, \mathrm{is}, 1}\right)
\end{aligned}
$$

where

$\mathrm{R}_{\mathrm{ig}, \mathrm{s}, \mathrm{l}}$ are the regional supplies (RIGISL: EJ) of uranium (see Figure 5), and $\mathrm{n}$ is the grade level below which extraction can take place for the global production demands $(\mathrm{Q})$ to be met $(\mathrm{Q} \leq \mathrm{W})$.

Extraction costs are then calculated based on regional supply and global production demands

$$
\text { Extr } \cos \mathrm{t}_{\mathrm{is}=\text { uranium }, 1, \mathrm{~m}}=\frac{(\mathrm{R}-\mathrm{Q})}{\mathrm{W}} \bullet \mathrm{C}_{\mathrm{ig}, \mathrm{is}}+\left(1-\frac{(\mathrm{R}-\mathrm{Q})}{\mathrm{W}}\right) \bullet \mathrm{C}_{\mathrm{ig}-1, \mathrm{is}}
$$

and uranium costs are calculated based on environmental costs $\left(V_{i s, l, m}\right)$, raw fuel costs $\left(C_{i g, i s}\right)$ and technological change which is calculated as time period dependent as

Tech $_{\mathrm{m}}=\mathrm{Tech}_{\mathrm{m}-1} \bullet\left(1+\mathrm{ST}_{\mathrm{is}, \mathrm{m}}\right)^{\mathrm{Nstep}}$ starting with the second period's technological change as unity: Tech $_{\mathrm{m}=2}=1$

The price of uranium is then

$$
\mathrm{P}_{\mathrm{i}=\text { uranium }, 1, \mathrm{~m}}=\frac{\mathrm{C}_{\mathrm{ig}, \mathrm{is}}+\mathrm{V}_{\mathrm{is}, 1, \mathrm{~m}}}{\text { Tech }_{\mathrm{m}}}
$$

where

$\mathrm{C}_{\mathrm{ig}, \mathrm{i}}$ is the exogenous global raw fuel-specific minimum extraction cost of a grade in a supply curve (CIGIS: J:\$/GJ),

$\mathrm{V}_{\mathrm{is}, 1, \mathrm{~m}}$ is a regional, exogenous time-specific the environmental costs input parameter (VISLM: $\$ / G J)$ 
$\mathrm{Tech}_{\mathrm{m}}$ is calculated from input $\mathrm{ST}_{\mathrm{is}, \mathrm{m}}$ a global, exogenous fuel-specific technological change coefficient (STISM: unitless).

\section{Biomass supply}

Biomass supply has two components. The first is biomass from waste which includes landfills, agricultural waste, wood wastes, etc. For most regions this supplies almost all of the present biomass demands. The second component of the biomass resource base is biomass from dedicated biomass farms.

A global supply function, analogous to the regional supply curves for coal, gas, oil, and uranium is described by an exogenous parameter set (BIOPSM) relating the costs of waste biomass (1975 $\$ / G J)$ to the fraction of total waste biomass supply available at a given biomass price. This supply function differs from the $R_{i g i s} l / C_{i g i s}$ resource curve in that it has cumulative shares on the horizontal axis and cost on the vertical axis. Future biomass supply in each region is calculated relative to the current supply and depends on the level of economic activity as follows:

$$
\text { ESILM }_{\mathrm{i}, 1, \mathrm{~m}}=\mathrm{BIO}_{1, \mathrm{~m}=1990} \bullet\left(\frac{\mathrm{GDP}_{1, \mathrm{~m}}}{\mathrm{GDP}_{1, \mathrm{~m}=1990}}\right)^{\text {rysht }} \quad \text { (EJ/year) } \quad \text { Eq. } 22
$$

where

the waste resource supply rate in the base year $\left(\mathrm{BIO}_{1, \mathrm{~m}=1990}\right.$ : $\mathrm{BIOLM}$ in $\left.\mathrm{EJ} / \mathrm{yr}\right)$ is an exogenous regional input for the base year (not time-specific),

$\mathrm{GDP}_{1, \mathrm{~m}}$ is as described in Section 2.2.4, and

rysht is the elasticity coefficient ${ }^{13}$ (RYSHT: unitless) which is set to 0.1 for all regions, such that the total amount of waste biomass available increases only slowly with increases in GDP.

The cost of much of the available waste biomass is lower than the cost for biomass produced as a crop; this type of biomass resource is therefore used first. If the price paid for biomass increases enough to exceed the fixed costs of production of agricultural biomass, additional biomass can be supplied by output from the AgLU module. This (second) component of the biomass resource base is biomass from dedicated biomass farms. A biomass price (calculated according to the methodology described in Section 2.2.3) is passed to the AgLU model, which returns the amount of biomass in each region that can be produced at that price. That amount of biomass in EJ per year is added to the biomass supply $\left(\operatorname{ESILM}_{i, l, m}\right)$ available at that point in time. ${ }^{14}$

The AgLU module is described in Part III. Note that biomass can be used directly in the end-use sectors, or converted to a synthetic liquid, a synthetic gas, or can be used for hydrogen production or electricity generation (see Figure 4).

\section{Hydroelectric power}

Hydroelectric power is a resource constrained renewable technology. Thus, electricity generation by hydropower is assumed to approach an exogenously specified limit within each region. Regional production of hydropower is simulated by three parameters that determine its production expectations into the future:

\footnotetext{
${ }^{13}$ Representing that a one percent change in the biomass resource base at time $t$ results from a one percent 1 $\%$ change in the GDP ratio; the GDP ratio represents the change in economic activity at time $t$ over the base year.

${ }^{14}$ This addition is done when synfuel production is calculated
} 
ESILM $_{i=\text { hydro, }, \mathrm{m}}=\mathrm{HydrO}_{3} \bullet \frac{\mathrm{e}^{\mathrm{Hydra}_{1}+\mathrm{Hydro}_{2} \bullet \mathrm{m} \bullet \mathrm{Nstep}}}{1+\mathrm{e}^{\mathrm{Hydro}_{1}+\mathrm{Hydro}_{2} \bullet \mathrm{m} \bullet \mathrm{Nstep}}}$

where

Hydro3 is the resource amount in (E) J,

Hydro1 determines the production path over time, which is modified by by

Hydro2 which determines the shape of that production path over time after being multiplied

Nstep which is MiniCAM's time step of 15 years, and

$\mathrm{m}$ which is the number of timesteps.

The price of hydropower is determined by non-fuel costs only. If, for some reason, total electricity demand in a region falls below the specified hydropower production level, then all electricity demand is assumed to be supplied by hydropower and total hydropower production is scaled back to meet this demand.

\section{Solar PV and Wind}

Generation of electricity by solar PV (photovoltaic) and wind turbines are considered unconstrained renewable resources. The cost of solar PV and wind are each input as exogenous parameters by region and time period.

The amount of electricity that can be usefully delivered by solar PV and wind are limited by the intermittence of these sources. This effect is represented by an exogenously specified capacity limit in the form of the maximum share of regional electricity demand that can be supplied by each of these forms (see below).

\section{Other Renewables}

Geothermal power is not modeled separately, but is assumed included in the hydropower category.

Space solar power (SSP) is implemented as a source of electricity with no capacity constraints. The cost of SSP is specified as a fixed cost for each time period.

Solar-wind (SW) storage is also implemented as a means of storing and then delivering solar PV or wind energy. With this technology, solar PV and wind energy is generated and then stored for delivery into the electric grid as needed. The additional cost of operating the SW-Storage technology is specified. The cost of generating solar and/or wind energy is added to the cost of the SW Storage technology.

\subsubsection{Energy prices}

The MiniCAM calculates a sequence of energy prices that are internally consistent and that ultimately determine supply and demand. Prices are per unit energy (\$/GJ) for primary and secondary energy, and per unit energy services for tertiary energy. The energy service units are technology dependent and can be transformed to energy units (Joules) by technology-specific coefficients (energy services/GJ) (see Figure 4). 


\section{Global primary fuel prices}

The global primary fuel prices $\left(P_{i, l, m}\right)$ are the market prices of each of the primary fuels. They will be identical for each region $l$. They are determined by the solution mechanism when global supplies and demands are balanced.

\section{Base year regional fuel supply prices}

Base year regional fuel prices function only as initial conditions $\left(\operatorname{Pin}_{i n, l, m}\right)$. These initial starting market prices for goods are in (1975) \$/GJ for oil, gas, coal, and biomass and are replaced during the model solution's first iteration in the base year (1990) by the market prices resulting from the solution algorithm. Thus, $P_{i, l, m}$, as $P i n_{i n, l, m}$ equal initial-condition fuel prices that only have a role for model initiation.

\section{Regional fuel prices}

Market prices $\left(P_{i, l, m}\right)$, obtained when supply and demand are balanced are transformed to regional fuel supply prices by adding fuel-specific transportation costs and a regional fee multiplier which represents any regional tax, tariff or subsidy such that reasonable differentiation between regions can be represented:

$\mathrm{P}_{\mathrm{i}, \mathrm{l}, \mathrm{m}}=\left(\mathrm{P}_{\mathrm{i}, \mathrm{l}, \mathrm{m}}+\mathrm{Tr}_{\mathrm{i}}\right) \bullet \mathrm{Pfi}_{\mathrm{i}, 1, \mathrm{~m}}$

$(\$ / G J) \quad$ Eq. 24

where

$\mathrm{P}_{\mathrm{i}, 1, \mathrm{~m}}$, is the global primary fuel price described above.

$\operatorname{Tr}_{\mathrm{i}}$ is the transportation cost which is an exogenous input parameter for oil, gas, coal, or biomass (TRI: \$/GJ), and

$\mathrm{Pfi}_{\mathrm{i}, \mathrm{l}, \mathrm{m}}$ represents regional taxes or subsidies for oil, gas, coal, and biomass (TXILM: unitless) (an exogenous regional and time-period specific through 2050 input parameter). These multipliers can also be interpreted as trade barriers or as a scale factors to regionalize the global fuel prices; the coefficients range from 1.8 to 0.75 ; for biomass they equal one.

\section{Refined regional fuel price}

The refined regional fuel prices or cost of a secondary fuel $\left(P j_{j, l, m}\right)$ is calculated by means of a Leontief production equation (Edmonds and Reilly 1985:248):

$\mathrm{Pj}_{\mathrm{j}, 1, \mathrm{~m}}=\mathrm{P}_{\mathrm{i}, 1, \mathrm{~m}} \bullet \mathrm{gij}_{\mathrm{i}}+\mathrm{hij}_{\mathrm{i}} \quad$ for oil, gas, coal, and biomass/waste $\quad(\$ / \mathrm{GJ}) \quad$ Eq. 25

where

$P \mathrm{j}_{\mathrm{j}, 1, \mathrm{~m}}$ is the regional processed/refined fuel-specific price $(\$ / \mathrm{GJ})$,

$\mathrm{P}_{\mathrm{i}, 1, \mathrm{~m}}$ is the regionalized primary fuel-specific price $(\$ / \mathrm{GJ})$,

$\mathrm{gij}_{\mathrm{i}}$ is an exogenous input parameter representing a conversion coefficient that is not time dependent nor region-specific and has values close to or equal to one; gij i $_{\mathrm{i}}$ represents the relationship of the unrefined input producing one unit of secondary fuel; gij $j_{i}$ is also called conversion intensity of oil, gas, coal, and biomass (GIJ: unitless or GJ of primary energy/GJ refined fuel), and

$\mathrm{hij}_{\mathrm{i}}$ is the non-energy refining costs associated with a unit of secondary fuel (HIJ: $\$ / \mathrm{GJ}$ ), which is an exogenous input parameter that is not time dependent nor region-specific; these costs are also described as mark-up costs or accounting costs of refining and distributing energy in the form of oil, gas, coal, and biomass.

Thus, the production costs or transformation costs from primary fuels to secondary fuels are calculated with fuel-specific input-output coefficients representing conversion efficiency and 
additional non-fuel cost. The refinery coefficients, $g i j_{i}$, have been set to one in recent versions. The non-fuel costs, $h i j_{i}$, are small for biomass and coal, moderate for gas, and much more significant for oil.

The regional refined (secondary) fuel-specific costs $\left(P j_{j, l, m}\right)$ resulting from oil refining and gas processing compete with the costs of synliquid and syngas technology costs, respectively, in determining the final secondary fuel prices for the end-use sectors (see Equation 36). This cost determination in the form of synfuel shares is described in the next section.

\section{Production and production costs of synfuels}

Synfuels are produced from the "raw" fuels. The process is simulated analogously to the refining process described above with the Leontief equation. There are, however, a number of additional considerations. Synfuels are produced for domestic end-use consumption only. They are produced from coal, gas, and biomass with seven potential technologies. When synliquids or syngas are produced from coal, both scrub and non-scrub technologies can be active (four technologies total). Only synthetic liquid is produced from natural gas (one technology); no syngas is produced from natural gas. Either liquids or gas can be produced from biomass (two technologies). The final price of syncrude (synliquid) and syngas production is captured in Equation 36 below. The variables leading up to that equation are described next.

The non-energy costs of syncrude and syngas production from coal, gas and biomass are calculated as follows:

$\mathrm{hc}_{\mathrm{j}, \mathrm{i}}=\mathrm{HCILT}_{1} \frac{(1-(\mathrm{m}-1) \bullet \mathrm{Nstep})}{\mathrm{HCIL}_{3}} \bullet \mathrm{HCLT}_{2} \frac{(\mathrm{m}-1) \bullet \mathrm{Nstep}}{\mathrm{HCLT}_{3}}$

where

$\mathrm{j}$ is the feedstock: gas, coal, or biomass,

$\mathrm{i}$ is the produced crude or gas,

HCILT1, 2, and 3 are the initial non-energy costs, final costs, and the time when final costs are reached, respectively (HCLT parameters are region- and crude and gas specific),

Nstep is 15 (years), and

$\mathrm{m}$ is the number of time periods since the base year.

The basic calculation for the cost of each technology $\left(P C_{j, i, l, m}\right.$ where $i=$ synliquid from $j=$ coal, gas, or biomass; and $i=$ syngas from $j=$ coal or biomass) is as follows (see Equation 36 how $P C_{j, i, l, m}$ is used):

$$
\mathrm{PC}_{\mathrm{j}, \mathrm{i}, 1, \mathrm{~m}}=\left(\mathrm{P}_{\mathrm{i}, \mathrm{l}, \mathrm{m}}+\mathrm{syn} \cos \mathrm{ts}\right) \bullet \mathrm{gc}_{\mathrm{j}, \mathrm{i}}+\mathrm{hc}_{\mathrm{j}, \mathrm{i}}
$$
synliquid from coal, gas, or biomass; syngas from coal or biomass

where

j denotes the feedstock: gas, coal, or biomass,

i denotes the produced crude or gas,

$\mathrm{P}_{\mathrm{i}, \mathrm{l}, \mathrm{m}}$, is the market price for the input fuel feedstock (before transportation costs and taxes are added),

$\mathrm{gc}_{\mathrm{j}, \mathrm{i}}$ is an intensity conversion coefficient of synfuel production (GCI: input GJ/output GJ; a fuel source-specific (coal, gas, biomass) and synfuel-specific (liquid, gas) exogenous conversion coefficient that is the same for each region, does not change over time and has values of 1.5,

$\mathrm{hc}_{\mathrm{j}, \mathrm{i}}$ is the non-energy costs of synfuel production from coal, gas and biomass, as calculated above (Equation 26) for syncrude and syngas when no scrub technology is implemented, but to 
which carbon disposal costs (calculated below) are added when scrub technology is added (see

$\mathrm{h}_{\mathrm{ci}=\text { coal-scrubbed }}$, and

syncosts are the additional costs due to any carbon fee and are calculated in a number of steps that are explained below.

Scrub technologies can be simulated when synfuel is produced from coal. If scrubbing is implemented, carbon sequestration is calculated for the difference in carbon content between coal and the final synfuel type: liquid or gas. The fractional difference of carbon content in emissions from coal, compared to liquids or gas is for example:

$$
\text { SeqFractMax }=\frac{\mathrm{CO}_{\mathrm{i}=\text { coal }}-\mathrm{CO}_{\mathrm{i}=\text { oil }}}{\mathrm{CO}_{\mathrm{i}=\text { coal }}}
$$

(fraction) Eq. 28

where

$\mathrm{CO}_{\mathrm{i}}$ are the fuel-specific carbon contents of fuels, directly related to carbon emission coefficients, in ton $\mathrm{C} / \mathrm{EJ}$.

To calculate the disposal costs of the carbon potentially scrubbed and sequestered, the "carbon penalty" is determined first. Disposal costs are based on capital costs of sequestration equipment for electricity generating plants $\left\{\left(h u_{\text {scrubbed }}-h u_{\text {unscrubbed }}\right) / g u\right\}$, adjusted for synfuel production through multiplication with synfuel-specific conversion rates that are specific for the fuels to be processed $\left(g_{c, j, i}\right)$. When this levelized capital cost $(\$ / G J)$ is divided by the carbon emission rates, an estimate of the levelized capital costs per unit carbon sequestered is obtained ( $\$ /$ tonC).

$$
\text { Cpenalty }_{\mathrm{j}}=\frac{\left(\mathrm{hu}_{\mathrm{ui}, \mathrm{l}, \mathrm{m}, \mathrm{scrubbed}}-\mathrm{hu}_{\mathrm{ui}, \mathrm{l}, \mathrm{m}, \text { non-scrubbed }}\right)}{\mathrm{gu}_{\mathrm{ui}, \mathrm{l}, \mathrm{m}}} \bullet \mathrm{gc}_{\mathrm{j}, \mathrm{i}} \bullet \frac{1}{\mathrm{CO}_{\mathrm{i}=\text { coal }}} \quad \text { (\$/ton C) } \quad \text { Eq. } 29
$$

where

$\mathrm{j}$ is the feedstock: gas, coal, or biomass,

i refers to the crude fuel sources,

ui refers to the utilities,

$\mathrm{hu}_{\mathrm{ui}, 1, \mathrm{~m}}$ are the non-energy costs in 1975 dollars per GJ, which does not include technology and development (HUILM: exogenous regional time- and fuel specific parameters),

$\mathrm{gu}_{\mathrm{ui}, \mathrm{l}, \mathrm{m}}$ is a conversion or energy intensity coefficient, which is unitless (GUILM: units GJ/GJ and values larger than one); an exogenous regional time- and fuel specific parameter representing the ratio of Joules energy input to Joules electricity generated; these conversion factors tend to be larger than one, and

$\mathrm{gc}_{\mathrm{j}, \mathrm{i}}$ is the intensity rate coefficient of synfuel production (GCI: input GJ/output GJ with values of 1.5), and

$\mathrm{CO}_{\mathrm{i}}$ is the fuel-specific emission rate in ton $\mathrm{C} / \mathrm{EJ}$ before refining.

To obtain the total additional cost for carbon sequestration, we must add the cost for disposal of the sequestered carbon, which are assumed to be proportional to the amount sequestered. The cost of disposal is calculated by (1) multiplying the carbon disposal rate (input parameter) by the maximum fraction a plant can sequester, (2) adding the calculated carbon penalty, and (3) multiplying with a converted carbon emission rate $\left(P f O_{u i, l, m}\right)$ that is calculated from the carbon emission rates $C O_{i}$ and a conversion factor (CVRT90: GDP deflator from 1975\$ to 1990\$ hardwired: $C V R T 90=2.212)$. The carbon disposal costs $\left(C s t_{d i s p}\right)$ are then correctly expressed in \$/GJ: 
$\mathrm{Cst}_{\text {disp }}=\operatorname{Pf}_{\mathrm{uil,}, \mathrm{m}} \bullet\left(\right.$ Carbdisp $_{1, \mathrm{~m}} \bullet$ SeqFractMax + Cpenalty $\left._{\mathrm{j}}\right)$

Eq. 30

where

$\mathrm{PfO}_{\mathrm{j}, 1, \mathrm{~m}}$ is explained above (ton $\mathrm{C} / \mathrm{GJ}$ ),

Carbdisp $p_{\mathrm{Im}}$ are the exogenous regional time-specific carbon disposal or sequestration costs in units of (1990) $\$ / \mathrm{mtC}$,

SeqFractMax is explained above (a fraction: Equation 28), and

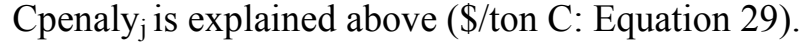

Under a carbon policy the carbon disposal costs plus the price penalty for the carbon that is not sequestered play a role in the final cost determination:

$\mathrm{C}_{\mathrm{seq}}=\mathrm{Cst}_{\mathrm{disp}}+\mathrm{Pfu}_{\mathrm{ui}, 1, \mathrm{~m}} \bullet(1-$ SeqFractMax $)+0.0001$

where

Cst $_{\text {disp }}$ is the carbon sequestration cost described above (units are \$/GJ Equation 33),

SeqFractMax is described above (unitless), and

$\mathrm{Pfu}_{\mathrm{ui}, 1, \mathrm{~m}}$ (in \$/GJ) is the carbon fee based on the fuel-specific carbon contents, which in this case are the $\mathrm{PfO}_{\mathrm{j}, 1, \mathrm{~m}}$ values (tons $\mathrm{C} / \mathrm{GJ}$ ) and $\mathrm{PCR}_{1, \mathrm{~m}}$ in $\$ /$ tons $\mathrm{C}$ ) such that the resulting $\mathrm{Pfu}_{\mathrm{ui}, 1, \mathrm{~m}}$ fees are in units of $\$ / G J$. This type of carbon pricing is set to zero for biomass as energy source.

The variables determining the shares of scrub and non-scrub technology $\left(S_{\text {scrub }}\right.$ and $\left.S_{n o-s c r u b}\right)$ participating in determining the syncost $\left(P C_{i, j, l, m}\right.$ : Equation 27) are the carbon sequestration costs and the penalties for carbon emissions based on carbon prices levied on non-scrub technology. The exponents required in the logit share function are set to -4 . Thus,

$\mathrm{S}_{\mathrm{no-scrub}}=\frac{\mathrm{Pfu}_{\mathrm{ui}, \mathrm{l}, \mathrm{m}}^{-4}}{\mathrm{Pfu}_{\mathrm{ui}, 1, \mathrm{~m}}^{-4}+\mathrm{C}_{\mathrm{seq}}^{-4}}$

(unitless) Eq. 32

and

$\mathrm{S}_{\mathrm{scrub}}=\frac{\mathrm{C}_{\mathrm{seq}}^{-4}}{\mathrm{Pfu}_{\mathrm{ui}, 1, \mathrm{~m}}^{-4}+\mathrm{C}_{\mathrm{seq}}^{-4}}$

(unitless) Eq. 33

The syncost parameter (as part of Equation 27) that represents additional costs due to carbon fees are feedstock-dependent:

o from coal with scrub technology the syncost equals $P f u_{u i, l, m} *\left(1-S_{s c r u b} * R_{e m F r a c}, 1\right)$ where $P f u_{u i, l, m}$ is the carbon fee, RemFrac $_{i, l}$ is an exogenous regional input for the base year, which for coal is 0.9 implying that $90 \%$ of the carbon prices on plants with scrub technology (as determined by $S_{\text {scrub }}$ ) are not levied,

o from coal without scrub technology the syncost equals the carbon fee $P f u_{u i l, l, m}(\$ / \mathrm{GJ}$ : see the description of Equation 31),

0 from gas the syncost equals the carbon fee $P f u_{u i, l, m}$, and

0 from biomass the syncost is zero.

The non-fuel transformation costs, $h c_{j, i}$, (see Equation 26 for calculation of the base non-fuel costs of synfuel production) in the case of coal combustion are increased by the carbon disposal costs; these carbon disposal costs are weighted by the Scrub fraction, which represents the fraction of plants using scrub technology: 
$\mathrm{hc}_{\mathrm{j}, \mathrm{i}=\text { coal+scrubbed }}=\mathrm{hc}_{\mathrm{j}, \mathrm{i}}+\mathrm{S}_{\text {scrub }} \bullet \mathrm{Cst}_{\mathrm{disp}}$

where

$\mathrm{hc}_{\mathrm{j}, \mathrm{i}}$ is the updated for scrub technology non-fuel transformation costs (units are $\$ / G J$ ), and

$\mathrm{Cst}_{\text {disp }}$ is the cost of carbon sequestration described above in Equation 33 (units are \$/GJ).

Note that when electricity and hydrogen are produced from scrub and non-scrub technologies the shares and averaged fuel-specific prices of the two competing technologies (scrub and non-scrub) are determined; when synfuel generation is simulated the share calculations are performed among all secondary fuel liquid technologies and all secondary fuel gas technologies (see Figure 4 and below). Secondly, accounting for the carbon disposal costs is done slightly differently in the electricity and hydrogen generation cases ${ }^{15}$.

To simulate the participation of the synliquid technologies and refined oil in the secondary energy supply called "liquids" and the participation of the syngas technologies and processed natural gas in "gas" as secondary energy supply the following share equation was developed:

SynShare $_{\mathrm{j}, \mathrm{i}, \mathrm{l}, \mathrm{m}}=\frac{\left(\frac{\mathrm{PC}_{\mathrm{j}, \mathrm{i}, \mathrm{l}, \mathrm{m}}}{\mathrm{Pj}_{\mathrm{j}, \mathrm{l}, \mathrm{m}-\text { for-oil,or,gas }}+\mathrm{Pfu}_{\mathrm{ui}, \mathrm{l}, \mathrm{m}}}\right)^{R \mathrm{I}_{\mathrm{ji}}}}{\sum_{\mathrm{ns}}\left(\frac{\mathrm{PC}_{\mathrm{j}, \mathrm{i}, \mathrm{l}, \mathrm{m}}}{\mathrm{Pj}_{\mathrm{j}, \mathrm{l}, \mathrm{m}-\text { for-oil,or,gas }}+\mathrm{Pfu}_{\mathrm{ui}, \mathrm{l}, \mathrm{m}}}\right)^{R \mathrm{RI}_{\mathrm{ji}}}}$ for each of the technologies

(unitless) Eq. 35

where

$\mathrm{j}$ is the feedstock: gas, coal, or oil,

$\mathrm{i}$ is the produced crude or gas,

$\mathrm{PC}_{\mathrm{j}, \mathrm{i}, \mathrm{l}, \mathrm{m}}$ is the cost of each technology producing synfuels: synliquid from coal, gas, or biomass; syngas from coal or biomass, which includes sequestration costs as described above,

$\mathrm{Pj}_{\mathrm{j}, 1, \mathrm{~m}}$ is the cost of producing refined oil or processed natural gas $(\$ / \mathrm{GJ})$,

$\mathrm{Pfu}_{\mathrm{ui}, 1, \mathrm{~m}}$ is the consumption or carbon price (added to the refined oil or processed gas) (\$/GJ),

$\mathrm{RCI}_{\mathrm{ji}}$ is the exponent in the logit share equation; these elasticity coefficient values represent the relationship between syncrude produced from coal, gas and biomass, and syngas produced from coal and biomass, and

ns is 4 for synliquids (when produced from coal, gas, or biomass and competing with refined oil) and $n s=3$ for syngas (when produced from coal or biomass and competing with processed gas).

Note that this SynShare equation calculates the shares first for four liquid technologies and then for three gas technologies (there is no syngas produced from natural gas). Each of the technology costs are normalized against the refined oil costs (the fourth technology in refined oil production)

\footnotetext{
${ }^{15}$ Synfuel generation's cost from coal depends on the $\mathrm{S}_{\text {scub }}$ fraction which results in a weighted cost between scrubber and non-scrub technologies:

$\mathrm{PC}_{\mathrm{jilm}}=\left(\mathrm{P}_{\mathrm{inlm}}+\mathrm{Pfu}_{\text {uilm }} *\left(1-\mathrm{S}_{\text {scrub }} * \operatorname{RemFrac}_{\mathrm{il}}\right)\right)^{*} \mathrm{~g}_{\mathrm{cji}}+\mathrm{PfO}_{\text {uilm }} * \mathrm{~S}_{\text {scrub }}\left\{\right.$ Carbdisp $_{\mathrm{lm}} *$ SeqFractMax $+\left(\mathrm{hu}_{\text {uilm,scrubbed }}{ }^{-}\right.$ $\left.\left.\left.\mathrm{hu}_{\text {uilm,non-scrubbed }}\right) / \mathrm{gu}_{\mathrm{uilm}} * \mathrm{~g}_{\mathrm{cji}} * 1 / \mathrm{CO}_{\mathrm{i}}\right)\right\}+\mathrm{h}_{\mathrm{cji}}$

Hydrogen and electricity generation costs from scrub technologies are formulated as

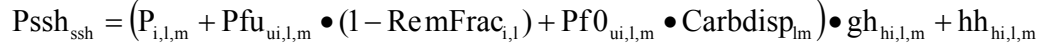


resulting in an endogenous weighting scheme that is represented by exogenous weight parameters in share equations described in the next paragraphs (e.g., $b s u_{i, l, m}$ parameters). Similarly, each of the liquid producing technology costs is normalized against the processed natural gas costs. In Figure 4 sharing is depicted by diagonal boxes. In the case of tracing the synfuel calculations the word "logit" in the diagonal boxes from the raw fuels to synfuel conversions is omitted given that the final share equations are implemented only when the four technologies for liquid production and the three technologies for gas production participate in the cost determination of the secondary fuels.

The final price of liquids, $P j_{j=l i q u i d s, l, m}$, is the summation of the products of the SynShares and the technology-specific prices of synliquids generated from gas, biomass and coal, with the latter generated with or without scrub technology, plus the product of the calculated SynShare and the price of conventional (fossil) refined oil. Similarly, the final price of gas, $P j_{j=g a s, l, m}$, as secondary fuel is the summation of the products of the SynShares and prices of syngas generated from biomass and coal, with the latter generated with or without scrub technology, plus the product of the SynShare of processed natural gas and the price of processed natural gas. Note that the sectorspecific consumption taxes are added to the refined oil and processed natural gas prices. Note also that carbon fees were not applied in the production of secondary fuels (Equation 25).

$$
\mathrm{Pj}_{\mathrm{j}=\text { liquids-or-gas, }, \mathrm{m}}=\sum_{\mathrm{ns}} \text { SynShare }_{\mathrm{j}, \mathrm{i}, \mathrm{l}, \mathrm{m}} \bullet \mathrm{PC}_{\mathrm{j}, \mathrm{i}, \mathrm{l}, \mathrm{m}}+\operatorname{SynShare}_{\mathrm{j}, \mathrm{i}, 1, \mathrm{~m}} \bullet\left(\mathrm{Pj}_{\mathrm{j}=\text { liquids-or-gas, }, \mathrm{m}}+\mathrm{Pfjk}_{\mathrm{j}, \mathrm{k}, \mathrm{l}, \mathrm{m}}\right)
$$

$(\$ / G J) \quad$ Eq. 36

Note that $P f j k_{j, k, l, m}$ is added here while in the SynShare calculation $P f u_{u i l, m}$ was added to $P j_{j, l, m}$ of oil and gas; this can be considered alright given that only unitless shares are calculated in the SynShare equation while secondary prices are calculated in Equation 36.

Synfuels are not used for electricity or hydrogen generation; they are only in end-use sectors.

\section{Hydrogen generation}

Hydrogen fuel can be generated from oil, gas, coal, biomass, and through electrolysis. When oil, gas or solids (comprised of coal and biomass) are converted to hydrogen, technologies with carbon scrubbing and without carbon scrubbing compete if a carbon-policy is in effect.

Without carbon scrubbing the hydrogen generation costs are calculated as follows:

$$
\operatorname{Pssh}_{\text {ssh }}=\left(\mathrm{P}_{\mathrm{i}, 1, \mathrm{~m}}+\mathrm{Pfu}_{\mathrm{ui}, \mathrm{l}, \mathrm{m}}\right) \bullet \mathrm{gh}_{\mathrm{hi}, 1, \mathrm{~m}}+\mathrm{hh}_{\mathrm{hi}, 1, \mathrm{~m}}
$$

where

$P_{i, 1, m}$ is the price of a regional primary fossil fuel (in units of $\$ / G J$ ),

$\mathrm{gi}_{\mathrm{i}, \mathrm{l}, \mathrm{m}}$ is the inverse of conversion efficiency, which is unitless (GHILM: GJ/GJ; an exogenous technology-, regional- and time-period specific input parameter); these conversion factors tend to be larger than one, resulting in prices going up during the transformation process,

$\mathrm{hh}_{\mathrm{i}, \mathrm{l}, \mathrm{m}}$ are non-fuel costs associated with the conversion process (HHILM: \$/GJ) (an exogenous technology-, regional- and time-period specific input parameter),

$\mathrm{Pfu}_{\mathrm{ui}, \mathrm{l}, \mathrm{m}}$ raises the cost of the regional primary fuel consumption in producing hydrogen representing a carbon fee (TXUILM: \$/GJ).

If scrubbing and sequestration are simulated, then the competing technology costs, when oil, gas or solids are transformed, are calculated as follows: 
$\operatorname{Pssh}_{\mathrm{ssh}}=\left(\mathrm{P}_{\mathrm{i}, \mathrm{l}, \mathrm{m}}+\operatorname{Pfu}_{\mathrm{ui}, \mathrm{l}, \mathrm{m}} \bullet\left(1-\operatorname{RemFrac}_{\mathrm{i}, \mathrm{l}}\right)+\operatorname{Pf}_{\mathrm{ui}, \mathrm{l}, \mathrm{m}} \bullet \operatorname{Carbdisp}_{\mathrm{lm}}\right) \bullet \mathrm{gh}_{\mathrm{hi}, \mathrm{l}, \mathrm{m}}+\mathrm{hh}_{\mathrm{hi}, \mathrm{l}, \mathrm{m}}$

where

$(\$ / G J) \quad$ Eq. 38

RemFrac $_{\mathrm{i}, 1}$ is the carbon removal rate (REMFRAC: a regional fuel-specific input for the base year); as with synfuels, any carbon not sequestered is subject to a carbon price,

$\mathrm{PfO}_{\mathrm{i}, 1, \mathrm{~m}}$ is a conversion factor that accounts for the carbon content of the fuel used and is calculated from carbon content factors $\mathrm{CO}_{\mathrm{i}}(\mathrm{COI}$ : tons $\mathrm{C} / \mathrm{J}$ ) and a conversion factor (CVRT90: GDP deflator from $1975 \$$ to $1990 \$$ ) for accounting purposes, such that when these carbon emission rates (tons C/EJ divided by CVRT90) are multiplied with

Carbdisp $\mathrm{p}_{1, \mathrm{~m}}$, the carbon disposal cost (CARBDISP $_{\operatorname{lm}}$ an exogenous regional time dependent disposal cost in units of $\$ /$ Mton $C$ ), the correct result is expressed in $\$ / G J$.

$S s h_{h i, l}$ are the shares of the scrubbed and non-scrubbed oil, or scrubbed and non-scrubbed gas, or scrubbed and unscrubbed coal:

$\operatorname{Ssh}_{\mathrm{hi}, 1}=\frac{\text { bssh }_{\mathrm{hi}, 1, \mathrm{~m}} \bullet \mathrm{Pssh}_{\text {ssh }^{\text {ruiss }}}}{\sum_{\mathrm{nc}}\left(\mathrm{bssh}_{\mathrm{hi}, 1, \mathrm{~m}} \bullet \mathrm{Pssh}_{\mathrm{ssh}^{\text {ruiss }}}\right)}$

(unitless) Eq. 39

where

nc equals two (the competingscrub and non-scrub technologies),

$\mathrm{bssh}_{\mathrm{hi}, \mathrm{l}, \mathrm{m}}$ is the base share or weight of a scrub or non-scrub technology (BSSHILM: unitless) (an exogenous regional time-period fuel/technology-specific input parameter),

$\mathrm{Pssh}_{\text {ssh }}$ is the cost of each technology participating (competing) in producing hydrogen, and

$r_{\text {uiss }}$ is the logit exponent for the technology cost (RUISS: unitless; an exogenous technology specific input parameter set to -6 for all technologies).

When a scrub and non-scrub technologies compete, the costs of the fuel-specific hydrogen generation are the weighted sums of the technology-specific costs:

$\mathrm{PH}_{\mathrm{hi}, 1, \mathrm{~m}}=\sum_{\mathrm{nc}}\left(\mathrm{Ssh}_{\mathrm{hi}, 1} \bullet \mathrm{Pssh}_{\mathrm{ssh}}\right) \quad$ generated from oil, gas, or solids $\quad(\$ / \mathrm{GJ}) \quad$ Eq. 40

The cost of hydrogen generation from biomass is calculated as follows, given that no taxes are levied when produced and no scrub technology is deployed:

$\mathrm{PH}_{\mathrm{hi}, 1, \mathrm{~m}}=\mathrm{P}_{\mathrm{i}, 1, \mathrm{~m}} \bullet \mathrm{gh}_{\mathrm{hi}, 1, \mathrm{~m}}+\mathrm{hh}_{\mathrm{hi}, 1, \mathrm{~m}} \quad$ generated from biomass $\quad(\$ / \mathrm{GJ}) \quad$ Eq. 41

Hydrogen can also be generated through electrolysis. The cost calculation is the same as the equation above, except that the price $\left(P_{i, l, m}\right)$ is not the price of biomass but is the price of electricity $\left(P U_{u i, l}\right.$ : see Equation 47$)$. Several options exist for specifying the electricity price used for $\mathrm{H}_{2}$ production. It can be the average price of electricity before capacity limitations are implemented (see next section) or the weighted price of wind and solar. 


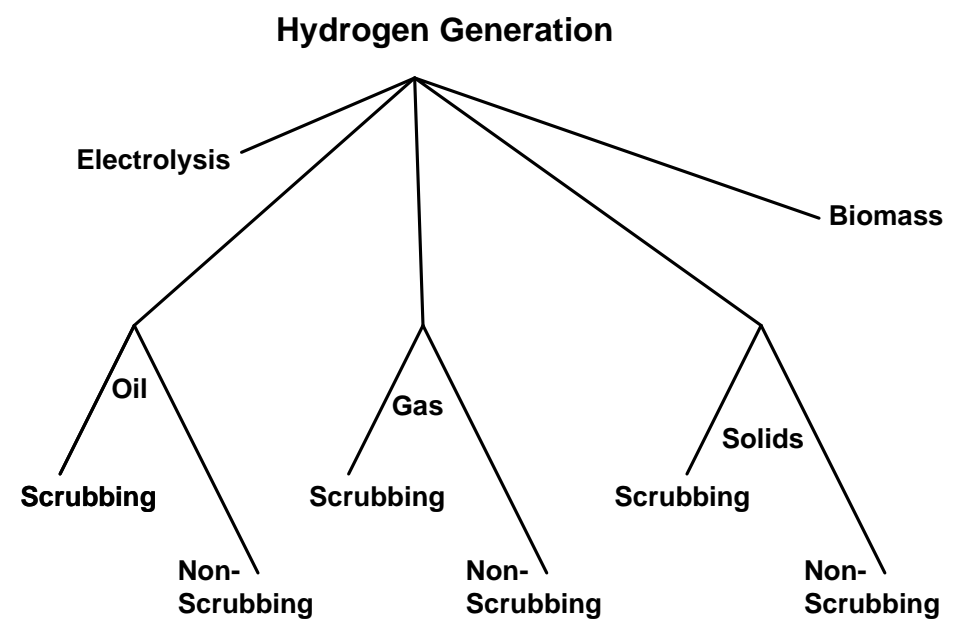

Figure 7 Nesting of cost calculations of hydrogen generation

The final price of hydrogen, $P j_{J=h y d r o g e n, l, m}$, is calculated by summing the weighted hydrogen costs. Figure 7 illustrates the nesting of the weights.

$$
\mathrm{Pj}_{\mathrm{j}=\text { hydrogen }, 1, \mathrm{~m}}=\sum_{\text {nhprices }} \mathrm{Sh}_{\mathrm{hi}, 1} \bullet \mathrm{PH} \mathrm{hi}, 1, \mathrm{~m}
$$

where

$\mathrm{PH}_{\mathrm{hi}, \mathrm{l}, \mathrm{m}}$ is the technology-specific and/or resulting from competing technologies hydrogen generation cost,

$\mathrm{Sh}_{\mathrm{hi}, \mathrm{l}}$ are the shares of the competing sources (in the form of prices) in generating hydrogen; the shares are calculated with the share equation as follows:

$$
\mathrm{Sh}_{\mathrm{hi}, \mathrm{l}}=\frac{\mathrm{bsh}_{\mathrm{hi}, 1, \mathrm{~m}} \bullet \mathrm{PH}_{\mathrm{hi}, 1, \mathrm{~m}}{ }^{\text {rhi }}}{\sum_{\text {nhprices }}\left(\mathrm{bsh}_{\mathrm{hi}, \mathrm{l}, \mathrm{m}} \bullet \mathrm{PH}_{\mathrm{hi}, \mathrm{l}, \mathrm{m}}{ }_{\text {rhi }}\right)}
$$

where

nhprices equals four for hydrogen generation,

$\mathrm{bsh}_{\mathrm{hi}, \mathrm{l}, \mathrm{m}}$ are the fuel-specific time-dependent global base share coefficients or weights of hydrogen technologies, presently set to one,

rhi is a global technology specific logit exponent reflecting the responses of hydrogen prices to changes in technology costs (RHI: unitless).

When scrub technology competes with non-scrub technologies, an option exists to allow the scrub share of the technology to be set as a fraction of the non-scrub technology based on "grandfathering" existing plants. This means that a fraction of the old plants remains active until the plants' lifetimes have been reached. The fraction of plants with scrub technology is determined by the number of time periods past the policy start date (maximally three) divided by three, given that the maximum lifetime of a non-scrub technology is set to three time periods. The share parameters are consequently adjusted accordingly. 


\section{Electricity generation}

Electricity can be generated directly by any one of the following sources and technologies: (1) oil, (2) gas, (3) coal, (4) nuclear power, (5) solar PV, (6) hydro power, (7) biomass, (8) coal with scrub technology and carbon sequestration, (9) oil with scrub technology and carbon sequestration, (10) gas with scrub technology and carbon sequestration, (11) hydrogen fuel cells, (12) fusion, (13) wind power, (14) solar-wind storage, and (15) space satellite PV solar.

\section{Electricity Generation}

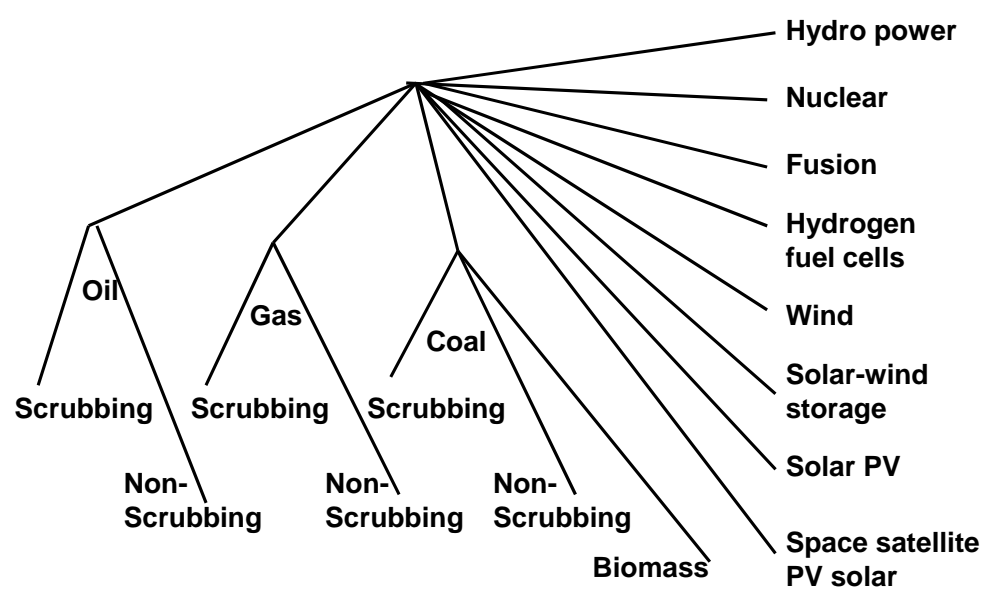

Figure 8 Nesting of cost calculations of electricity generation

Electricity generation cost is computed, as for hydrogen generation with two levels of nesting using the logit approach (Figure 8).

The costs of electricity generated through scrub and non-scrub technologies using oil, gas or solids (which are comprised of coal and biomass) as feedstock are calculated similarly to hydrogen production cost calculations from these fuels. Additional electricity generation coefficients (or price adjusters: $\left.p a_{i, l} s\right)$ adjust the regionalized fossil fuel prices $\left(P_{i, l, m} \mathrm{~s}\right.$ for oil, gas and solids), however, to account for fuel use in utilities given the fact that electric generators, in general, get lower rates than other sectors. Thus, $P_{s s u}$, the cost of each fossil-fuel combusting technology participating (competing) in producing electricity is calculated for non-scrub technologies as:

$$
\operatorname{Pssu}_{\mathrm{ssu}}=\left(\mathrm{P}_{\mathrm{i}, 1, \mathrm{~m}} \bullet \mathrm{pa}_{\mathrm{ui}, 1}+\mathrm{Pfu}_{\mathrm{ui}, 1, \mathrm{~m}}\right) \bullet \mathrm{gu}_{\mathrm{ui}, 1, \mathrm{~m}}+\mathrm{hu}_{\mathrm{ui}, 1, \mathrm{l}, \mathrm{m}}
$$

from oil, gas, and solids (\$/GJ) Eq. 44

and for scrub technologies as:

$$
\begin{array}{r}
\left.\operatorname{Pssu}_{\mathrm{ssu}}=\mid \mathrm{P}_{\mathrm{i}, 1, \mathrm{~m}} \bullet \mathrm{pa}_{\mathrm{ui}, 1}+\mathrm{Pfu}_{\mathrm{ui}, 1, \mathrm{~m}} \bullet\left(1-\operatorname{RemFrac}_{\mathrm{j}, 1}\right)+\operatorname{Pf0}_{\mathrm{ui}, 1, \mathrm{~m}} \bullet \operatorname{Carbdisp}_{1, \mathrm{~m}}\right\rfloor \bullet \mathrm{gu}_{\mathrm{ui}, 1, \mathrm{~m}}+\mathrm{hu}_{\mathrm{ui}, 1, \mathrm{~m}} \\
\text { from oil, gas, or solids }
\end{array}
$$

where

$\mathrm{pa}_{\mathrm{ui}, 1}$ is the electricity generation coefficient (or price adjuster), which adjusts the regionalized fossil fuel price (oil, gas, solids) to account for fuel use in utilities (unitless: PAUIL exogenous 
regional fossil fuel-specific parameter), and all other parameters are as described for hydrogen production,

$\mathrm{Pfu}_{\mathrm{ui}, 1, \mathrm{~m}}$ raises the cost of the regional primary fuel consumption in producing electricity representing a carbon fee (TXUILM: \$/GJ),

RemFrac $_{i, 1}$ is the carbon removal rate (REMFRAC: a regional fuel-specific input for the base year); as with synfuels, any carbon not sequestered is subject to a carbon price,

$\mathrm{PfO}_{\mathrm{ui}, \mathrm{l}, \mathrm{m}}$ is a conversion factor that accounts for the carbon content of the fuel used and is calculated from carbon content factors $\mathrm{CO}_{\mathrm{i}}(\mathrm{COI}$ : tons $\mathrm{C} / \mathrm{J})$ and a conversion factor $(\mathrm{CVRT} 90$ : GDP deflator from $1975 \$$ to $1990 \$$ ) for accounting purposes, such that when these carbon emission rates (tons C/EJ divided by CVRT90) are multiplied with

Carbdisp $\mathrm{p}_{\mathrm{l}, \mathrm{m}}$, the carbon disposal cost (CARBDISP ${ }_{\mathrm{lm}}$ an exogenous regional time dependent disposal cost in units of $\$ / M t o n C$ ), the correct result is expressed in $\$ / G J$.

$\mathrm{gu}_{\mathrm{ui}, \mathrm{l}, \mathrm{m}}$ is the inverse of conversion efficiency specific to the technology, which is unitless (GUILM: GJ/GJ; an exogenous technology-, regional- and time-period specific input parameter); these conversion factors tend to be larger than one, resulting in prices going up during the transformation process, and

$\mathrm{hu}_{\mathrm{ui}, \mathrm{l}, \mathrm{m}}$ are non-fuel costs specific to the technology associated with the conversion process (HUILM: \$/GJ) (an exogenous technology-, regional- and time-period specific input parameter representing operation and maintenance costs and plant costs levelized over its lifetime).

When (pure) biomass is used as feedstock the $P f u_{u i, l, m}$ carbon fees are set to zero ${ }^{16}$ :

$$
\operatorname{Pssu}_{\mathrm{ssu}}=\left(\mathrm{P}_{\mathrm{i}, 1, \mathrm{~m}}+\mathrm{Pfu}_{\mathrm{ui}, \mathrm{l}, \mathrm{m}}\right) \bullet \mathrm{pa}_{\mathrm{ui}, \mathrm{l}} \bullet \mathrm{gu}_{\mathrm{ui}, \mathrm{l}, \mathrm{m}}+\mathrm{hu}_{\mathrm{ui}, 1, \mathrm{~m}} \quad \text { for biomass }(\$ / \mathrm{GJ}) \quad \text { Eq. } 46
$$

The costs of electricity generation for oil or gas are the weighted sums of the scrub and non-scrub technology costs $(n c=2)$. The cost of electricity generated from 'solids' is the weighted sum of thescrub and non-scrub technologies of coal and the biomass technology $(n c=3)$.

$$
\mathrm{PU}_{\text {ui }, 1, \mathrm{~m}}=\sum_{\mathrm{nc}} \mathrm{Ssu}_{\text {ui }, 1} \bullet \mathrm{Pssu}_{\text {ssu }}
$$

where

$\mathrm{Ssu}_{\mathrm{ui}, 1}$ are the electricity generation shares of the scrub and non-scrub technologies using the logit share equation:

$$
\mathrm{Ssu}_{\mathrm{ui}, \mathrm{l}}=\frac{\mathrm{bssu}_{\mathrm{ui}, 1, \mathrm{~m}} \bullet \mathrm{Pssu}_{\mathrm{uus}}^{\text {ruiss }}}{\sum_{\mathrm{nc}}\left(\mathrm{bssu}_{\mathrm{ui}, 1, \mathrm{~m}} \bullet \mathrm{Pssu}_{\text {uus }}^{\text {ruiss }}\right)}
$$

where

$\mathrm{nc}$ is the number of competing technologies; $\mathrm{nc}=2$ for oil and gas representingscrub and nonscrub technologies; $n c=3$ for 'solids' represented byscrub and non-scrub technologies of electricity generation from coal and an additional technology from biomass,

$\mathrm{bssu}_{\mathrm{ui}, \mathrm{l}, \mathrm{m}}$ are the base shares or weights (sometimes called scale parameters) of each of the electricity generating scrub and non-scrub fuel technologies (BSSUILM: unitless exogenous regional time-period fuel technology-specific input parameters as initial values); these share parameters are zero in the base year for the carbon sequestration technologies (there is no carbon

\footnotetext{
${ }^{16}$ the fuel-price adjuster $\left(\mathrm{pa}_{\mathrm{uil}}\right)$ and carbon prices $\left(\mathrm{Pfu}_{\mathrm{uilm}}\right)$ are potentially interacting differently: $\mathrm{Pfu}_{\text {uilm }} * \mathrm{pa}_{\text {uil }}$
} 
scrubbing in 1990) while values for other fuels for the base year are calculated by the model during the base year calibration,

$r_{\text {uiss }}$ is the elasticity of the fuel price (RUI(SS): unitless), that is, a parameter that is related to the variance of the fuel price distribution; $r_{u i}$ determines the rates that shares change in response to a change in generation $\operatorname{cost}^{17}$ (an exogenous technology and time-period specific input parameter).

When scrub technologies competes with non-scrub technologies, the scrub share of the technology can simply be set to be a fraction of the non-scrub technology based on "grandfathering" of existing plants. This means that a fraction of the old plants remains active until the plants' lifetimes have been reached. This concept can be applied to hydrogen production as well.

Note that when prices are calculated for non-fossil fuels, as shown below, the $P f u_{u i, l, m}$ parameters do not represent the so-called "carbon fees"; they are separate input parameters (e.g., utility consumption fees) or set to zero.

The cost calculation of electricity generated by nuclear energy is similar to those above, although with no price adjustment since uranium fuel is only used for nuclear power:

$$
\mathrm{PU}_{\mathrm{ui}, 1, \mathrm{~m}}=\left(\mathrm{P}_{\mathrm{i}=\text { uranium, }, \mathrm{m}, \mathrm{m}}+\mathrm{Pfu}_{\mathrm{ui}, \mathrm{l}, \mathrm{m}}\right) \bullet \mathrm{gu}_{\mathrm{ui}, \mathrm{l}, \mathrm{m}}+\mathrm{hu}_{\mathrm{ui}, \mathrm{l}, \mathrm{m}} \quad \text { from nuclear energy } \quad(\$ / \mathrm{GJ}) \quad \text { Eq. } 49
$$

Electricity generation from hydropower, fusion, solar PV, space-solar power, or wind differs from the above in that $P_{i, l, m}$ equals zero:

$$
\mathrm{PU}_{\mathrm{ui}, 1, \mathrm{~m}}=\left(0+\mathrm{Pfu}_{\mathrm{ui}, 1, \mathrm{~m}}\right) \bullet \mathrm{gu}_{\mathrm{ui}, 1, \mathrm{~m}}+\mathrm{hu}_{\mathrm{ui}, 1, \mathrm{~m}} \quad \text { from solar PV or wind } \quad(\$ / \mathrm{GJ}) \quad \text { Eq. } 50
$$

When wind-solar storage is calculated a simple weighted price is calculated with price elasticities of -3 plus an additional non-fuel storage cost:

$$
\begin{aligned}
& \mathrm{PU}_{\text {ui, }, \mathrm{m}, \mathrm{m}}=h u_{\text {ui, }, \mathrm{m}, \mathrm{m}}+\mathrm{P}_{\text {wind }} \cdot \frac{\mathrm{P}_{\text {uus, wind }}^{-3}}{\mathrm{P}_{\text {uus,wind }}^{-3}+\mathrm{P}_{\text {uus, solar }}^{-3}}+\mathrm{P}_{\text {solar }} \cdot \frac{\mathrm{P}_{\text {uus,solar }}^{-3}}{\mathrm{P}_{\text {uus, wind }}^{-3}+\mathrm{P}_{\text {uus, solar }}^{-3}} \\
& \text { from wind-solar storage (\$/GJ) Eq. } 51
\end{aligned}
$$

When electricity is generated by means of hydrogen fuel cells, the fuel price is from hydrogen, as calculated above. No carbon fees are applied in this case:

$$
\mathrm{PU}_{\mathrm{ui}, 1, \mathrm{~m}}=\mathrm{Pj}_{\mathrm{j}=\text { hydrogen,l, } \mathrm{m}} \bullet \mathrm{gu}_{\mathrm{ui}, 1, \mathrm{~m}}+\mathrm{hu}_{\mathrm{ui,l, \textrm {m }}} \quad \text { from hydrogen fuel cells }(\$ / \mathrm{GJ}) \quad \text { Eq. } 52
$$

\footnotetext{
${ }^{17}$ Elasticities are parameters representing the relationship between the percentage change in output resulting from a one percentage change in the value of the base parameter. Thus, when $\mathrm{Z}=\mathrm{X}^{\mathrm{B}}, \mathrm{B}=d \ln \mathrm{Z} / \mathrm{d} \ln$ $\mathrm{X}$, or, the percentage change in $\mathrm{Z}$ results from a one percentage change in $\mathrm{X}$ (Edmonds and Reilly 1985:248-249).
} 
The final price of electricity, $P j_{j=e l e c t r i c i t y, l, m}$, is the simple summation of the cost of each of the generation processes (technologies) weighted by that generation process' share of all processes (technologies):

$$
\mathrm{Pj}_{\mathrm{j}=\text { electricity,l,m }}=\sum_{\text {neprices }} \mathrm{SU}_{\text {ui,l }} \bullet \mathrm{PU}_{\text {ui,l, } \mathrm{m}}
$$

where

$\mathrm{PU}_{\mathrm{ui}, 1, \mathrm{~m}}$ is the technology-specific electricity generation cost,

$\mathrm{SU}_{\mathrm{ui}, 1}$ are the shares of a the competing fuels (technologies) (in the form of prices) in generating electricity as secondary fuel; these shares are calculated with the logit share equation:

$$
\left.\mathrm{SU}_{\mathrm{ui}, \mathrm{l}}=\frac{\mathrm{bsu}_{\mathrm{ui}, \mathrm{l}, \mathrm{m}} \bullet \mathrm{PU}_{\mathrm{ui}, \mathrm{l,m}}{ }^{\text {rui }}}{\sum_{\text {neprices }}\left(\mathrm{bsu}_{\mathrm{ui}, \mathrm{l,m}} \bullet \mathrm{PU}_{\mathrm{ui}, \mathrm{l}, \mathrm{m}}\right. \text { rui }}\right)
$$

where

neprices are the number of participating electricity generating technologies,

$\mathrm{bsu}_{\mathrm{uil}, \mathrm{lm}}$ are the regional fuel-specific and time dependent base shares or weights of the fuels/technologies participating in electricity generation. These parameters are overridden during the calibration process; most shares are assumed to have equal values by 2050; Coal is an exception -- deviates from price-derived shares are found in many regions, so extrapolation is extended to 2065 and is non-linear (BSUILM: unitless), and

rui is a global technology specific elasticity parameter reflecting the responses of electricity prices to changes in technology costs (RUI: unitless).

The MiniCAM does not explicitly model dispatch for electricity generation. One of the more important implications of this is that direct use of intermittent sources such as wind or solar PV is limited unless some storage mechanism is provided. Therefore, each electricity generation technology is assigned a capacity limit (EcapLim; an exogenous technology-specific fraction representing the maximum contribution of that technology to the generation of electricity). This can also be used to represent technologies that are generally used for base-load generation such as coal-fired plants or nuclear generation that cannot be rapidly shifted to follow changing loads.

The technology-specific capacity limit is the maximum share that any of the electricity generation technology can supply which feeds back into the fossil fuel balance of supply and demand. This is particularly important for intermittent renewable technologies such as solar photovoltaics and wind. The technology-specific capacity limit capacity limit is implemented by rescaling the fuel shares $\left(S u_{u i, l}\right)$ that partake in the generation of electricity if any of the technologies exceeds the limit (see Equation 54). Hydropower contribution remains fixed.

Note that the capacity limits set in variable ECapLim apply to end-use electricity only, not to the total electricity generated, which includes electricity used to make $\mathrm{H}_{2}$. The capacity limit does not apply to electrolytic hydrogen production. Solar PV, for example, may be limited to supplying $10 \%$ of the total end-use electricity demand but can supply an unlimited amount of electrolytic hydrogen.

\section{The costs of energy services in the form of fuel mode prices}

Energy services are envisioned as energy available for a specific end-use demand in the end-use or demand sectors. Energy services are generated by processes transforming the secondary energy into meeting sector-specific demands, e.g., meeting heating and cooling demands for liquids in 
buildings will be met by different fuel transformation processes than meeting liquid demands for the transportation sector. Since the MiniCAM operates on a very aggregate level, the transformation parameters do not represent specific technologies, but broad classes of technologies aggregated by sector (transportation, buildings, industry) and secondary fuel-type (liquids, gas, coal, biomass, electricity, hydrogen). For example, we aggregate all energy services provided by liquid fuels in the building sector.

The fuel mode price $P j k_{j, k, l, m}$ is the cost of an energy service to an end-use sector $k$, for region $l$ at time $m$. This is (again) a Leontief equation which combines the secondary fuel price $\left(P j_{j=l i q u i d s s, l, m}\right.$, $P j_{j=\text { gases }, l, m}, P j_{j=\text { coal }, l, m}, P j_{j=e l e c t r i c i t y, l, m}, P j_{j=h y d r o g e n, l, m}$ or $\left.P j_{j=\text { biomass }, l, m}\right)$, the energy service-specific conversion coefficients or input-output coefficients $\left(g j k_{j, k}\right)$ and the non-energy costs of the transformation process $\left(h j k_{j, k}\right)$ :

$P \mathrm{jk}_{\mathrm{j}, \mathrm{k}, 1, \mathrm{~m}}=\left(\mathrm{Pj}_{\mathrm{j}, 1, \mathrm{~m}} \bullet \mathrm{gj \textrm {k }} \mathrm{j,k}_{\mathrm{j}, \mathrm{hj}}\right)$

(\$/energy service) Eq. 55

where

$\mathrm{gjk}_{\mathrm{j}, \mathrm{k}} \mathrm{s}$ an energy service-specific conversion coefficient or input-output coefficient, representing the relative amount of energy that is needed to provide energy services by fuel $j$ (liquids, gas, coal, electricity, hydrogen, and biomass) for use in end-sector $k$ (GJK: GJ/energy service; an exogenous sector-specific input parameter); these coefficients are further disaggregated for the transportation sector as sectoral-, regional- and time-specific (as $\left.\mathrm{gjk}_{\mathrm{j}, \mathrm{k}, \mathrm{l}, \mathrm{m}}\right)$, and for the hydrogen fuel cell technology unique and sector- and time-specific (as gjk $\mathrm{k}_{\mathrm{j}, \mathrm{k}, \mathrm{m}}$ ),

$\mathrm{hjk}_{\mathrm{j}, \mathrm{k}}$ is the non-energy cost of the end-use technology that uses fuel $j$ (liquids, gas, coal, electricity, hydrogen, or biomass) in end-sector $k$ (HJK: \$/energy service; an exogenous sector specific input parameter): these coefficients are also more disaggregated for the transportation sector (as hjkl $\mathrm{j}_{\mathrm{j}, \mathrm{k}, \mathrm{l}, \mathrm{m}}$ ) and hydrogen fuel cells (as hjk $\left.\mathrm{k}_{\mathrm{j}, \mathrm{k}, \mathrm{m}}\right)$, and

$P \mathrm{j}_{\mathrm{j}, 1, \mathrm{~m}}$ is the price of a secondary fuel $\mathrm{j}$ in region 1 at time $\mathrm{m}(\$ / \mathrm{GJ})$, where

o $P j_{j=l i q u i d s, l, m}$ and $P j_{j=\text { gases }, l, m}$ were discussed under the synfuel generation section (see final liquids and gas calculation in Equation 36), which contain any carbon fees for these fuels;

o Carbon fees (Pfjk; \$/GJ) are added to the price of coal (see Equation 25 and Equation 56 below) before Equation 55 is calculated:

$$
\mathrm{Pj}_{\mathrm{j}=\mathrm{coal}, 1, \mathrm{~m}}=\mathrm{Pj}_{\mathrm{j}=\mathrm{coal}, 1, \mathrm{~m}}+\mathrm{Pfj}_{\mathrm{j}, \mathrm{k}, 1, \mathrm{~m}}
$$

o The cost of biomass production, $P j_{j=b i o m a s s, l, m}$, does not incur carbon fees and is determined with Equation 25;

- Sector- and time-specific transmission and distribution costs (PUTD; \$/GJ) are added to the cost of electricity (see Equation 53 and Equation 57 below) before Equation 55 is calculated:

$\mathrm{Pj}_{\mathrm{j}=\text { electricity, }, \mathrm{m}}=\mathrm{Pj}_{\mathrm{j}=\text { electicity }, 1, \mathrm{~m}}+\mathrm{PUTD}_{\mathrm{k}, \mathrm{m}}$

o Sector- and time-specific distribution costs (PH2TD; \$/GJ) are added to the cost of hydrogen fuel (see Equation 42 and Equation 58 below) before Equation 55 is calculated:

$$
\mathrm{Pj}_{\mathrm{j}=\text { hydrogen,1,m }}=\mathrm{Pj}_{\mathrm{j}=\text { hydrogen, }, \mathrm{m}}+\mathrm{PH}_{2} \mathrm{TD}_{\mathrm{k}, \mathrm{m}} \quad \text { (\$/GJ) Eq. } 58
$$

\section{Total cost of energy services to an end-sector}

The total cost of energy services to an end-sector $k$ ( $P k_{k, l, m}$ in $\$$ /energy services) can now be calculated from the fuel mode-specific prices $P j k_{j, k, l, m}$ and the shares $S P j k_{j, k, l}$ of the fuels in an endsector $k$ : 
$\mathrm{Pk}_{\mathrm{k}, \mathrm{l}, \mathrm{m}}=\sum_{\mathrm{j}}\left(\mathrm{SPjk}_{\mathrm{j}, \mathrm{k}, \mathrm{l}} \bullet P j \mathrm{k}_{\mathrm{j}, \mathrm{k}, \mathrm{l,m}}\right)$

(\$/energy service) Eq. 59

where

$\mathrm{Pjk}_{\mathrm{j}, \mathrm{k}, \mathrm{l}, \mathrm{m}}$ is the energy service price of fuel mode $j$ to end-sector $k$ (\$/energy service), and

$\mathrm{SPj}_{\mathrm{j}, \mathrm{k}, \mathrm{l}}$ are the shares of the fuel modes $j$ in end-sector $k$ (unitless); these share coefficients are read in for the base year (SJKLP: unitless regional sector shares that are specific for oil, gas, coal, biomass, electricity, and hydrogen); they are overridden after future demands for energy services are calculated by the (lagged for one time period) $\mathrm{Sjk}_{\mathrm{j}, \mathrm{k}, \mathrm{l}}$ demand shares as calculated for the previous period. These demand shares are calculated as follows:

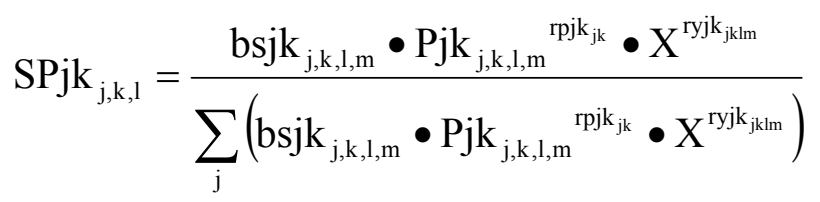

where

$\mathrm{bsjk}_{\mathrm{j}, \mathrm{k}, \mathrm{l}, \mathrm{m}}$ is the base share or weight of a given fuel mode $j$ in end-use sector $k$ and is unitless (BSJK); BSSJKLM separates out coal and biomass and is also an exogenous regional sector- and time period-specific parameter used in calibration in the base year; these weights are recalculated during the model's re-iteration process and may be used in the calibration process,

$\mathrm{Pjk}_{\mathrm{j}, \mathrm{k}, 1, \mathrm{~m}}$ is the price of the service as provided by a given fuel mode $j$ in sector $k$ (\$/energy service),

$\mathrm{rpjk}_{\mathrm{j}, \mathrm{k}}$ is the price elasticity of that service in sector $k$ (RPJK: unitless; exogenously sector- and secondary fuel-specific parameter for liquids, gas, solids (coal+biomass), electricity, and hydrogen (hydrogen 's rpjk value is that of electricity's); RSSPJK is the price elasticity when separating out coal and biomass,

$\mathrm{X}$ represents economic activity by the ratio (unitless) of GDP per capita at time $t(m)$ and GDP per capita in the base year,

ryjk $_{\mathrm{jklm}}$ is the economic activity elasticity (RYJKLM: unitless) (regional sector- and fuel mode-specific time-dependent input parameter). This elasticity exponent of $\mathrm{X}$ represents the relationship between the fuel mode demand and the economic activity (represented by the change in GDP at time $m$ from the base year). ${ }^{18} 19$

\section{The energy service price index}

The energy service price index or aggregate service price index represents the change in aggregate energy prices between two model periods. This is computed as the ratio of the sum of the cost of energy services in each service sector weighted by that sector's share of all energy services at time $t$ divided by the weighted sum calculated during the previous model period. Thus, the weighted sum of the individual energy service prices, $P S$ (unitless), is

\footnotetext{
${ }^{18} \mathrm{r}_{\mathrm{yklm}}$ : hydrogen's economic elasticity value equals that for electricity; in the case of biomass it equals that for coal.

${ }^{19}$ In the demand equation for energy services by the transportation and building sectors the elasticity coefficient $\left(r y_{k l m}\right)$ of $X$ represents the relationship between energy services demands and the change in income (represented by GDP per capita) from the base year
} 


$$
\mathrm{PS}_{\text {ratio }}=\frac{\sum_{\mathrm{k}} \mathrm{bsk}_{\mathrm{k}, \mathrm{l}} \mathrm{Pk}_{\mathrm{k}, \mathrm{l}, \mathrm{m}}}{\sum_{\mathrm{k}} \mathrm{bsk}_{\mathrm{k}, \mathrm{l}, \mathrm{m}-1} \mathrm{Pk}_{\mathrm{k}, \mathrm{l}, \mathrm{m}-1}}
$$

(unitless ratio) $\quad$ Eq. 61

where

$\mathrm{Pk}_{\mathrm{k}, 1, \mathrm{~m}}$ is the cost of energy services to end-sector $k$ (\$/energy service), and

$\mathrm{bsk}_{\mathrm{k}, 1}$ is the regional base year energy consumption (BSKL: in EJ) of sector $k$ of the aggregate energy service demand (an exogenous regional sector-specific input parameter).

The weighted sum of the individual energy service prices, $P S_{\text {ratio }}$, is used in the iterative GDP adjustment (see Section 2.2.4).

\subsubsection{GDP}

$G D P$ is a major determinant of energy demands. It functions as a proxy for both the overall level of economic activity and as an index of income (Edmonds and Reilly, 1985:15). GDP is primarily a function of labor force levels and exogenously set rates of labor productivity increases. GDP as a determinant of energy demands is normalized against the base year. The impact of labor productivity and the labor force on $G D P$ is simulated as follows:

$$
\text { GDPindex }_{1, \mathrm{~m}}=\text { GDPindex }_{1, \mathrm{~m}-1} \bullet\left(1+\operatorname{Pro}_{1, \mathrm{~m}}\right)^{\text {Nstep }} \bullet \text { LBFindex }_{1, \mathrm{~m}} \quad \text { (unitless) } \quad \text { Eq. } 62
$$

where

GDPindex $x_{1, \mathrm{~m}}$ is the normalized GDP value (normalized against the base year GDP value, which makes the GDPindex for the base year equal to one),

Pro $_{1, m}$ is the labor productivity increase (labor productivity growth) from one point in time to the next (PROLM: unitless rate; a regional time-dependent input parameter),

Nstep is the time span from one time period to the next (15 years in MiniCAM) and,

LBFindex $_{1, m}$ is the ratio of the size of the labor force in the current period to that in the previous period. The size of the labor force is calculated by one of two methods:

0 The product of the population and the fraction of the population in the labor force (both exogenously set parameters at time $t, Z L M$ : regional time-dependent population; LFPerc: unitless fraction; a regional time-dependent input) (see Tables 1 and 6 in Appendix 6 for data examples), or

0 the working age population as calculated using an internal demographics module. The first method is used in most current work.

Base year $G D P$ and $G D P$ values in baseline scenarios are calibrated to base year data and exogenous $G D P$ scenario specifications by adjusting labor productivities. When MiniCAM is used for alternative scenario analyses (i.e., policy cases), GDP values are allowed to vary as energy prices influence $G D P$.

To reflect the impact energy prices can have on GDP, the normalized GDP value (GDPindex) is adjusted for the overall energy service price (PS) (Edmonds and Reilly 1985:260). This feedback is part of the iterative process of finding the energy balances. A first order approximation of this effect is represented with the following elasticity relationship: 
GDPindex $_{1, \mathrm{~m}}=$ GDPindex $_{1, \mathrm{~m}} \bullet \mathrm{PS}_{\text {ratio }}$ rGDP $_{\text {adj }} \quad$ (unitless) Eq. 63

where

GDPindex $\mathrm{x}_{1, \mathrm{~m}}$ is the normalized regional GDP at time $t(m)$,

$\mathrm{PS}_{\text {ratio }}$ is the ratio of the aggregate price for all energy services at time $t(m)$ divided by the calculated aggregate price for all energy services at the previous point in time, and

$r_{\text {GDPadj }}$ is the elasticity coefficient representing the percentage change in GDP resulting from a one percent change in the PS ratio ${ }^{20}$ (see Table 4 in Appendix 6 for example values).

This GDP feedback is intended to provide a simple long term feedback from changing energy prices to GDP when used as the driver of energy and non-energy emissions. This formulation is not intended to provide a measure of the change in GDP due to changes in energy prices or policy. Such changes are far more complex to calculate. Note that the change in GDP due to changes in energy prices is small.

\subsubsection{Energy Demand}

The demand for energy is determined by the population level, the level of economic activity $(G D P)$ and the market prices of primary energy, adjusted step-wise from market prices of primary fuels, to regional prices for secondary fuels, to prices or costs of energy services as described in the previous section.

The three end-use sectors for energy services are (see Figure 4):

- Transportation

- Buildings (residential/commercial)

- Industry

\section{Demand for energy services}

The demand by the end-use sectors for energy services is modeled as a demand for the least costly energy service fuel mode (Edmonds and Reilly 1985:248). "The constant elasticity equation structure offers a first-order approximation to an arbitrary energy service demand function at a point. That is, it can replicate not only the total demand for service, given an arbitrary set of exogenous variables, but also provides a log-linear estimate of the effect on total demand of a change in these independent variables. It does not provide a second-order approximation of an arbitrary demand function at a point. That is, it does not provide an estimate of the rate at which elasticities change as exogenous variables change for an arbitrary demand function" (Edmonds and Reilly 1985:249) ${ }^{21}$.

\footnotetext{
${ }^{20}$ Elasticities are parameters representing the relationship between the percentage change in output resulting from a one percentage change in the value of the base parameter. Thus, when $\mathrm{Z}=\mathrm{X}^{\mathrm{B}}, \mathrm{B}=d \ln \mathrm{l} / \mathrm{d} \ln$ $\mathrm{X}$, or, the percentage change in $\mathrm{Z}$ results from a one percentage change in $\mathrm{X}$ (Edmonds and Reilly 1985:248-249).

${ }^{21}$ Edmonds and Reilly 1985:248-249: "The demand for total energy services is derived from a constant elasticity equation, generally written as $Z=A X^{B} Y^{C}$ where the dependent variable $Z$ (e.g., aggregate service demand) is a function of $X$ (e.g., the price of the aggregate energy services) and $Y$ (e.g., income) and where $A$ is a scale term and $B$ and $C$ are elasticities (parameters), where $B=d \ln Z / d \ln X$ and $C=d \ln Z / d \ln Y$ (percentage change in $Z$ (energy service demand) resulting from a percent change in either $X$ (price) or $Y$ 
Energy service demand by the transportation and building sectors is simulated as follows:

$\mathrm{Fk}_{\mathrm{k}=\text { transportation-or-buildings, }, \mathrm{m}, \mathrm{m}}=\mathrm{bsk}_{\mathrm{k}, 1} \bullet\left(\frac{\mathrm{Pk}_{\mathrm{k}, \mathrm{l}, \mathrm{m}}}{\mathrm{Pk}_{\mathrm{k}, 1, \mathrm{~m}=2}}\right)^{\mathrm{rpk}_{\mathrm{k}, 1}} \bullet \mathrm{X}^{\mathrm{ryk}_{\mathrm{k}, \mathrm{l}, \mathrm{m}}} \bullet \mathrm{Pop}_{\text {index }} \quad$ (EJ/year) Eq. 64

where

bsk $_{k, 1}$ is the regional base year energy consumption (BSKL: in EJ) of sector $k$ of the aggregate energy service demand (an exogenous regional sector-specific input parameter),

$\mathrm{Pk}_{\mathrm{k}, 1, \mathrm{~m}} / \mathrm{Pk}_{\mathrm{k}, 1, \mathrm{~m}=\text { base year }}$ is the ratio (unitless ratio) of the total cost of energy services to an endsector $k$ at a point in time (in $\$ / G J$ calculated in the price-processing) and the total cost of energy services to an end-sector $k$ in the base year (1990). The value of $\mathrm{Pk}_{\mathrm{k}, 1 . \mathrm{m}}$ is part of the iterative process,

$\mathrm{rp}_{\mathrm{k}, 1}$ is the regional sector-specific energy service price elasticity of the energy services price ratio $\mathrm{Pk}_{\mathrm{k}, 1, \mathrm{~m}} / \mathrm{Pk}_{\mathrm{k}, 1, \mathrm{~m}=\text { baseyear }}$ (unitless); this elasticity parameter is recalculated as part of the iterative process (see Equation 66 below),

$\mathrm{X}$ represents the economic activity in the form of the regional GDP per capita (income) at time $t(m)$ divided by the regional GDP per capita in the base year (a unitless ratio) (The value of the GDP is part of the iterative process in policy impact scenario analyses: after the calculation of energy prices the GDP is adjusted (see Section 2.3); the adjusted GDP impacts income, which impacts the demand for services, etc.),

ry $_{\mathrm{k}, 1, \mathrm{~m}}$ is the sector-specific economic activity elasticity (RYKLM: unitless) (an exogenous regional sector- and time period-specific input parameter), and

Pop $_{\text {index }}$ is the ratio of the population at time $t$ divided by the population in the base year (unitless).

Demand for energy services by the industrial sector is determined similarly except that, instead of population size index, demand is indexed to the change in GDP over the base year:

$\mathrm{Fk}_{\mathrm{k}=\text { industry,l,m }}=\mathrm{bsk}_{\mathrm{k}, 1} \bullet\left(\frac{\mathrm{Pk}_{\mathrm{k}, 1, \mathrm{~m}}}{\mathrm{Pk}_{\mathrm{k}, 1, \mathrm{~m}=2}}\right)^{\mathrm{rpk}_{\mathrm{k}, \mathrm{l}}} \bullet \mathrm{Y}^{\mathrm{ryk}_{\mathrm{k}, \mathrm{l}, \mathrm{m}}} \quad$ (EJ/year) Eq. 65

where

$\mathrm{Y}$ as economic activity is represented by the regional GDP at time $m$ divided by the regional GDP in the base year (unitless).

Demands for a particular energy service, such as transportation, may be assumed to grow even if population stabilizes, because income continues to increase. However, the amount of energy needed to meet those demands may not grow at the same rate due to technological improvements as well as to shifts in fuel service shares as described below.

\section{Elasticities}

The energy service price elasticities, $\boldsymbol{r}_{\boldsymbol{k}, \boldsymbol{l}}$, in the equations above (Equation 65), measure the relationship between energy service price and energy service demand for the given sector. This elasticity is negative because demand decreases as prices increase. The (regional) energy service price elasticities $r p_{k, l}$ are iteratively updated for four time periods $(1990,2005,2020,2035)$. This

(income). (B and $C$ are the price and income elasticities, respectively). See also Equation 23 in Edmonds and Reilly 1985:260. 
update is performed because energy service elasticies in developing economies can change significantly as their energy systems evolve into ones that use modern energy forms. After 2035, that is, from the year 2050 on, the energy service price elasticity coefficients $r p_{k, l} \mathrm{~s}$ are held at the 2035 value. The update is calculated by means of the following equation:

$\mathrm{rpk}_{\mathrm{k}, \mathrm{l}}=\mathrm{Rpk}_{\mathrm{k}} \cdot \frac{\mathrm{Pk}_{\mathrm{k}, 1, \mathrm{~m}}}{\mathrm{Pfk}_{\mathrm{k}, \mathrm{l}, \mathrm{m}}} \quad$ (unitless) Eq. 66

where

$\mathrm{R} \mathrm{pk}_{\mathrm{k}}$ is the energy price elasticity - with one value for each end-use sector (an exogenous service sector specific input parameter; RPKK: unitless),

$\mathrm{Pk}_{\mathrm{k}, 1, \mathrm{~m}}$ is the regional time-dependent total energy services cost (\$/energy services) to a regional end sector $k$ (the value of $\mathrm{Pk}_{\mathrm{k}, 1, \mathrm{~m}}$ is part of the iterative process); $\mathrm{Pk}_{\mathrm{k}, 1, \mathrm{~m}}$ represents the costs of all secondary fuels that partake in the sector-specific energy services (liquids, gases, coal, biomass, electricity, and hydrogen) according to their shares in that energy service,

$\mathrm{Pfk}_{\mathrm{k}, 1, \mathrm{~m}}$ represents the fuel costs only, of the regional total energy services cost (\$/energy services) to a regional end-sector $k$ at a point in time; $\mathrm{Pfk}_{\mathrm{k}, \mathrm{l,m}}$ represents the costs of all secondary fuels minus their non-energy cost of transformation of fuel $j$ for end-sector $k$, that partake in the sector-specific energy services (liquids, gases, coal, biomass, electricity, and hydrogen) according to their shares in that energy service.

The economic activity elasticity, $\boldsymbol{r y j}_{\mathbf{j}} \boldsymbol{k}_{\mathbf{j}, \boldsymbol{k}, \mathbf{l}, \boldsymbol{m}}$, represents the elasticity of economic activity in the form of the change in GDP at time $m$ from the base year when determining the shares of the fuelmode demands (see Equation 60).

The economic activity elasticity, $r \boldsymbol{y} \boldsymbol{k}_{\boldsymbol{k}, \boldsymbol{l}, \boldsymbol{m}}$, represents the elasticity of economic activity in the form of changes in income (GDP per capita) at time $m$ from the base year when determining the transportation and building sectors' energy services demand (see Equation 64).

For the industry sector, the economic activity elasticity, $r y \boldsymbol{k}_{\boldsymbol{k}, \mathbf{l , m}}$, represents the elasticity of economic activity in the form of the change in $G D P$ at time $m$ from the base year when determining the energy services demand by industry (see Equation 65).

Note that the economic activity elasticities of demand as used here relate to the demand for energy services, not the demand for energy itself.

The values of these elasticities, particularly over long time periods, are not certain and there are large variations in estimated values.

\section{Demand for each fuel mode}

Determining fuel demand from the total demand for energy services for an end-use sector has two parts. The first part is a transformation from energy service demand to energy use. The second is a logit share equation that splits the service demand between the individual fuel modes.

Two parameters embody the transformation from energy service demand to energy use. Each fuel has a coefficient that represents the efficiency at which that fuel is transformed into an energy service. In addition, the overall transformation between energy service and fuel use is adjusted by the amount of cumulative technological change as represented by an annual rate of end-use energy intensity improvement (AEII). This latter parameter is the way by which the relationship between energy service demand and fuel use changes over time. In practice, this parameter 
embodies both efficiency improvements and changes such as the shift to a more service oriented economy, which results in a lower rate of energy demand for a given increase in income.

In more detail, demand for each fuel mode $\left(F j k_{j, k, l, m}\right.$ in energy units, EJ) by each end-use sector $k$ is equal to the product of total service demand $\left(F k_{k, l, m}\right.$ in energy services units), the fuel service share $\left(S j k_{j, k, l}\right.$ unitless) and the fuel requirement per unit service $\left(g j k_{j, k}\right)$, divided by the level of technological improvement ( Tech $_{j k}$ unitless) (Edmonds and Reilly 1985:260 eq 24).

$$
\mathrm{Fjk}_{\mathrm{j}, \mathrm{k}, \mathrm{l}, \mathrm{m}}=\mathrm{gjk}_{\mathrm{j}, \mathrm{k}} \bullet \mathrm{Sjk}_{\mathrm{j}, \mathrm{k}, \mathrm{l}} \bullet \frac{\mathrm{Fk}_{\mathrm{k}, \mathrm{l}, \mathrm{m}}}{\text { Tech }_{\mathrm{jk}}}
$$

where

$\mathrm{gjk}_{\mathrm{j}, \mathrm{k}}$ is an energy service-specific conversion coefficient or input-output coefficient, which represents the energy intensity of transformation of secondary fuel $j$ (liquids, gas, coal, biomass, electricity, or hydrogen) for use in end-sector $k$ (GJK: GJ/energy service; the energy service unit depends on the technology-specific transformation process) (an exogenous sector-specific input parameter); note that $\mathrm{gj}_{\mathrm{j}, \mathrm{k}, \mathrm{l}, \mathrm{m}}$ is a regional and time-specific parameter for the transportation sector, and gj $\mathrm{k}_{\mathrm{j}, \mathrm{k}, \mathrm{m}}$ is an exogenous sector- and time-specific input parameter for hydrogen fuel cells,

$\mathrm{Fk}_{\mathrm{k}, 1, \mathrm{~m}}$ is the energy service demand of sector $k$ (in energy services units), and

$\mathrm{Tech}_{\mathrm{jk}}$ is the level of technological progress (calculated from TKLM, which is unitless), which may act to conserve energy even when prices fall. "This specification allows for both continued progress and stagnation to be explicitly considered" (Edmonds and Reilly 1985:260); this technology parameter can be set by region and end-use sector for future points in time:

$$
\operatorname{Tech}_{\mathrm{j}, \mathrm{k}, \mathrm{m}}=\operatorname{Tech}_{\mathrm{j}, \mathrm{k}, \mathrm{m}-1} *\left(1+\mathrm{T}_{\mathrm{k}, \mathrm{l}, \mathrm{m}}\right)^{\mathrm{Nstep}}
$$

(unitless)

where

Nstep is the time step of 15 years, and

$\mathrm{T}_{\mathrm{k}, 1, \mathrm{~m}}$ is the sector dependent regional technology dependent technological rate change (TKLM: unitless). This technological change parameter, also called efficiency parameter or autonomous end-use energy intensity improvement parameter (the AEII), is a time-dependent index. It represents the annual rate of change in the relationship between the demand for energy services and actual energy use that would go on independent of such other factors as energy prices and real incomes. The inclusion of an exogenous end-use energy efficiency improvement parameter allows scenarios to be developed that incorporate different levels of improvement in end-use energy intensity. This parameter is used in the final calibration step in sectoral energy consumption for scenarios with specified final energy demand pathways (see Tables 57 and 58 for example values), and,

$\mathrm{Sjk}_{\mathrm{j}, \mathrm{k}, \mathrm{l}}$ is described in Equation 60 as $\mathrm{SPj}_{\mathrm{j}, \mathrm{k}, \mathrm{l}}$, which represent the shares of the fuel modes $j$ competing in obtaining the lowest total cost of energy services, $\mathrm{Pk}_{\mathrm{k}, \mathrm{l}}$ at time $\mathrm{m}$, to an end-sector $k$, Calculation of these shares is part of the iterative process of the model solution of balancing supply and demand. In the final solution, the share values (Equation 60) used in determining the total costs of energy services to an end-sector $k$ (Equation 59) are the lagged (by one time period) share values of the fuel-specific energy demand shares. The share value $S j k_{j, k, 1}$ depends on (1) $\mathrm{bsjk}_{\mathrm{j}, \mathrm{k}, \mathrm{l}, \mathrm{m}}$, the share or weight of a given fuel mode $j$ in sector $k$, on (2) $\mathrm{Pjk}_{\mathrm{j}, \mathrm{k}, \mathrm{l}, \mathrm{m}}$ the price of the service as provided by a given fuel mode $j$ in sector $k$, on (3) $\mathrm{rpj}_{\mathrm{j}, \mathrm{k}}$, the price elasticity of that service in sector $k$, on (4) X, which represents economic activity as a ratio income at time $t$ and income in the base year, and on (5) ryjk $\mathrm{k}_{\mathrm{j}, \mathrm{k}, 1, \mathrm{~m}}$, the sector's economic activity elasticity: 


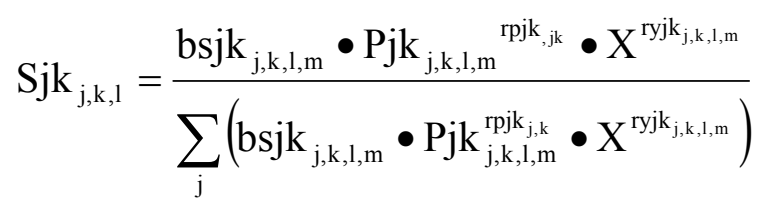

(unitless) Eq. 69

The shares of the fuel modes $\left(S j k_{j, k, l}\right)$ that, initially for the base year, are calculated from input parameters for weights $\left(b s j k_{j, k, l, m}\right)$, are re-calculated during the calibration process by adjusting these weights ( $b s j k_{j, k, l, m}$ for $j=$ liquids, gas, solids and electricity). In addition, adjustments have to be made through the calibration process for the correct split between coal and biomass which fall both under "solids".

\section{Demand for each secondary fuel}

A region's total demands for each of the secondary fuels $j\left(F j_{j, l, m}\right.$ where $j$ are liquids, gas, coal and biomass; see Figure 4) are calculated as summations of the sectoral end-use fuel demands:

$$
\mathrm{Fj}_{\mathrm{j}, 1, \mathrm{~m}}=\sum_{\mathrm{k}} \mathrm{Fjk}_{\mathrm{j}, \mathrm{k}, 1, \mathrm{~m}}
$$

where

$\mathrm{Fjk}_{\mathrm{j}, \mathrm{k}, \mathrm{l}, \mathrm{m}}$ are the fuel mode demands by the end-use sectors.

Secondary fuel demands, $F j_{j, l, m}$, of electricity and hydrogen are calculated in a more complex way, given that they are interdependent. This is described in the next section.

\section{Electricity and hydrogen interaction}

In the MiniCAM framework, each electricity and hydrogen production technology is described by a share, which represents the fraction of the total generation that is provided by that technology $\left(S u_{u i, l}\right.$ and $S h_{h i, l}$, respectively; Equations 54 and 43, respectively). If electricity and hydrogen were used only by end-use sectors, then the shares could be multiplied by the total secondary fuelspecific end-use demand and their transformation coefficients ( $g u_{u i l, m}$ and $g h_{h i, l, m}$, respectively) and the fuel demand by each technology would be known as would electricity and hydrogen production after solving for the energy balance.

Total electricity and hydrogen production are, however, mutually interdependent. The total generation of electricity is equal to the total amount of electricity needed for end-uses plus the total amount needed for generation of hydrogen. The same is true for hydrogen production where the total hydrogen demand is equal to that needed for end-uses plus the hydrogen needed to generate electricity via fuel cells.

This interaction requires a set of linear equations that can be solved algebraically. They are solved for the total demand for hydrogen and electricity as a function of the end-use demands by means of the fuel shares $\left(S u_{u i, l}\right)$ for electricity generation by fuel cells and the fuel shares $\left(S h_{h i, l}\right)$ for hydrogen production through electrolysis and the transformation coefficients $\left(g u_{u i, l, m}\right.$ and $\left.g h_{h i, l, m}\right)$.

The consistency coefficient for the amount of electricity that is needed to generate hydrogen by electrolysis $\left(h_{\text {coeff }}\right)$ is calculated as the product of the share $\left(S h_{h i, l}\right)$ of the hydrogen in generating hydrogen as secondary fuel from electricity and the transformation coefficient or energy intensity $\left(g h_{h i, l, m}\right)$ of that process. Similarly, the consistency coefficient for the amount of hydrogen that is needed to generate electricity from fuel cell technology $\left(e_{\text {coeff }}\right)$, is the product of the share $\left(S u_{u i, l}\right)$ of the electricity in generating electricity as secondary fuel from fuel cells and the transformation coefficient or energy intensity $\left(g u_{u i, l, m}\right)$ of that process. As long as the product of the two 
coefficients is less than one the total demands for hydrogen and electricity can be adjusted as follows:

$$
\begin{aligned}
& \mathrm{Fj}_{\mathrm{j}=\text { hydrogen, }, \mathrm{m}}=\frac{\mathrm{Fj}_{\mathrm{j}=\text { hydrogen }, \mathrm{l}, \mathrm{m}}+\mathrm{Fj}_{\mathrm{j}=\text { electricity }, \mathrm{l}, \mathrm{m}} \bullet \mathrm{e}_{\text {coeff }}}{1-\mathrm{e}_{\text {coeff }} * \mathrm{~h}_{\text {coeff }}} \\
& F j_{j=\text { electricty, }, \mathrm{m}}=\frac{F j_{\mathrm{j}=\text { electricity }, 1, \mathrm{~m}}+F \mathrm{j}_{\mathrm{j}=\text { hydrogen }, \mathrm{l}, \mathrm{m}} \bullet \mathrm{h}_{\text {coeff }}}{1-\mathrm{e}_{\text {coeff }} * \mathrm{~h}_{\text {coeff }}}
\end{aligned}
$$

where

$$
\mathrm{h}_{\text {coeff }}=\mathrm{Sh}_{\mathrm{hi}, 1} \bullet \mathrm{gh}_{\mathrm{hi}, 1, \mathrm{~m}}
$$

and

$$
\mathrm{e}_{\text {coeff }}=\mathrm{Su}_{\mathrm{ui}, 1} \bullet \mathrm{gu}_{\mathrm{ui}, 1, \mathrm{~m}}
$$

where

$\mathrm{Sh}_{\mathrm{hi}, \mathrm{l}}$ is the share of hydrogen that is generated by electrolysis and $\mathrm{gh}_{\mathrm{hi}, \mathrm{l}, \mathrm{m}}$ is the inverse of the transformation efficiency, that is the energy intensity, of that process. Similarly, $\mathrm{Su}_{\mathrm{ui}, l}$ is the share of electricity that is generated from fuel cell technology and $\mathrm{gu}_{\mathrm{ui}, \mathrm{l}, \mathrm{m}}$ is the inverse of the efficiency of that process.

The potential for an inconsistency exists if either of the denominators in Equations 71 or 72 is negative, that is, if either of the share coefficients $\left(S h_{h i, l}\right.$ or $\left.S u_{u i, l}\right)$ is too large. This would be the case if, for example, most of the electricity would be generated by hydrogen and insufficient electricity would be generated by non-fuel cell sources to meet the demand for electrolytic hydrogen. The product of the two consistency coefficients $\left(e_{\text {coeff }}\right.$ and $\left.h_{\text {coeff }}\right)$ is therefore checked and if that product is greater than one, the shares $\left(S u_{u i, l}\right.$ and $\left.S h_{h i, l}\right)$ are automatically rescaled and only then the process outlined is executed.

In addition, the solution described above interacts with capacity limits in a complex manner since intermittent renewable technologies have no capacity limits for electricity generation, the amount of which is not known before these equations are solved. An iterative solution is implemented which converges within a few iterations. The electricity shares are re-balanced while keeping the hydropower share constant.

\section{Primary fuel demand}

Primary fuel demands are the total amounts of each fuel that are needed to meet the requirements for direct use of fuels in the end-use sectors plus fuel needed as inputs to the transformation sectors (electricity, hydrogen, and synfuels).

Primary fuel demand ( $E D R I K L_{i, k, l}$ Energy Demand of Regional primary fuels $\boldsymbol{I}$ by end-use sector $\boldsymbol{K}$ in regions $\boldsymbol{L})$ to meet the direct demands of fuel modes by the end-use sectors $\left(F j k_{j, k, l, m}\right.$; see Equation 67) (see also Figure 4) is calculated by end-use sector for oil, gas, coal and biomass, respectively, as:

$$
\text { EDRIKL }_{\mathrm{i}, \mathrm{k}, \mathrm{l}}=\mathrm{Fjk}_{\mathrm{j}, \mathrm{k}, \mathrm{l}, \mathrm{m}} \bullet \operatorname{gij}_{\mathrm{i}} \quad \mathrm{i}=\text { oil, gas, coal or biomass } \quad \text { (EJ/year) Eq. } 75
$$
where

$\mathrm{Fjk}_{\mathrm{j}, \mathrm{k}, \mathrm{l}, \mathrm{m}}$ are the fuel mode demands by end-use sectors $k$ (EJ; Equation 67), 
gij $_{\mathrm{i}}$ represents the relationship between the unrefined input producing one unit of secondary fuel; also called conversion intensity of oil, gas, coal, and biomass (GIJ: unitless or $j$ of primary energy/J refined fuel), and

$\mathrm{i}$ in $\mathrm{EDRIKL}_{\mathrm{ikl}}$ stands for regional primary fuel energy demand calculated from the regional $l$ secondary fuel mode demand for each sector $k$.

Regional direct primary fuel demands for oil, gas, coal and biomass $\left(E D R I L_{i, l}\right.$ : Energy Demand of Regional primary fuels $\boldsymbol{I}$ in regions $\boldsymbol{L}$ ) are found by summing over the end-use sectors:

$$
\text { EDRIL }_{\mathrm{i}, 1, \mathrm{~m}}=\sum_{\mathrm{k}} \mathrm{EDRIKL}_{\mathrm{i}, \mathrm{k}, 1} \quad \mathrm{i}=\text { oil, gas, coal or biomass } \quad(\mathrm{EJ} / \text { year) Eq. } 76
$$

Primary sectoral end-use fuel demand $\left(E D R I K L_{i, k, l}\right)$ to meet synfuel generation demand is equal to the end-use demand for each synthetic fuel times the conversion ratio for the appropriate feedstock. The end-use demand for each synthetic fuel is, however, a shared demand as described under synfuel production (Equations 35 and 36). These shares determine the demands of primary energy and need to be summed in a number of steps. The generated synliquids compete with refined oil; the generated syngas compete with processed gas. The primary fuel demands to meet synfuel generation demands are summed over the end-use sectors $k$ after multiplication with the share values for each of the synfuels:

SFuel $_{\mathrm{j}, \mathrm{i}, \mathrm{l}, \mathrm{m}}=\sum_{\mathrm{k}}$ EDRIKL $_{\mathrm{i}, \mathrm{k}, \mathrm{l}} \bullet$ SynShare $_{\mathrm{j}, \mathrm{i}, \mathrm{l}, \mathrm{m}}$ (EJ/year) Eq. 77

where

$\mathrm{j}$ is the feedstock: gas, coal, or biomass,

$\mathrm{i}$ is the produced crude or gas,

EDRIKL $_{\mathrm{i}, \mathrm{k}, \mathrm{l}}$ stands for regional sectoral end-use primary fuel energy demand (see Equation 75), and

SynShare $_{\mathrm{j}, \mathrm{i}, \mathrm{l}, \mathrm{m}}$ are the shares (see Equation 35) of feedstocks $j$ when producing liquids or gas $i$.

The primary fuel demands for synfuel production are then transformed to their primary fuel equivalents by multiplying with the appropriate conversion factor and summing over the synfuels (i); next they are added to the previously calculated direct primary fuel demands (Equation 76):

EDRIL $_{\mathrm{i}, 1, \mathrm{~m}}=\mathrm{EDRIL}_{\mathrm{i}, 1, \mathrm{~m}}+\sum_{\mathrm{j}} \mathrm{SFuel}_{\mathrm{j}, \mathrm{i}, \mathrm{l}, \mathrm{m}} \bullet \mathrm{gc}_{\mathrm{ji}} \quad \mathrm{i}=$ oil, gas, coal or biomass $\quad(\mathrm{EJ} /$ year) Eq. 78 where

Sfuel $_{\mathrm{j}, \mathrm{i}, \mathrm{l}, \mathrm{m}}$ are the primary fuel demands for synfuel generation (Equation 77), and

$\mathrm{gc}_{\mathrm{j}, \mathrm{i}}$ is an intensity conversion coefficient of synfuel production (GCI: input $\mathrm{J} /$ output $\mathrm{J}$; a fuel source-specific (coal, gas, biomass) and synfuel-specific (liquid, gas) conversion coefficient that is the same for each region, does not change over time and has values of 1.5.

Primary fuel demand to meet hydrogen demand for fossil fuels is calculated as follows and added to the previously calculated primary fuel demands (Equation 78):

$$
\begin{aligned}
\text { EDRIL }_{\mathrm{i}, 1, \mathrm{~m}}=\mathrm{EDRIL}_{\mathrm{i}, 1, \mathrm{~m}}+\mathrm{Fj}_{\mathrm{j}=\text { hydrogen, }, \mathrm{m}, \mathrm{m}} \bullet \mathrm{Sh}_{\mathrm{hii}, 1} \bullet \mathrm{gh}_{\mathrm{hi}, 1, \mathrm{~m}} \bullet \mathrm{gij}_{\mathrm{i}} \\
\mathrm{i}=\text { oil, gas, coal or biomass } \quad \text { (EJ/year) Eq. } 79
\end{aligned}
$$

where 
$\mathrm{Fj}_{\mathrm{j}, 1, \mathrm{~m}}$ is the total secondary fuel demand (Equation 68 ) that needs to be shared out with the $\mathrm{Sh}_{\text {hi,l }}$ share coefficient by fossil fuel type: oil, coal, gas, biomass, etc. and (re)transformed to primary fuel,

$\mathrm{Sh}_{\mathrm{hi}, 1}$ are the shares of the competing fuels in generating hydrogen,

$\mathrm{gh}_{\mathrm{hi}, \mathrm{l}, \mathrm{m}}$ is a conversion coefficient which is unitless (GHILM: units GJ/GJ); an exogenous regional time- and fuel specific parameter representing the ratio of Joules energy input to Joules hydrogen fuel generated, and

gij $_{\mathrm{i}}$ is the conversion intensity coefficient representing the ratio of Joules primary energy as input and Joules of secondary energy generated (GIJ: unitless or GJ of primary energy/GJ refined fuel); gi $j_{\mathrm{i}}$ is an exogenous input parameter that is not time dependent nor region-specific.

Primary fuel demand to meet electricity demand for fossil fuels is calculated as follows and added to the previously calculated primary fuel demand (Equation 79):

$$
\begin{aligned}
& \text { EDRIL }_{\mathrm{i}, 1, \mathrm{~m}}=\mathrm{EDRIL}_{\mathrm{i}, 1, \mathrm{~m}}+\mathrm{Fj}_{\mathrm{j}=\text { electricity, }, \mathrm{m}, \mathrm{m}} \bullet \mathrm{Su}_{\mathrm{ui}, 1} \bullet \mathrm{gui}_{\mathrm{ui}, 1, \mathrm{~m}} \bullet \mathrm{gij}_{\mathrm{i}} \\
& \mathrm{i}=\text { oil, gas, coal or biomass } \quad \text { (EJ/year) Eq. } 80
\end{aligned}
$$

with the same methodology as described for hydrogen.

The regional primary fuel demands $\left(E D R I L_{i, l, m}\right)$, thus determined, are the summed over the transformation sectors regional primary fuel demands for oil, gas, coal and biomass.

In cases where the fuel market is global (as set by the user), the regional demands are summed to obtain a global fuel demand ( $\sum E D R I L_{i, l, m}$, summed over the regions $\left.l\right)$. This demand must be met by an equivalent supply, which is described in the next section.

\subsubsection{The energy balance and other markets}

The variables for which the markets are solved are the global supplies and global demands of the primary fuels ${ }^{22}$.

The global primary energy demands are the summations of the regional primary energy demands (EDRIL) as described above:

$$
\mathrm{EDRI}_{\mathrm{i}, \mathrm{m}}=\sum_{1} \mathrm{EDRIL}_{\mathrm{i}, 1, \mathrm{~m}} \quad \text { for oil, gas, coal, and biomass } \quad \text { (EJ/year) Eq. } 81
$$

The global primary fossil fuel supplies required to meet the demands are based on the calculated potential regional supplies, which are based on the prices of the demanded fuels and

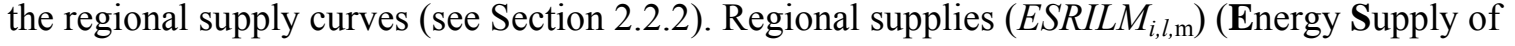
Regional primary fuels $\boldsymbol{I}$ of regions $\boldsymbol{L}$ at time period $\boldsymbol{M}$ ) are set equal to the calculated supply $\left(E S I L M_{i, l, m}\right)$, that is, equal to the number of Joules that can be supplied regionally. In addition, to meet regional synfuel generation demand, the synfuel primary fuel demands $\left(\right.$ Sfuel $\left._{j, i, l, m}\right)$ as calculated in Equation 77 are added to the (raw) oil and gas supplies. Thus,

$$
\text { ESRILM }_{\mathrm{i}, 1, \mathrm{~m}}=\text { ESILM }_{\mathrm{i}, \mathrm{l}, \mathrm{m}}+\sum_{\mathrm{i}} \text { Sfuel }_{\mathrm{j}, \mathrm{i}, 1, \mathrm{~m}} \quad \text { for oil and gas } \quad \text { (EJ/year) Eq. } 82
$$

${ }^{22}$ With regard to emissions these are the markets of importance. 
where for $\mathrm{Sfuel}_{\mathrm{j}, \mathrm{i}, \mathrm{l}, \mathrm{m}}, i$ denotes the produced liquid or gas and $j$ denotes the feedstock of gas, coal, or biomass corresponding to the $i$ indicators in the supply notations, ESILM $M_{i, l, m}$ and $E S R I L M_{i, l, \mathrm{~m}}$.

To determine the global supplies, the regional primary fossil fuel supplies are summed over the regions:

$$
\mathrm{ESRI}_{\mathrm{i}, \mathrm{m}}=\sum_{1} \mathrm{ESRILM}_{\mathrm{i}, 1, \mathrm{~m}} \quad \text { oil, gas, coal, and biomass } \quad \text { (EJ/year) Eq. } 83
$$

The balance between the supply $\left(\boldsymbol{E} \boldsymbol{S} \boldsymbol{R} \boldsymbol{I}_{i, m}\right)$ and demand $\left(\boldsymbol{E} \boldsymbol{D} \boldsymbol{R} \boldsymbol{I}_{i, m}\right)$ of the primary fuels is reached when the model is solved for an excess demand of zero - the difference between demand and supply. Thus, for any period, an equilibrium will exist when a set of prices are found for which all excess demands are zero. To reach an excess demand of zero, both demand and supply has to be determined iteratively.

The part of the market-supply vector ${ }^{23}$ that is comprised of the primary fossl fuels is determined by the $E S R I_{i, m}$ elements:

$$
\mathrm{MrkPRD}_{\mathrm{mk}}=\mathrm{ESRI}_{\mathrm{i}, \mathrm{m}} \quad \text { oil, gas, coal } \quad \text { Eq. } 84
$$

The part of the market-demand vector that is comprised of the primary fossl fuels is determined by the $E D R I_{i}$ elements:

$$
\operatorname{MrkDEM}_{\mathrm{mk}}=\text { EDRI }_{\mathrm{i}, \mathrm{m}} \quad \text { oil, gas, coal } \quad \text { Eq. } 85
$$

For the biomass market the market vector elements are comprised of AgLU biomass from dedicated biomass farms and ERB biomass:

$\operatorname{MrkPrd}_{\mathrm{mk}=4}=\mathrm{ESRI}_{\mathrm{i}=4}+\sum \operatorname{Agsup}_{\mathrm{i}=\text { biomass }, 1}$ where $\mathrm{ESRI}_{\mathrm{i}=4}$ refers to the ERB related biomass and Agsup $_{\mathrm{i}=\text { biomass, }, 1}$ refers to the $\mathrm{AgLU}$ generated biomass $\mathrm{CDR}_{\mathrm{i}=\text { biomass, }, \mathrm{m}}$ after converting calories to EJ, and

MrkDem $_{\text {mk }=4}=$ EDRI $_{\mathrm{i}=4}+\sum \operatorname{Agdem}_{\mathrm{i}=4=\text { biomass }, 1}$ where $\mathrm{EDRI}_{\mathrm{i}=4}$ refers to the ERB related biomass and Agdem $_{\mathrm{i}=4=\text { biomass, },}$ refers to the AGLU demanded biomass after converting calories to EJ

For the greenhouse gas emission market the market vector elements are the emissions produced and the emission targets or constraints:

\begin{tabular}{l}
\hline 23 \\
\begin{tabular}{|l|l|}
\hline Fuel markets & Agricultural product markets \\
\hline $1=$ Oil & $6=$ Wood \\
\hline $2=$ Gas & $7=$ Forward Wood \\
\hline $3=$ Coal & $8=$ Food Grains \\
\hline $4=$ Biomass & $9=$ Coarse Grains \\
\hline & $10=$ Oil Crops \\
\hline GHG market & $11=$ Miscellaneous Crops \\
\hline $5=$ Carbon, Methane, etc. & $12=$ Pasture Products \\
\hline
\end{tabular}
\end{tabular}


The part of the market-supply vector representing GHG emissions can be determined by carbon emissions produced (CemTot: Equation 114):

$\operatorname{MrkPRD}_{\mathrm{mk}=5}=$ CemTot

Analogously, the part of the market-demand vector representing GHG emissions can be determined by carbon emission targets (Emiss: exogenous):

$\operatorname{MrkDEM}_{\mathrm{mk}=5}=$ Emiss $_{1, \mathrm{~m}}$

The part of the market-supply vector comprised of the agricultural products is determined by agricultural supplies $\left(\mathrm{AgSup}_{\mathrm{i}, 1}\right)$ (see Part III) where supplies depend on yield. The supply, in brief, of crops, biomass, pasture, and forest products is calculated as the product of amount of land allocated to each land use (Equation 125) and that land's use average yield (Equation 129). Agricultural supplies are expressed in calories for crops and animal products and in cubic meters wood for forest products.

$\operatorname{MrkPRD}_{\mathrm{mk}=6: 12}=\sum_{\mathrm{l}=1}^{\mathrm{nr}} \operatorname{AgSup}_{\mathrm{i}, 1}$

where

$\operatorname{MrkPrd}_{\mathrm{mk}=6}=\sum$ Agsup $_{\mathrm{i}=\text { wood, }, \mathrm{l}}$ refers to wood produced;

$\operatorname{MrkPrd}_{\mathrm{mk}=7}=\sum$ Agsup $_{\mathrm{i}=\text { fwood,l }}$ refers to forward wood;

$\operatorname{MrkPrd}_{\mathrm{mk}=8}=\sum$ Agsup $_{\mathrm{i}=\text { beef_mutton,l }}$ refers to beef and mutton produced;

$\operatorname{MrkPrd}_{\mathrm{mk}=9}=\sum \mathrm{Agsup}_{\mathrm{i}=\text { foodgrains, },}$ refers to food grains produced;

$\operatorname{MrkPrd}_{\mathrm{mk}=10}=\sum$ Agsup $_{\mathrm{i}=\text { coarsegrains, } 1}$ refers to coarse grains produced;

$\operatorname{MrkPrd}_{\mathrm{mk}=11}=\sum \mathrm{Agsup}_{\mathrm{i}=\text { oilcrops,l }}$ refers to oilcrops produced; and

$\operatorname{MrkPrd}_{\mathrm{mk}=12}=\sum \mathrm{Agsup}_{\mathrm{i}=\text { misccorps,l }}$ referes to miscellaneous crops produced.

The part of the market-demand vector comprised of agricultural products is determined by agricultural demands $\left(A g D e m_{i, l}=C D R_{i, l, m}\right.$, for crops, processed crops, and animal products: see Equation 120; $\mathrm{AgDem}_{i, l}=W D R_{i, l, m}$, for wood products: see Equation 121). Agricultural demands are expressed as constant elasticity demand equations where for the agricultural demands the total amount of calories demanded for each of the agricultural demands, $C D R_{i, l, m}$, are further described in Part III, Equation 120, and demands for cubic meters industrial wood and fuel wood are further described in Part III, Equation 121) Thus,

$\operatorname{MrkDEM}_{\mathrm{mk}=6: 12}=\sum_{\mathrm{l}=1}^{\mathrm{nr}} \operatorname{AgDem}_{\mathrm{i}, 1}$

where

$\operatorname{MrkDem}_{\mathrm{mk}=6}=\sum \operatorname{Agdem}_{\mathrm{i}=\text { wood, },}$ refers to the over the regions summed wood production for wood products and wood fuels $\mathrm{WDR}_{\mathrm{i}=\text { present,l,m; }}$;

$\operatorname{MrkDem}_{\mathrm{mk}=7}=\sum$ Agdem $_{\mathrm{i}=\text { fwood,l }}$ refers to the over the regions summed forward wood production for wood products and wood fuels $\mathrm{WDR}_{\mathrm{i}=\text { forward, }, \mathrm{m} \text {; }}$;

MrkDem $_{\mathrm{mk}=8}=\sum \mathrm{Agdem}_{\mathrm{i}=\text { beef\&mutton,l }}$ refers to the total amount of calories demanded from beef and mutton, $\mathrm{CDR}_{\mathrm{i}=\text { beef_mutton, }, \mathrm{m}}$ multiplied by PastOut which is the ratio of pasture-based feed calories needed per calorie of animal product, which is based on land demand for pasture. The 
total amount of calories demanded from beef and mutton is first corrected for self consumption and fixed trade, however;

$\operatorname{MrkDem}_{\mathrm{mk}=9}=\sum$ Agdem $_{\mathrm{i}=\text { foodgrains,l }}$ refers to the sum of two types of foodgrain demands, $\mathrm{CDR}_{\mathrm{i}=\text { food grains, }, \mathrm{m} \text {; }}$

MrkDem $_{\mathrm{mk}=10}=\sum \operatorname{Agdem}_{\mathrm{i}=\text { coarsegrains,l }}$ refers to the sum of two types of coarse grain demands,

$\mathrm{CDR}_{\mathrm{i}=\text { coarse grains }, 1, \mathrm{~m} \text {; }}$

MrkDem $_{\mathrm{mk}=11}=\sum \operatorname{Agdem}_{\mathrm{i}=\mathrm{oilcrops}, \mathrm{l}}$ refers to the sum of two types of oil crop demands, $\mathrm{CDR}_{\mathrm{i}=\text { oilcrops, }, \mathrm{m} \text {; }}$ and

$\operatorname{MrkDem}_{\mathrm{mk}=12}=\sum \operatorname{Agdem}_{\mathrm{i}=\text { miscorps, } 1}$ refers to the summed two types of miscellaneous crop demands, $\mathrm{CDR}_{\mathrm{i}=\text { misccrops, }, \mathrm{m} \text {. }}$

Processed crop demand fractions are calculated analogously to all other agricultural demands as $\mathrm{CDR}_{\mathrm{i}=\text { processedcrops, }, \mathrm{m}, \mathrm{m}}$ and corrected for net exports. These fractions are then multiplied by the overall demands for food grain, coarse grain, oil crop and miscellaneous crop and the results are added to the food grain, coarse grain, oil crop and miscellaneous crop demands, respectively. Pork and poultry demand fractions are calculated similarly to other agricultural demands as $\mathrm{CDR}_{\mathrm{i}=\text { poultry,l,m }}$ and $\mathrm{CDR}_{\mathrm{i}=\text { pork,1,m, }}$, multiplied by exogenous input of animal products and added to the food grain, coarse grain, oil crop and miscellaneous crop demands.

Excess demand is then calculated as:

$\operatorname{ExDem}_{\mathrm{mk}}=\operatorname{MrkDEM}_{\mathrm{mk}}-\operatorname{MrkPRD}_{\mathrm{mk}}$

where

$m k$ refers to the markets as described above.

Global market prices are retained in the market price array, $P_{i, l=1, m}$. with the region indicator $l$ set to one.

When equilibrium occurs, the markets are said to "clear." The mechanism for clearing the markets is through the solution algorithm, which adjusts market prices (e.g., primary fuel prices) until the excess demand is less than the solution criteria, typically a small number (less than one but greater than zero). The solution algorithm needs only to access the price, supply, demand, and excess demand information to operate. The solution algorithm adjusts prices until supplies and demands are balanced or the excess demand meets the solution criteria. Prices adjusted by the solution algorithm affect technology costs, demand for inputs and sector outputs.

Note that calibration is achieved through the iterative process of recalculating the shares of the different technologies such that ultimately the energy service demands of the end-use sectors are met. Calibration is part of the iterative process of clearing the markets (see Section 2.2.8).

After balancing the total demand and supply of each of the primary fuels in energy units (GJ) emissions can be calculated by multiplying the consumed energy with the appropriate emission coefficients, after subtracting the non-combusting fuel amounts and after accounting for scrub technologies.

\subsubsection{Imports, Exports}


The crux of MiniCAM's treatment of trade is that any surplus (or deficit) in regional production relative to regional supply results in an implicit export (or import) of that fuel to other regions. Global demand is met, but the specific amount traded from one region to another is not defined. Only global and regional total net export (or import) volumes are defined.

\subsubsection{Calibration procedures}

There are two parts to the calibration process: calibration to base year data and calibration to future scenario assumptions.

The base year calibration procedure adjusts parameters such that the following quantities match base year values for each region: (a) GDP, (b) electricity generation by fuel, (c) total energy use, (d) fuel-specific energy use by end-use sector, and (e) total $\mathrm{CO}_{2}$ or carbon-equivalent emissions: $G D P$ calibration is achieved by adjusting regional labor productivity.

Calibrating the participation of oil, gas, coal, biomass, nuclear and hydro energy in the generation of electricity is achieved in a number of steps: First the weights of coal and biomass are reevaluated (the $b s s u_{u i, l, m}$ parameters are re-scaled based on the input end-use energy shares for each fuel); then, the weights of the input fuel shares, the $b s u_{u i, l, m}$ parameters for oil, gas, coal, biomass and nuclear energy are rescaled and the hydro weight, $b s u_{u i, l, m}$ is set equal to its fixed fuel share (needed by the electricity price routine).

To calibrate the total and fuel-specific sectoral distributions of the end-use sectors, the first check is on the transportation sector: if the new module for US transportation is activated and if there are discrepancies with external data (the transportation and industry sectoral shares are readjusted. Then, on the basis of input sector and secondary fuel-specific final demand data, the weights for oil, gas, coal, and electricity, $b s j k_{j k l m}$, are adjusted and the correct split between coal and biomass confirmed. Biomass supplies are adjusted if biomass supply in each region is not sufficient to meet demand (no biomass is assumed for the first period). Given that hydrogen fuels are not a factor in the base year, the fuel share weight readjustments are limited to the fuels listed.

The sectoral total energy use is calibrated by adjusting the sectoral technological efficiency parameters, $T_{k, l, m}$, which determine levels of technological change and innovation. These end-use efficiency parameters represent the level of sectoral technology (e.g., transportation, buildings, industry). The sectoral technological efficiency parameters, $T_{k, l, m} \mathrm{~s}$, are rescaled based on the ratio of the summed energy services demands simulated and the summed energy service demands from the input data.

$\mathrm{CO}_{2}$ emissions in the base year are calibrated by adjusting the carbon emission coefficients $\left(\mathrm{CO}_{i}\right.$ : tons $\mathrm{C} / \mathrm{EJ} / \mathrm{year}$ ), which are based on the carbon content of the fuels. Since $\mathrm{CO}_{2}$ emissions coefficients can be based on different assumptions for energy units (higher versus lower heating values for example), this calibration assures that accurate base year emissions values are obtained.

Calibration to future paths for $G D P$ and final energy use can be done when simulations are intended to meet certain criteria with regard to changes in economic activity and/or certain assumed developments in energy use, as in prescribed scenarios. For a prescribed GDP path step (a) is followed. Calibration to a regional path for final (or primary) energy consumption follows 
step (d). Note that exact regional calibrations to primary energy consumption cannot always be achieved due to different regional assumptions on conversion losses and primary-energy equivalents for non-fossil energy sources. Therefore, primary energy calibration is only assured for global calibration.

\subsection{Calculating Greenhouse and Non-Greenhouse Gas Emission}

One of the main focus points of MiniCAM's integrated assessment modeling is the calculation of the greenhouse gas emissions. In the MiniCAM, carbon dioxide, nitrous oxide, methane, sulfur dioxide, reactive gas, and halocarbon emissions are calculated once global fuel use has been determined. Reactive gas and halocarbon emissions are recent additions to the model and are not documented here, although the mathematical procedures followed are identical to those for methane and nitrous oxide with the substitution of appropriate driver values and emissions coefficients.

\subsubsection{Carbon dioxide emissions from the ERB module}

In the ERB module carbon dioxide emissions from fossil fuel use are calculated after global fuel demands have been determined. Emissions are equal to the carbon emission coefficient times the amount of fuel used. Emissions associated with energy transformations (synthetic fuels, electricity generation, and hydrogen production) are allocated to the region where the transformation occurs.

Global average carbon coefficients for oil, gas, and coal combustion, unconventional oil and biomass $\left(\mathrm{CO}_{i}\right.$ : fuel-specific emission coefficients) represent carbon release, based on the carbon content of the fuel, during combustion or processing in teragrams carbon per EJ energy. The emissions coefficient for unconventional oil represents combustion's carbon release related to oils from heavy oil deposits, tar sands, or oil shales. Emissions are calculated after

a) gas flaring losses have been accounted for in the case of gas production (see Equation 92),

b) the non-fuel use fraction has been subtracted,

c) the amount of secondary fuel combusted with and without scrub technologies is determined,

d) after synfuel production is accounted for; note that previously the raw fuels required for synfuel production had been added to primary fuel demands

$$
\text { EDRIL }_{\mathrm{i}, 1, \mathrm{~m}}=\text { EDRIL }_{\mathrm{i}, 1, \mathrm{~m}}+\sum_{\mathrm{j}} \text { SFuel }_{\mathrm{j}, \mathrm{i}, 1, \mathrm{~m}} \bullet \mathrm{gc}_{\mathrm{ji}} \text { (see Equations } 76 \text { through 80). The }
$$

raw fuel requirements (gas, coal and biomass) for synfuel production are referred to in the next set of equations as

$$
\text { SynInput }_{\mathrm{i}, \mathrm{l}, \mathrm{m}}=\sum_{\mathrm{j}} \text { SFuel }_{\mathrm{j}, \mathrm{i}, \mathrm{l}, \mathrm{m}} \bullet \mathrm{gc}_{\mathrm{ji}}
$$

where

Sfuel $\mathrm{j}_{\mathrm{j}, \mathrm{i}, \mathrm{l}, \mathrm{m}}$ are the primary fuel demands for synfuel generation (Equation 77), and $\mathrm{gc}_{\mathrm{j}, \mathrm{i}}$ is an intensity conversion coefficient of synfuel production. 
e) emissions from primary fuels can now be calculated.

(a) Gas lost in gas production (which implicitly includes non-commercial gas use) due to flaring is calculated from flaring coefficients (Flr,$F l r 2$, and Flr3) as FLR. Emissions due to burning of gas flaring are determined by flared gas burning parameters ( $S b r 1, S b r 2$, and $S b r 3)$ as $S B_{l, m}$. Burning of shales is determined by shale burning parameters (Shale1, Shale2, and Shale3) as $S H A L_{l, m}$. The equation that determines gas flaring $\left(F L R_{l, m}\right)$, gas burning $\left(S B_{l, m}\right)$ and shale burning $\left(S H A L_{l, m}\right)$ is illustrated in Equation 92 for gas flaring, where $F l r 1$ is the initial proportion of flared gas lost, FLr2 is the ultimate fraction that is lost at time $m$ and Flr3 is the number of years losing FLr2;

$\mathrm{FLR}_{1, \mathrm{~m}}=\mathrm{Flr}_{1} \frac{(1-(\mathrm{m}-1) \bullet \mathrm{Nstep})}{\mathrm{Fl} l_{3}} \bullet \mathrm{Flr}_{2} \frac{(\mathrm{m}-1) \bullet \mathrm{Nstep}}{\mathrm{Fl} r_{3}}$

(unitless) Eq. 92 where

Nstep equals 15 and $m$ is the number of time periods since the base year, and Flr11, Flr12, and Flr13 are regional gas flare parameters; we may substitute the regional gas burn parameters Sbr1, $\mathrm{Sbr} 2$ and Sbr3 to calculate gas venting and burning, $\mathrm{SB}_{1, \mathrm{~m}}$ used in Equation 93, or the regional shale burn parameters Shale1, Shale2 and Shale3 to calculate shale burning, $\mathrm{SHAL}_{1, \mathrm{~m}}$ used in Equation 104.

Emissions due to gas venting and flaring are calculated as follows:

Cemissions $_{\mathrm{i}=\text { gasflare }, \mathrm{l}}=\mathrm{CO}_{\mathrm{i}=\mathrm{gas}} \bullet \mathrm{SB}_{\mathrm{l}, \mathrm{m}} \bullet \frac{\mathrm{FLR}_{1, \mathrm{~m}}}{\left(1-\mathrm{FLR}_{1, \mathrm{~m}}\right)} \bullet \mathrm{ESILM}_{\mathrm{i}=\text { gas }, 1, \mathrm{~m}} \quad$ (MMTC) Eq. 93

(b) Carbon dioxide is not released from fossil fuels due to fossil fuel used as asphalt, lubricants, and waxes; "1-SFEDIL" represents regional feed stock shares for oil, gas, coal, and biomass (unitless fractions).

(c) The amount of secondary fuel combusted with and without scrub technologies needs to be determined. The fuel demanded for scrub technologies and non-scrub technologies is calculated from the total electricity demanded $\left(F j_{j, l, m}\right)$ and the shares of the fuel-specific $\left(S u_{u i, l}\right)$ scrub and non-scrub technologies $\left(S s u_{u i, l}\right)$ where $u i$ is the technology. Thus the demanded electricity supply through fuel-specific scrub and non-scrub technologies, $E S U_{u i, l, m}$, is calculated as follows where $E S U_{u i, l, m}$ is the energy in Joules that needs to be combusted as secondary energy to meet demand (and that needs to be converted to primary energy for emission calculations by multiplying with the conversion coefficients $g u_{u i, l, m}$ or $g h_{h i, l, m}$ and $g i j_{i}$; see Equation 99).

$$
\mathrm{ESU}_{\mathrm{ui}, 1, \mathrm{~m}}=\mathrm{Su}_{\mathrm{ui}, 1} \bullet \mathrm{Ssu}_{\mathrm{ui}, 1} \bullet \mathrm{Fj}_{\mathrm{j}, 1, \mathrm{~m}}
$$

where

ui is an indicator of any of the electricity generating technologies,

$\mathrm{Fj}_{\mathrm{j}, 1, \mathrm{~m}}$ is the total electricity $(j)$ demand for region $l$ at time $m$,

$\mathrm{Su}_{\mathrm{ui}, 1}$ is the share coefficient of the competing fuels (in the form of prices) in generating electricity, and

$\mathrm{Ssu}_{\mathrm{ui}, \mathrm{l}}$ are the electricity generation shares of the scrub- and non-scrub technologies.

For hydrogen production the demanded fuel supplies through fuel-specific scrub and non-scrub technologies, $E S H_{h i, l, m}$, is calculated in an analogous fashion:

$$
\mathrm{ESH}_{\mathrm{hi}, 1, \mathrm{~m}}=\mathrm{Sh}_{\mathrm{hi}, 1} \bullet \mathrm{Ssh}_{\mathrm{hi}, 1} \bullet \mathrm{Fj}_{\mathrm{j}, 1, \mathrm{~m}}
$$


where

hi is an indicator of any of the hydrogen generating technologies,

$\mathrm{Fj}_{\mathrm{j}, 1, \mathrm{~m}}$ is the total hydrogen $(j)$ demand for region $l$ at time $m$,

$\mathrm{Sh}_{\mathrm{hi}, \mathrm{l}}$ is the share coefficient of the competing fuels (in the form of prices) in generating hydrogen, and

$\mathrm{Ssh}_{\mathrm{hi}, 1}$ are the shares of the scrubbed and unscrubbed oil, or scrubbed and unscrubbed gas, or scrubbed and unscrubbed coal in generating hydrogen.

(d) Synfuels are assumed to emit carbon via the appropriate product coefficient, that is, syngas is assumed to emit carbon by means of the gas coefficient; and synoil by means of the oil carbon coefficient. The difference in emissions between the emissions of the product and that of the feedstock is assigned to the production sector. If carbon is sequestered during the synfuel production processes, that carbon is subtracted from the emissions of the production sector.

Emissions from liquified gas are calculated as follows:

$$
\begin{aligned}
& \text { Cemissions }_{\mathrm{i}=\text { synfuel_gas }}=\operatorname{SynInput}_{\mathrm{i}=\text { gas }} \bullet \mathrm{CO}_{\mathrm{i}=\text { coal }}- \\
& \text { SFuel }_{\mathrm{i}=\text { gas }, \mathrm{j}=\mathrm{liq}, \mathrm{l}, \mathrm{m}} \bullet\left(1-\operatorname{SedFil}_{\mathrm{i}=\mathrm{oil}, \mathrm{l}}\right) \bullet \mathrm{CO}_{\mathrm{i}=\text { coal }}
\end{aligned}
$$

Emissions from synliquids derived from coal and syngas derived from coal are calculated as follows, which includes carbon removed in the transformation process due to scrub technology if $\operatorname{RemFrac}_{1,1}$ is not equal to one:

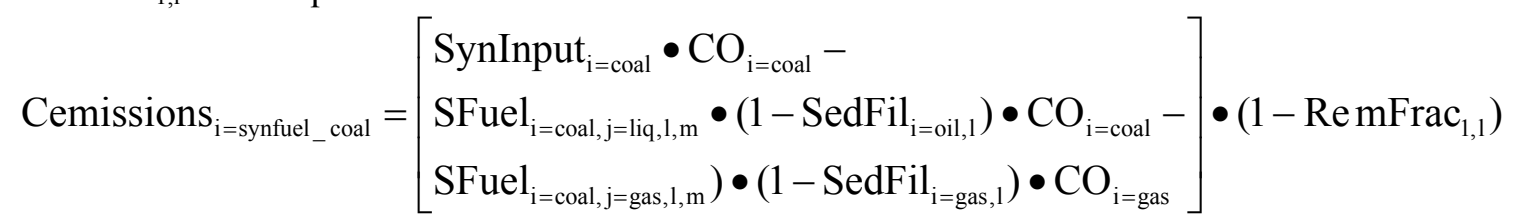

(MMTC) Eq. 97

where

$\operatorname{RemFrac}_{1,1}$ is the fraction of the emissions that can be scrubbed during synfuel generation checked for maximum sequestration criteria, SeqFractMax (Equation 28).

Emissions from synliquids derived from biomass and syngas derived from biomass are calculated as follows:

Cemissions $_{\mathrm{i}=\text { synfuel_b }}=\left(\right.$ SynInput $_{\mathrm{i}=\text { biomass }} \bullet \mathrm{CO}_{\mathrm{i}=\text { biomass }}-$

$\mathrm{SFuel}_{\mathrm{i}=\text { biomass, } \mathrm{j}=\text { liquid, }, \mathrm{m}, \mathrm{m}} \bullet\left(1-\mathrm{SedFil}_{\mathrm{i}=\text { oil, }, 1}\right) \bullet \mathrm{CO}_{\mathrm{i}=\text { biomass }}-\quad$ (MMTC) Eq. 98

SFuel $\left.\left._{\mathrm{i}=\text { biomass }, j=\text { gas }, 1, \mathrm{~m}}\right) \bullet\left(1-\mathrm{SedFil}_{\mathrm{i}=\mathrm{gas}, 1}\right) \bullet \mathrm{CO}_{\mathrm{i}=\mathrm{gas}}\right)$

(e) For conventional oil, gas, coal, and biomass emissions are calculated as follows, which includes, if the RemFrac $2, j$ parameter is not equal to zero, carbon removal through scrubbing by utility scrub technology and hydrogen production scrub technology. Emissions from direct biomass burning are set to zero in most scenarios, however. 
Cemissions $=\mathrm{CO}_{\mathrm{i}} \bullet\left[\begin{array}{l}\text { FFcons } \bullet\left(1-\operatorname{SedFil}_{\mathrm{i}, 1}\right)- \\ \operatorname{RemFrac}_{2,1} \bullet\left(\mathrm{ESU}_{\mathrm{ui}, 1, \mathrm{~m}} \bullet \mathrm{gu}_{\mathrm{ui}, 1, \mathrm{~m}} \bullet \mathrm{gij}_{\mathrm{i}}+\right. \\ \left.\mathrm{ESH}_{\mathrm{hi}, 1, \mathrm{~m}} \bullet \mathrm{gh}_{\mathrm{hi}, \mathrm{m}} \bullet \mathrm{gij}_{\mathrm{i}}\right)\end{array}\right]$

where

$\mathrm{CO}_{\mathrm{i}}$ is the emission coefficient of oil, gas, coal or biomass,

SedFil $i_{i, 1}$ is the fraction of the feedstock that is not combusted,

RemFrac $_{2,1}$ is the fraction of the emissions that can be scrubbed during electricity and/or hydrogen generation,

$\mathrm{ESU}_{\mathrm{ui}, 1, \mathrm{~m}}$ is the energy in Joules (Equation 94) that needs to be combusted as secondary energy, electricity, to meet demand and that needs to be converted to primary energy for emission calculations by multiplying with the conversion coefficients $\mathrm{gu}_{\mathrm{ui}, \mathrm{lm}}$ and $g \mathrm{ij}_{\mathrm{i}}$.

$\mathrm{ESH}_{\mathrm{hi}, 1, \mathrm{~m}}$ is the energy in Joules (see Equation 94) that needs to be combusted as secondary energy, hydrogen, to meet demand and that needs to be converted to primary energy for emission calculations by multiplying with the conversion coefficients $\mathrm{gh}_{\mathrm{hi}, \mathrm{lm}}$ and gij $\mathrm{i}_{\mathrm{i}}$

$\mathrm{gu}_{\mathrm{ui}, \mathrm{l}, \mathrm{m}}$ is the transformation efficiency when electricity is produced,

$\mathrm{gh}_{\mathrm{hi}, 1, \mathrm{~m}}$ is the transformation efficiency when hydrogen is produced,

gij ${ }_{\mathrm{i}}$ is the transformation efficiency from primary to secondary fuel conversion, and

FFcons equals the primary fuel demanded for transformation into secondary fuel supply, but for the primary fuels demanded for synfuel production, which implies that for conventional oil, fossil fuel consumption is represented by conventional plus unconventional oil; thus

FFcons $_{\mathrm{i}=\text { oil }, 1}=\mathrm{EDRIL}_{\mathrm{i}=\mathrm{oil}, \mathrm{l}}+\mathrm{ESIL}_{\mathrm{i}=\text { unconventionaloil }}$ (EJ/year) Eq. 100 refined gas fossil fuel consumption refers to refined gas consumption (EDRIL $L_{\mathrm{i}=\text { gas }, 1}$ ) without the additional syngas (Syninput $\mathrm{i}_{\mathrm{i}=\mathrm{gas}, \mathrm{l}, \mathrm{m}}$ ) that can be consumed; thus

FFcons $_{\mathrm{i}=\mathrm{gas}, 1}=$ EDRIL $_{\mathrm{i}, 1}-$ SynInput $_{\mathrm{i}=\mathrm{gas}, \mathrm{l}, \mathrm{m}}$

(EJ/year) Eq. 101

for conventional coal, fossil fuel consumption refers to EDRIL $_{\mathrm{i}=\text { coal, }, 1}$ while subtracting for the coal that is used for gasification and/or liquefaction; thus

FFcons $_{\mathrm{i}=\text { coal }, 1}=$ EDRIL $_{\mathrm{i}, 1}-$ SynInput $_{\mathrm{i}=\text { coal }, 1, \mathrm{~m}}$

(EJ/year) Eq. 102

and for biomass fuel, consumption refers to $\mathrm{EDRIL}_{\mathrm{i}=\text { biomass, } 1}$ while subtracting for the biomass that is used for gasification and/or liquefaction; thus

FFcons $_{\mathrm{i}=\text { biomass }, 1}=$ EDRIL $_{\mathrm{i}, 1}-$ SynInput $_{\mathrm{i}=\text { biomass }, 1, \mathrm{~m}}$

(EJ/year) Eq. 103

Emissions from shale oils are calculated based on shale oil burning $\left(S H A L_{l, m}\right)$ as follows:

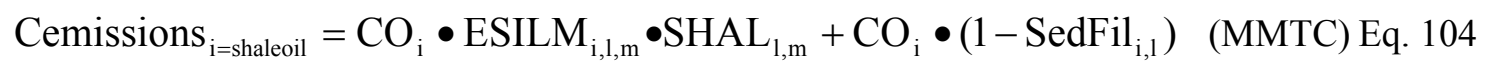
where

$\mathrm{SHAL}_{1, \mathrm{~m}}$ is the shale burning fraction.

For each of the end-use sectors emissions are based on fuel mode demands, attributing shale oil production emissions and flared emissions to the industrial sector. Thus, for transportation, buildings and industry

$$
\mathrm{CO} 2_{\mathrm{k}}=\sum_{\mathrm{j}} \mathrm{CO}_{\mathrm{j}} \bullet \mathrm{Fjk}_{\mathrm{j}, \mathrm{k}, 1, \mathrm{~m}} \bullet\left(1-\operatorname{SedFil}_{\mathrm{j}, 1}\right)
$$

(MMTC) Eq. 105 
For hydrogen production carbon emissions are calculated from the primary fuel demands meeting hydrogen demand $\left(E D R I K L_{j, l, m}\right)$ from which the amounts potentially sequestered have to be subtracted:

$$
\mathrm{CO} 2_{\text {hydrogen }}=\sum_{\mathrm{j}} \mathrm{CO}_{\mathrm{j}} \bullet \mathrm{EDRIKL}_{\mathrm{j}, 1, \mathrm{~m}} \bullet\left(1-\mathrm{SedFi1}_{\mathrm{j}, 1}\right)-\mathrm{C}_{\text {scrub_hydrogen }} \quad \text { (MMTC) Eq. } 106
$$

Electric utilities carbon emissions are calculated from the primary fuel demands meeting electricity demand $\left(E D R I K L_{j, l, m}\right)$ from which the amounts potentially sequestered have to be subtracted:

$$
\mathrm{CO} 2_{\text {electricty }}=\sum_{\mathrm{j}} \mathrm{CO}_{\mathrm{j}} \bullet \mathrm{EDRIKL}_{\mathrm{j}, 1, \mathrm{~m}} \bullet\left(1-\mathrm{SedFil}_{\mathrm{j}, \mathrm{l}}\right)-\mathrm{C}_{\text {scrub_electricty }} \quad \text { (MMTC) Eq. } 107
$$

Emissions from the processing of limestone during cement production are input exogenously and are added to fossil emissions before emissions are passed to the climate module.

\subsubsection{Carbon sequestered in the ERB module}

If carbon is removed in synfuel generation processes, the removed carbon is kept track of as "carbon sequestered".

$\mathrm{C}_{\text {seq }}=\left[\begin{array}{l}\operatorname{SynInput}_{\mathrm{i}=\text { coal }} \bullet \mathrm{CO}_{\mathrm{i}=\text { coal }}-\mathrm{SFuel}_{\mathrm{i}=\text { coal }, \mathrm{j}=\mathrm{liq}, \mathrm{l}, \mathrm{m}} \bullet\left(1-\mathrm{SedFil}_{\mathrm{i}=\mathrm{oil}, \mathrm{l}}\right) \bullet \mathrm{CO}_{\mathrm{i}=\text { coal }}- \\ \left.\operatorname{SFuel}_{\mathrm{i}=\text { coal }, \mathrm{j}=\text { gas }, \mathrm{l}, \mathrm{m}}\right) \bullet\left(1-\operatorname{SedFil}_{\mathrm{i}=\text { gas }, \mathrm{l}}\right) \bullet \mathrm{CO}_{\mathrm{i}=\text { gas }}\end{array}\right] \bullet \operatorname{RemFrac}_{1,1}$ (tons C) Eq. 108

When emissions are removed by electric utilities' scrub technologies when oil, gas, or coal are combusted, the scrubbed carbon is calculated from the total electricity demanded $\left(F_{j l m}\right)$ and the shares of the fuel-specific $\left(S u_{u i, l}\right)$ scrub technologies $\left(S s u_{u i, l}\right)$ where $i$ is the scrub technology. The demanded electricity supply from fuel-specific scrub technologies, is based on $E S U_{u i l, m}$, when $u i$ represents a scrub technology.

The amount that is scrubbed and then sequestered is:

$\mathrm{C}_{\text {scrub }}=\mathrm{CO}_{\mathrm{i}} \bullet \mathrm{ESU}_{\mathrm{ui}, 1, \mathrm{~m}} \bullet \mathrm{gu}_{\mathrm{ui}, 1, \mathrm{~m}} \bullet \mathrm{gij}_{\mathrm{i}} \bullet \operatorname{RemFrac}_{2,1} \quad$ (tons C) Eq. 109 where

$\mathrm{CO}_{\mathrm{i}}$ is the carbon emission coefficient based on the carbon content of the fuel combusted (COI: tons C/EJ for oil, gas, or coal),

$\mathrm{ESU}_{\mathrm{ui}, 1, \mathrm{~m}}$ is the energy in Joules that needs to be combusted as secondary energy to meet demand and that needs to be converted to primary energy for emission calculations by multiplying with the conversion coefficients $\mathrm{gu}_{\mathrm{ui}, \mathrm{l}, \mathrm{m}}$ and gij $\mathrm{j}_{\mathrm{i}}$.

During hydrogen production carbon can be removed through scrub technology when oil, gas, or coal is combusted and $h i$ denotes a scrub technology in quantities calculated as above:

$$
\mathrm{C}_{\text {scrub }}=\mathrm{CO}_{\mathrm{i}} \bullet \mathrm{ESH}_{\mathrm{hi}, 1, \mathrm{~m}} \bullet \mathrm{gh}_{\mathrm{hi}_{1, \mathrm{l}, \mathrm{m}}} \bullet \mathrm{gij}_{\mathrm{i}} \bullet \mathrm{RemFrac}_{2,1} \quad \text { (tons C) Eq. } 110
$$


where

$\mathrm{ESH}_{\mathrm{hi}, 1, \mathrm{~m}}$ and $\mathrm{ghi}_{\mathrm{i}, 1, \mathrm{~m}}$ are equivalents to the utility variables $\left(\mathrm{ESU}_{\mathrm{ui}, \mathrm{l}, \mathrm{m}}\right.$ and $\left.\mathrm{gu}_{\mathrm{ui}, \mathrm{l}, \mathrm{m}}\right)$, but specific to hydrogen generation.

\subsubsection{Non- $\mathrm{CO}_{2}$ Greenhouse Gas and Reactive Gas Emissions from the ERB module}

Emissions of radiatively important substances other than $\mathrm{CO}_{2}$ are more difficult to model since these emissions are not simply proportional to fuel use or other activity factors. These emissions are often by-products of some activity and depend, in general, on the technology used. The "activity factor" can be any quantity calculated by the model. Units vary with the gases. The model works internally in terms of gas weights for the non- $\mathrm{CO}_{2}$ greenhouse gases. When the calculations incorporate GWP (Global Warming Potentials: see Table 4; or alternative indices) unit conversions are therefore not required.

Radiatively important substances are often controlled for reasons other than climate concerns and these reductions, are not modeled at the same level of detail as are changes within the energy system. Instead, an aggregate formulation based on income-driven controls is used. Reductions in these gases due to a climate policy are implemented using marginal abatement cost curves. Mathematically, non- $\mathrm{CO}_{2}$ greenhouse gas emissions are modeled as follows

$$
\mathrm{Em}_{\mathrm{t}}=\mathrm{Em}_{-} \text {factor } \bullet \operatorname{Driver} \bullet\left(1-\operatorname{Control}\left(\mathrm{GDP} / \mathrm{Cap}_{\mathrm{t}}\right)\right) \bullet\left(1-\mathrm{USER}_{\mathrm{t}}\right) \bullet\left(1-\operatorname{MAC}\left(\mathrm{C}_{-} \text {Pr ice }\right)_{\mathrm{t}}\right)
$$

where

(variable units) Eq. 111

Em_factor is an emission factor, which is either input by technology, or derived from base year emissions. All $\mathrm{CH}_{4}$ and $\mathrm{N}_{2} \mathrm{O}$ emissions factors are currently derived by the model directly from base year emissions data,

Control(GDP/Cap $)$ is an emission control due to non-climate policy (e.g., $\mathrm{SO}_{2}$ or $\mathrm{NO}_{\mathrm{X}}$ specific),

MAC(C_Price)t is a Marginal Abatement Curve (MAC) that represents emissions reductions due to climate policy as a function of the price of carbon (or carbon-equivalents). The MAC's used are adapted from EPA studies, and

USER $_{t}$ is an user-defined reduction in emissions intensity over time that represents efficiency improvements or adjustments for other factors not directly modeled.

Drivers and controls for each source are listed in Appendix 6 and summarized in Table 4.

Table 4 ERB non- $\mathrm{CO}_{2}$ emissions

\begin{tabular}{|l|}
\hline Methane: $\mathbf{C H}_{4}$ \\
\hline Industrial Sources \\
\hline Transportation (Mobile Sources) \\
\hline Coal Mining \\
\hline Electric Utilities (Stationary) \\
\hline Natural Gas Systems \\
\hline Petroleum Systems \\
\hline Wastewater Treatment \\
\hline Biofuel Combustion \\
\hline
\end{tabular}




\begin{tabular}{|l|}
\hline Nitrous oxide: $\mathbf{N}_{\mathbf{2}} \mathbf{O}$ \\
\hline Elec Utilities (Stationary) \\
\hline Transportation (Mobile) \\
\hline Adiphic Acid \\
\hline Nitric Acid \\
\hline
\end{tabular}

Most cost curves for non-CO2 greenhouse gases are estimated using bottom-up methodologies. Such curves often include reductions that are cost effective even without carbon cost pricing. Such "below zero" options can be dealt with in a number of ways. The MiniCAM contains an option to phase in any "below zero" options over a number time steps as specified by the user.

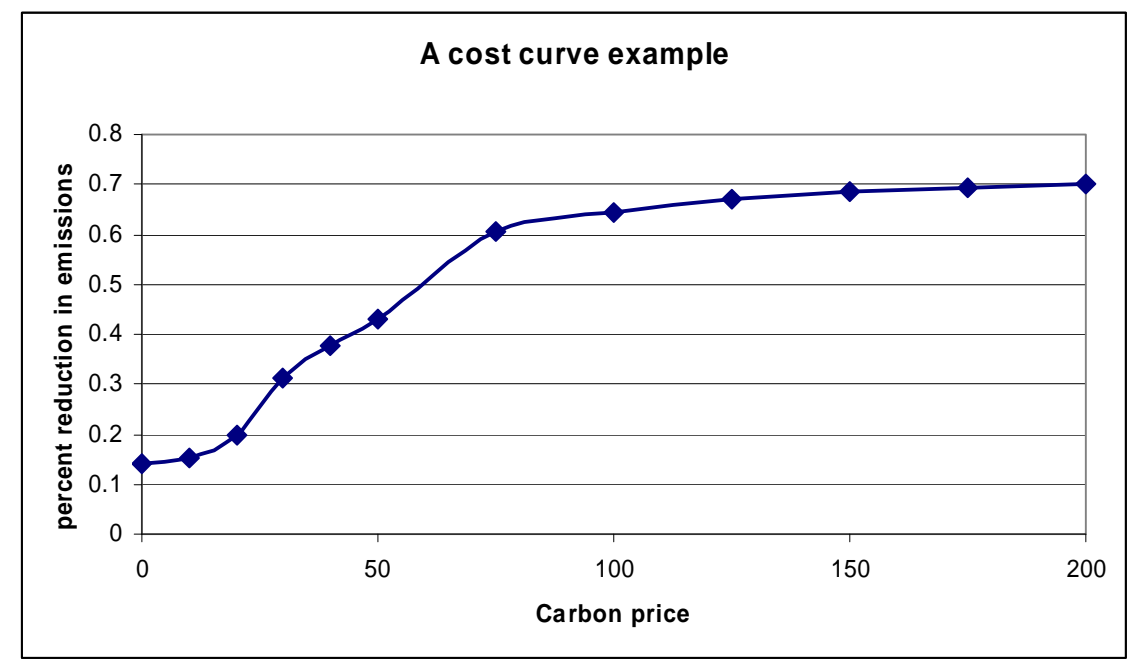

Figure 9 Cost curve example relating carbon prices to emission reductions

Each cost curve is, for a particular emissions source, defined by two indices; the first specifies the gas (e.g., $1=\mathrm{ERB} \mathrm{CH}_{4} ; 2=\mathrm{ERB} \mathrm{N} \mathrm{N}_{2} \mathrm{O} ; 3=\mathrm{Ag} \mathrm{CH}_{4} ; 4=\mathrm{Ag} \mathrm{N}_{2} \mathrm{O}$ ), and a second index that defines the source. The cost curves can be defined for a variable number of points in each curve. An example cost curve is shown above. The $\mathrm{x}$-axis is the carbon price, the $\mathrm{y}$-axis is the percentage reduction in emissions that corresponds to the carbon fee. The model finds a percentage reduction in emissions through linear interpolations based on the carbon fee.

The model works in one of two modes. In one mode, as depicted in Equation 111, the base year emissions level for each of source is read in for every region. The model then calculates an emissions coefficient using the base year activity factor so that emissions are calibrated to base year emissions data.

Alternatively, an emissions factor can be read-in directly for each source sector and region. These methods can be applied separately by source and region as needed by the nature of the available data.

\subsubsection{Emissions from the AgLU module}


While net land-use emissions are small relative to fossil fuel carbon emissions, their treatment can have a major impact on the initial cost of achieving any emissions mitigation objective (e.g., PNNL12021)

In the AgLU calculations, carbon densities are applied to each land-use category to provide an estimate of the carbon stock during each 15-year time step (see Table 81 in Appendix 6 for data estimates). Carbon emissions from land-use change are calculated as the difference in carbon stock between periods.

The land allocated to crops, pasture, forests, commercial biomass, and unmanaged land changes over time in response to changing demands, income, agricultural technologies, and prices of agricultural products. Each regional land-use category is assigned a carbon density for soils

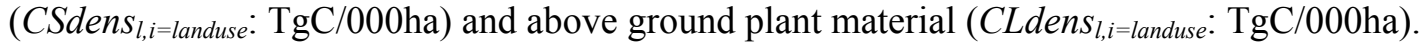
Changes in land use are translated directly to changes in carbon stocks with net carbon emissions equal to the product of land use changes (ha/000) multiplied by carbon densities ( $\mathrm{Tg} / 000 \mathrm{ha})$ for each land-use class.

Historical land use changes are used when vegetation change and soil emissions are calculated for the first time period and for soils when the more refractory carbon decays (slower) in subsequent time periods.

For crops, biomass, pasture, forests, and unmanaged land the carbon emissions from above ground are calculated as follows:

$\mathrm{EmLC}_{\mathrm{i}, 1, \mathrm{~m}}=\sum_{\mathrm{l}=1}^{\mathrm{nr}}\left(\mathrm{CLdens}_{1, \mathrm{i}} \bullet \frac{\text { Landuse }_{\mathrm{i}, 1, \mathrm{~m}}-\text { Landuse }_{\mathrm{i}, 1, \mathrm{~m}-1}}{\text { Nstep }}\right) \quad$ (MMTC) Eq. 112 where III)

$\mathrm{i}$ is an index for land use: crops, biomass, pasture, forests, and unmanaged land (see also Part

For soils the carbon emissions are not only based on changes in land use, but also on a fractionation of the carbon according to decay rates. Thus, $60 \%$ of the soil carbon is assumed to decay when land use change occurs during the simulated time period PercDecay ${ }_{m}=0.6$ ); $30 \%$ of the soil carbon is assumed to only decay in the next time period PercDecay ${ }_{m-1}=0.3$ ), and $10 \%$ of the soil carbon is assumed to decay during the second time period - 30 years - after the land use change occurs $\left(\right.$ PercDecay $\left._{m-2}=0.1\right)$ :

$\mathrm{EmSC}_{\mathrm{i}, \mathrm{m}}=\sum_{\mathrm{l}=1}^{\mathrm{nr}}\left[\sum_{\mathrm{m}=\mathrm{m}-2}^{\mathrm{m}}\left(\right.\right.$ CSdens $_{1, \mathrm{i}} \bullet$ PercDecay $\left.\left._{\mathrm{m}} \bullet \frac{\text { Landuse }_{\mathrm{m}}-\text { Landuse }_{\mathrm{m}-1}}{\text { Nstep }}\right)\right]$

(MMTC) Eq. 113

\subsubsection{Non- $\mathrm{CO}_{2}$ greenhouse gas emissions from the AgLU module}

Variables and drivers for the calculation of non- $\mathrm{CO}_{2}$ greenhouse gas emissions from the AgLU module are listed in Table 5. Methane emissions resulting from agricultural processes are due to enteric fermentation and animal waste (scaled to livestock production) and rice cultivation (scaled to overall crop production). Nitrous oxide emissions from agricultural processes result from 
fertilizer use (scaled to overall crop production), and managed and unmanaged manure (scaled to livestock production).

Drivers and controls for each source are listed in Appendix 6 and summarized in Table 5.

Table 5 AgLU non- $\mathrm{CO}_{2}$ emissions

\begin{tabular}{|l|}
\hline Methane: $\mathbf{C H}_{4}$ \\
\hline Land Use/Burning \\
\hline Enteric Fermentation \\
\hline Manure Management \\
\hline Rice Cultivation \\
\hline Agricultural Residue Burning \\
\hline Temperate Forest Fires \\
\hline
\end{tabular}

\begin{tabular}{|l|}
\hline Nitrous oxide: $\mathbf{N}_{\mathbf{2}} \mathbf{O}$ \\
\hline Human Sewage \\
\hline Agricultural Soils \\
\hline Manure Management \\
\hline Biomass Combustion \\
\hline Agricultural Residue Burning \\
\hline Land Use/Burning \\
\hline Unmanaged Manure \\
\hline Temperate Forest Fires \\
\hline
\end{tabular}

\subsubsection{Total carbon emissions}

Carbon emissions are accounted for in two separate categories, those from industry and fossil fuel use and those as net land-use emissions. This is necessary because land-use emissions have different implications for the carbon-cycle than industrial emissions.

Industrial emissions are the sum of emissions from fossil-fuel production and from cement production. Cement emissions are currently exogenously specified and are added to fossil emissions before they are passed to MAGICC.

Total net land-use emissions are calculated by the AgLU module as indicated above.

Emissions from energy use can be reported for each point in time by fuel, end-use or transformation sector, and region.

CemTot $=\sum_{\mathrm{i}=\text { oil,gas, coal }}^{4}$ Cemissions $_{\mathrm{i}} \quad$ from oil, gas, and oil $\quad$ (MMTC) Eq. 114

\subsubsection{Sulfur Dioxide Emissions}

Sulfur dioxide is thought to be an important climate forcing agent. Once emitted into the atmosphere, sulfur dioxide forms sulfate aerosols which are light in color, reflect sunlight, and act as a cooling agent. Aerosol particles tend to make clouds more dense and reflective. The magnitude of both these effects are very uncertain. The radiative effects of aerosol particles 
depends on the mix of particles, particularly the presence or absence of absorbing black carbon or soot particles.

Emissions of sulfur dioxide depend primarily on the amount of coal and oil combusted and any emission controls in place. Emission controls in this context include de-sulfurization of fuels, using a lower sulfur source for the same fuel, and end-of-pipe sulfur removal. Additional anthropogenic sulfur sources include industrial process emissions, natural gas processing, use of traditional biomass fuels, and biomass burning (savanna burning and deforestation).

Sulfur dioxide emission calculations are implemented as shown in Equation 115 (Smith et al. 2002). Sulfur emissions from fossil fuel combustion are modeled using region and fuel-specific sulfur contents (see Table 72 in Appendix 6), ash retention percentages (for coal) (see Table 71 in Appendix 6), and appropriate control percentages (see Tables 73-79 in Appendix 6).

The effect of advanced energy transformation technologies has a significant impact on sulfur emissions. Fuels used in advanced electric combustion technologies like combined-cycle gasification systems, hydrogen production, or the production of synthetic fuels are assumed to emit no, or almost no sulfur dioxide. Given that the MiniCAM is an aggregated model the average electricity generation efficiency for each region and time step for these technologies is specified as follows: if electric generation efficiency is $55 \%$ or greater, $99 \%$ of the sulfur is removed while zero removal is assumed for an average efficiency of $40 \%$ or less. A linear interpolation between these two efficiency values determines actual sulfur removal (Smith et al. 2002). For liquid fuels a final sulfur content is used to calculate $f_{\max }$, the maximum control percentage in Equation 115. This allows the future sulfur content of end-use petroleum products to be directly set as an input parameter.

The degree (percentage) to which regional emissions will be controlled is simulated as a logistic function of income based on the assumptions that attention to local and regional air pollution will increase with increased affluence (for which there is historical evidence) and that increasing affluence allows for an increase in resources that can be devoted to pollution controls (Smith et al. 2002). Income is measured in terms of purchasing power parity, which is, in this case a better measure of relative wealth than simply exchange-rate-based $G D P$.

EmSulfur $_{\mathrm{t}}=\frac{\text { FuelUse }}{\text { EnergyContent }} \bullet$ SulfurContent $\bullet\left(1-\mathrm{f}_{\text {ash }}\right) \bullet\left(1-\mathrm{f}_{\text {control }}\right)$

(TgS) Eq. 115

where

FuelUse is the regional and sectoral-specific fuel consumption in EJ, EnergyContent of each fuel is measured in $\mathrm{GJ} / \mathrm{kg}$,

SulfureContent is a constant percentage over time,

$\mathrm{f}_{\text {ash }}$ is the ash-retention fraction, and

fcontrol is determined as follows fcontrol $=\frac{\mathrm{f}_{\text {max }}}{\left(1+\mathrm{e}^{\left.\frac{-\mathrm{c}\left(\text { (GDPprcap }_{\mathrm{t}} / \text { GDPpercap }_{\text {midpo int }}\right)}{\tau}\right)}\right)}$

where

$\mathrm{f}_{\max }$ is the ultimate reduction percentage,

GDPpercap ${ }_{\text {midpoint }}$ is the midpoint of the GDP control curve at which point emissions are reduced by $0.5 *$ GDPpercap, and 
$\mathrm{T}$ is the per GDP per capita range over which the control percentage goes from $10 \%$ to $90 \%$ of $\mathrm{f}_{\max }$.

The regional, sectoral, and fuel-specific emissions can be summed to obtain and estimate of the global sulfur emissions. Only regional fuel consumption (FuelUse) and control percentages change in the future. The regional energy content, sulfur content, and ash retention are held constant at the 1990 base year emissions in the projections. How these regional base year emissions are obtained is described in Smith et al. (2001). In brief, 56\% of 1990 world emissions were estimated as being derived from coal, $24 \%$ from oil, $15 \%$ from industrial processes and 3\% from biomass burning. 


\section{PART III}

\section{AgLU: the Agriculture Land Use module}

Projections of global greenhouse gas emissions over the next century show that the agricultural sector will likely play a significant role in potential future increases in radiative forcing and climate change. Greenhouse gas emissions associated with agriculture include methane, nitrous oxide and carbon dioxide (Sands and Leimbach 2001; Sands and Edmonds 2002; Edmonds et al. 1996).

The agricultural sector can reduce net emissions of carbon dioxide through the production of carbon-neutral biomass fuels to substitute for some portion of fossil fuels that would otherwise be used. Conversely, carbon dioxide emissions may result from deforestation. Carbon, methane and nitrous oxide emissions may be reducible through improved agriculture management techniques and/or technological innovation. Conversely, increasing demand of agriculture products may cause increasing emissions.

The Agriculture and Land Use (AgLU) model was initially developed to simulate global land use change and carbon emissions as responding to a carbon policy. Edmonds et al. (1996) constructed the first version of the AgLU model as an addition to the ERB model. The current version (Sands and Leimbach 2001; Gillingham et al. 2002; Sands and Edmonds 2002) expands on the original version with a revised demand structure; a supply structure derived in analogy with the ERB logit sharing mechanism; and a future forests market that eliminates instabilities in forest production.

The AgLU model is a top-down economic model with sufficient structure to simulate regional land use change and the resulting emissions over one century, that is, over the same time period as the ERB model. AgLU adds markets for composite crops, animal products, and forest products to the original ERB world markets for oil, gas, coal, and biomass (see Table 2 for a list of the final 12 markets) ${ }^{24}$. Commercial biomass, along with the shared (with ERB) driving forces of GDP and population provide the link between the energy structure of ERB and land use in AgLU.

The AgLU model contains enough complexity to (1) provide estimates of carbon emissions from land-use change over the next century in response to changing population, income, and agricultural technologies, (2) evaluate the role of commercial biomass and its impact on land use

${ }^{24}$ ERB's and AgLU's markets (Table 2)

\begin{tabular}{|l|l|}
\hline Fuel markets & Agricultural product markets \\
\hline $1=$ Oil & $6=$ Wood \\
\hline $2=$ Gas & $7=$ Forward Wood \\
\hline $3=$ Coal & $8=$ Food Grains \\
\hline $4=$ Biomass & $9=$ Coarse Grains \\
\hline & $10=$ Oil Crops \\
\hline Carbon market & $11=$ Miscellaneous Crops \\
\hline $5=$ Carbon & $12=$ Pasture Products \\
\hline
\end{tabular}


in a carbon-constrained world, and to (3) provide estimates of methane and nitrous oxide emissions from the agricultural sector.

AgLU is a dynamic ${ }^{25}$ partial equilibrium economic model; it has 1990 as base year and performs its calculations in 15-year time steps as does ERB. The three primary drivers of land use change are population growth, income growth, and autonomous increases in future crop yields. Even small changes in the rate of increase in future yields can have a large impact on the amount of cropland needed to maintain adequate diets, expressed as calories in the AgLU model. Changes in the regional composition of consumption in response to higher incomes can also be important, especially if people in developing countries increase per-capita consumption of animal products to the level seen today in the United States and Europe (Sands and Edmonds 2002).

At the core of the AgLU model is a mechanism that allocates land among crops, pasture, forests, and unmanaged land such that economic return from each land use type in each region is maximized (see Figure 10). A joint probability distribution is defined over yield in each alternative land use. Yield is measured in units of calories per hectare for crops and pasture, and in cubic meter wood for forests. With additional information on prices and non-land cost of production, landowners are assumed to select the land use with the greatest economic return calculated as revenue less non-land cost of production. With simplifying assumptions on the geographic distribution of yield, a reduced form solution can be obtained for the share of total land in each region allocated to each land use as a function of prices and non-land costs of production.

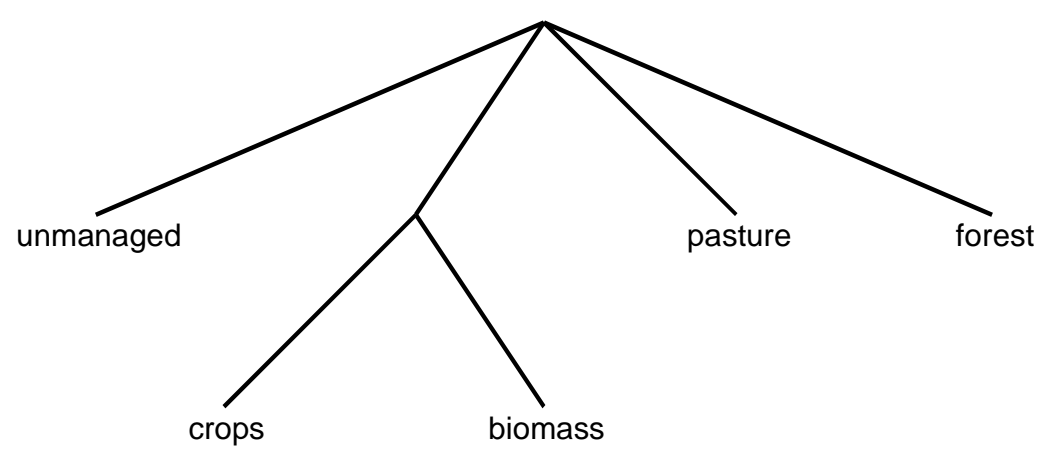

Figure 10 Nested approach to land use

Carbon densities appropriate for each land-use category provide an estimate of the carbon stock during each 15-year time step. Carbon emissions from land-use change are calculated as the difference in carbon stock between periods. Methane emissions resulting from agricultural processes are due to enteric fermentation and animal waste (scaled to livestock production) and rice cultivation (scaled to rice production area). Nitrous oxide emissions from agricultural processes result from fertilizer use (scaled to overall crop production), and managed and unmanaged manure (scaled to livestock production).

\footnotetext{
${ }^{25}$ The dynamic aspect results from the fact that changes that have occurred up to one point in time form the initial conditions for the calculations for the next point in time, analogous to the ERB module. Land allocation is, however, input as an initial condition at each point in time and then, for that point in time, recalculated as explained in the text below.
} 
The land allocation methodology used is adapted from Clarke and Edmonds (1993) which considers the related problem of selecting a set of energy technologies to produce a given energy service at minimum cost.

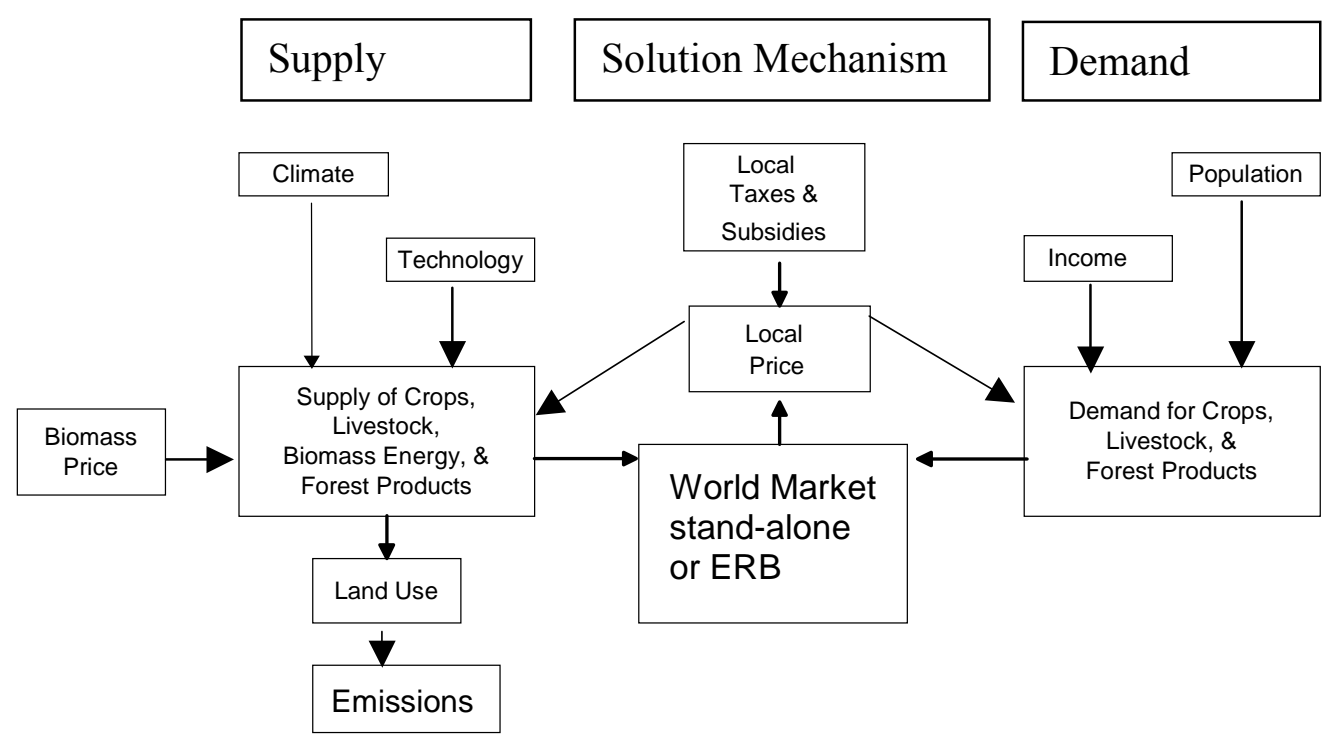

Figure 11 AgLU schemata

Figure 11 shows how AgLU can be run as a stand-alone model once time paths of gross domestic product and population are specified for each region. Note that two other arrows impacting AgLU's production are climate and technology. Climate impact as such can be simulated explicitly (with no input or feedback from MAGICC and/or SCENGEN outputs, however) through climate parameters. These climate parameters are multipliers representing climate, implemented to simulate changes in yield. Technological change is simulated as an autonomous process as in the ERB module. Commercial biomass is simulated through regional-specific input parameters. The price of biomass calculation in the stand-alone AgLU is described in Section 3.2.

When the AGLU module is linked with the ERB module, the price of biomass as feedstock (in $\$ / G J)$ is determined through a global market by adding biomass supply and demand to waste biomass supply and demand in the ERB module. The AgLU land use allocation responds to the demand for biomass as competitive fuel for energy production. Given a high enough biomass feedstock price, regions are capable of growing commercial biomass. Production and markets for biomass are separate from forest products; commercial biomass is envisioned as short-rotation trees, switch grass, etc. Biomass production is, in general, not competitive with the ERB biomass waste given that ERB's biomass waste is produced at lower costs than commercial biomass. Commercial biomass is only produced if the global biomass price is greater than the fixed cost of biomass production, which is an input parameter to the AgLU. 


\subsection{Data that are required}

Agricultural data for base year calibration were obtained from the Food and Agricultural Organization (FAO 2000) of the United Nations. The four composite crops are built from FAO data on cereals, starchy roots, sugar crops, oil crops, fruit, and vegetables. Each individual crop is first converted from the original FAO units of kilograms to calories using weights with units of kilocalories per kilogram. Individual crops are then aggregated to composite crops (markets are active for food grains; coarse grains; oil crops; and other crops) using units of calories. A similar procedure is used for animal products. The three animal composite products (beef and mutton; pork; and poultry) are built from FAO data on meat, animal fats, milk, and eggs (trade in animal products between regions is fixed at 1990 levels; crops and forest products have global markets). Forest products use the original FAO units of cubic meters (markets are for wood and for future wood).

Productivity of field crops is calibrated in the model base year to match historical FAO data. However, these crop yields do not necessarily remain constant over the simulation time frame. Historical crop yields have been steadily increasing over time and AgLU allows crop yields to increase in the future at a rate specified by the model user. Average productivity tends to fall, however, as agricultural production expands into more marginal lands. Conversely, average productivity will tend to increase if agricultural production in a region contracts. The net of the modeled agricultural productivity is the combination of these two forces.

\subsection{The price of biomass in AgLU in stand-alone mode}

When the AgLU is executed in stand-alone mode or linked with ERB the role the carbon price plays in the model solution is analogous to the market prices for wood, crops and animal products. Once (regional) population and income over time are specified the remaining key inputs are the price of biomass and the carbon price. Increases in the carbon price create incentives for production of commercial biomass, given that the carbon price in part determines the price received by growers of commercial biomass. As a consequence, carbon price affects land allocation and, therefore, (carbon) emissions from land use change. Carbon prices can be provided exogenously or set to zero for land use simulations without a carbon policy. Carbon prices are assumed to have units of $\$$ /metric ton $C$. When a carbon policy is implemented, it is represented by a positive carbon price; that is, emissions partake in the calculations of the fuel price by linking emissions with a carbon price.

In the AgLU market equilibrium, in the stand-alone mode ${ }^{26}$, the price paid for biomass liquids will equal the price of refined petroleum-based liquids. Therefore, the price received for a biomass-based fuel is calculated with the Leontief equation, similar to cost and price determinations of fuels described in the ERB module. The Leontief cost calculation needs the price of crude oil, the cost of refining oil to a transportation fuel (OilTranCost), and the nonenergy costs in the form of carbon content of oil (OilCarb) valued at the price of carbon $\left(P_{\text {carbon }}\right)$ :

\footnotetext{
${ }^{26}$ When the AgLU module is linked with the other MiniCAM modules the biomass price is part of the iterative supply and demand equilibrium solution with the AgLU land use allocation responding to the demand of biomass as competitive fuel for energy production and carbon price is not simulated.
} 
$\mathrm{P}_{\text {biofulfromoil }}=\mathrm{P}_{\text {oil }}+$ OilTranCost $+\mathrm{P}_{\text {carbon }} \bullet$ OilCarb

where

$\mathrm{P}_{\text {oil }}$ is the price of crude oil $\$ / G J$,

OilTranCost is the cost of refining oil to a transportation fuel $(\$ / G J)$ which is an equivalent to a combination of the non-fuel cost parameters in the ERB module,

$\mathrm{P}_{\text {carbon }}$ is the market price of carbon ( $\$$ metric ton or $\mathrm{Kg} \mathrm{C}$ ) which in principle does not differ from a carbon penalty as described in the ERB module when scrub technology in synfuel generation was described, and

OilCarb is the carbon content of oil ( $\mathrm{kg} \mathrm{C} / \mathrm{GJ})$.

Biomass-based liquid fuels are competitive with oil when the price of biomass feedstock adjusted by its net energy content after conversion plus the cost of transformation to liquid fuel, is equal to the price received for biomass-based fuels:

$\mathrm{P}_{\text {biofuelfrombiomass }}=\frac{\mathrm{P}_{\text {biomass }}}{\text { EtoBio }}+$ BioTranCost

$(\$ / G J) \quad$ Eq. 118

where

$\mathrm{P}_{\text {biomass }}$ is the price of the biomass feedstock (\$/cubic meter biomass feedstock),

EtoBio is the energy efficiency of converting solid biomass to a liquid fuel (GJ of biofuel per metric ton of biomass) (is as the fuel cost $(g)$ parameter in the traditional Leontief; see Section 2.2), and

BioTranCost is the cost of transformation biomass feedstock to liquid fuel (\$/GJ) (is a nonfuel cost $(h)$ parameter in the traditional Leontief; see Section 2.2).

If we solve for the price of biomass feedstock $\left(P_{\text {biomass }}\right.$ in $\left.\$ / \mathrm{m}^{3} \mathrm{C}\right)$ using Equations 117 and 118 (in a market equilibrium, the price paid for biomass liquids will equal the price of refined petroleum-based liquids), we obtain the price received for biomass as a function of the crude oil price and the carbon price:

$$
\mathrm{P}_{\text {biomass }}=\text { EtoBio } \bullet\left(\mathrm{P}_{\text {oil }}+\mathrm{P}_{\text {carbon }} \bullet \text { OilCarb }+ \text { OilTranCost }- \text { BioTranCost }\right)
$$

$$
\left(\$ / \mathrm{m}^{3} \mathrm{C}\right) \quad \text { Eq. } 119
$$

To convert this biomass feedstock price from $\$ / \mathrm{m}^{3} \mathrm{C}$ to $\$ / \mathrm{J}$ it is multiplied by a conversion factor (GJperGCAL which is an input parameter).

\subsection{AgLU markets}

In the AgLU module, in the stand alone mode or linked with the ERB module, markets are modeled globally for each composite crop, for the forest products, future forest products and biomass (after commercial biomass supply from the AgLU module is added to the biomass supply of waste if AgLU is linked to the ERB module). The markets are modeled regionally for composite animal and pasture products - if production of animal products is not sufficient to meet regional demand then grain must be imported to produce more animal products.

International trade is an important mechanism in $\mathrm{AgLU}$ allowing regions with a growing population to maintain adequate diets even when limited amounts of unmanaged land can be converted to agriculture. 
The composite crops in AgLU are traded freely among regions so that increases in global demand are supplied wherever it is least expensive to grow them. The four composite crop types are food grains, coarse grains, oil crops, and other crops. The food grains composite is a combination of wheat and rice, and is actually the total number of calories of wheat and rice produced within a region. The coarse grains composite crop in AgLU includes corn and all other cereals. Oil crops consist primarily of soybeans in the United States, but other oil crops are included. The "other crops" category includes the total calories of all remaining food crops, such as fruits, vegetables, and starchy roots. Even though trade in animal products is limited, trade in coarse grains used for animal feed provides a mechanism for indirect trade in animal products.

Animal products are limited to regional markets. Regional supply must equal regional demand, adjusted for trade in animal products between regions at fixed 1990 levels. This assumption is reasonable given the relatively small amount of trade between regions in animal products, due mostly to high transport costs for these products. Animal products are treated separately from grains because people in developing countries are assumed to consume a greater share of calories from animal products as per capita incomes rise.

A composite forest product is used to meet demand for both industrial wood and fuel wood. Unlike the other products, forest products are measured in units of cubic meters. The forest product markets are also cleared globally with one world price. Two markets for forest products are brought into equilibrium within each AgLU time step. One market is for trees cut today and another market is for trees planted today but harvested in the future. The current market determines today's price of forest products and the forward market determines a future price of forest products.

Current supply of forest products depends on the number of trees planted in the past. AgLU operates in 15-year time steps and assumes that tree lifetime is 45 years, or three model time steps. During any given AgLU time step, the vintage of trees that was planted three time steps previously is cut to provide current supply of forest products. Supply of current forest products is therefore fixed, and AgLU searches for a price that brings global demand for industrial wood and fuelwood into equilibrium with this fixed global supply.

\subsubsection{Demand}

Demand for biomass is not computed directly. Instead, a price for biomass is exogenously supplied, which determines the amount of land demanded to be dedicated to producing biomass. If the AgLU module is linked with the ERB module, determination of the biomass price is dependent on the linked model solution process.

Consumer demand for food (calories) creates direct demands for crops as well as indirect demands through animal products. FAO food balance data for 1990 were aggregated into three broad food categories: crops consumed directly, crops consumed indirectly as processed crops, and animal products. Direct crop consumption consists primarily of cereals, but also includes starchy roots, fruits and vegetables. Processed crops include vegetable oils from oil crops, sweeteners from sugar crops, and alcoholic beverages. Animal products include meat, milk, butter, eggs, and animal fats. As shown in Figure 12, consumption of processed crops and animal products varies greatly across regions. 


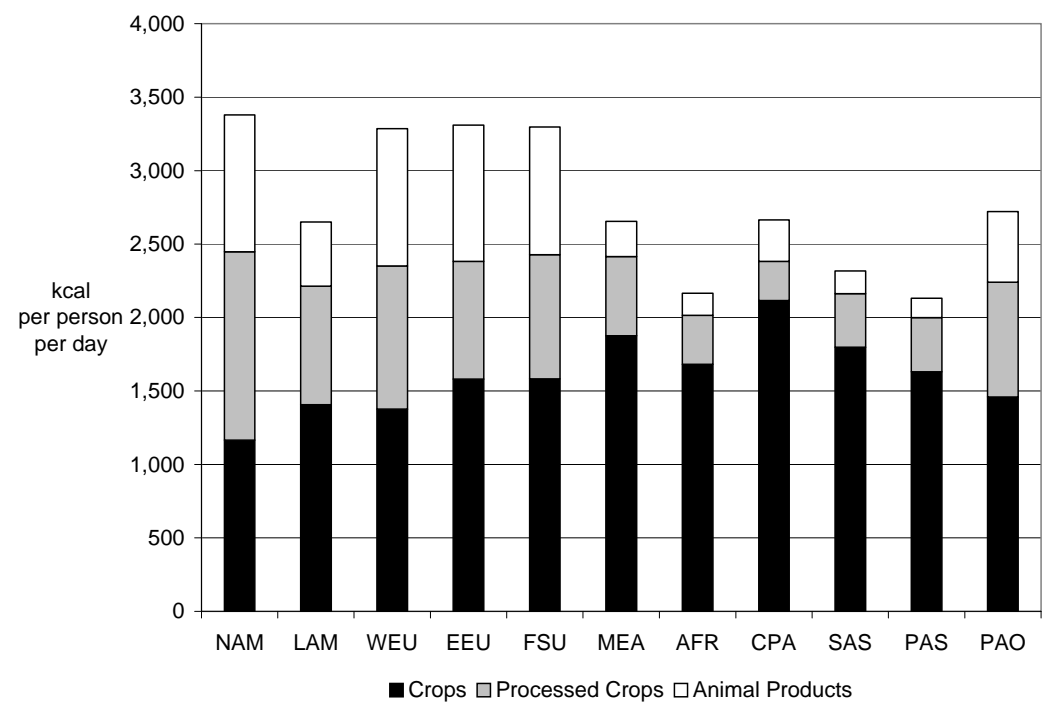

Figure 12 Food consumption in 11 regions in 1990 (from Sands and Leimbach 2001)

The demand equation for each of the crops, processed crops, and animal products is expressed similarly to the (constant elasticity) demand equations for transportation, buildings and industry in the ERB module:

$\mathrm{CDR}_{\mathrm{i}, 1, \mathrm{~m}}=\mathrm{A}_{\mathrm{i}, \mathrm{l}} \bullet\left(\frac{\mathrm{P}_{\mathrm{i}, 1, \mathrm{~m}}}{\mathrm{P}_{\mathrm{i}, \mathrm{l}, \mathrm{m}=\text { baseyear }}}\right)^{\alpha_{\mathrm{jl}}} \bullet \mathrm{Y}_{\mathrm{i}, 1, \mathrm{~m}}^{\beta_{\mathrm{jl}}} \bullet \mathrm{N}_{1, \mathrm{~m}} \bullet \mathrm{C}_{\mathrm{i}, 1, \mathrm{~m}}$

(total calories demanded per year) Eq. 120

where

$\mathrm{CDR}_{\mathrm{i}, 1, \mathrm{~m}}$ is the demand for calories (total calories demanded per year in a region at time $t$ ),

i can be crops, processed crops, animal products,

1 is a region index,

$\mathrm{m}$ is the point in time of the calculation,

$\mathrm{A}_{\mathrm{i}, \mathrm{l}}$ is a scaling coefficient (unitless) to calibrate the price and income feedback terms in the base year,

$\mathrm{P}_{\mathrm{i}, \mathrm{l}, \mathrm{m}}$ is the market price of the commodity ( $\$$ /calories consumed per person per day),

$\alpha_{i, 1}$ is the price elasticity,

$\mathrm{Y}_{\mathrm{i}, 1, \mathrm{~m}}$ is per-capita income index $\{\$ \mathrm{GDP} /$ population/(\$ GDP/population in base year) $\}$,

$\beta_{\mathrm{i}, 1}$ is the income elasticity for the calories demanded which implies it may differ from income elasticity in the demand equation for transportation, industry, or buildings $\left(\mathrm{r}_{\mathrm{yklm}}\right)$,

$\mathrm{N}_{\mathrm{l}, \mathrm{m}}$ is the total population by region (which differs from the population index, the ratio of the regional population at time $t$ divided by the regional population in the base year, in the demand equation for energy services in the transportation and building sector), and

$\mathrm{C}_{\mathrm{i}, \mathrm{l}, \mathrm{m}}$ is calories consumed per person per day (multiplied by 365 to get yearly consumption).

Demand for agricultural products may vary over time in two ways. The first is through directly varying $C_{i, l, m}$ (calories consumed) as an exogenous input by region and food category, providing a simple way to create scenarios of alternative future diets. The second way is through the price and 
income elasticities, $\alpha_{i, l}$ and $\beta_{i, l}$, respectively. Care must be taken in setting price and income elasticities so that simulated consumption stays within a plausible range in each region and food category. Income elasticities for crops and processed crops are set to be small and positive, or zero. Similarly, price elasticities for these two food categories are set to be small and negative, or zero. Data from Figure 11 suggest that consumption of animal products is more responsive to income and price than is consumption of crops and processed crops. Price elasticities for animal products are negative and greater (in absolute value) than price elasticities for crops and processed crops. This price feedback on consumption of animal products is necessary to find an AgLU market solution for scenarios with slow rates of improvement in crop yield over time.

A broader view of global food supply and demand is shown in Table 6, which is a simplified food use table in units of kilocalories per person per day derived from FAO food balances. Total production of crops, including crops used in the production of animal products, is much larger than final demand for crops. Table 6 is structured with each column representing a production or consumption activity, and each row containing inputs to these activities. For example, the first row of Table 6 shows all uses for crops. The first entry in the row for crops represents selfconsumption as seed and waste; the third entry is the amount of crops used as feed in the production of animal products.

Table 6 FAO production and demand example (from Sands and Leimbach 2001)

\begin{tabular}{|c|c|c|c|c|c|c|c|}
\hline & \multicolumn{3}{|c|}{ Production Activity } & \multicolumn{3}{|c|}{ Final Demand } & \multirow[b]{2}{*}{$\begin{array}{l}\text { Total } \\
\text { Production }\end{array}$} \\
\hline & Crops & $\begin{array}{l}\text { Processed } \\
\text { Crops }\end{array}$ & $\begin{array}{l}\text { Animal } \\
\text { Products }\end{array}$ & Food & $\begin{array}{l}\text { Other } \\
\text { Uses }\end{array}$ & $\begin{array}{l}\text { Stock } \\
\text { Change }\end{array}$ & \\
\hline Crops & 344 & 748 & 1,041 & 1,726 & 51 & 49 & 3,959 \\
\hline Processed Crops & 0 & 0 & 2 & 532 & 80 & -4 & 609 \\
\hline Animal Products & 0 & 0 & 37 & 382 & 38 & 0 & 457 \\
\hline
\end{tabular}

By comparing the number of calories of crops fed to animals with calories of animal products consumed as food, we see that the global average efficiency of converting crops into animal products is roughly $37 \%$. The efficiency would be even lower if we considered the caloric content of pasture used as feed. This illustrates the importance of preferences for consumption of animal products as a driver of future land use changes.

We could also compare the number of calories of crops used to make vegetable oils, sweeteners, and alcoholic beverages to the calories of these processed crops consumed as food. This conversion process has a much higher efficiency than converting crops into animal products.

AgLU computes demand for two types of forest products: industrial wood and fuel wood.

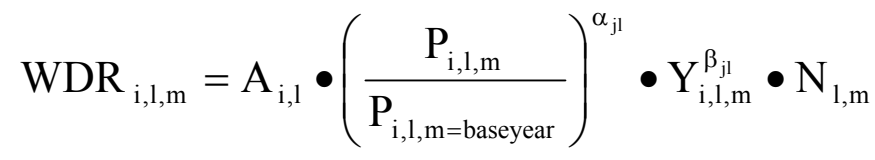

where

$$
\text { (total } \mathrm{m}^{3} \text { wood demanded per year) }
$$

$\mathrm{WDR}_{\mathrm{i}, 1, \mathrm{~m}}$ is industrial wood and fuel wood in cubic meters demanded,

$\mathrm{i}$ is industrial wood, or fuel wood,

1 is a region index,

$\mathrm{m}$ is the point in time of the calculations,

$\mathrm{A}_{\mathrm{i}, \mathrm{l}}$ is used to calibrate base year demands $\left(\$ / \mathrm{m}^{3}\right.$ wood) to historical data by region 
$\mathrm{P}_{\mathrm{i}, 1, \mathrm{~m}} / \mathrm{P}_{\mathrm{i}, 1, \mathrm{~m}=\text { baseyear }}$ is the price ratio of the commodity ( $\$ / \mathrm{m}^{3}$ wood/ same in base year),

$\alpha_{\mathrm{I}, 1}$ is the price elasticity,

$\mathrm{Y}_{\mathrm{i}, \mathrm{l}, \mathrm{m}}$ is per-capita income index $\{\text { GDP/population/(\$ GDP/population } \text { in base year })_{\text {, }}$,

$\beta_{\mathrm{I}, 1}$ is the income elasticity for the wood demanded which implies it differs from income elasticity in the demand equation for transportation, industry, or buildings $\left(\mathrm{r}_{\mathrm{yklm}}\right)$,

$\mathrm{N}_{\mathrm{l}, \mathrm{m}}$ is the total population by region (which differs from the population index, the ratio of the regional population at time $t$ divided by the regional population in the base year, in the demand equation for energy services in the transportation and building sector).

The price per cubic meter is assumed the same for industrial wood and fuel wood. Income elasticity is positive for industrial wood and negative for fuel wood. With rising income, demand for industrial wood increases and demand for fuel wood decreases.

Consumer demand for food grains and miscellaneous crops creates a demand for cropland directly. Demand for processed crops creates an indirect demand for cropland through the conversion of crops to vegetable oils, sweeteners, and alcoholic beverages. Demand for animal products creates an indirect demand for crop land and pasture land used as animal feed but with a net loss of calories through the conversion from crops to animal products. Demand for biomass fuels also requires cropland especially in scenarios with high prices of fossil fuels or scenarios that place a high value on limiting carbon dioxide emissions.

Prices of agricultural products are adjusted when solutions are sought in balancing demand and supply while supply is determined by a land allocation mechanism and assumptions on yield.

\subsubsection{Land allocation}

The land allocation diagram (Figure 10) shows how land is allocated among alternative land uses. During any model time step, some land is already committed to trees previously planted. Other land will be allocated among crops/biomass, pasture, and newly planted trees. Crops and commercial biomass are grouped in a nest because we assume that land for growing crops competes directly with land for growing commercial biomass, e.g., the case of a biomass crop such as switchgrass that could be used for energy.

The land allocation scheme used in the AgLU model is based on profit; this is described next.

\section{Profit rates}

Selection of land use is based on maximizing economic return at each location. Profit per hectare is equal to revenue (yield per hectare times price received) less production cost (yield per hectare times non-land cost per unit of output). This relationship is shown in Equation 122 where $i$ is an index for land use type, $l$ is the region index, and $p$ is an index for geographical location within a region.

$$
\left.\pi \mathrm{r}_{\mathrm{i}, 1, \mathrm{~m}, \mathrm{p}}=\mathrm{y}_{\mathrm{i}, 1, \mathrm{~m}, \mathrm{p}} \bullet\left(\mathrm{P}_{\mathrm{i}, 1, \mathrm{~m}}-\mathrm{G}_{\mathrm{i}, 1, \mathrm{~m}}\right) \quad \mathrm{i}=\text { crops, biomass, pasture } \quad \text { (annual } \$ / \mathrm{ha}\right) \quad \text { Eq. } 122
$$

where

$\pi \mathrm{r}_{\mathrm{i}, 1, \mathrm{~m}, \mathrm{p}}$ is the economic return of the land as a profit rate $(\$ / \mathrm{ha}-\mathrm{yr})$,

$\mathrm{i}$ is an index for land use: crops, biomass, pasture, forests and unmanaged land

1 is the region index, 
$\mathrm{p}$ is an index for geographical location within a region,

$\mathrm{y}_{\mathrm{i}, 1, \mathrm{~m}, \mathrm{p}}$ is yield per hectare for land use $i$ in region $j$ at location $p$ (calories/ha),

$\mathrm{P}_{\mathrm{i}, 1, \mathrm{~m}}$ is the market price for the product produced by land use $i$ (units $\$$ yield units: calories or $\mathrm{m}^{3}$ ); prices of biomass are obtained from the ERB module; market prices of animal products $\left(\mathrm{P}_{\mathrm{i}=\text { animal }}\right)$ and crops $\left(\mathrm{P}_{\mathrm{i}=\text { crops }}\right)$ are solved for within the model; prices of pasture are obtained as shown in Equation 126 as dependent on crop-feed and pasture-feed calories, non-land costs per unit output, and the prices of crops and pasture; and

$\mathrm{G}_{\mathrm{i}, \mathrm{l}, \mathrm{m}}$ is the non-land cost per unit of output in land use (units are $\$$ /yield units: calories or $\mathrm{m}^{3}$ ).

The profit rate $(\pi \mathrm{r})$ calculation for forest products is somewhat different because of the time lag between planting and harvest. The profit rate expression for forest products includes a term that discounts future earnings into the present and levelizes those earnings over 45 years; this forward price is denoted by $\widetilde{\mathrm{P}}_{\mathrm{i}, 1, \mathrm{~m}}$.

$\pi r_{i, 1, m, p}=\frac{r}{(1+r)^{45}-1} \bullet y_{i, 1, m, p} \bullet\left(\widetilde{P}_{i, 1, m}-G_{i, 1, m}\right) \quad i=$ forests $\quad$ (annual \$/ha) Eq. 123

where

$\mathrm{r}$ is the interest rate $(\$ / \$$ that is unitless).

\section{Land shares and yields}

Implicit in the equations below are the assumptions that a yield distribution exists for each land use where yield varies by geographic location, and that geographic location captures variation across temperature, precipitation, available sunlight, soil quality, and slope of land. A joint probability distribution of yield is defined over each alternative land use within a region. Some locations may offer a high crop and pasture yield, but low forest yields. Other locations may show the opposite pattern, or other patterns. Given a joint probability distribution of yield, information on prices received, and non-land costs of production, it is possible to determine the share of land allocated to each use and the average yield within each land use (Sands and Edmonds 2002).

To determine the share of land allocated to each land use type, land use shares would, in general, be calculated numerically, by summing over the land distributions implied in Equations 122 and 123. In the usual integrated modeling context, however, we wish to work on large regional scales. We use instead a reduced-form expression for land shares that effectively sums over the index $p$ in Equations 122 and 123 based on maximizing profit rates which is at the core of finding land shares that provide the yields leading to maximum profits. This suggests using a Gumbel distribution because the maximum extreme of a Gumbel distribution is again Gumbel. This is described in more detail in Appendix 5. An interesting feature of this land allocation mechanism is that for any given land use, average yield may fall as the amount of land allocated to that use increases. For example, if the most productive land is first allocated to crops, cropland can only expand into land less suitable for crops (Sands and Edmonds 2002).

If all land within a region were allocated to a single use, say crops, then we could construct a distribution of crop yields, even though most of those yields would never be observed in practice. This distribution is characterized by a scale parameter and variance, and covers all potential yields for a crop, whether observed or not. The scale parameter can be thought of as a type of average, such as the mean or mode. We consider this an intrinsic parameter of the yield distribution, $\overline{\mathrm{y}}_{\mathrm{i}}$, because it is invariant with respect to prices or land use shares, and is an average across all locations that a particular crop could possibly be grown. This parameter is allowed to 
vary between time steps to represent autonomous increases in yield over time, represented by technological change (as described in Section 2.2 and below.)

Yield distributions may be correlated. For example, land that produces high yields for crops is likely to also provide high yields for commercial biomass. Land use $i$ will be selected only at locations where its profit rate is greater than that of all alternative land uses. Given a joint probability distribution for yield across alternative land uses, the set of potential yields at any particular location can be considered a random sample from that joint probability distribution. Since yield is a random variable, profit rate as defined by Equations 122 and 123 is also a random variable.

With specific assumptions on the functional form of the yield distribution, the share of land allocated to use $i$ is given by a logit share equation:

$\mathrm{S}_{\mathrm{i}, 1, \mathrm{~m}}=\frac{\bar{\pi} \mathrm{r}_{\mathrm{i}, 1, \mathrm{~m}}^{1 / \lambda}}{\sum_{\mathrm{p}} \bar{\pi} \mathrm{r}_{\mathrm{i}, 1, \mathrm{~m}, \mathrm{p}}^{1 / \lambda}}$

(unitless) Eq. 124

where

$\lambda$ is a positive parameter that determines the rate that land shares change in response to a change in profit rate (see Section 2.2 for a description of the logit share equation exponent), the denominator is summed over all possible uses for land, and

$\bar{\pi} \mathrm{r}_{\mathrm{i}, 1, \mathrm{~m}, \mathrm{p}}$ is the average profit rate using land $i$, which is the profit rate evaluated at an average or intrinsic yield, $\overline{\mathrm{y}}_{\mathrm{i}}$, for land use $i$, where $\overline{\mathrm{r}}_{\mathrm{i}, 1, \mathrm{~m}, \mathrm{p}}=\overline{\mathrm{y}}_{\mathrm{i}, 1, \mathrm{~m}, \mathrm{p}} \bullet\left(\mathrm{P}_{\mathrm{i}, 1, \mathrm{~m}}-\mathrm{G}_{\mathrm{i}, 1, \mathrm{~m}}\right)$ is the average profit rate for crops, biomass, and pasture; and $\bar{\pi}_{\mathrm{i}, 1, \mathrm{~m}, \mathrm{p}}=\frac{\mathrm{r}}{(1+\mathrm{r})^{45}-1} \bullet \overline{\mathrm{y}}_{\mathrm{i}, 1, \mathrm{~m}, \mathrm{p}} \bullet\left(\widetilde{\mathrm{P}}_{\mathrm{i}, 1, \mathrm{~m}}-\mathrm{G}_{\mathrm{i}, 1, \mathrm{~m}}\right)$ is the average profit rate for new forests (see Equations 122 and 123).

Land use for a specific purpose (see Figure 10) is calculated based on this logit-based share of total land

Landuse $_{i, 1, \mathrm{~m}}=\mathrm{S}_{\mathrm{i}, 1, \mathrm{~m}} \bullet$ Totalland $_{1}$ Eq. 125

This allocation mechanism is convenient because greater profit rates imply greater shares of land, it can be calculated quickly, and the shares sum to one. The profit rate calculations required for Equation 124 are given by Equations 122 (general) or 123 (new forests). The profit rate calculation for pasture requires a price for pasture-based feed, $P_{i=\text { pasture. }}$ AgLU calculates the price of pasture indirectly from the market prices of animal products $\left(P_{i=\text { animal }}\right)$ and crops $\left(P_{i=\text { crops }}\right)$, both of which are solved for within the model. Given these two prices, $\mathrm{P}_{\mathrm{i}=\text { pasture }}$ is found by solving:

$\mathrm{P}_{\mathrm{i}=\text { animal }, 1, \mathrm{~m}}=\mathrm{P}_{\mathrm{i}=\text { crops }, 1, \mathrm{~m}} \bullet$ FeedOut $+\mathrm{P}_{\mathrm{i}=\text { pasture }, 1, \mathrm{~m}} \bullet$ PastOut $+\mathrm{G}_{\mathrm{i}=\text { animal }, 1, \mathrm{~m}} \quad(\$ /$ cal $) \quad$ Eq. 126 where

FeedOut is the ratio of crop-based feed calories needed per calorie of animal product; PastOut is the ratio of pasture-based feed calories needed per calorie of animal product, and

$\mathrm{G}_{\text {animal,1,m }}$ is the non-land cost per unit of output (an exogenous region and time-specific input parameter in units of $\$ / \mathrm{cal}$ or $\$ / \mathrm{m}^{3}$ ). 


\section{Observed Yield}

In the previous section, we showed how land use shares were calculated using profit rates evaluated at an intrinsic yield for each land use. Intrinsic yield should be thought of as an average yield across all possible locations where a crop could be grown, regardless of the actual land use selected by profit-maximizing land owners. This intrinsic yield does not vary with prices or land shares. However, the average yield of land for any given land type that survives the land allocation process is always greater than the corresponding intrinsic yield. We call this the observed average yield.

In modeling practice, intrinsic yields and base year prices are used as calibration parameters to match base year data on observed average yield and land allocated to each use. The following equations show how the observed average yield is calculated for each land use type.

An observed average profit rate for all land within a region is written as a function of the profit rates evaluated at intrinsic yields. This is shown in Equation 127 where $p$ is an index across land use types. The observed average profit rate is greater than any of the individual (unobserved) profit rates.

$\hat{\pi} r_{i, 1, m}=\left[\sum_{p} \bar{\pi} r_{i, p, 1, m}^{1 / \lambda}\right]^{\lambda}$

$(\$ /$ cal or $\$ / \mathrm{m} 3)$

Eq. 127

where

$\lambda$ is a positive parameter that determines the rate that land shares change in response to a change in profit rate (unitless).

An interesting result is that observed average profit rates $\left(\hat{\pi} r_{i}\right)$ are equal across land use types as indicated in Equation 127. This result is not derived here, but is a consequence of assuming economic optimization. Clarke and Edmonds (1993) derive a similar result in the context of selecting a set of cost-minimizing energy technologies.

$\hat{\pi} r_{i}=\hat{\pi} r \quad i=$ crops, biomass, pasture, forest $\quad(\$ /$ cal or $\$ / \mathrm{m} 3) \quad$ Eq. 128

We exploit this result to calculate an observed average yield $\left(\hat{y}_{i}\right)$ for each land use analogous to Equation 122. The observed average yield for crops, biomass, and pasture is given by

$\hat{\mathrm{y}}_{\mathrm{i}}=\frac{\hat{\pi}_{\mathrm{i}}}{\mathrm{P}_{\mathrm{i}, 1, \mathrm{~m}}-\mathrm{G}_{\mathrm{i}, 1, \mathrm{~m}}} \quad \mathrm{i}=$ crops, biomass, pasture $\quad$ (\$/cal)Eq. 129

where

$\mathrm{P}_{\mathrm{i}, 1, \mathrm{~m}}$ is the market price for the product produced by land use $i$ (units $\$ /$ yield units: calories or $\mathrm{m}^{3}$ ), and

$\mathrm{G}_{\mathrm{i}, \mathrm{l}, \mathrm{m}}$ is the non-land cost per unit of output (an exogenous region and time-specific input parameter in units of $\$ / \mathrm{cal}$ or $\$ / \mathrm{m}^{3}$.

Therefore, the observed average yield $\left(\hat{\mathrm{y}}_{\mathrm{i}}\right)$ is defined to be the yield at which the profit rate is equal to the observed profit rate $\hat{\pi} r_{i}$. Average yield is multiplied by the amount of land, given by the land share from Equation 125, to determine supply. 


\subsubsection{Supply}

Supplies of crops, biomass, pasture, and forest products are calculated as average yields, multiplied by the amount of land allocated to each land use.

Yield per hectare for land use $i$ in region $j$ at location $p\left(y_{i, l, p} ; \mathrm{m}^{3} / \mathrm{ha} / \mathrm{yr}\right)$ are projected by multiplying the intrinsic yields with a climate factor and a technological change factor.

Animal products are produced with a combination of crop-based feed and pasture-based feed.

\section{Technical change}

All of the technical change parameters, $T e c h_{i, m}$, are functions of time $m$ according to

$$
\operatorname{Tech}_{\mathrm{i}, \mathrm{m}}=\mathrm{Tech}_{\mathrm{i}, \mathrm{m}-1}\left(1+\mathrm{S}_{\mathrm{i}, \mathrm{m}}\right)^{\mathrm{Nstep}} \quad \text { (unitless) } \quad \text { Eq. } 130
$$

where

$\mathrm{Tech}_{\mathrm{i}, \mathrm{m}}$ is the rate of technological change, set to one in the base year,

$\mathrm{S}_{\mathrm{i}, \mathrm{m}}$ is the technology change parameter used in calculating the rate of technological change over time (unitless: exogenous time- and purpose-specific), and

Nstep is the time span from one time period to the next (15 years in MiniCAM)

Equation 130 provides a way to simulate exogenous increases in yield, especially for crops. Crop yields will likely increase in the future, but the rate of increase is uncertain. We simulate increases in AgLU crop yield in a range of $0.0 \%$ to $1.5 \%$ per year, with the amount of land needed for crops varying widely in later years depending on this assumption.

\subsubsection{Nested Model}

Previous equations cover the non-nested case for allocating land. However, Figure 10 shows a nested structure for land allocation. The top nest allocates land to a crops/biomass aggregate, but does not allocate land between them. The lower nest allocates land between crops and biomass depending on their relative profit rates. The share of land allocated to crops within the crops/biomass nest is given by Equation 131 .

$$
\frac{\mathrm{s}_{\text {crops }}}{\mathrm{s}_{\text {crops }}+\mathrm{s}_{\text {biomass }}}=\frac{\bar{\pi} \mathrm{r}_{\text {crops }}^{1 / \lambda_{2}}}{\bar{\pi} \mathrm{r}_{\text {crops }}^{1 / \lambda_{2}}+\bar{\pi} \mathrm{r}_{\text {biomass }}^{1 / \lambda_{2}}}
$$

where

$\lambda_{2}$ is a positive parameter that determines the rate that land shares change in response to a change in profit rate.

If we calculate the following profit rate for the crops/biomass composite,

$$
\bar{\pi} \mathrm{r}_{\text {crops } / \text { biomass }}=\left[\bar{\pi} \mathrm{r}_{\text {crops }}^{1 / \lambda_{2}}+\bar{\pi} \mathrm{r}_{\text {biomass }}^{1 / \lambda_{2}}\right]^{\lambda_{2}}
$$


then it can be used in Equation 124, the land share equation for the top nest, and in Equation 127, the observed average profit rate for all land uses. If the exponent term $\lambda$ from the top nest is equal to $\lambda_{2}$ from the lower nest, then the land share equations collapse to a single nest. A single nest is used for the case where the correlation coefficient is the same between all yield distributions. If not, a nested model is used. 


\section{Part IV}

\section{MAGICC: Model for the Assessment of Greenhouse-gas Induced Climate Change}

MAGICC is a 'Simple Climate Model' as defined by the IPCC (1997) that uses a series of reduced-form models to emulate the behavior of fully three-dimensional, dynamic General Circulation Models (GCMs) (Wigley and Raper 1992, 1987, 2002). MAGICC is coupled with the MiniCAM's emission outputs for greenhouse gases (carbon dioxide, nitrous oxide and methane) and aerosol or ozone precursor compounds (sulfur dioxide, nitrogen oxides, carbon monoxide, and volatile organic hydrocarbons). From these emissions MAGICC calculates greenhouse gas concentrations, radiative forcings, global mean temperature changes and sea level rise. MAGICC makes its calculations with annual time steps. The MINICAM currently incorporates the version of MAGICC used to calculate the temperature and sea-level projections for the Intergovernmental Panel on Climate Change (IPCC) assessment reports. ${ }^{27}$

MAGICC is a global energy balance model. Through its simple hierarchy the climate system is conceptualized as consisting of atmosphere, land, and ocean that absorb incoming solar radiation. Changes in the atmospheric concentrations of greenhouse gases and other forcing agents such as ozone and aerosols change the radiative balance of the earth system. This change is termed radiative forcing. A change in radiative forcing moves the earth system toward a (new) equilibrium temperature where incoming and outgoing radiation will be in balance. The ocean acts as a large heat reservoir slowing the approach to this temperature equilibrium.

The net response to a change in radiative forcing is determined by the climate sensitivity, which is an input parameter for MAGICC. The value chosen for the climate sensitivity is one of the principle determinants of the level of future climate change. Estimates of the climate sensitivity are generated by general circulation models, with each model having a characteristic climate sensitivity as well as historical reconstructions.

The version of MAGICC described here is the one used in the second assessment report (SAR; Kattenberg et al. 1996). A more recent version of MAGICC, as used in the third assessment report (TAR) can also be used with the MiniCAM. The TAR version of MAGICC is very similar in overall structure and operation, with some changes and additional feedbacks included (Wigley and Raper 2002).

\subsection{Atmospheric Concentrations}

Determining future atmospheric concentrations of greenhouse gases requires an emissions scenario and a specification of relevant atmospheric chemical processes, sinks, and other sources. Atmospheric concentrations in MAGICC are annually calculated from linearly interpolated larger time-step input emission, which are then converted into radiative forcing.

${ }^{27}$ Kattenberg et al. (1996) 
MAGICC uses the historical record of greenhouse gas emissions and concentrations to assure consistency with specified emissions from 1990. In order to avoid an unrealistic jump in concentrations at the beginning of a model run, model parameters are adjusted so that the input emissions are consistent with the historical record. Emissions of methane and nitrous oxide are adjusted to conform with the historical record by changing the assumed (constant) natural source and not the gas-cycle parameters. An adjustment to net land-use change emissions is also applied over the first portion of the simulated period in order to match the land-use history assumed in MAGICC.

\subsubsection{Carbon Dioxide}

The atmospheric concentration of carbon dioxide is determined using a reduced form model of the carbon cycle. ${ }^{28}$ The carbon dioxide sources considered are fossil fuel use and land-use changes and the sinks are the ocean and the terrestrial biosphere including enhanced biotic uptake due to carbon dioxide fertilization.

The change in the amount of atmospheric carbon dioxide ( $\Delta C$ in units of carbon weight.) is given by $^{29}$

$$
\frac{\mathrm{d} \Delta \mathrm{C}}{\mathrm{dt}}=\mathrm{E}+\mathrm{D}_{\mathrm{n}}-\mathrm{F}_{\text {ocean }}-\mathrm{F}_{\text {fert }}
$$

where in units of $\mathrm{GtC} / \mathrm{yr}$,

$\mathrm{E}$ is total carbon emissions, which are the sum of fossil fuels and cement emissions. The latter are not calculated by this version of MiniCAM but are an exogenous input,

$\mathrm{D}_{\mathrm{n}}$ is the carbon flux due to land-use changes. These can be either provided by the AgLU module or set as an exogenous input,

$\mathrm{F}_{\text {ocean }}$ is the carbon flux into the oceans (see below), and

$\mathrm{F}_{\text {fert }}$ is carbon storage changes due to terrestrial feedbacks, considered by MiniCAM to be due to carbon dioxide fertilization; a positive value for $\mathrm{F}_{\text {fert }}$ indicates a transfer from the atmosphere to the terrestrial biosphere.

Through this equation, the carbon cycle is balanced at each time step.

\section{The ocean and carbon dioxide}

An increase in atmospheric levels of carbon dioxide causes carbon dioxide to dissolve in ocean surface waters. This excess carbon is transported through the oceans by turbulent mixing and ocean currents until equilibrium is reached. This transport is represented by a set of oceanic "sinks" with different time scales that map onto set fractions of the atmospheric carbon increase going into each sink. The parameter values are obtained from the results of a three-dimensional ocean circulation model. The time scales used in MAGICC are 330, 80, 20, and 1.6 years. ${ }^{30} \mathrm{~A}$ fraction of any emissions simply stays in the atmosphere, representing the long-term equilibrium of the system. ${ }^{31}$ A first-order approximation to account for ocean carbon-cycle non-linearity is obtained by using a second response function for large changes. The overall strength of the

\footnotetext{
${ }^{28}$ Wigley (1983). Some notations have been changed.

${ }^{29}$ In units of carbon weight.

${ }^{30}$ Wigley (1991). See Maier-Reimer and Hasselmann (1987) for the initial development of this formalism.

${ }^{31}$ Dissolved carbon will eventually be removed by the system as biotic remains form sediments. However, over time scales of interest here, carbon dioxide stays in the ocean/atmosphere system.
} 
oceanic sink is specified by setting, as an input parameter, the total oceanic carbon $\operatorname{sink}\left(F_{\text {ocean }}\right.$ in Eq. 133) over the decade of the 1980s.

\section{The terrestrial system and carbon dioxide}

The modeled change in atmospheric carbon dioxide concentrations due to the terrestrial biosphere will depend on the net deforestation and the amount of carbon dioxide fertilization. These depend on the amount of terrestrial biomass and how it is distributed. These are modeled by the terrestrial component of the model, which represents on a global level how carbon cycles through living plants into dead plant material, soils and back into the atmosphere. In this version of the model, these calculations are independent of those in the AgLU module except for the possible input of global net-deforestation from AgLU to MAGICC.

The model divides carbon stocks into four parts: fast turnover, living biomass, detritus, and soil carbon. A fraction of the carbon contained in the biological material produced each year returns to the atmosphere immediately, that is, on time scales shorter than the yearly time step of the model. The remaining material remains either as living plants (perennials, trees, etc.) or becomes detritus or part of the soil.

A similar partition is applied at each time step to living plants and detritus. Some fraction of the carbon in living plants either returns to the atmosphere or becomes part of either detritus or soil. Detritus either remains in place, returns to the atmosphere or is incorporated into soils.

In addition, the amount of carbon in each category can be altered by land-use changes, which return carbon to the atmosphere. This is measured by the net deforestation, which is the gross deforestation minus forest regrowth, which is input to the model along with anthropogenic emissions. The time scale for litter production is also the time scale for forest regrowth. This is the time scale over which the system will return to its initial state after a land-use change.

There are thus three time scales in the terrestrial carbon model: litter production (the transfer of carbon from living plant material to either detritus or soil), biological decay of detritus (transfer to either atmosphere or soil), and oxidation resulting in transfer to the atmosphere. These time scales are determined by the initial size of the four carbon reservoirs and the partitioning between them. For the parameters used, the regrowth (litter) time scale is $\sim 60$ years, the detritus decay time scale is $\sim 1.4$ years, and the oxidation time scale is $\sim 209$ years.

The effect of carbon dioxide fertilization is also included as a hyperbolic formula that tends to go to zero as carbon dioxide concentrations reduce to a limiting value (31 ppmv) and to a constant value as concentrations tend to infinity.

\section{Carbon balance}

In principle, all the parameters on the right side of Equation 133, above, could be specified. This would not, however, assure constancy between the specified parameters and the historical change in carbon dioxide concentrations. MAGICC is set up so that the primary input parameters for the carbon cycle model are the net deforestation over the 1980's $\left(D_{n}\right)$ and mean ocean flux $\left(F_{\text {ocean }}\right)$ over the 1980's. The strength of the carbon dioxide feedback is adjusted to assure consistency between the two specified fluxes and the historical atmospheric concentrations over this period. There is no "missing sink" since the carbon cycle is balanced at all times. 


\subsubsection{Methane and other gases}

Modeling the other greenhouse gases is much simpler. The atmospheric concentrations of methane, nitrous oxide, and the halocarbons are modeled as:

$\frac{\mathrm{d} \Delta \mathrm{C}}{\mathrm{dt}}=\frac{\mathrm{E}}{\beta}-\frac{\mathrm{C}}{\tau}$

where

$\mathrm{C}$ is the atmospheric concentration of each gas,

$\mathrm{E}$ is emissions,

$\beta$ is a numerical conversion factor, ${ }^{32}$ and

$\tau$ is an atmospheric lifetime.

Nitrous oxide is modeled with a single lifetime, taken to be constant ( $\sim 120$ years).

Methane has two primary sinks, oxidation by the hydroxyl radical and a small sink due to oxidation within soils. Therefore two sink terms appear in the equation for methane, one with a constant lifetime for the soil sink and another with a variable lifetime for atmospheric oxidation. The oxidation time scale depends on the concentration of various precursor gases $(C O, N O$, and non-methane hydrocarbons), ${ }^{33}$ however the most important effect is the dependence on methane concentration.

As atmospheric methane concentrations increase, $\mathrm{OH}$ concentrations will decrease due to methane oxidation and therefore the methane lifetime will increase. Thus methane has a positive feedback on its own lifetime. The formula for methane lifetime was derived by fitting analytic forms to the results of a number of atmospheric chemistry models (Osborne and Wigley 1994).

Methane in the troposphere eventually oxidizes to carbon dioxide and this small source of carbon dioxide is added to the direct emissions.

There are a large number of halocarbons and, for simplicity, MAGICC treats theses in a limited number of specified groups. ${ }^{34}$ The first group is composed of those substances that cause stratospheric ozone depletion. Emissions of these gases are controlled under the Montreal protocol and its amendments and are set exogenously. The amount of stratospheric ozone depletion due to these gases is estimated through an equivalent chlorine loading concept. ${ }^{34,35}$

Stratospheric ozone depletion also results in cooling of the troposphere, thus offsetting some of the direct warming caused by these gases. The initial (1990) strength of this warming effect is specified as an input parameter and is scaled in the future by the estimated level of stratospheric ozone depletion. Changes in stratospheric ozone will affect the amount of UV light that penetrates to lower levels, which may alter tropospheric chemistry, but this effect is not included in the model. Any such changes are likely to be small in comparison to the present uncertainties in tropospheric chemistry modeling results.

\footnotetext{
${ }^{32}$ For methane $\beta=2.75 \mathrm{TgCH}_{4} / \mathrm{ppbv}$, and for nitrous oxide $\beta=4.81 \mathrm{TgN} / \mathrm{ppbv}$.

${ }^{33}$ The model includes the production of CO from methane oxidation (Osborn and Wigley 1994).

${ }_{35}^{34}$ Wigley and Raper (1992).

${ }^{35}$ Ramaswamy et al. (1992)
} 
Emissions for eight species of halocarbons that do not deplete ozone can be input into MAGICC. These are: HFC125, HFC134a, HFC143, HFC227, HFC245, CF4, C2F6, and SF6. MAGICC can provide radiative forcing and concentrations for each of theses gases. Included are changes in the lifetimes of $H F C$ 's due to changes in the oxidation state of the atmosphere from methane and (in the "TAR version") reactive gas emissions. The forcing due to remaining gases not explicitly covered can be added as an exogenous input. Alternatively, emissions not explicitly covered can be "mapped" to the gas with the closest lifetime.

\subsubsection{Tropospheric ozone and aerosols}

Tropospheric ozone and aerosols are also considered by the model. The model does not calculate an explicit concentrations for these substances but, instead, uses relationships between emissions of precursor substances and the resulting radiative forcing.

The effect of tropospheric ozone is taken to be proportional to fossil fuel use for historical periods. In the "SAR version" of MAGICC used in MiniCAM 2001, future changes in ozone concentrations are due to methane oxidation only. The updated "TAR version" of MAGICC includes the effect of reactive gas emissions $(N O x, V O C$, and $C O)$ on global ozone forcing.

Sulfate aerosol forcing is split into a direct effect, taken to be proportional to sulfur dioxide emissions, and an indirect effect that is logarithmic in emissions. Forcing is split into three regions (North Atlantic, Eurasia, and Southern Hemisphere) in order to provide regional sulfur forcing data to SCENGEN (see below). Emissions of sulfur dioxide are passed to MAGICC from the rest of the MiniCAM. In the present version of MAGICC, forcing from black and organic carbon is assumed to be proportional to sulfur dioxide emissions. The net aerosol forcing from biomass burning is also included and is taken to be proportional to gross deforestation, an output of the MAGICC carbon-cycle model. The base-year (1990) values of all aerosol forcings are specified as input parameters.

\subsection{Radiative forcing}

Given the atmospheric concentrations of greenhouse gases, MAGICC then calculates the resulting radiative forcing. This gives the amount of extra solar energy trapped by solar radiation. The direct radiative forcing caused by changing concentrations of carbon dioxide, methane, nitrous oxide, and $C F C$ 's are calculated using standard analytic approximations for the relationship between concentration and forcing for each gas.

Forcing from ozone and aerosols is calculated as described above. No explicit concentration values are calculated for these substances.

There are also a number of indirect effects. Tropospheric oxidization of methane produces ozone, which contributes a positive forcing proportional to methane concentrations. In the stratosphere, the oxidation of methane produces water vapor, which also contributes a positive forcing.

The total radiative forcing is the sum of all the above: well mixed greenhouse gases, tropospheric ozone, aerosols, and indirect effects. Note that spectral overlap between methane and nitrous oxide is taken into account in the forcing formulas. Other forcings, such as changes in solar irradiance or those due to volcanic activity can be included as external inputs. 


\subsection{Temperature change: terrestrial, atmospheric and in the ocean}

A positive radiative forcing does not immediately translate into a global temperature increase ${ }^{36}$ largely because of the heat capacity of the oceans. The temperature change is found by modeling the global energy balance, that is, by considering how the extra energy added due to a change in radiative forcing is redistributed within the earth system. Four components of the climate system are considered: the atmosphere, the land surface, the ocean's mixed layer, and the ocean's deep water.

The ocean energy balance over time is calculated using the global radiative energy balance and an upwelling-diffusion model of ocean heat transport. In the upwelling-diffusion model the average vertical temperature structure of the ocean is explicitly calculated. This estimates the thermal "lag" effects of the ocean along with an estimate of the thermal expansion of the ocean. Melting from small glaciers and estimated net changes in Antarctic and Greenland ice masses are added to this value to obtain total sea-level rise.

\section{Terrestrial and atmospheric compartments}

The land surface and atmosphere are assumed to be instantly heated by absorbed solar radiation and by any heat that is transported from any other climate "box". This assumption is justified because the time scale over which the land surface and atmosphere will come into (rough) equilibrium with an addition heat source is much less than the yearly time steps used by the model.

\section{The ocean}

Solar radiation not only heats the land surface and the atmosphere, it also heats the surface of the ocean. The oceans are divided into two parts: the mixed layer which is the top layer of $\sim 100$ meters depth, and the deep ocean. The internal heat mixing time of the top layer is less than a year with mixing driven primarily by wind stress. Any heat input into the mixed layer is assumed to heat the entire mixed layer at once. Since water has a higher heat capacity than air or land, the heat storage effects of the mixed layer are important.

Heat is transported from the mixed layer into the deep ocean by two processes. One is heat diffusion, where heat from the warmer mixed layer diffuses downward into the colder deep ocean. The second process is associated with a large-scale circulation known as upwelling. Cold, salty water near the poles sinks down where it spreads over most of the ocean floor (known as ocean "deep water"). The return flow is a general rising or upwelling over the rest of the ocean.

In this framework, global average temperatures do not respond instantly to forcing changes because of thermal inertia of the mixed layer and heat transport into the deep ocean. Even though both upwelling and diffusion result in downward heat transport over the bulk of the oceans, the two processes have different mathematical dependencies and both are needed for a realistic

\footnotetext{
${ }^{36}$ See Hoffert, Callegari, and Hsieh (1980) for a detailed description of this type of energy balance model. The specific model used here is described in Wigley and Raper $(1987,1991,1992)$. Some notation has been changed.
} 
approximation of oceanic heat transport. ${ }^{37}$ The primary parameters that characterize the strength of upwelling and diffusion components are the upwelling velocity and vertical thermal diffusivity, respectively.

If the deep ocean were neglected, the climate system would come into equilibrium with a radiative forcing change within a few years. When the deep ocean is included the time scale for equilibrium increases to one to several centuries. Since the ocean carbon sink has a very long time scale response, the inclusion of the ocean is critical for modeling long-term climate effects. Results are sensitive to the upwelling rate, the ocean diffusivity rate $(\kappa)$, and the deep-water temperature. Results are not very sensitive to the assumed depth of the mixed layer - again highlighting the importance of the deep ocean.

The model will produce a temperature change time series when given a time series of future greenhouse gas emissions, parameters describing heat transport into the deep ocean, a climate sensitivity parameter, and a number of secondary parameters. Note that the climate model actually runs from 1795 onward, using the user specified parameters, instead of simply starting from the present day. This avoids the "cold start" problem that occurs when past radiative forcing changes are ignored.

The mathematical realization of this model is developed by considering the energy that flows into and out of each of the "boxes". Each atmosphere, land, and mixed layer "box" can be described by an energy balance equation as follows:

$$
\frac{\mathrm{dT}}{\mathrm{dt}} \propto \mathrm{S}-\mathrm{F}-\mathrm{H}
$$

where

$\mathrm{T}$ is the average temperature,

$\mathrm{S}$ is the amount of solar radiation absorbed,

$\mathrm{F}$ is the net flux of radiation from the given box, and

$\mathrm{H}$ represents other heat transport from the box including diffusive/convective heat transport, latent heat transport, and for the mixed-layer ocean box, heat transport into the deep ocean.

The equation describing the deep ocean is slightly more complicated since the vertical structure of the deep ocean must also be described. However when the equations for each "box" are added together many terms cancel. The final equation for global average energy balance is: ${ }^{38}$

$$
\frac{\mathrm{dT}_{\mathrm{a}}}{\mathrm{dt}}=\frac{\mathrm{T}_{\mathrm{eq}}-\mathrm{Ta}}{\tau_{\mathrm{a}}}-\left(\frac{\tau_{\mathrm{m}}}{\tau_{\mathrm{a}}}\right) \bullet\left[\frac{\mathrm{dT}_{\mathrm{m}}}{\mathrm{dt}}+\left(\frac{\mathrm{h}_{\mathrm{d}}}{\mathrm{h}_{\mathrm{m}}}\right) \bullet \frac{\mathrm{d} \bar{\theta}_{\mathrm{d}}}{\mathrm{dt}}\right]
$$

where

the subscripts refer to the atmosphere (a), ocean mixed layer (m), and deep ocean (d),

$\tau$ is the radiative relaxation time scale,

\footnotetext{
${ }^{37}$ Heat transport by upwelling is proportional to the temperature gradient $(\mathrm{dT} / \mathrm{dz})$ while diffusive transport is proportional to the second derivative $\left(\mathrm{d}^{2} \mathrm{~T} / \mathrm{dz}^{2}\right)$. Note that, since heat transport depends on the vertical (global average) ocean temperature profile this must be included in the model. The evolution of this profile is explicitly calculated in MAGICC.

${ }^{38}$ From Hoffert, et al (1980)
} 
$\mathrm{h}$ is the height of the ocean mixed layer and deep ocean, and

$\bar{\theta}$ is the mean potential temperature of the deep sea.

The first term on the right hand side indicates that, in the absence of the ocean, the atmospheric temperature would approach an equilibrium value $\left(T_{e q}\right)$ over an atmospheric equilibrium time scale, $\tau_{a}$, of about a month. Storage of heat in the mixed layer and deep ocean slows the approach to equilibrium. The mixed layer time scale is a few years and the deep ocean would take a couple centuries to come into equilibrium.

The equilibrium temperature $\left(T_{e q}\right)$ is determined by the amount of incoming solar radiation, the planetary albedo and the climate sensitivity ${ }^{39}$. Much of the complexity of the climate system is folded into this last parameter, the climate sensitivity, which is the global mean temperature change that results from doubling of carbon dioxide concentrations. In MAGICC, as in all other current models of this type, the climate sensitivity is assumed to be the same for all radiative forcings regardless of source.

The energy balance equation for MAGICC is slightly more complex than this simple depiction. Each hemisphere contains land and ocean "boxes" with inter-box heat transfer coefficients tuned to match the mean seasonal temperature cycle over each hemisphere. Different temperature sensitivities for land and ocean areas are included. For the same increase in solar radiation, the land will heat up more than the ocean since the ocean is more reflective. The land/ocean and hemispheric split also allows regionally-differentiated aerosol forcing.

The assumptions that are made in order to construct a model such as this are not only necessary so that calculations can be performed in a reasonable amount of time but are also prudent since further detail is not warranted given the level of uncertainty as to the magnitude and nature of anthropogenic climate change. For example the "best estimate" values of the climate sensitivity vary by a factor of two, while some argue for an even larger range. If, in the future, the basic response of the climate system becomes better known, it will be useful to examine some of the other simplifying assumptions that are used in such models. At present, however, the global-mean results produced by almost any of the more complex models can be reproduced by varying model parameters in MAGICC, the two most important of which are the climate sensitivity and the ocean thermal diffusivity.

\subsection{Sea-level rise}

In addition to temperature change, global mean sea-level rise ${ }^{40}$ is also calculated by MAGICC. As temperatures increase, sea-level will rise due to thermal expansion of the ocean, melting of small glaciers, and possible changes in Antarctic and Greenland ice sheets.

Such projections, particularly at large time scales, are quite uncertain. The relative magnitude of each component varies. Ocean thermal expansion will increase as long as temperatures are increasing, and even long after radiative forcing is stabilized. Greenland runoff and Antarctic accumulation (see below) will follow the atmospheric temperature trend closely, but will depend

\footnotetext{
${ }^{39}$ The climate sensitivity is the global mean temperature change that results from the forcing equivalent to a doubling of carbon dioxide concentrations

${ }^{40}$ Further details can be found in Wigley and Raper (1993).
} 
on the net balance of a changing melt rate and precipitation, which are very uncertain. If warming becomes significant enough, practically all the mass in small terrestrial glaciers will disappear.

Thermal expansion of the ocean is a complex phenomenon, which will depend on the temperature distribution within the ocean and the expansion properties of sea-water. The expansion rate of sea-water depends on pressure, temperature and salinity, and is well quantified. The results of the model, as with any model of sea-level rise, are sensitive to the choice of the initial temperature profile.

The vertical distribution of ocean temperature is calculated as part of the upwelling-diffusion model described above. This can be used to calculate thermal expansion of the ocean. However, use of the global-mean ocean temperature profile directly would lead to errors since the coefficient of thermal expansion is highly non-linear with respect to temperature. ${ }^{41}$ To reduce this problem, the ocean is divided into six regions by latitude. The mean ocean temperature profile for each hemisphere is scaled for each latitudinal region by the "doubling of carbon dioxide concentration" equilibrium results from a coupled atmospheric/ocean general circulation model. As a result, thermal expansion is greater at higher latitudes. The global-mean expansion is found by averaging the zonal values, weighted by the ocean area of each zone.

As global temperatures have increased over the last century glaciers have been melting and this trend is expected to continue under the influence of greenhouse warming. The contribution of small glaciers to sea level change, $z$, is modeled with a simple mass balance equation.

$$
\frac{\mathrm{dz}}{\mathrm{dt}}=\frac{-\mathrm{z}+\left(\mathrm{z}_{0}-\mathrm{z}\right) \bullet \beta \bullet \Delta \mathrm{T}}{\tau}
$$

where

$\mathrm{z}$ is sea-level change

$\tau$ is the characteristic time scale of melting,

$\beta$ denotes a melting rate response parameter to a temperature increase, $\Delta \mathrm{T}$.

Glaciers have a sensitivity $\beta$ to melting in response to a global temperature increase $\Delta T$. They melt in a characteristic time scale, $\tau$, starting with an initial ice mass $z_{o}$ (in units of sea level rise). These parameters are calibrated using $0.46 \pm 0.2 \mathrm{~mm} / \mathrm{yr}$ as the estimate of the historical glacial melt. ${ }^{42}$ A set of low, medium, and high estimates were derived for these parameters (Wigley and Raper, 1993).

All but one percent of the land ice on earth is contained in the Antarctic and Greenland ice sheets. ${ }^{43}$ Overall, these ice masses change very slowly - the turnover time scales ${ }^{44}$ are about 13,000 and 6,000 years respectively. However the total equivalent sea-level rise of the ice contained in the large ice sheets is approximately 70 meters - so even a relatively small change can be significant. Note that only melting or calving of ice that is grounded - resting on continental or sea-floor rock - can contribute to sea-level rise.

\footnotetext{
${ }^{41}$ In other words, the amount that sea water will expand under a, say, one degree increase in temperature depends very strongly on the pre-existing temperature of the water.

42 Meier (1993), for the period 1900-1961.

${ }^{43}$ For a detailed discussion of the Greenland and Antartic ice sheets see Oerlemans et al. (1992).

${ }^{44}$ Total ice mass divided by the accumulation rate.
} 
The Greenland ice sheet is assumed to have a sensitivity to warming of $0.3 \pm 0.2 \mathrm{~mm} / \mathrm{yr} /{ }^{\circ} \mathrm{C}$, with the positive value indicating a net increase in sea-level with warming. Accumulation changes in Antarctica are assumed to be $-0.3 \pm 0.1 \mathrm{~mm} / \mathrm{yr} /{ }^{\circ} \mathrm{C}$, a decrease in sea-level with temperature. The West Antarctic ice sheet sensitivity is assumed to be $0.1 \pm 0.1 \mathrm{~mm} / \mathrm{yr} /{ }^{\circ} \mathrm{C}$. Large scale ice changes are assumed to be $0.0 \pm 0.1 \mathrm{~mm} / \mathrm{yr}$, that is, zero for the middle case.

The level of uncertainty about the state of the Antarctic and Greenland is greater than that for small glaciers because of increased measurement difficulties. There are three main effects that control the net contribution of the ice sheets to sea-level: (1) accumulation of snow, (2) ablation, and (3) ice sheet dynamics. Ablation - the process that removes snow and ice - increases as temperature increases. Accumulation, however, increases up to $0^{\circ}$ centigrade, and then decreases rapidly. The net direct effect of temperature is the sum of these two processes.

Ice sheet dynamics in the form of ice sheets discharging into the ocean through runoff and calving of icebergs will have an impact on sea-level rise. The West Antarctic ice sheet is an area of particular concern since this ice sheet is grounded below sea level. Some think that the West Antarctic ice sheet might therefore be particularly sensitive to changes in sea level or melting rates. Neither the Antarctic nor Greenland ice sheets are likely to be in an equilibrium state. The assumptions used in MAGICC are that both ice sheets were in balance some time before the historical (since 1880) warming trend. Contributions to sea-level rise are split into four sources: (1) Greenland, (2) possible instability in the West Antarctic ice sheet, (3) changes in Antarctic accumulation, and (4) other large-scale changes in Antarctic ice sheet dynamics. All but the last are assumed to be linearly proportional to temperature. Since ice-sheet dynamic time-scales are large, the latter factor (4) is assumed to be constant for the time horizons of interest.

For many applications, regional details of climate change are required. A global energy balance model such as MAGICC cannot supply regional temperature changes and cannot produce any meaningful results for precipitation. Therefore, global average temperature change, calculated as described above (Equation 136), is used to scale results from general circulation models in order to obtain regional climate change scenarios. This procedure is described in the next section. 


\section{Part V}

\section{SCENGEN: Regional Climate Change Scenario Generator}

MAGICC, described above, calculates global average temperature changes due to changes in radiative forcing from emissions of greenhouse gases and other forcing agents as simulated by the MiniCAM. As was noted, regionally-differentiated aerosol forcings for hemisphere-specific land and ocean can be calculated. To transform global change into still more spatially explicit information the climate change generator SCENGEN (Hulme, Jiang, and Wigley 1995) can be linked to MAGICC's modules.

SCENGEN generates global and regional climate-change scenarios based on one or more GCM experiments. SCENGEN results are based on a library of data generated from a number of general circulation models. For each GCM, the spatial pattern of results for variables such as mean, minimum, and maximum temperatures; wind speed; and precipitation are stored. Surface level results are needed for most climate impacts assessments and therefore a latitude-longitude grid of results is stored with all variables interpolated onto the same $5^{\circ}$ by $5^{\circ}$ grid.

GCM results are then normalized through the pattern-scaling method developed by Hulme et al. (2000). For example, temperature change is expressed as the difference between the value found in the GCM projection and the climatological (1961-1990) average, divided by the global temperature change. For temperature and most other variables the difference between a control (no greenhouse forcing) model run and the greenhouse run is scaled by the climate sensitivity of the model. ${ }^{45}$ After normalization the resulting spatially explicit data are multiplied by a factor representing the global-mean temperature change as determined by MAGICC resulting in spatially explicit ERB-scenario related climate change.

The climate change produced by each GCM is different, in both magnitude and pattern. This is due to the different, and necessarily limited, representations of the relevant physical processes in each GCM and also indicates our uncertain knowledge of the climate system. Therefore, no one model can be considered definitive and this uncertainty must be included in assessments.

SCENGEN allows two methods of indicating this uncertainty. The first, and most widely used, is to use different GCM patterns for the impacts assessment (see below) and compare results. Using normalized patterns is particularly useful since this allows the effect of the different GCM patterns to be seen without the additional effect of the different climate change magnitudes.

However, the normalized patterns from a set of models can also be averaged together to form a composite climate change pattern. In the composite pattern, differences between models tend to cancel out, and the resulting pattern will tend to reflect where the models agree. High and low scenarios can also be generated by assuming that the models in the database are drawn from a normal distribution and generating scenarios that reflect the $90 \%$ limits of the distribution. While this assumption is open to question, this procedure does allow derivation of a reasonable range of scenarios based on a set of GCM results.

45 For some variables, such as precipitation and wind speed, changes are expressed as percentages. 
The use of composite scenarios in an impact assessment gives, in a rough sense, the location, and magnitude at that location, of the most likely impacts. The high and low scenarios give rough limits on impacts. However composite scenarios may not have the same level of spatial variability as individual GCM results.

Using the SCENGEN approach results in losing some degree of consistency between assumptions used to generate global average temperature and sea-level changes and regional patterns emerging the assumptions underlying the GCMs. Moreover, with composite scenarios, the assumptions of the individual GCMs do not relate to the averaged outputs.

A GCM, or as sometimes referred to now as 'earth systems models' can take a month or more to run for just one scenario; and even then it may not include all the relevant greenhouse gases, carbon cycle aspects, and atmospheric chemistry, ocean, and other relevant feedbacks. Moreover, this does not guarantee that the relationship between, say, temperature and precipitation in a given model run is fully representative of the relationships in the 'real world'. Therefore it is prudent to explore multiple scenarios. Approaches such as described here and other types of simplified climate models, are useful for their speed and flexibility. With SCENGEN, multiple scenarios can be explored quickly. 


\section{PART VI}

\section{Results}

When using an integrated assessment model like MiniCAM, model output will be directed to the specific questions asked. Here we will only provide some results to give an overview of MiniCAM's types of output.

\section{Global outputs}

The initial long-term scenarios that the Intergovernmental Panel of Climate Change (IPCC) developed between 1990 and 1992 were widely used in the analysis of possible climate change, its impacts, and options for mitigation. After evaluation of the scenarios in 1995, a new set of scenarios were developed, the so-called SRES scenarios, based on the Special Report on Emissions Scenarios Terms of Reference which called for the use of multiple models, an "open process" and a better understanding of the driving forces, such as demographic development, socio-economic development, and technical change. Scenarios were defined as "alternative images of how the future might unfold" (Nakicenovic et al. (2000).

The results shown below are based on MiniCAM's participation in the SRES scenario analyses.

The scenarios are based on "business as usual"; that is, the scenarios incorporate neither additional climate mitigation options nor adaptation to projected climate change. The descriptions that follow are from Nakicenovic et al. (2000), Moss et al. (2001), and Smith et al. (2002).

In the "convergent and rapid growth" scenario (A1) economic development is robust and population growth moderate. Population peaks around the year 2065. Over time, current distinctions between "poor" and "rich" countries decrease. There is great improvement in the health and social conditions of most. With increases in income, dietary patterns shift towards increased consumption of meat and dairy products. Land use shifts to sprawling urbanization and intensification of agriculture. In the analyses shown, the A1B represents a balance across all energy sources with high energy demands through which coal becomes a particularly important energy source by the end of the century; A1G represents a scenario where technological developments focus on fossil fuels, particularly unconventional natural gas; the A1T represents a focus on energy efficiency and non-fossil energy sources.

The B1 scenario describes a "convergent and sustainable" world with the same population peak around 2065 as in the A1 scenario, but with rapid changes in economic structures toward a service and information economy with reductions in material intensity, and the introduction of clean and resource-efficient technologies. Global solutions are sought to economic, social, and environmental sustainability, including improved equity.

The A2 scenario may be called the "heterogeneous with delayed development" scenario. In this scenario, economic development in Africa and parts of Asia and Latin America is less vigorous because of continuing institutional setbacks. People, ideas, and capital are less mobile so that technology diffuses slowly with the result that international disparities in productivity, and hence income per capita, are maintained or increased. Fertility rates decline only slowly, although they vary among regions, and high population growth results in low global income per capita. Some 
attention is given to potential local and regional environmental damage (sulfur and particulate emissions are reduced in Asia) but this is not uniform $\left(\mathrm{SO}_{2}\right.$ emissions increase in Africa as a result of the intensified exploitation of coal).

In the "heterogeneous world with local sustainability" scenario (B2) there is increased concern for environmental and social sustainability. Global average income per capita grows at a moderate rate. International income differences are reduced considerably. Education and welfare programs lead to reductions in mortality and fertility. Environmental protection is a priority, although strategies to address global environmental challenges are less successful than in other scenarios. There is a gradual reduction in the current reliance on fossil resources, but the energy supply is still predominately hydrocarbon-based even in 2100 . Another way of capturing this scenario would be by calling it the "coal-use" scenario. Scenario results show relatively high sulfur emissions offsetting the high carbon emissions. In this world, there is less wealth for adaptation, but social networks would be presumed to be more effective. Ecosystems would also be under less stress than in the rapid growth scenario.

Figure 13 illustrates results with regard to economic strength in the four SRES scenarios analyzed by PNNL's modelling group using the MiniCAM2001 model documented in this manuscript. Average incomes are highest for the A1 scenario, followed, in order, by the B1 scenario, the B2 scenario and the $\mathrm{A} 2$ scenario.
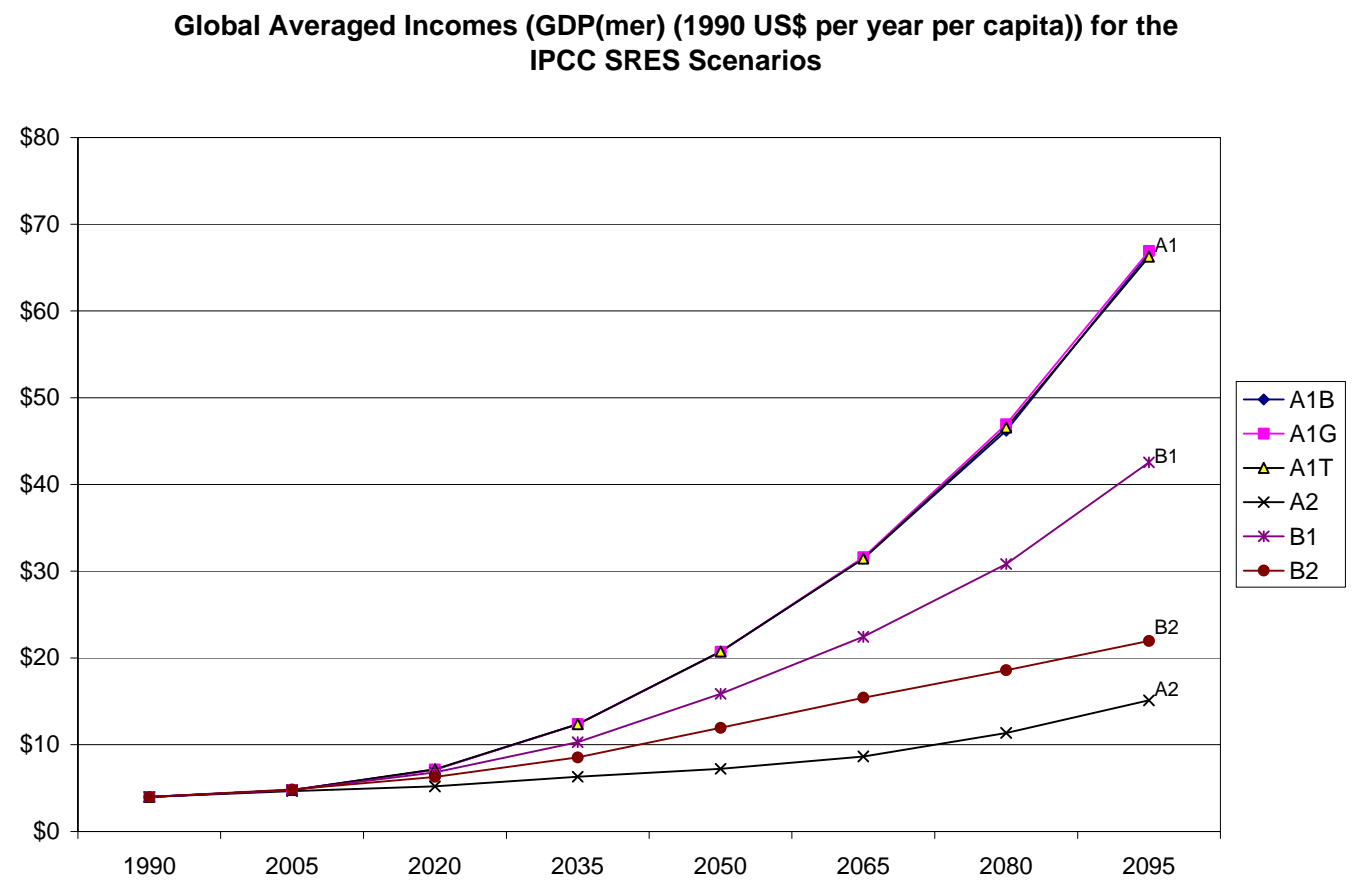

Figure 13 Average incomes, globally, in the four SRES scenarios

Electricity generation in the four scenarios reflect the SRES storylines as follows:

The A1 scenario, as a "rapid growth" scenario shows through 2085 by far the highest generation capacity. The A1G scenario lags behind the A1B and A1T scenarios, having focused on unconventional natural gas, while A1B's "balanced" approach had more coal technologies 
available and A1T focused on energy efficiency. Electricity generation is low in the B1 scenario, the scenario with high population growth (as the A1 scenario) and reductions in material intensity. The A2 pathway of electricity generation shows clearly its "delayed development", while the B2 scenario can be best considered as the most "average" and "to be expected" pathway.

Global Electricity Generation (EJ per year) in the IPCC SRES Scenarios

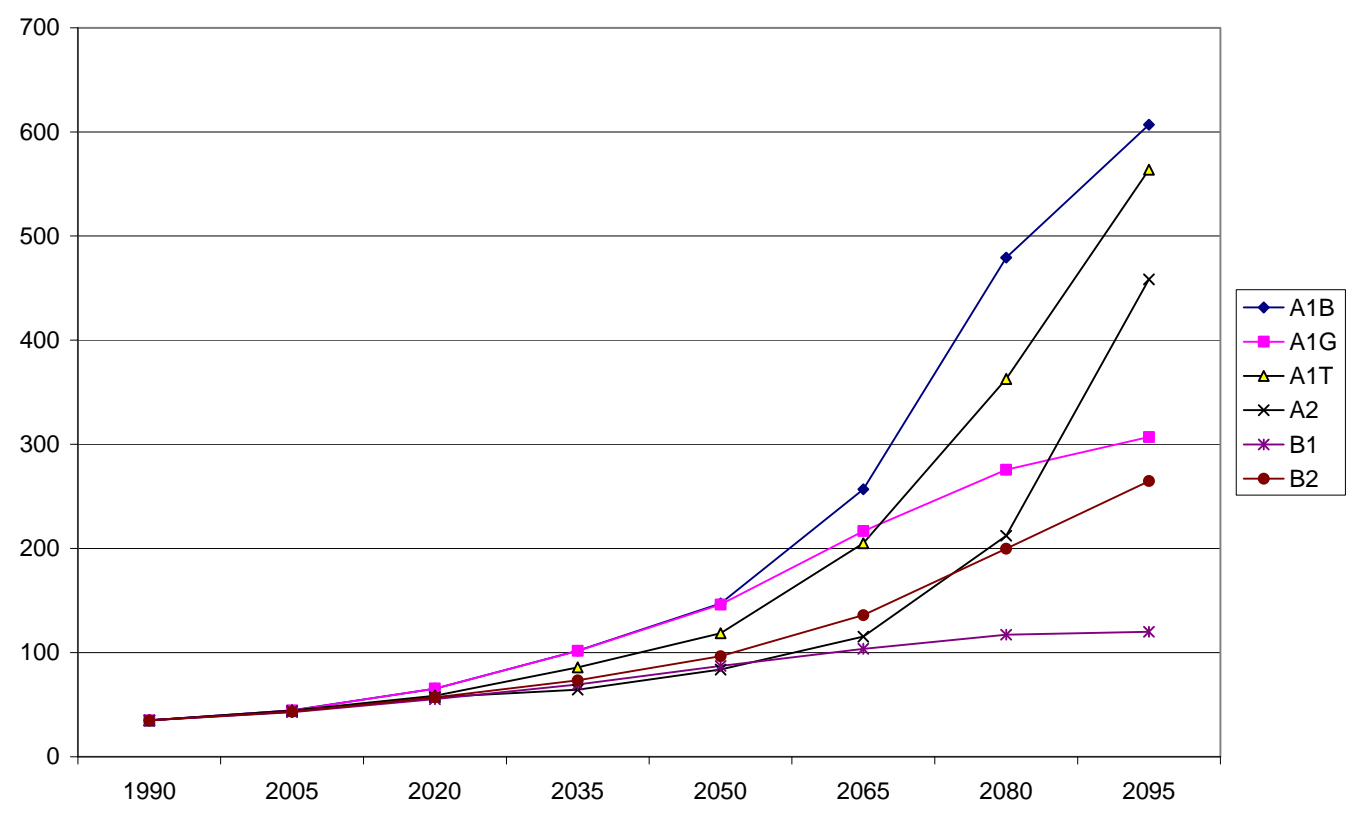

Figure 14 Total global electricity generation in the four SRES scenarios showing divergence in the A1 scenario due to various assumptions with regard to fossil fuel use and technological change.

Diets in the scenarios show much the same pattern as income with the A1 scenario allowing for the highest caloric intake, followed by the B1, B2, and A2 scenarios. The B2 and A2 scenarios diverge more for caloric intake compared to income, however. 
Average Diets (kcal per person per year) in the IPCC SRES Scenarios

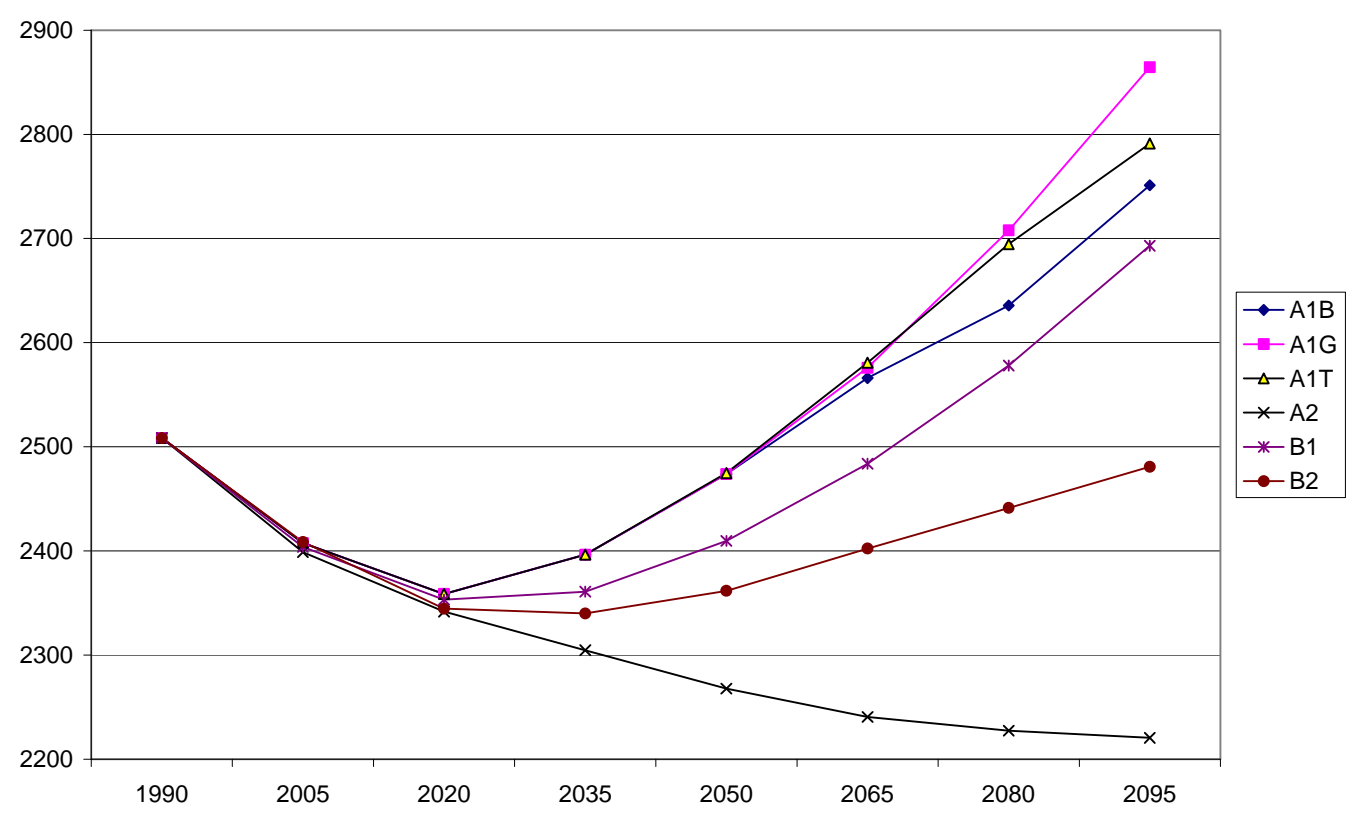

Figure 15 Average diets in the four SRES scenarios with divergence in the A1 scenario.

Given that the MiniCAM model is not just an "energy and economics" model but that it includes the agriculture module AgLU, not only differences in diets can be determined based on different driver-related assumptions, but also agricultural GHG emissions like methane and nitrous oxides (Figures 19-20).

Figure 16 shows total carbon-equivalent emissions. From this graph it can be observed that in the A2 scenario, the "delayed development" scenario emissions emissions surpass those of the A1B and $\mathrm{A} 1 \mathrm{G}$ scenarios as is the case for electricity generation (Figure 14). The A1T and A1G scenarios are reversed in order however (anthropogenic carbon-equivalent emissions versus electricity), given that the A1T scenario focused non-fossil energy resources.

Projected carbon dioxide concentrations, calculated in the MAGICC module are shown in Figure 17. The carbon dioxide concentrations patterns are analogous to the total anthropogenic GHG emissions. 
Global Carbon-Equivalent Emissions (GtCE per year) in the IPCC SRES

Scenarios

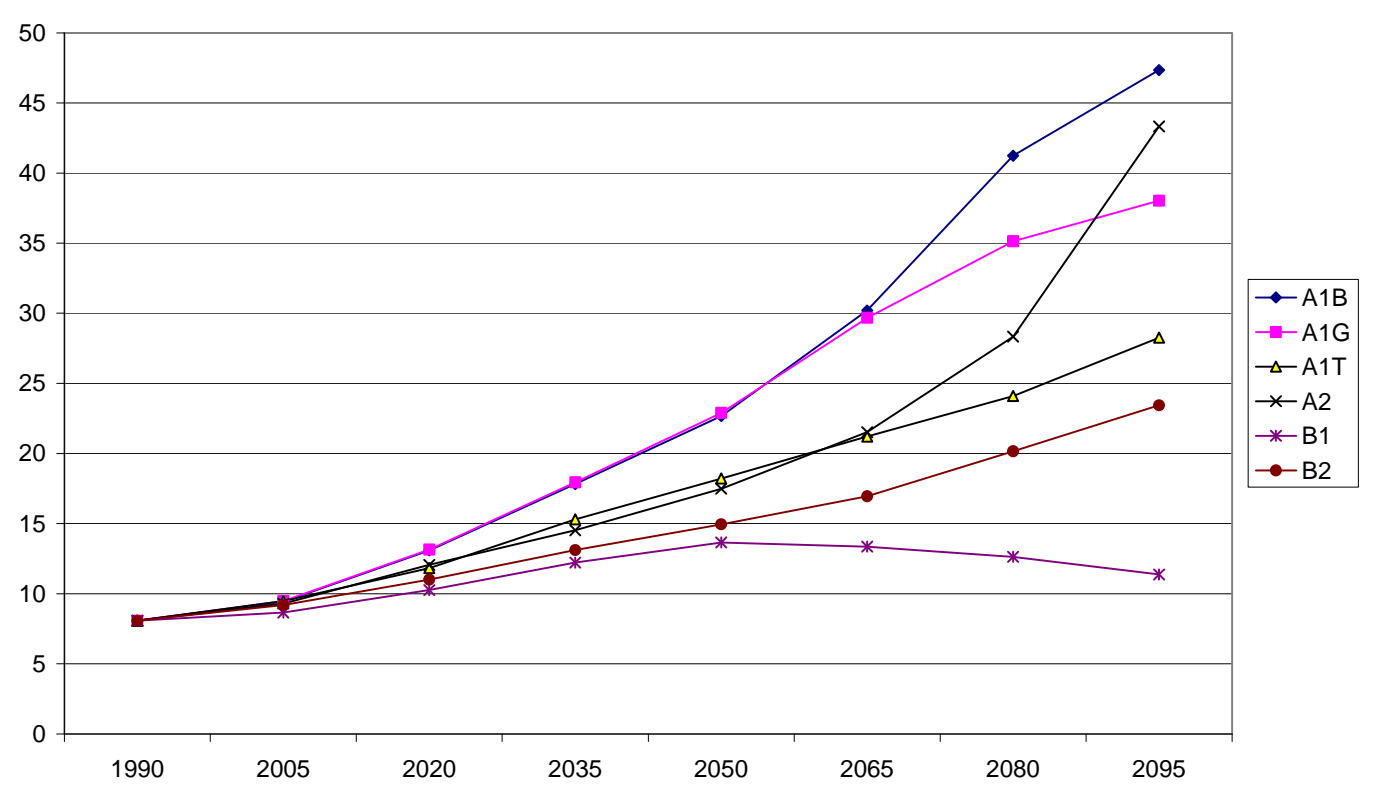

Figure 16 Global anthropogenic carbon-equivalent emissions in the four SRES scenarios

MAGICC's Global Carbon Dioxide Concentrations (ppm) in the IPCC SRES Scenarios

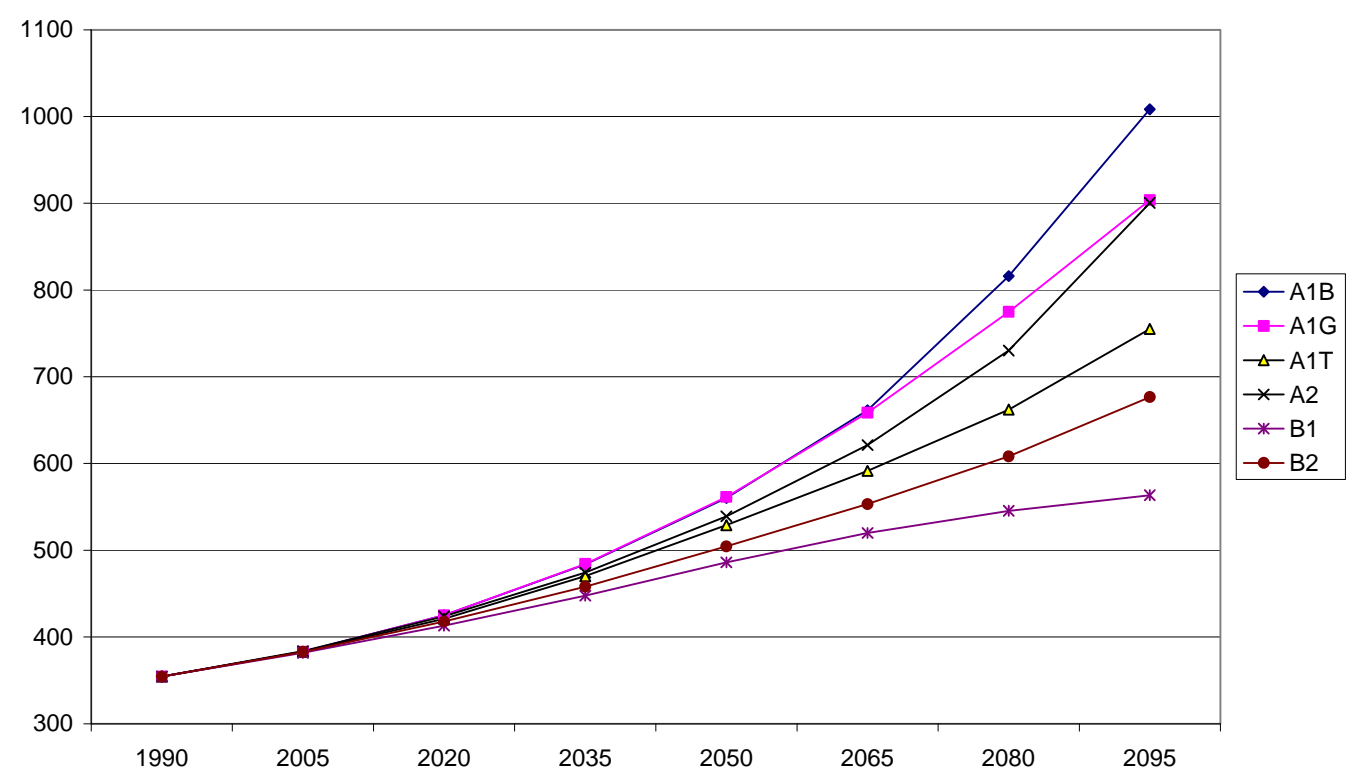

Figure 17 Carbon dioxide concentrations in the four SRES scenarios 
Total sulfur, nitrous oxide and methane emissions are shown in the next set of figures. Sulfur emissions are assumed to decline over time but for the A2 scenario, with the B1 scenario showing the largest decline. These patterns can be explained by the assumptions that in the A2 scenario with its delayed development investments are less in sulfur removal while very dependent on coal in, for example, Africa. The B1 scenario is based on assumptions of clean and efficient technologies pared with low material intensity which results in a decline of global sulfur emissions. Nitrous oxide emissions show a similar scenario differentiation as sulfur emissions. Methane emission, however, show the A1B scenario with largest declines over time, while following the same path as the other A1 and the B1 and B2 scenarios through 2065. Only the A2 scenario stands out with increasing methane emissions over time, illustrating its "delayed development' aspects.

Total Global Sulfur Emissions (TgS per year) in the IPCC SRES Scenarios

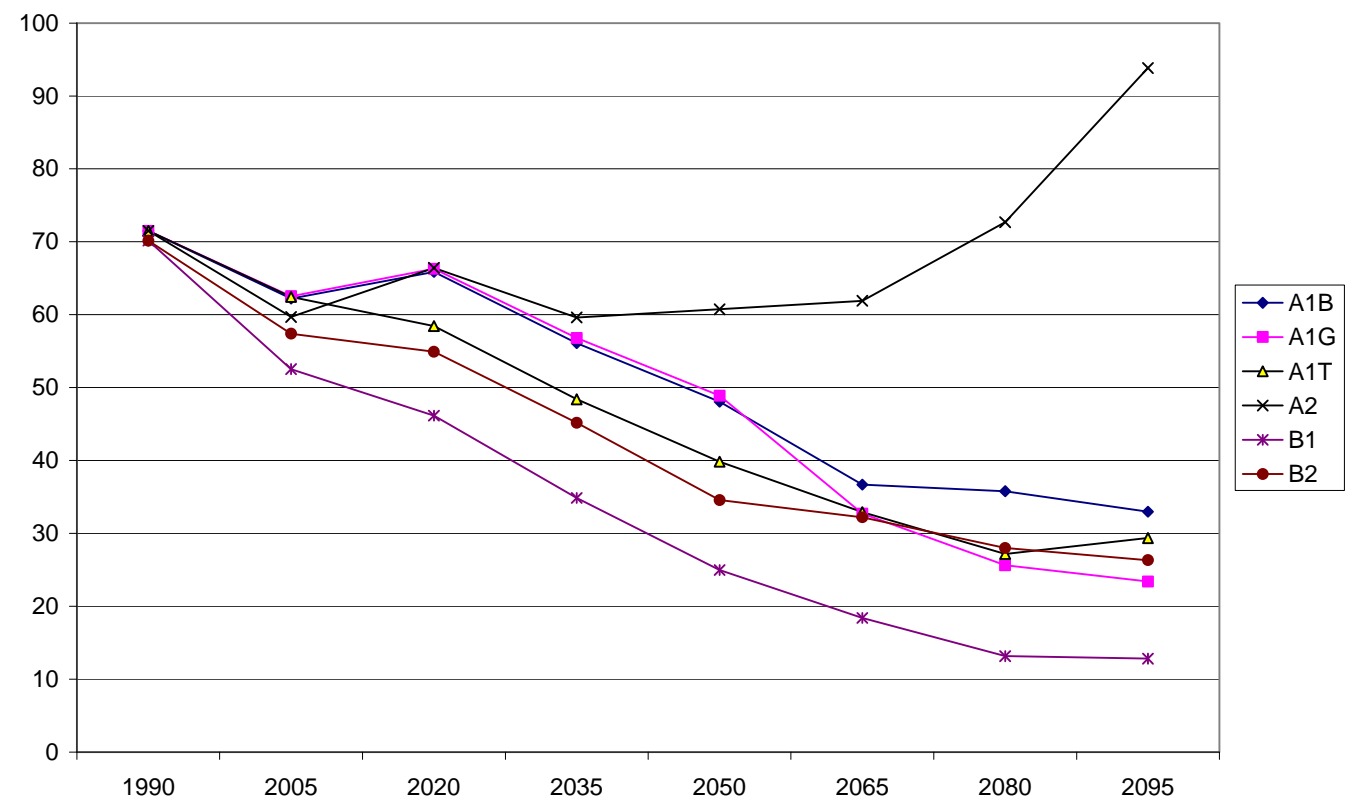

Figure 18 Sulfur emissions in the four SRES scenarios with divergence in the A1 scenarios. 
Total Agricultural Nitrous Oxide Emissions (TgN per year) in the IPCC SRES Scenarios

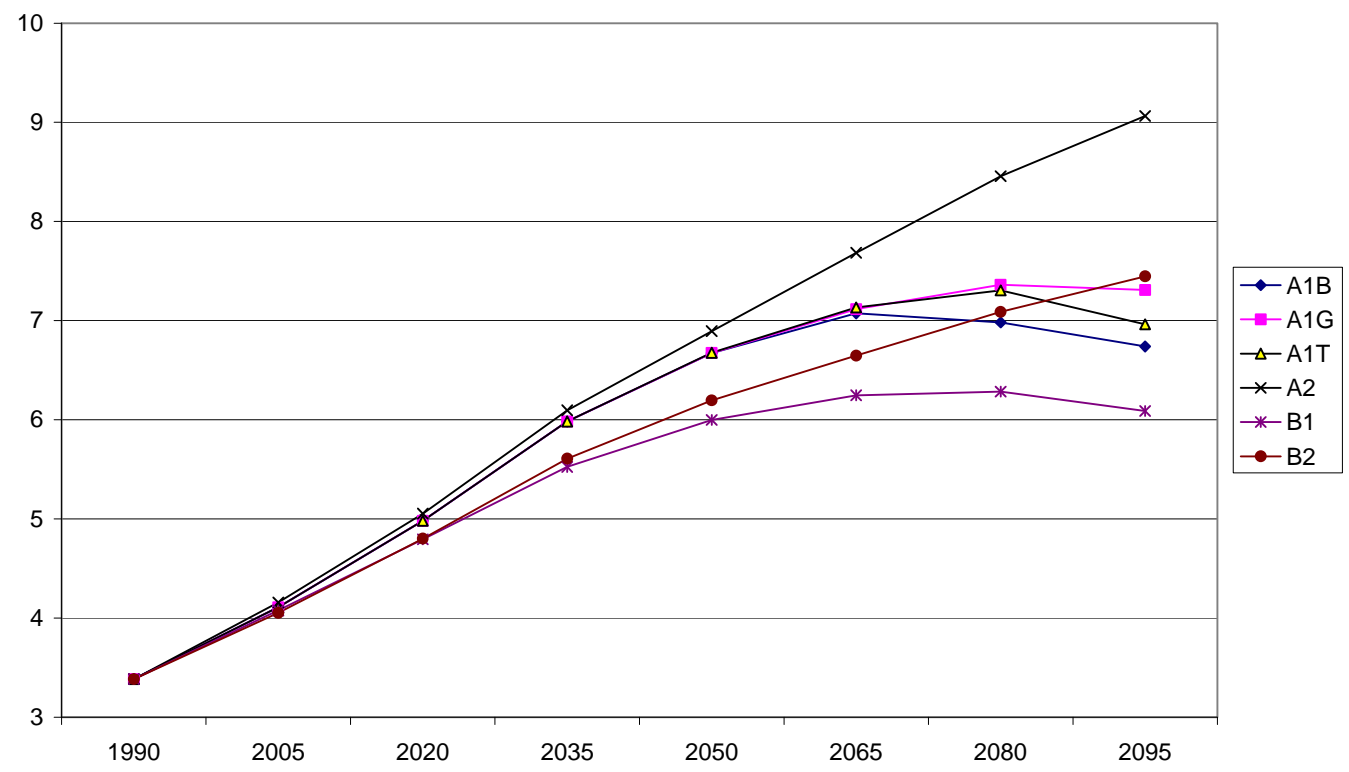

Figure 19 Nitrous oxide emissions in the four SRES scenarios with divergence in the A1 scenarios.

Total Global Agricultural Methane Emissions ( $\mathrm{Tg} \mathrm{CH} 4$ per year) in the IPCC SRES Scenarios

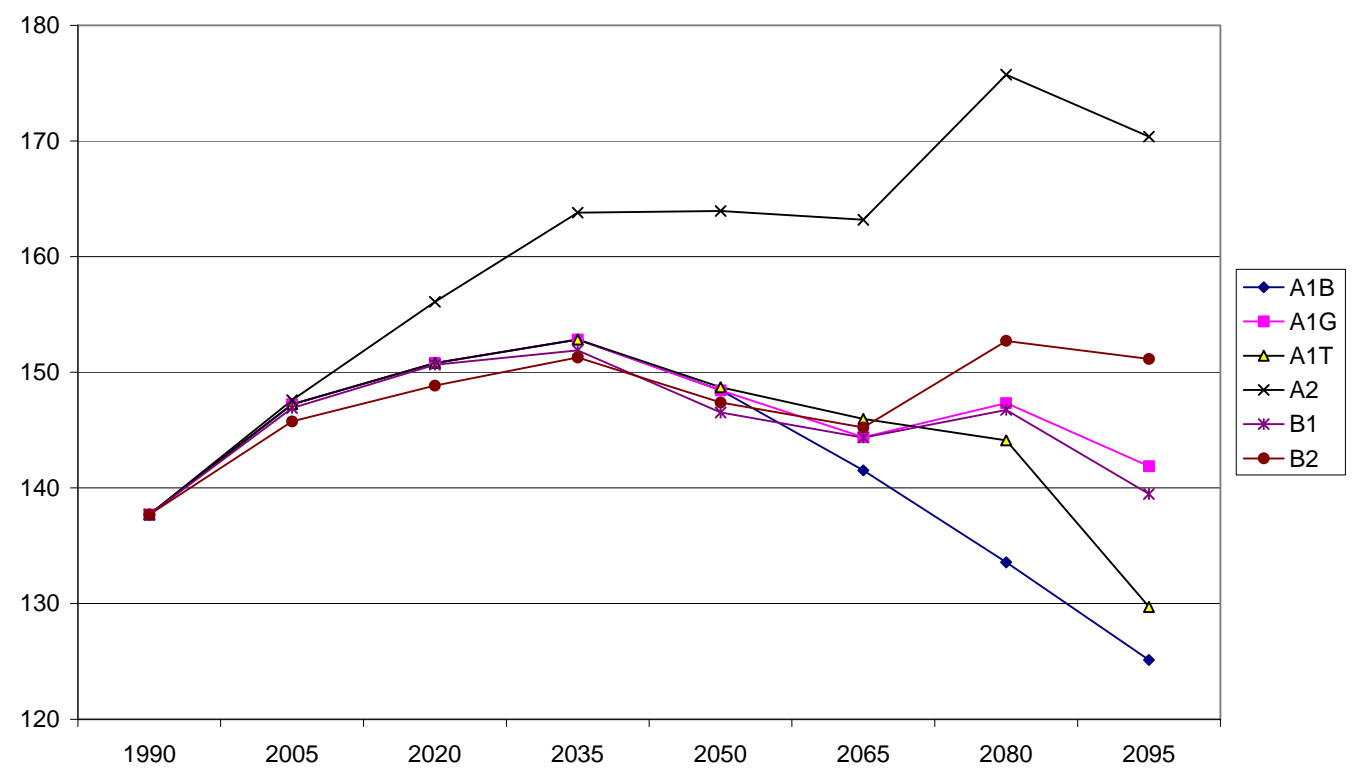

Figure 20 Methane emissions in the four SRES scenarios with divergence in the A1 scenarios. 
Temperature changes and sea-level rise are calculated in the MAGICC module and are illustrated in the next two graphs for the SRES scenarios. Differences between the scenarios remain considerably smaller than the changes over time from 1990 through the end of the twenty-first century.

Global Temeperature Rise (degrees C) in the IPCC SRES Scenarios

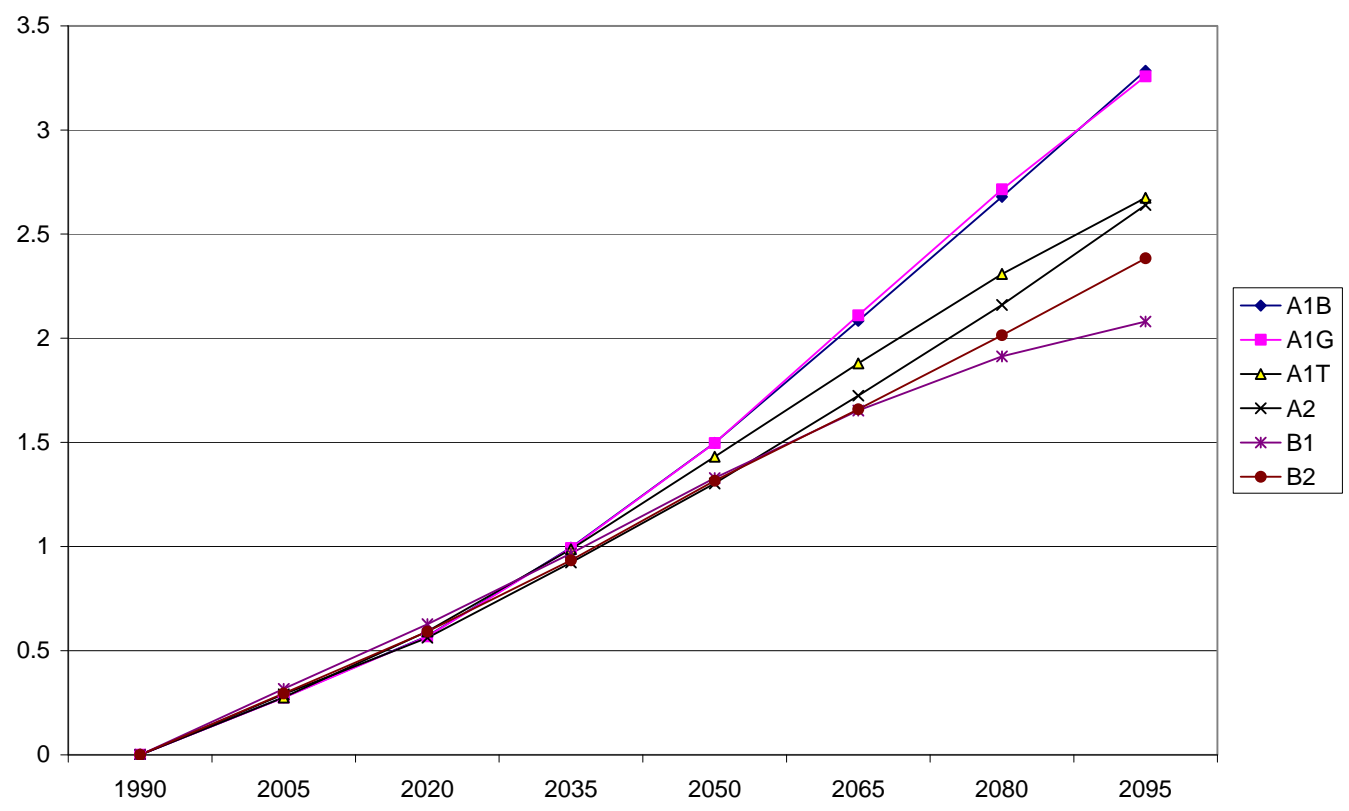

Figure 21 Projected global temperatures in the SRES scenarios

Global Sealevel Rise (cm) in the IPCC SRES Scenarios

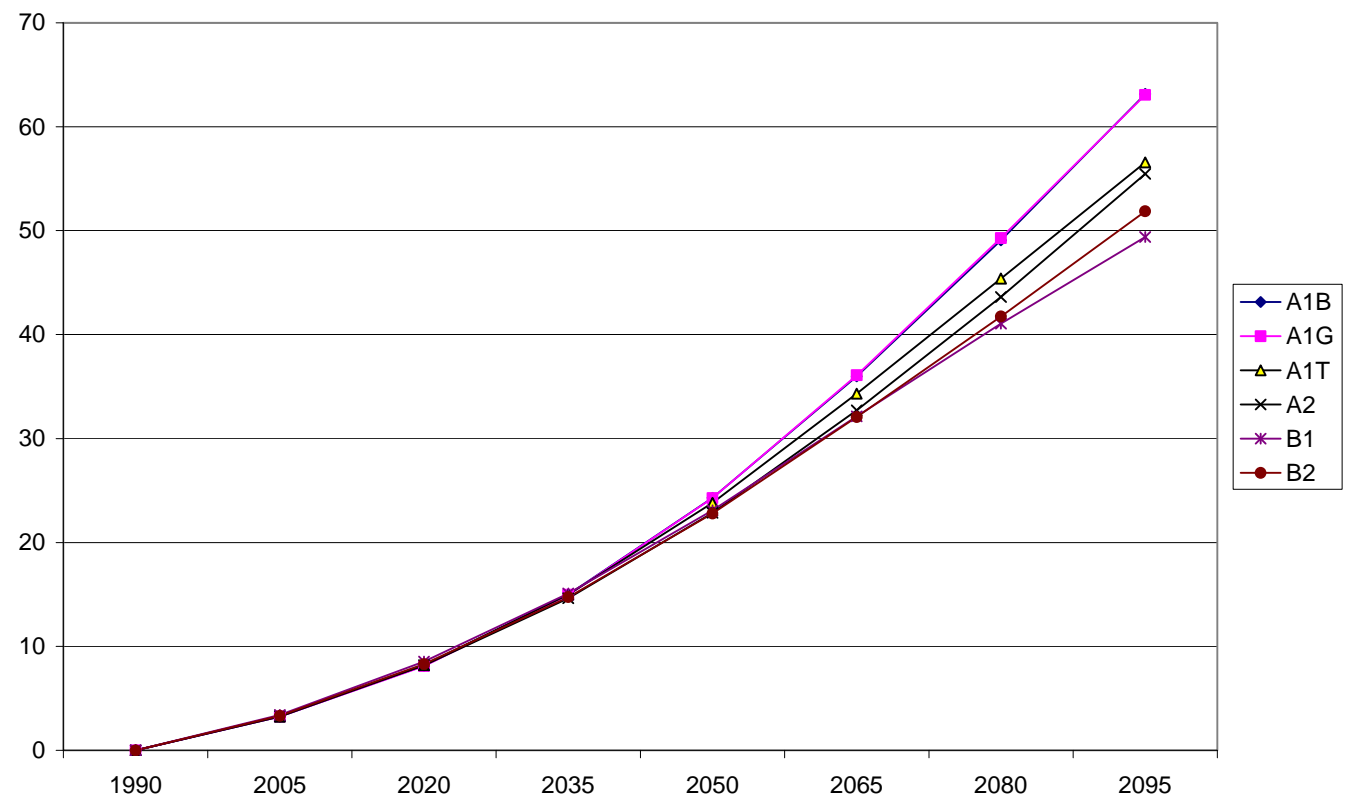

Figure 22 Projected sea-level rise in the SRES scenarios 


\section{Regional outputs}

Regional differences are illustrated in the next set of graphs.

Most regions show a steady increase in personal income in the projections of the B2 scenario. Exceptions are the Former Soviet Union and Korea. These gradual patterns do not translate into similar regional patterns of caloric intake, however, although both the Former Soviet Union and Korea show the largest differences.

Regional Differences over Time in Income (GDP (mer) (1990 US\$ per year per capita)) for IPCC's B2 Scenario

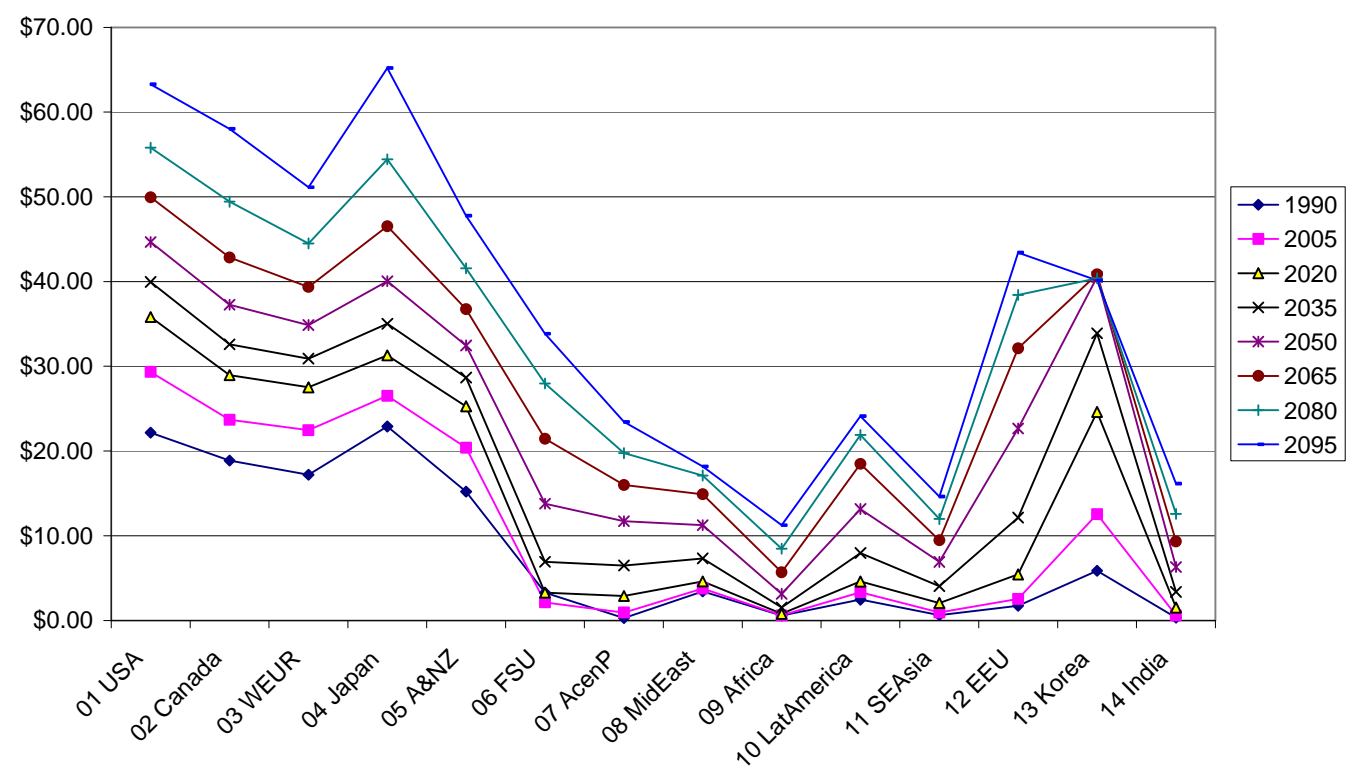

Figure 23 Regional differences in income over time in IPCC's B2 scenario

Changes in caloric intake (Figure 24) are partly due to assumed changes in diet from cereals to animal proteins related to increased income, especially in developing economies. Developed economies still show, however, large increases in expected electricity consumption (Figure 25). 
Regional Differences over Time in Caloric Intake (Kcal per year per person) in IPCC's B2 Scenario

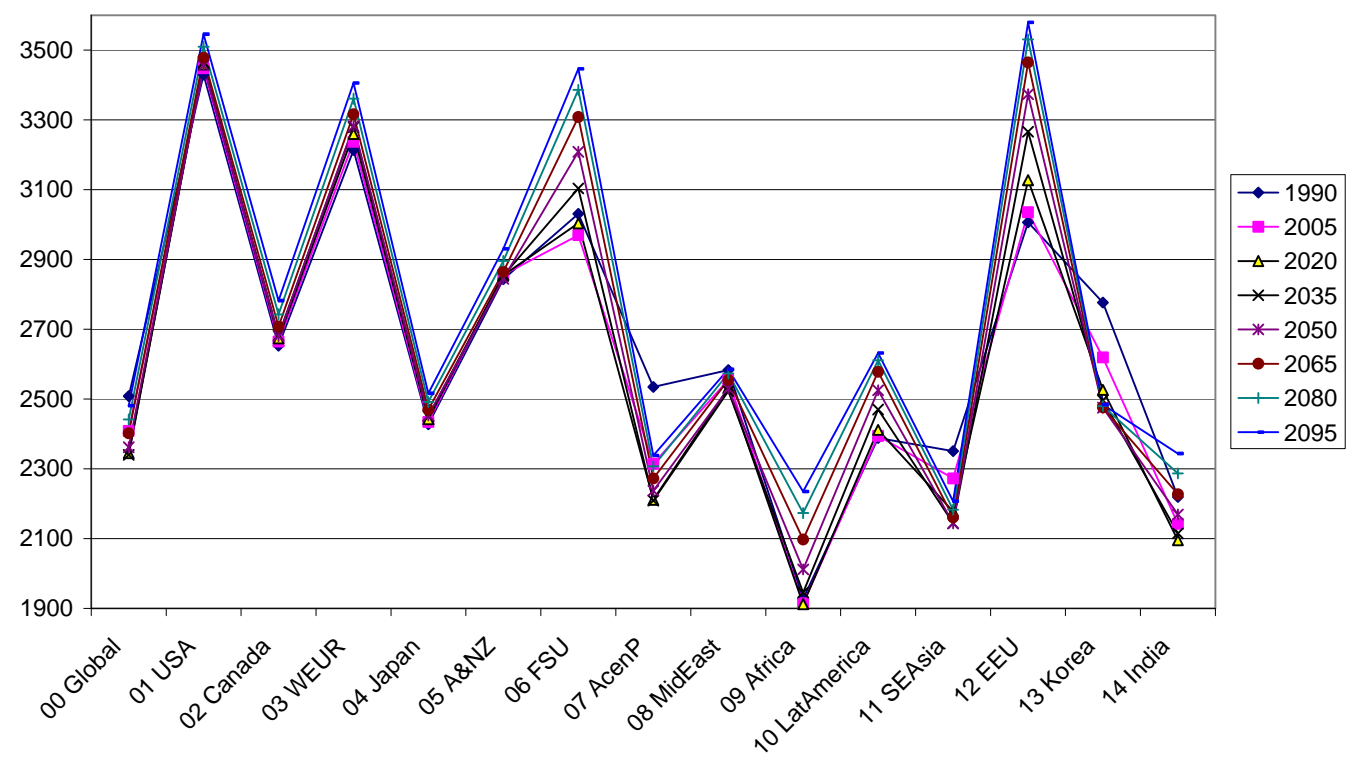

Figure 24 Regional differences in caloric intake in IPCC's B2 scenario

Figure 26 shows the regional changes over time in total anthropogenic emissions, showing still different patterns, which can be explained not only by electricity consumption (Figure 24), but also by differences in industrialization, energy efficiencies and changes in land use. Note that Canada's average carbon equivalent emissions are expected to change significantly more that the USA's; also note that Korea's emissions increased significantly between 1990 and 2005 but then increased only minimally afterwards in this B2 scenario. 
Regional Differences over Time in Electricity Consumption per Capita (GJ per year per capita)

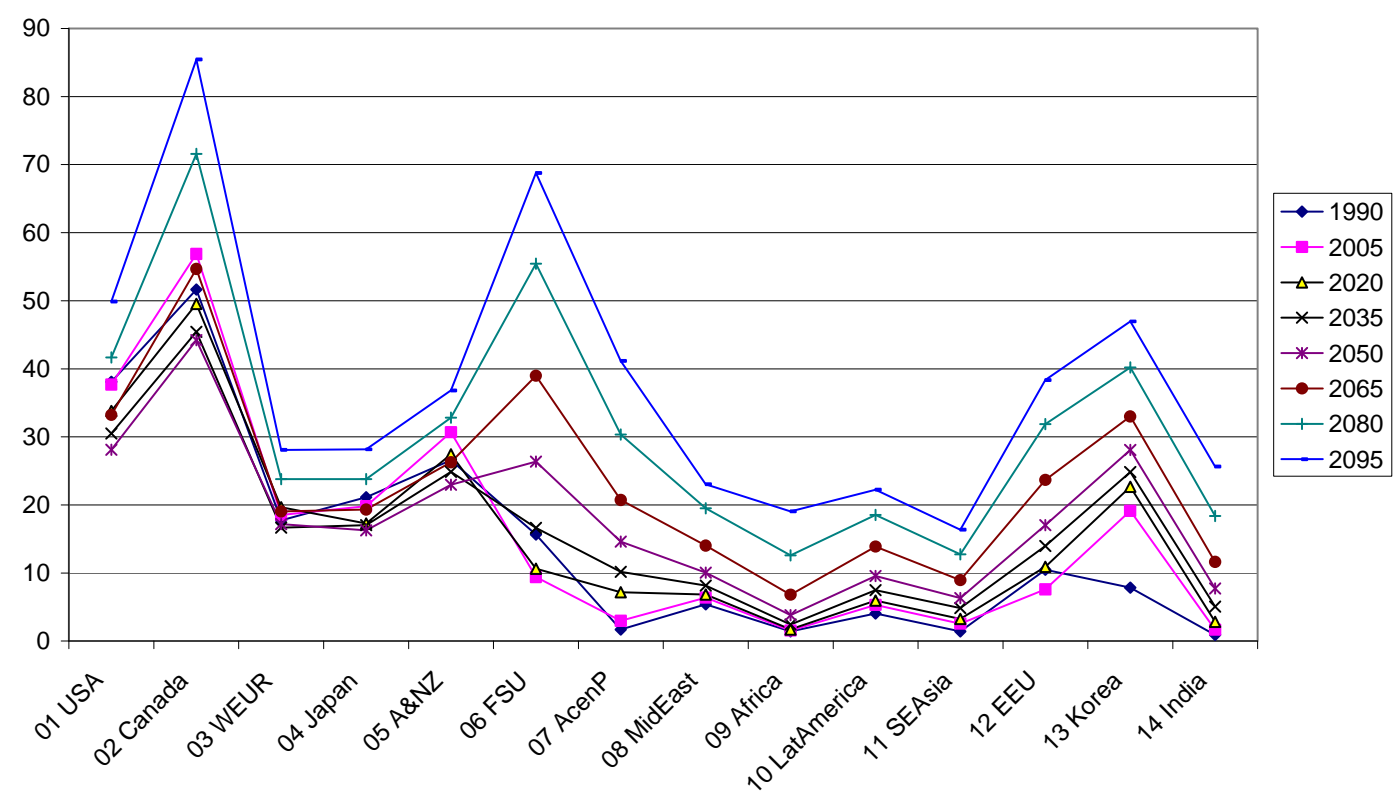

Figure 25 Regional differences in electricity consumption per capita in IPCC's B2 scenario

Regional Differences in Base Year Values and Projections in Antrhropogenic Emissions per Capita (metric tons CE per year per capita) in IPCC's B2 Scenario

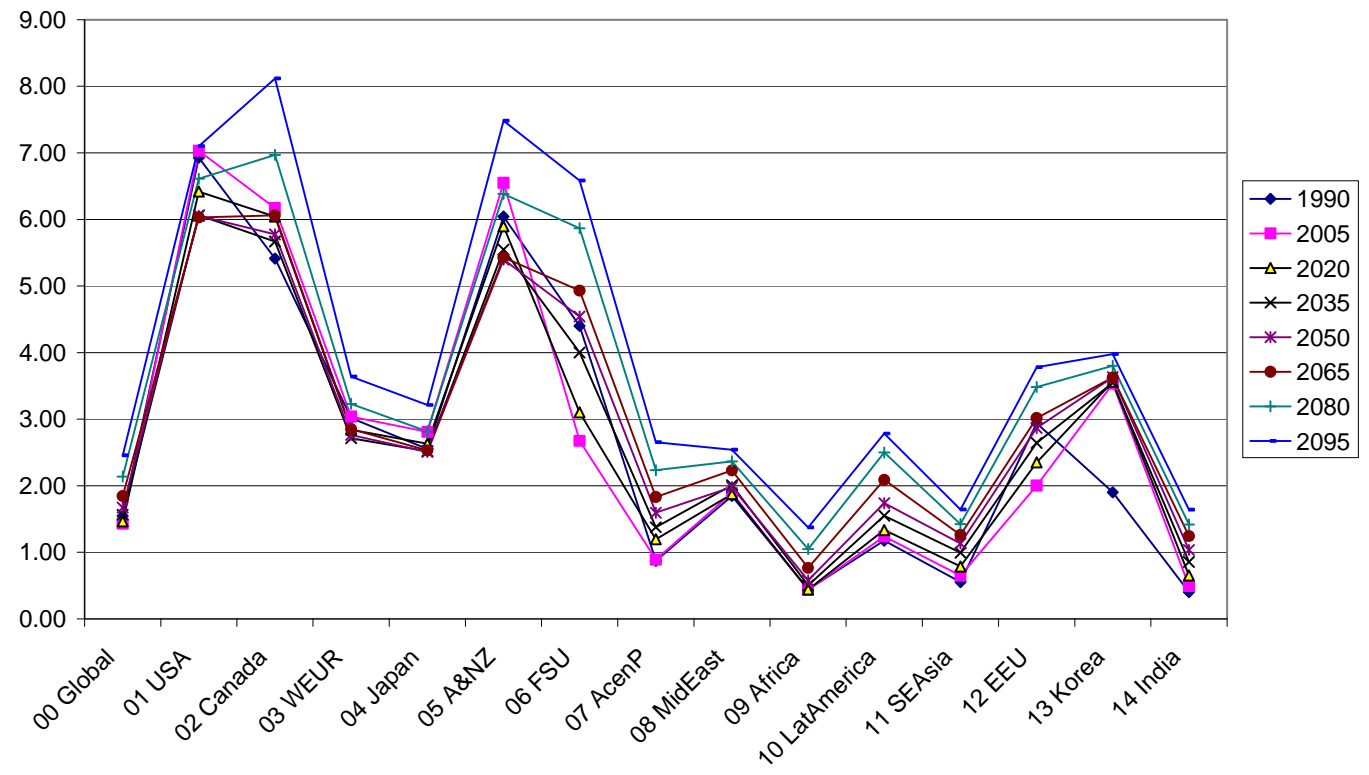

Figure 26 Regional differences in anthropogenic emissions in IPCC's B2 scenario 


\section{Policy cases}

Results of carbon policy implantation are illustrated in the next set of graphs. Carbon policies can be implemented by determining a carbon fee upfront and having the model solve for the emissions that are then constraint by an increase in fuel prices. Alternatively emission limits can be set upfront as targets to be met at a certain point in time and have the model solve for the necessary carbon fees to be imposed to reach the targets. Thirdly, through scrub technology and sequestration some relaxation of carbon constraints can be implemented by actively sequestering carbon such that atmospheric emissions remain constraint.

Figure 27 illustrates for the USA, for the B2 scenario results of implementing emission constraints such that by the year 2050 carbon dioxide atmospheric concentrations either reach 450 or $550 \mathrm{MM} \mathrm{ppm}$, with and without the sequestration option. Those results are compared with the unconstrained B2 scenario emissions. Figure 28 illustrates the amounts of carbon captured in the USA (MMtC).

USA's Anthropogenic Emissions (MMtCE per year) in IPCC's B2 Scenario with Policy Implemetations of Emission Constraints with and without Carbon Sequestration

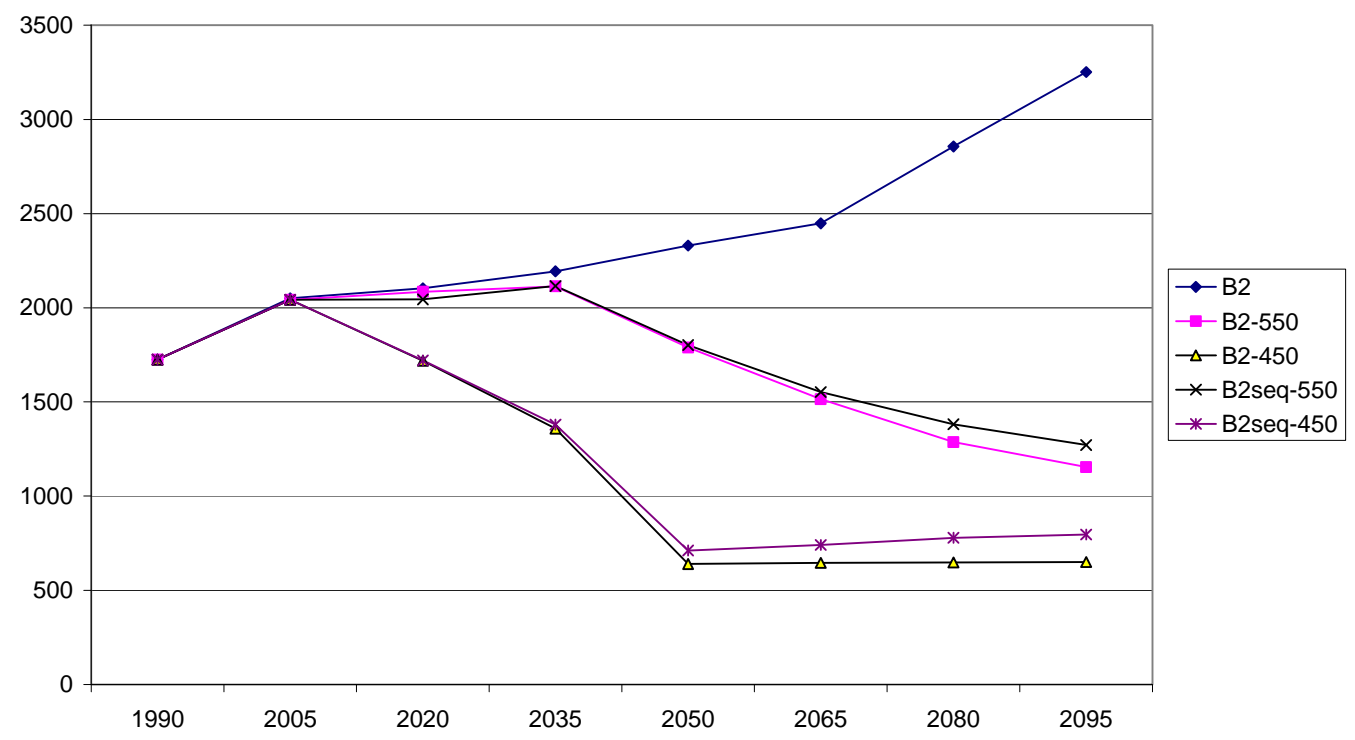

Figure 27 An example of anthropogenic carbon-equivalent emissions under carbon policy implementations in the USA IPCC's B2 scenario 
Carbon Sequestered (MMtC) in the USA's IPCC's B2 Scenario with a Sequestration Policy

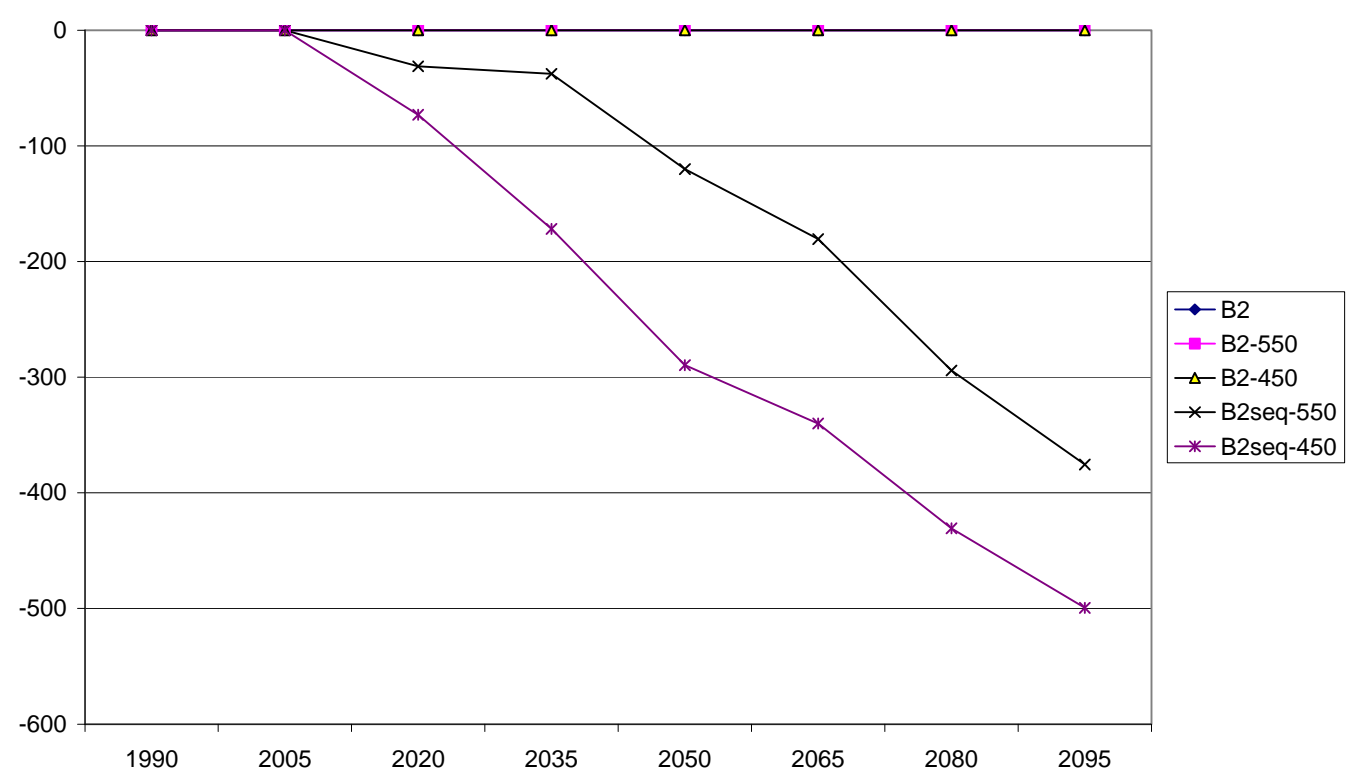

Figure 28 Carbon sequestered in the USA IPCC's B2 carbon policy scenarios

Carbon policies do not only impact carbon emissions but also impact emissions from industrial processes such as sulfur dioxide. Figure 29 illustrates the beneficial effects on sulfur emissions. When emissions are sequestered the beneficial effect is reduced given that the emission constraints are relaxed due to the sequestration offset.

Figure 30 shows examples of the carbon prices required to constrain the emissions at the 450 and $550 \mathrm{ppm}$ levels with and without the sequestration options. Carbon prices will be scenario and policy dependent. Timing of policy implementations is an important factor in this case. 
Sulfur emissions over time (TgS) in the USA's IPCC B2 Scenario with and without Carbon Policies

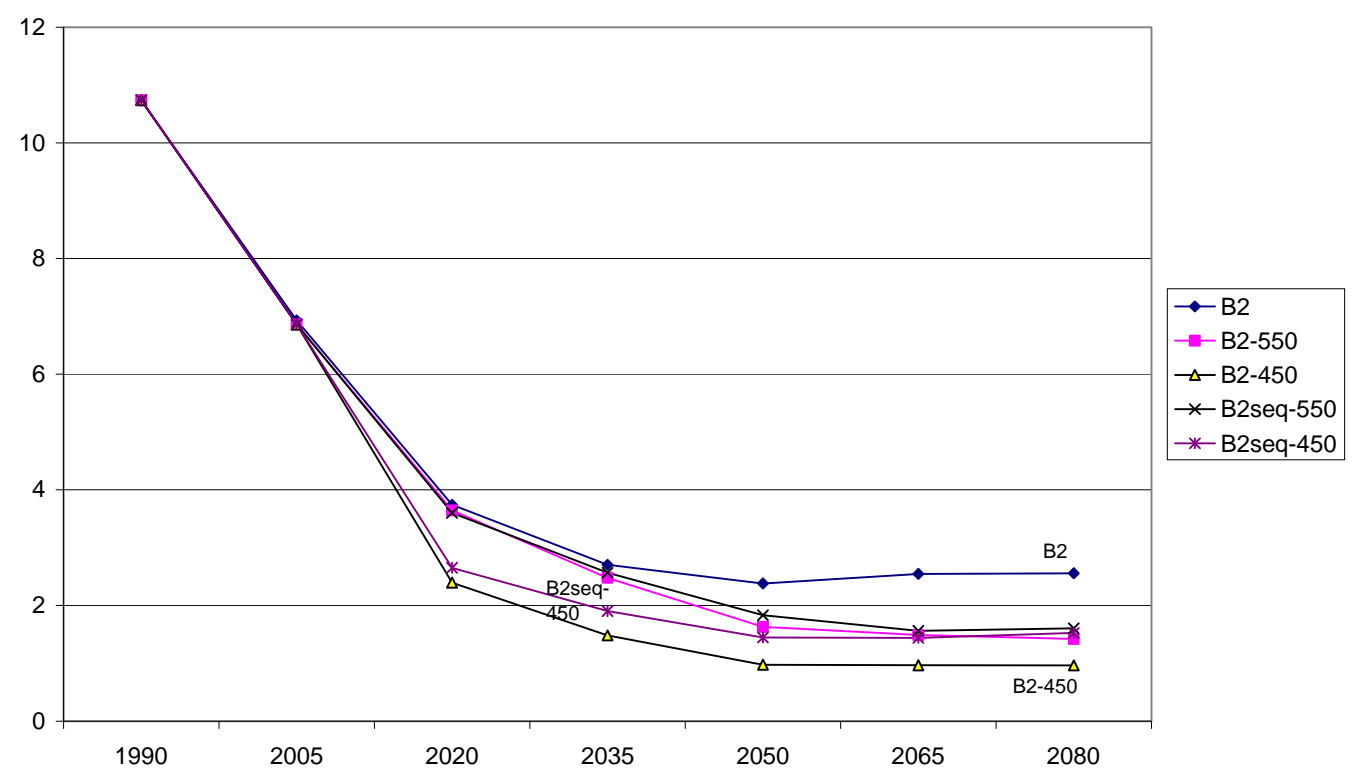

Figure 29 Sulfur emissions in the USA in IPCC's B2 carbon policy scenarios

Carbon prices in the IPCC SRES B2 Senarios with carbon pollcies imposed in the form of emission with and without sequestration

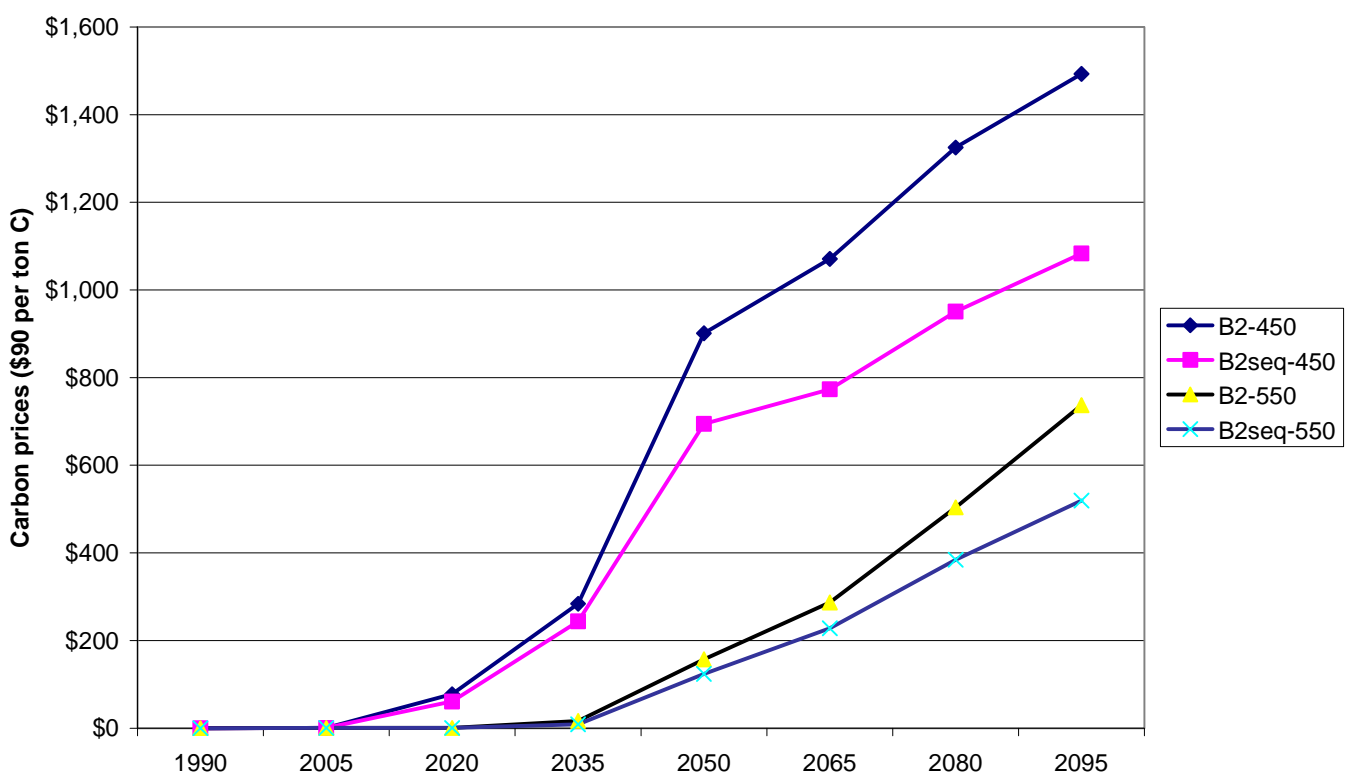

Figure 30 Carbon prices in the USA in IPCC's B2 carbon policy scenarios 


\section{References}

Amemiya, Takeshi. 1985. Advanced Econometrics. Harvard University Press, Cambridge, Massachusetts.

Beck, Peter, and Knut Sydsaeter. 1991. Economists' Mathematical Manual. Springer-Verlag.

CEA (Council of Economic Advisers). 1998. The Kyoto Protocol and the President's Policies to Address Climate Change: Administration Economic Analysis. Washington, D.C.

Clarke, J. F., Edmonds, J. A. 1993 "Modeling Energy Technologies In A Competitive Market", Energy Economics, April 1993, Butterworth-Heinemann. page 123

Edmonds, J.A., H.M. Pitcher, D. Barns, R. Baron and M.A. Wise. 1993. "Modeling Future Greenhouse Gas Emissions: The Second Generation Model Description," in Modelling Global Change, Lawrence R. Klein and Fu-chen Lo, eds. United Nations University Press, New York.

Edmonds, J.A., R.A. Brown, M.A. Wise, H. Kheshgi, R.D. Sands 1996. "Agriculture, Land Use, and Commercial Biomass Energy." Report No. PNNL-SA-27726, Pacific Northwest National Laboratories, Washington, DC. 25 pp.

Fisher-Vanden, K.A., R. Baron, J.A. Edmonds, H.M. Pitcher, R.D. Sands and M.A. Wise. 1993. Calibration of the Second Generation Model, draft report. Pacific Northwest National Laboratory, Washington, D.C.

Fisher-Vanden, K.A., P.R. Shukla, J.A. Edmonds, S.H. Kim, and H.M. Pitcher. 1997. “Carbon Taxes and India," Energy Economics 19, 289-325.

Food and Agriculture Organization of the United Nations: FAOSTAT data base available at http://apps.fao.org, 2000.

Gillingham et al. 2002 In preparation

Hulme, M., T. Jiang, and T.M.L. Wigley. 1995. "SCENGEN, a climate change scenario generator, a user manual." (Norwich, U.K.: Climatic Research Unit, University of East Anglia).

Hoffert, M.I., A.J. Callegari, and C.-T. Hsieh. 1980. "The role of deep sea heat storage in the secular response to climate forcing." Journal of Geophysical Research 85: 6667-6679.

IPCC 1997: An Introduction to Simple Climate Models used in the IPCC Second Assessment Report; IPCC Technical Paper II; Lead Authors: Danny Harvey, Jonathan Gregory, Martin Hoffert, Atul Jain, Murari Lal, Rik Leemans,Sarah Raper, Tom Wigley, Jan de Wolde

Kattenberg, A., F. Giorgi, H. Grassl, G.A. Meehl, J.F.B. Mitchell, R.J. Stouffer, T. Tokioka, A.J. Weaver and T.M.L. Wigley, 1996. Climate models - projections of future climate. pp285-357 In: Climate Change 1995. The Science of Climate Change. Contribution of Working Group I to the Second Assessment Report of the Intergovernmental Panel on Climate Change. [Houghton, J.T., L.G.M. Filho, B.A. Callander, N. Harris, A. Kattenberg, and K. Maskell (eds)] Cambridge University Press, Cambridge, UK, 572 pp. 
MacCracken, C.N., J.A. Edmonds, S.H. Kim, and R.D. Sands. 1999. "The Economics of the Kyoto Protocol," in The Costs of the Kyoto Protocol: A Multi-Model Evaluation, John Weyant (ed.), special issue of The Energy Journal.

Maier-Reimer, E., and K. Hasselmann. 1987. Transport and storage of CO 2in the ocean -- an inorganic ocean-circulation carbon cycle model, Climate Dynamics, 2, 63-90.

Meier, M.F., 1993: Ice, climate and sea level; do we know what is happening? (In) Ice in the Climate System, NATO ASI Series Vol. I 12 (ed. W.R. Peltier), Springer-Verlag, Berlin, Germany, 141-160.

Miller, Ronald E., and Peter D. Blair. 1985. Input-Output Analysis: Foundations and Extensions. Prentice-Hall, Inc., Englewood Cliffs, New Jersey.

Moss, Richard H., Antoinette L. Brenkert, and Elizabeth L. Malone 2001. Vulnerability to Climate Change: A Quantitative Approach. 2001. PNNL-SA-33642, Pacific Northwest National Laboratory, Washington, DC. http://www.pnl.gov/globalchange/projects/vul/index.htm

Oerlemans, J. and Fortuin, J.P.F., 1992: Sensitivity of glaciers and small ice caps to greenhouse warming. Science 258, 115-117.

Ramaswamy, V., Schwarzkopf, M.D. and Shine, K.P. 1992. Radiative forcing of climate from halocarbon-induced global stratospheric ozone loss. Nature 355, 810-812.

Rogner, H. 1997. An Assessment of World Hydrocarbon Resources. Annual Review of Energy and the Environment 22: 217-262.

Sands, R.D. and J.A. Edmonds, 2002 Climate Change Impacts for the Conterminous USA: An Integrated Assessment; In preparation

Sands, R.D., J.A. Edmonds, S.H. Kim, C.N. MacCracken, and M.A. Wise. 1998. "The Cost of Mitigating United States Carbon Emissions in the Post-2000 Period," in Economic Modelling of Climate Change: OECD Workshop Report, 17-18 September, 1998. Organization for Economic Cooperation and Development, Paris, France.

Sands, R. and Leimbach, M.: Modeling Agriculture and Land Use in an Integrated Assessment Framework. Climatic Change 56(1) (2003), pp.185-210.

Smith, Steven. J., Hugh Pitcher and T.M.L. Wigley. 2001. "Global and regional anthropogenic sulfur dioxide emissions". Global and Planetary Change 29:99-119

Smith, Steven. J., Hugh Pitcher and T.M.L. Wigley. 2002. "Future Sulfur Dioxide Emissions", submitted to Climatic Change

Wigley, T.M.L. and S.C.B. Raper. 2002. "Reasons for larger warming projections in the IPCC Third Assessment Report " J Climate 15 (20), 2945-2952; and http://sedac.ciesin.org/mva/magicc/MAGICC.html 
Wigley, T.M.L., 1991. A simple inverse carbon cycle model. Global Biogeochemical Cycles 5: 373-382.

Wigley, T.M.L., 1993. Balancing the carbon budget. Implications for projections of future carbon dioxide concentration changes. Tellus 45B, 409-425.

Wigley, T.M.L. and Raper, S.C.B., 1987. Thermal expansion of sea water associated with global warming. Nature 330, 127-131.

Wigley, T.M.L. and Raper, S.C.B., 1992. Implications for climate and sea level of revised IPCC emissions scenarios. Nature 357, 293-300.

Wigley, T.M.L. and Raper, S.C.B., 1993. Future changes in global-mean temperature and sea level. (In) Climate and Sea Level Change: Observations, Projections and Implications (eds.

R.A. Warrick, E.M. Barrow and T.M.L. Wigley), Cambridge University Press, Cambridge, U.K., 111-133.

Wigley, T.M.L. and Raper, S.C.B., 1995. An heuristic model for sea level rise due to the melting of small glaciers. Geophysical Research Letters (submitted). 


\section{Appendices to the Model Documentation for the MiniCAM}

Antoinette L. Brenkert

Steven J. Smith

Son H. Kim

Hugh M. Pitcher

July 2003

Prepared for the United States Environmental Protection Agency under Contracts AGRDW89939464-01 and AGRDW89939645-01

Joint Global Change Research Institute, College Park, MD

Pacific Northwest National Laboratory

Operated by Battelle for the U.S. Department of Energy 
TABLE OF CONTENTS

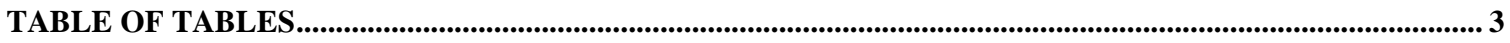

APPENDIX 1: INDICES AND NOMENCLATURE; DEFINITIONS; UNITS ..................................................... 5

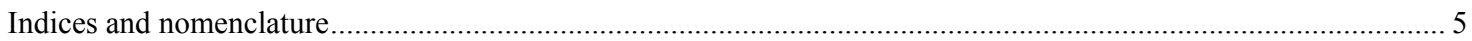

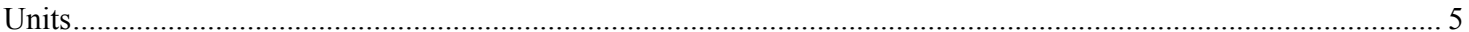

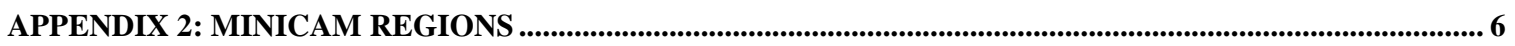

APPENDIX 3: DESCRIPTION OF THE SOLUTION ALGORITHMS................................................................ 8

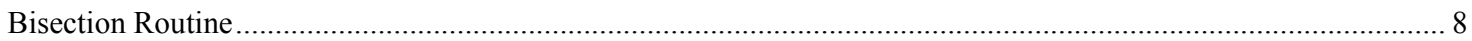

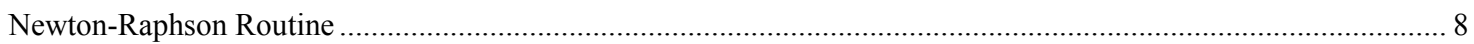

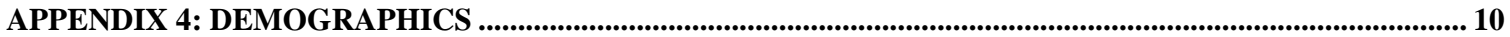

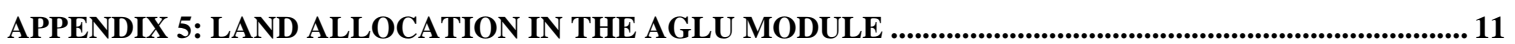

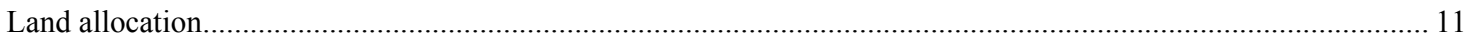

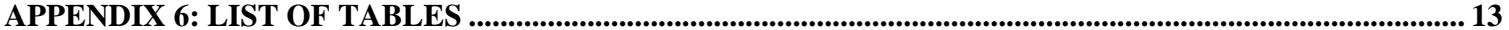

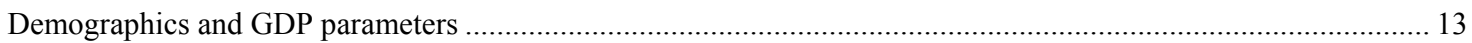

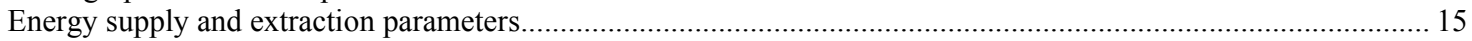

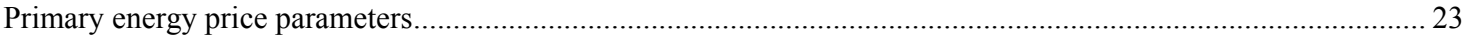

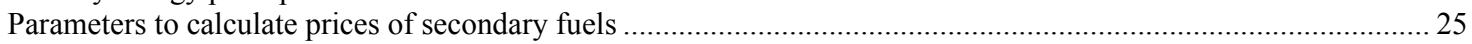

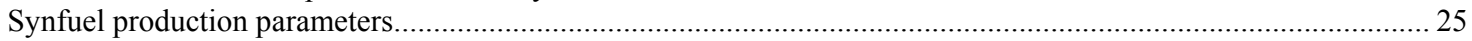

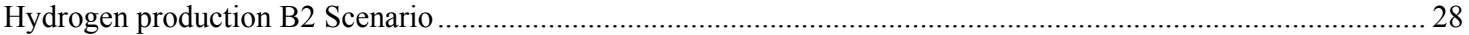

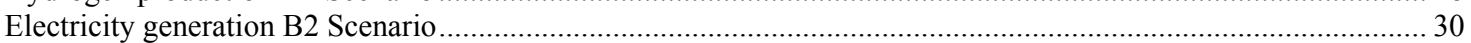

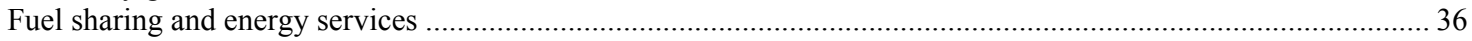

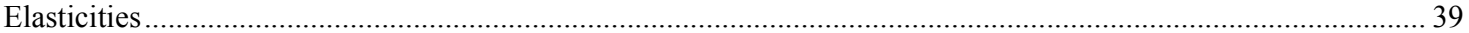

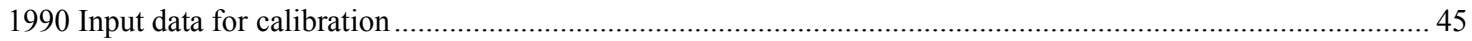

Resulting, for example, for the USA for the B2 scenario in Final Energy Demand:..........................................46

Resulting, for example, for the USA for the B2 scenario in electricty generation: ........................................46

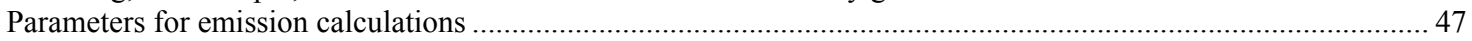

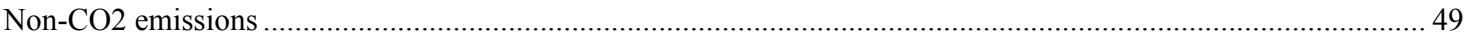

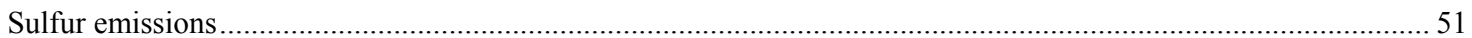

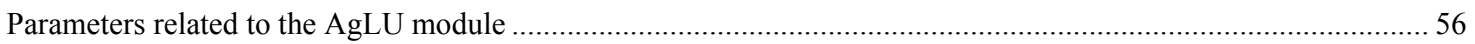

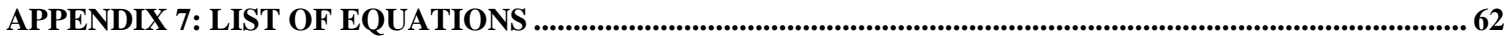




\section{TABLE OF TABLES}

Table 1 Regional population projections for the $\mathrm{B} 2$ story line .................................................................... 13

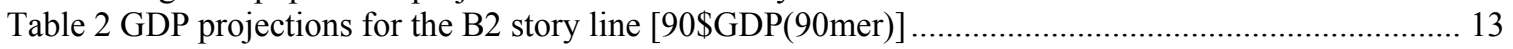

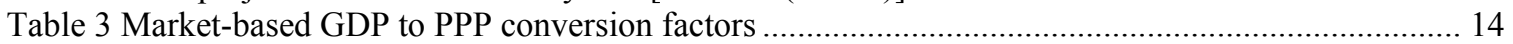

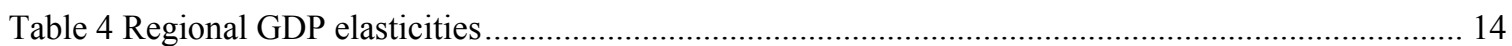

Table 5 Examples of projections of regional labor productivity increases and regional labor force

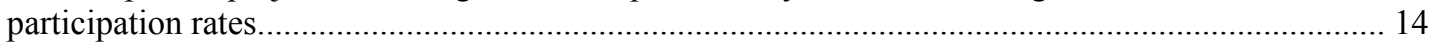

Table 6 Examples of projections of regional labor force participation......................................................... 15

Table 7 Minimum extraction costs by grade and fuel $(1975 \$ / G J)$......................................................... 15

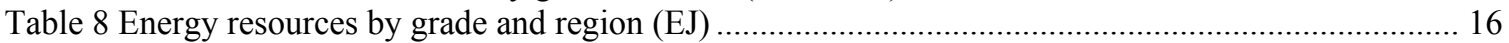

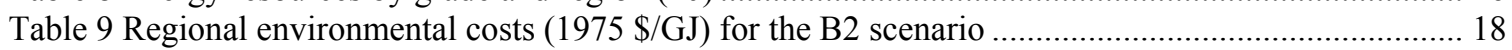

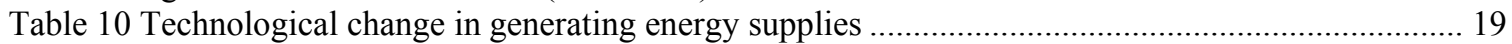

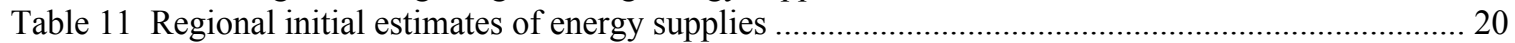

Table 12 Regional minimum production rates for fuel production ................................................................ 20

Table 13 Regional initial estimates of available biomass waste ................................................................ 21

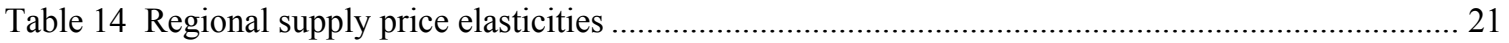

Table 15 Initial prices and base share weights for biomass supply shares .............................................. 21

Table 16 Aggregate income elasticity of biomass supply ........................................................................... 22

Table 17 Hydropower generation parameters.......................................................................................... 22

Table 18 Regional energy from hydropower obtained in the base year in the B2 scenario and the fixed

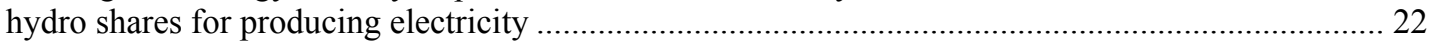

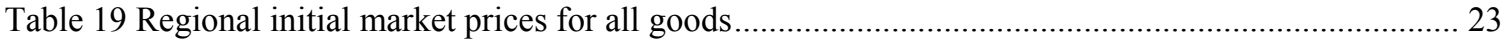

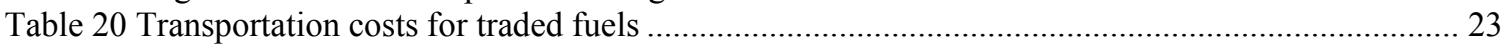

Table 21 Trade barrier scale factors such that fuel prices can be region specific........................................ 23

Table 22 Energy conversion factors from primary energy to secondary energy and markup costs ............. 25

Table 23 Synfuel parameters to calculate non-energy costs of synliquid production from natural gas........ 25

Table 24 Synfuel parameters to calculate non-energy costs of synfuel production from coal in $75 \$ / G J$.... 26

Table 25 Synfuel parameters to calculate non-energy costs of synfuel production from biomass ............... 26

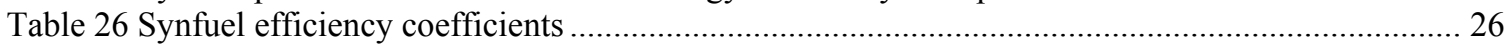

Table 27 Non-energy costs in synfuel and electricity generation (values are the same for each region) ..... 27

Table 28 Example of carbon coefficients: carbon release by source (in Teragrams C per ExaJoule) .......... 27

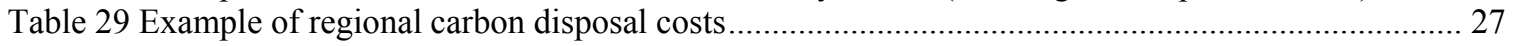

Table 30 Synfuel logit share exponent …………….............................................................................. 28

Table 31 Conversion factors to calculate carbon fees towards final consumption ....................................... 28

Table 32 Total System Efficiency of Hydrogen Production GHILM.......................................................... 28

Table 33 Non-energy costs in hydrogen generation (values are the same for each region)......................... 29

Table 34 Examples of carbon fractions to be removed when synfuels are produced or in coal-electric plants

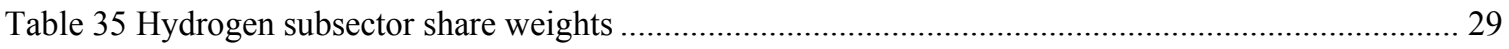

Table 36 Hydrogen and electricity generation logit exponent .................................................................. 30

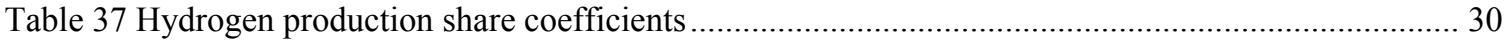

Table 38 Logit share exponent for hydrogen production....................................................................... 30

Table 39 Regional electricity generation efficiency coefficients for oil-, gas-, coal-, and biomass-generated

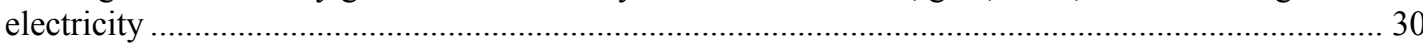

Table 40 Regional electricity price coefficients used to account for end-sector differences and distribution

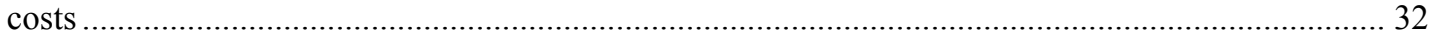

Table 41 Electricity generating subsector-specific base-share weights ................................................. 32

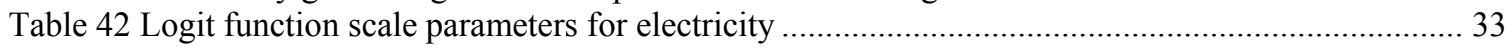

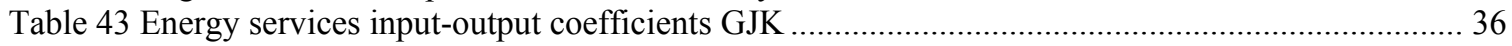

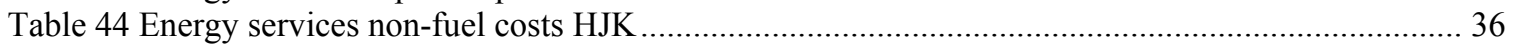

Table 45 Hydrogen energy service fuel-related efficiency coefficient (Gjk: j=hydrogen) ............................ 36

Table 46 Hydrogen energy service related non-fuel costs (Hjk: $\mathrm{j}=$ hydrogen) ............................................... 36

Table 47 Transportation sector fuel-related efficiency coefficients ............................................................. 37 


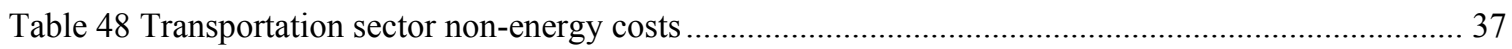

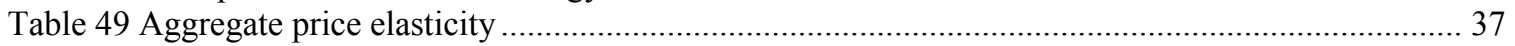

Table 50 End-use sector-specific price elasticities for oil, gas, coal and electricity ..................................... 37

Table 51 Transmission and Distribution Costs for Hydrogen ................................................................ 38

Table 52 Transmission and Distribution Cost of Electricity ...................................................................... 38

Table 53 Regional weights of fuel share coefficients and initial shares of energy services consumptions .. 38

Table 54 Regional income elasticities by secondary fuel (oil, gas, coal, electricity) for end-use sectors .... 39

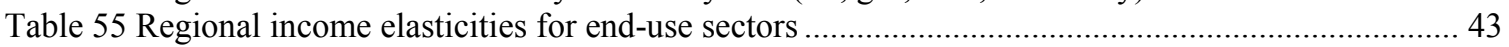

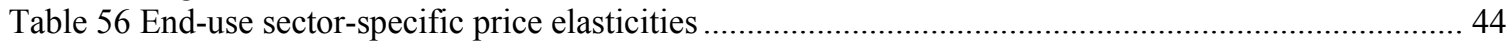

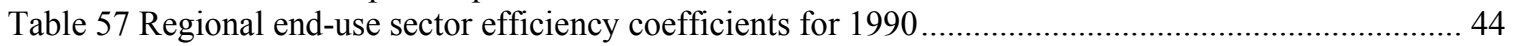

Table 58 End-use sector efficiency improvement coefficients for 2005 through 2095 ................................ 44

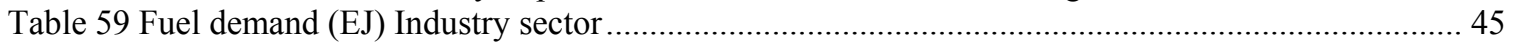

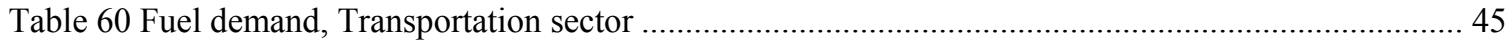

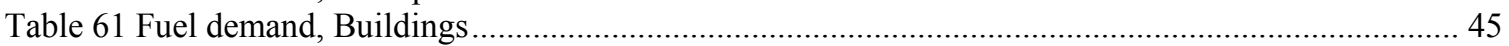

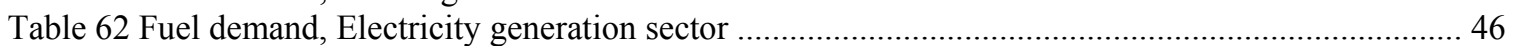

Table 63 Final energy demand, for example, for the USA for the B2 scenario (MiniCAM output) ............ 46

Table 64 Results, for example, for the USA for the B2 scenario in Electric Power Generation by

Technologies.

Table 65 An example of a cost curve …………………...................................................................... 47

Table 66 Global carbon emissions from oil, natural gas and coal combustion to calibrate against for 199047

Table 67 Global Warming Potential, Atmospheric Half-Lives and Climate Forcing Information of Non- $\mathrm{CO}_{2}$

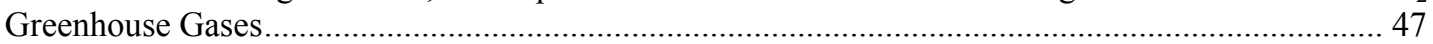

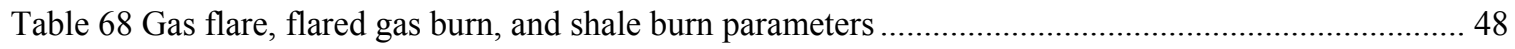

Table 69 Regional non-feedstock use of oil, gas, and coal (Sfedl)............................................................ 48

Table 70 Overview of variables and considerations of non-CO2 emission calculations.............................. 49

Table 71 Regional end-use sector specific ash retention parameters for coal ........................................... 51

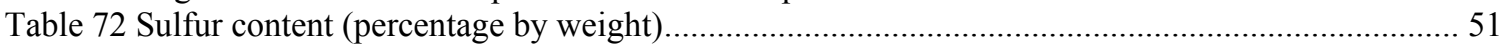

Table 73 Regional end-use specific and fuel-specific heat content values ............................................. 52

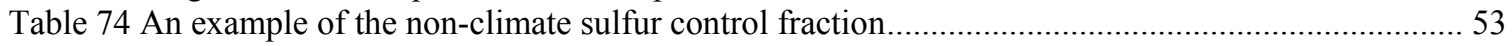

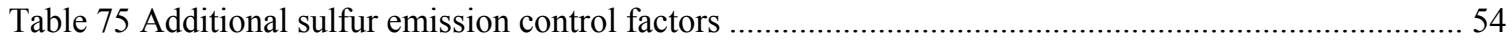

Table 76 Sulfur Emissions Control Mid-point GDP_0 (PPP-based GDPcap) S Emissions Control

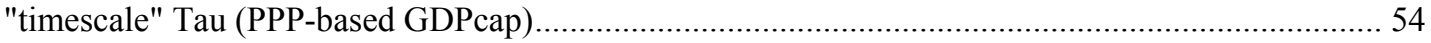

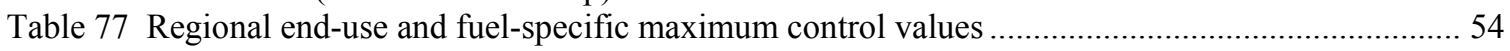

Table 78 Regional maximum percentages of non-energy related industrial sulfur emissions......................... 56

Table 79 Regional coefficients determining changes in industrial sulfur emissions over time .................... 56

Table 80 Example of historical land use data collected......................................................................... 56

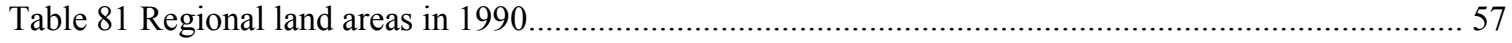

Table 82 Land Carbon Density Parameters, by Region (TgC/000ha) ...................................................... 57

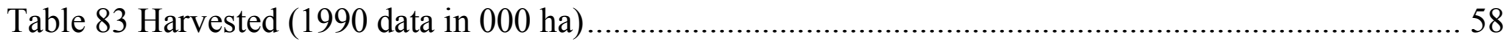

Table 84 Example of regional technical improvements in food production in two time periods ................. 58

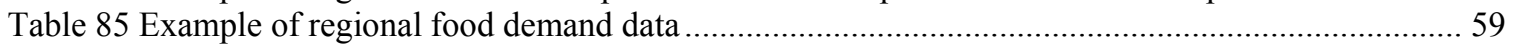

Table 86 Although not directly used, an example of data collected for the AgLU module........................... 61

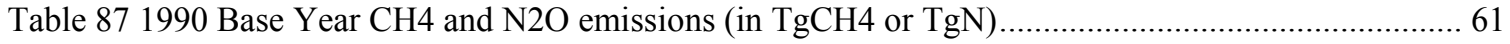




\section{Appendix 1: Indices and nomenclature; Definitions; Units}

\section{Indices and nomenclature}

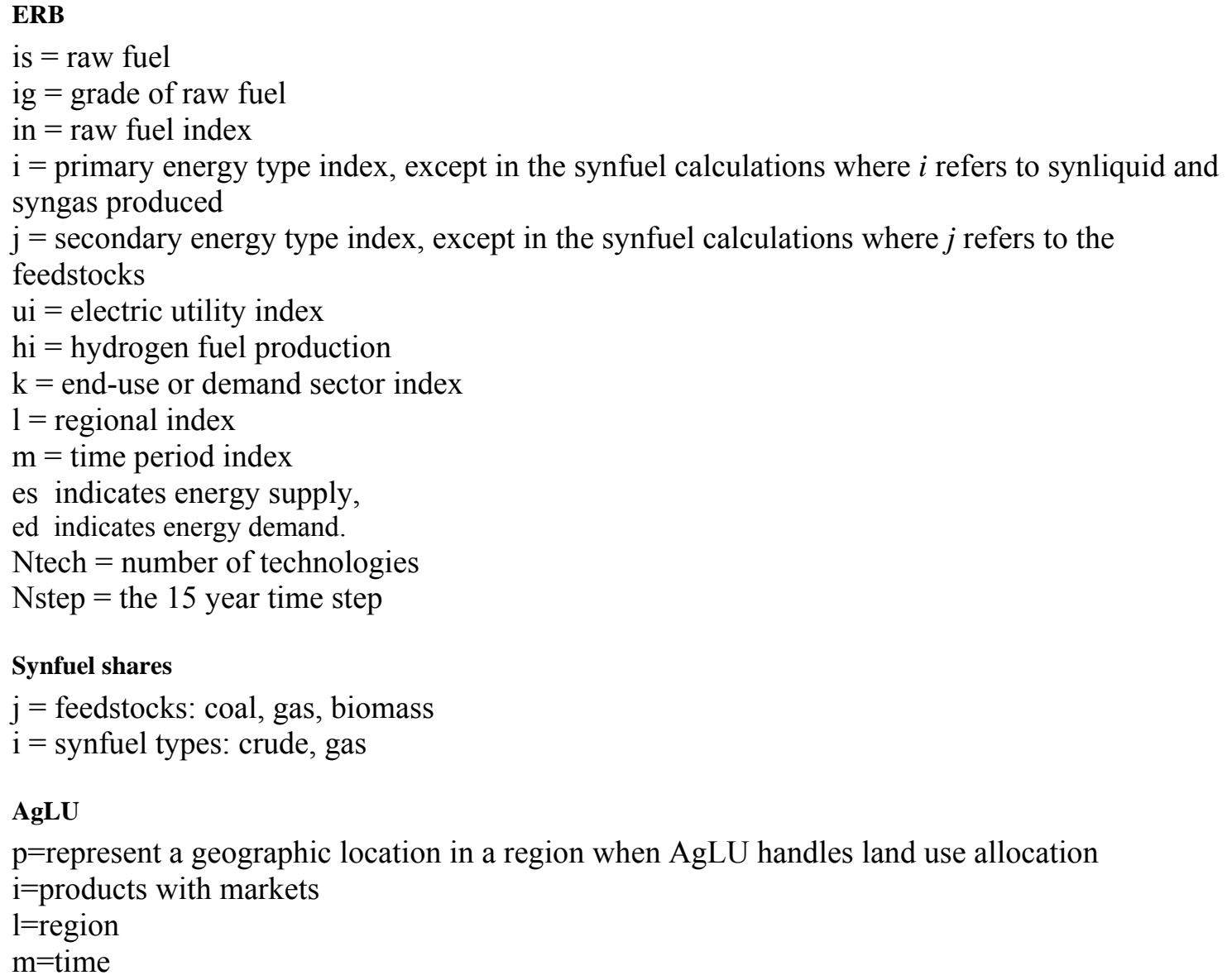

\section{Units}

Fossil/Primary Energy in terms of Net Energy (lower heating value);

Energy units: Joules [exa (1.e18), peta (1.e15), tera (1.e12), giga (1.e9)]; dimensions are omitted at times in text 


\section{Appendix 2: MiniCAM regions}

The 14 regions in the current MiniCAM are: USA, Canada, Japan, Western Europe, Australia \& New Zealand, Former Soviet Union, Eastern Europe, Centrally Planned Asia, India, Korea, (rest of) South \& East Asia, Middle East, Africa, and Latin America. The countries within regions are listed below. Note that these regions are determined by economic criteria and do not necessarily follow political divisions.

\section{4-region version}

\begin{tabular}{|c|c|c|c|}
\hline USA & FSU & Africa & Latin America \\
\hline United-States & Azerbaijan & Algeria & Antigua-and-Barbuda \\
\hline Canada & Armenia & Angola & Bahamas \\
\hline Canada & Belarus & Botswana & Barbados \\
\hline Japan & Estonia & Burundi & Bermuda \\
\hline Japan & Georgia & Cameroon & Bolivia \\
\hline Aus \& NZ & Kazakhstan & Central-African-Republic & Belize \\
\hline Australia & Kyrgyzstan & Chad & Virgin-Islands-(British) \\
\hline New-Zealand & Latvia & Comoros & Cayman-Islands \\
\hline OECD90 Europe & Lithuania & Congo & Chile \\
\hline Austria & Russia & Zaire & Colombia \\
\hline Belgium & Tadzhikistan & Benin & Costa-Rica \\
\hline \begin{tabular}{|l|} 
Cyprus \\
\end{tabular} & Turkmenistan & Equatorial-Guinea & Cuba \\
\hline Denmark & Ukraine & Ethiopia & Dominica \\
\hline Faroe-Islands & Uzbekistan & Djibouti & Dominican-Republic \\
\hline Finland & Eastern Europe & Gabon & Ecuador \\
\hline France & Albania & Gambia & El-Salvador \\
\hline Germany & Bulgaria & Ghana & Falkland-Islands \\
\hline Greece & Czechoslovakia & Guinea & French-Guiana \\
\hline Greenland & Hungary & Ivory-Coast & Grenada \\
\hline Iceland & Moldova & Kenya & Guadeloupe \\
\hline Ireland & Poland & Lesotho & Guatemala \\
\hline Italy & Romania & Liberia & Guyana \\
\hline \begin{tabular}{|l|} 
Luxembourg \\
\end{tabular} & Yugoslavia & Libya & Haiti \\
\hline Malta & China/CPA & Madagascar & Honduras \\
\hline \begin{tabular}{|l} 
Netherlands \\
\end{tabular} & Cambodia & Malawi & Jamaica \\
\hline Norway & China & Mali & Martinique \\
\hline Portugal & North-Korea & Mauritania & Aruba \\
\hline \begin{tabular}{|l} 
San-Marino \\
\end{tabular} & Laos & Mauritius & Nicaragua \\
\hline \begin{tabular}{|l|} 
Spain \\
\end{tabular} & Macau & Morocco & Niue \\
\hline Svalbard & Mongolia & Mozambique & Marshall-Islands \\
\hline Sweden & Vietnam & Namibia & Panama \\
\hline Switzerland & Korea & Niger & Paraguay \\
\hline
\end{tabular}




\begin{tabular}{|c|c|c|c|}
\hline Turkey & South-Korea & Nigeria & Peru \\
\hline United-Kingdom & India & Guinea-Bissau & Puerto-Rico \\
\hline Jan-Mayen & India & Reunion & Anguilla \\
\hline S\&E Asia & Middle East & Rwanda & St.-Lucia \\
\hline Afghanistan & Bahrain & Senegal & St.-Vincent \\
\hline Bangladesh & Iran & Sierra-Leone & Suriname \\
\hline Bhutan & Iraq & Somalia & Trinidad \\
\hline Solomon-Islands & Israel & South-Africa & Turks-And-Caicos-Islands \\
\hline Brunei & Jordan & Zimbabwe & Virgin-Islands-(USA) \\
\hline Myanmar & Kuwait & Western-Sahara & Uruguay \\
\hline Sri-Lanka & Lebanon & Sudan & Venezuela \\
\hline Taiwan & Oman & Swaziland & Canary-Islands \\
\hline Cook-Islands & Iraq-Saudi-Arabia-Neutral-Zone & Togo & St.-Martin \\
\hline Fiji & Qatar & Tunisia & \\
\hline Hong-Kong & Saudi-Arabia & Uganda & \\
\hline Indonesia & Syria & Egypt & \\
\hline Malaysia & United-Arab-Emirates & Tanzania & \\
\hline Maldives & Yemen & Burkina & \\
\hline Nepal & & Zambia & \\
\hline \multicolumn{4}{|l|}{ New-Caledonia } \\
\hline \multicolumn{4}{|l|}{ Vanuatu } \\
\hline \multicolumn{4}{|c|}{ Northern-Mariana-Islands } \\
\hline \multicolumn{4}{|l|}{ Micronesia } \\
\hline \multicolumn{4}{|l|}{ Palau-Islands } \\
\hline \multicolumn{4}{|l|}{ Pakistan } \\
\hline \multicolumn{4}{|l|}{ Papua-New-Guinea } \\
\hline \multicolumn{4}{|l|}{ Philippines } \\
\hline \multicolumn{4}{|l|}{ Seychelles } \\
\hline \multicolumn{4}{|l|}{ Singapore } \\
\hline Thailand & & & \\
\hline
\end{tabular}




\section{Appendix 3: Description of the Solution Algorithms}

\section{Bisection Routine}

The bisection routine is a simple but robust approach to finding roots. To begin the bisection routine, the solution or the root must be bracketed. Bracketing is achieved when the price of a good is adjusted up or down until the excess demand (demand minus supply) changes sign. The two prices at which the sign change occurs represent the initial bracketing interval. Bracketing price intervals are found for all markets.

Then, the midpoints of the price intervals are used to determine the sign of the new excess demands. The midpoint price is used to replace the initial bracketing price that has the same sign in excess demand. Each successive iteration reduces the bracketed price intervals by a factor of 2 . After $n$ iterations, if the solution is bound by an interval of size $\varepsilon_{n}$, then after the next iteration it will be bracketed by an interval of size

$\varepsilon_{\mathrm{n}+1}=\varepsilon_{\mathrm{n}} / 2$

From the initial bracketed interval, $\varepsilon_{0}$, to the desired tolerance, $\varepsilon$, the number of iterations to achieve the tolerance is given by

$\mathrm{n}=\log _{2}\left(\varepsilon_{0} / \varepsilon\right)$

Because there are multiple markets, however, the actual number of iterations to achieve the tolerance for all the markets is determined by the largest initial bracketed interval.

In certain situations, a market must be bracketed again and the bisection routine reapplied. Supply and demand for one market is dependent on the market prices of other goods. Thus, the solution may shift and no longer lie in the initial bracketing intervals. New bracketing intervals must be determined in such a case. In other situations, bracketing may not be possible at all. For instance, when resources are exhausted and there are no longer any supplies. In this case, the bisection routine cannot be applied.

Although the advantages of the bisection routine is its robustness and sureness in finding the solution price, it disadvantage is that it is slow. To improve the speed of finding solution prices, the bisection routine is combined with the Newton-Raphson routine, which relies on the use of derivative.

\section{Newton-Raphson Routine}

The Newton-Raphson routine is a numerical derivative approach to finding the solution. The advantage of this routine over the bracketing and bisection routine is that it converges quadratically near a solution as opposed to linearly and approaches the solution very quickly 
(Ref. Numerical Recipes). In the vicinity of the solution, each iteration of the routine approximately doubles the number of significant digits in the trial solution. The Newton-Raphson routine requires the evaluation of the function and its derivative at arbitrary points. The NewtonRaphson formula is given by

$x_{i+1}=x_{i}+f\left(x_{i}\right) / f^{\prime}\left(x_{i}\right)$

where $x_{i}$ is the trial solution, $x_{i+1}$ is the next trial solution, and $f^{\prime}\left(x_{i}\right)$ is the derivative of the function evaluated at $\mathrm{x}_{\mathrm{i}}$.

Graphically, the routine extends the tangent line of the function at a point until it crosses zero and sets the next trial solution to the abscissa of that zero-crossing. This is repeated until the solution is found.

The disadvantage of the Newton-Raphson routine is that it is unstable where there are discontinuities and therefore, the routine's global convergence properties are poor. For instance, at local discontinuities or extreme values, the tangent line of the trial point can move the next trial point hopelessly far away from the real solution.

An effective strategy for creating a solution algorithm that is both fast and robust it to utilize both the bracketing and bisection and the Newton-Raphson methods. This hybrid algorithm relies on bisection whenever Newton-Raphson takes the solution out of bounds, or whenever NewtonRaphson is not reducing the size of the brackets rapidly enough.

The bracketing and bisection routine is applied first to find the initial bracketing intervals and to come near the vicinity of the solution for all markets. The Newton-Raphson routine is then applied to quickly come to the solution. If the Newton-Raphson routine takes the solution out of bounds or does not find the solution within a set number of iterations, the bisection routine is called. This procedure is repeated until the solution is found. 


\section{Appendix 4: Demographics}

Using the age-cohort method, the total population (of a region) for any time period, is given by

$$
\mathrm{POP}_{\text {tot } \mathrm{m}}=\sum_{\mathrm{age}=1}^{\mathrm{NAGE}} \mathrm{POP}_{\mathrm{age}, \text { males }, \mathrm{m}}+\mathrm{POP}_{\mathrm{age}, \mathrm{females}, \mathrm{m}}
$$

where

$\mathrm{POP}_{\text {age,males }}$ is the number of males in age group age,

$\mathrm{POP}_{\text {age, females }}$ is the number of females in age group age, and

NAGE is the number of age groups defined.

For the youngest age group age $=1$ :

$$
\mathrm{POP}_{\text {age }=1, \mathrm{gender}, \mathrm{m}}=\sum_{\text {age }=2}^{\text {NAGE }} \mathrm{g}_{\text {age,gender }} \bullet \mathrm{f}_{\text {age }, \mathrm{m}} \bullet \mathrm{POP}_{\text {age, females }, \mathrm{m}}
$$

where

gender is male or female

$\mathrm{POP}_{\mathrm{age}=1, \text { gender,m }}$ is population in the youngest age group, age $=1$, by gender, in period $\mathrm{t}$,

$\mathrm{f}_{\text {age,m }}$ is the fertility rate for females in age group, age, in period $t$,

$\mathrm{g}_{\mathrm{age}, \mathrm{gender}}$ is the fraction of births by gender, with $\mathrm{g}_{\mathrm{age}, \mathrm{fr}}+\mathrm{g}_{\mathrm{age}, \mathrm{m}}=1$, and

$\mathrm{POP}_{\text {age,female, } \mathrm{m}}$ is population of females in age group age in period $t$.

For all other age groups, population is determined by survival:

$$
\mathrm{POP}_{\text {age,gender } \mathrm{m}}=\mathrm{sv}_{\text {age,gender } \mathrm{m}} \bullet \mathrm{POP}_{\text {age-1,gender }, \mathrm{m}-1}+\mathrm{POPmig}_{\text {age, gender, } \mathrm{m}}
$$

where

age is $2, \ldots$ NAGE,

$\mathrm{SV}_{\mathrm{age}, g e n d e r, m}$ is the survival rate from age group age to age +1 , and

POPmig $_{\text {age,gender, } m}$ is net immigration of population by gender into the region in age group, age. 


\section{Appendix 5: Land allocation in the AgLU module}

\section{Land allocation}

The text below is from Sands and Leimbach 2001.

Using the notation from Bury (1999), the univarite Gumbel distribution is defined as

$\mathrm{f}(\mathrm{x} ; \mu, \sigma)=\frac{1}{\sigma} \exp \left\{-\frac{\mathrm{x}-\mu}{\sigma}-\exp \left\{-\frac{\mathrm{x}-\mu}{\sigma}\right\}\right\} \quad \sigma>0$

where

$\mathrm{x}$ is the variable of interest, in our case profit rate,

$\mu$ is the mode of the distribution, and

$\sigma$ is a scale parameter.

If a random sample is drawn from each of several distributions with identical scale parameters but different modes, then the probability of selecting the $i^{t h}$ distribution is given by

$\operatorname{prob}_{i}=\frac{\exp \left(\rho^{-1} \sigma^{-1} \mu_{i}\right)}{\sum_{p} \exp \left(\rho^{-1} \sigma^{-1} \mu_{p}\right)} 0<\rho \leq 1$

where

$\mathrm{p}$ is the location index,

$\rho$ is a function of the correlation coefficient $r$ if certain land-uses are correlated (see Equation

A5.3 below),

$\sigma$ is a scale parameter, and

$\mu$ is the mode of the distribution $i$, where $i$ is the index for land use.

This implies that the distribution with the greatest average value, $\mu_{\mathrm{i}}$, has the highest probability of being selected. Notation here is similar to that of Amemiya (1985). See Amemiya for a discussion of these types of distributions in qualitative response models, often referred to as logit models. Equation A5.2 considers the possibility that the distributions are correlated, where $\rho$ is a function of the correlation coefficient $r$.

$\rho=\sqrt{1-r}$

Eq. A5.3

If we consider only the random samples that survive this selection process, they also are distributed Gumbel and the average (mode) of this distribution is $\hat{\mu}$, which is calculated using

$\exp (\hat{\mu})=\left[\sum_{i} \exp \left(\rho^{-1} \sigma^{-1} \mu_{i}\right)\right]^{\rho \sigma}$

It is possible to write A5.2 and A5.4 as closed form expressions because we started with a Gumbel distribution. Equations A5.2 and A5.4 are only approximate for other distributions. Note that if we substitute the following 
$\mu_{\mathrm{i}}=\ln \bar{\pi}_{\mathrm{i}}$

Eq. A5.5

into A5.2 we obtain

$\mathrm{S}_{\mathrm{i}}=\frac{\bar{\pi}_{\mathrm{i}}^{1 / \rho \sigma}}{\sum_{\mathrm{p}} \bar{\pi}_{\mathrm{p}}^{1 / \rho \sigma}}$

Eq. A5.6

which becomes Equation A5.5 if we let

$\lambda=\rho \sigma$

Eq. A5.7

Similarly, we obtain Equation A5.9 when we substitute A5.5 into A5.4) Here, we are trying to describe the implicit assumptions that justify the use of share equations A5.6 or A5.5. So far we have shown that share equation A5.6 can be derived if we accept substitution A5.5.

Next, we describe the assumptions needed to derive A5.5. If we write the profit rate calculation (Equation 122) in logarithmic form, then

$\ln \pi \mathrm{r}_{\mathrm{i}}=\ln \mathrm{y}_{\mathrm{i}}+\ln \left(\mathrm{P}_{\mathrm{i}}-\mathrm{G}_{\mathrm{i}}\right)$

Eq. A5.8

Assume that $\ln \mathrm{y}_{\mathrm{i}}$ is distributed Gumbel with mode $\eta_{\mathrm{i}}$ and scale parameter $\sigma$. Then $\ln \pi \mathrm{r}_{\mathrm{i}}$ is distributed Gumbel with mode

$\mu_{\mathrm{i}}=\eta_{\mathrm{i}}+\ln \left(\mathrm{P}_{\mathrm{i}}-\mathrm{G}_{\mathrm{i}}\right)$

The share equation operates as if the logarithm of profit rate has a Gumbel distribution and the mode of this distribution is $\mu_{i}$. Next define

$\overline{\mathrm{y}}_{\mathrm{i}}=\exp \left(\eta_{\mathrm{i}}\right)$

This just tells us where $\gamma_{\mathrm{i}}$ must lie on the distribution of crop yields. Equation A6.10 can be substituted into A5.9 to obtain

$\mu_{\mathrm{i}}=\ln \overline{\mathrm{y}}_{\mathrm{i}}+\ln \left(\mathrm{P}_{\mathrm{i}}-\mathrm{G}_{\mathrm{i}}\right)$

using Equation 122 for the intrinsic profit rate, we can write

$\mu_{\mathrm{i}}=\ln \bar{\pi} \mathrm{r}_{\mathrm{i}}$

Eq. A5.12

which is the same as A5.5.

We have covered only the non-nested case. See Amemiya (1985) for examples of nested logit models. The advantage of using these share equations is that, given somewhat restrictive assumptions on the distribution of crop yields, we can calculate land shares immediately using Equation A5.5. Otherwise, an exact solution of the land share problem requires numeric integration. 


\section{Appendix 6: List of Tables}

\section{Demographics and GDP parameters}

Table 1 Regional population projections for the $\mathrm{B} 2$ story line

\begin{tabular}{|l|l|l|l|l|l|l|l|l|}
\hline \multicolumn{9}{|l|}{ POPPOPULATION (ZLM) UNITS=THOUSANDS OF PERSONS } \\
\hline MiniCAM B2 storyline & 1990 & 2005 & 2020 & 2035 & 2050 & 2065 & 2080 & 2095 \\
\hline Region & 249,012 & 291,604 & 327,682 & 361,786 & 384,810 & 406,002 & 432,120 & 457,962 \\
\hline USA & 29,003 & 32,551 & 36,641 & 39,957 & 42,311 & 42,353 & 42,372 & 42,321 \\
\hline Canada & 409,134 & 461,601 & 469,347 & 463,994 & 445,148 & 416,434 & 387,266 & 373,396 \\
\hline OECD90 Europe & 128,901 & 127,457 & 123,893 & 114,987 & 104,921 & 96,127 & 88,023 & 80,469 \\
\hline Japan & 21,256 & 23,797 & 26,861 & 29,311 & 31,009 & 31,758 & 31,775 & 31,739 \\
\hline Aus \& NZ & 286,923 & 292,095 & 295,368 & 293,066 & 283,685 & 275,473 & 266,303 & 261,273 \\
\hline FSU & $1,210,204$ & $1,458,890$ & $1,613,709$ & $1,685,243$ & $1,674,223$ & $1,623,512$ & $1,571,503$ & $1,542,891$ \\
\hline China/CPA & 128,789 & 191,146 & 259,713 & 320,266 & 370,830 & 397,255 & 423,382 & 435,292 \\
\hline MiddleEast & 653,996 & 875,614 & $1,187,119$ & $1,504,410$ & $1,765,661$ & $1,942,835$ & $2,120,274$ & $2,207,827$ \\
\hline Africa & 439,633 & 556,548 & 663,663 & 749,413 & 806,986 & 836,324 & 865,418 & 879,127 \\
\hline Latin America & 653,975 & 861,736 & $1,061,895$ & $1,225,959$ & $1,345,722$ & $1,402,474$ & $1,458,874$ & $1,480,712$ \\
\hline S\&E Asia & 122,164 & 120,928 & 118,739 & 112,953 & 104,599 & 97,852 & 90,999 & 87,739 \\
\hline EEU & 42,869 & 48,548 & 51,893 & 52,979 & 51,275 & 49,608 & 47,774 & 45,932 \\
\hline Korea & 850,785 & $1,087,459$ & $1,272,166$ & $1,428,018$ & $1,528,853$ & $1,566,324$ & $1,603,203$ & $1,612,875$ \\
\hline India & $5,226,644$ & $6,429,974$ & $7,508,689$ & $8,382,342$ & $8,940,033$ & $9,184,331$ & $9,429,286$ & $9,539,555$ \\
\hline Global & & & & & & & \\
\hline
\end{tabular}

Table 2 GDP projections for the B2 story line [90\$GDP(90mer)]

\begin{tabular}{|c|c|c|c|c|c|c|c|c|}
\hline \multicolumn{9}{|c|}{ GDP Data in Billions $\$ 1990$} \\
\hline Region & 1990 & 2005 & 2020 & 2035 & 2050 & 2065 & 2080 & 2095 \\
\hline USA & 5520.983 & 8554.664 & 11737.339 & 14454.176 & 17187.665 & 20281.864 & 24110.795 & 5520.983 \\
\hline Canada & 547.423 & 771.262 & 1060.940 & 1302.592 & 1576.518 & 1815.001 & 2094.299 & 547.423 \\
\hline $\begin{array}{l}\text { OECD90 } \\
\text { Europe }\end{array}$ & 7036.162 & 10369.438 & 12914.397 & 14341.557 & 15521.928 & 16391.864 & 17235.901 & 7036.162 \\
\hline Japan & 2952.073 & 3379.307 & 3876.940 & 4026.639 & 4201.292 & 4473.005 & 4791.285 & 2952.073 \\
\hline Aus \& NZ & 323.320 & 485.527 & 678.994 & 840.315 & 1006.205 & 1167.175 & 1320.868 & 323.320 \\
\hline FSU & 944.363 & 626.271 & 973.510 & 2030.690 & 3908.101 & 5911.471 & 7450.930 & 944.363 \\
\hline China/CPA & 358.220 & 1366.404 & 4676.583 & 10941.509 & 19637.697 & 25967.952 & 31043.131 & 358.220 \\
\hline Middle East & 444.610 & 720.942 & 1202.268 & 2348.568 & 4173.202 & 5921.313 & 7246.299 & 444.610 \\
\hline Africa & 379.202 & 533.858 & 934.185 & 2293.770 & 5565.397 & 11082.333 & 17966.650 & 379.202 \\
\hline $\begin{array}{l}\text { Latin } \\
\text { America }\end{array}$ & 1085.387 & 1860.465 & 3061.945 & 5969.454 & 10614.602 & 15466.871 & 18958.356 & 1085.387 \\
\hline S\&E Asia & 416.740 & 818.041 & 2200.596 & 4974.567 & 9308.257 & 13274.558 & 17477.341 & 416.740 \\
\hline EEU & 212.252 & 308.553 & 647.203 & 1372.211 & 2370.169 & 3143.213 & 3496.310 & 212.252 \\
\hline Korea & 251.861 & 608.991 & 1277.191 & 1795.794 & 2078.325 & 2026.957 & 1929.923 & 251.861 \\
\hline
\end{tabular}




\begin{tabular}{|l|l|l|l|l|l|l|l|l|}
\hline India & 294.588 & 666.853 & 1954.793 & 4808.818 & 9643.295 & 14610.354 & 20155.099 & 294.588 \\
\hline Global & 20767.185 & 31070.572 & 47196.885 & 71500.660 & 106792.652 & 141533.931 & 175277.188 & 20767.185 \\
\hline
\end{tabular}

Table 3 Market-based GDP to PPP conversion factors

\begin{tabular}{|l|l|}
\hline \multicolumn{2}{|l|}{$\begin{array}{l}\text { Market-based GDP to PPP } \\
\text { conversion factors }\end{array}$} \\
\hline Region & PPPCONV(L) \\
\hline USA & 1 \\
\hline Canada & 1.12 \\
\hline WEUR & 0.88 \\
\hline Japan & 0.81 \\
\hline Aus\&NZ & 1 \\
\hline FSU & 1.86 \\
\hline ACENP & 4.4 \\
\hline MidEast & 1.51 \\
\hline Africa & 2.8 \\
\hline LatAmer & 1.76 \\
\hline SEAsia & 2.34 \\
\hline EEUR & 2 \\
\hline Korea & 1.23 \\
\hline India & 4.17 \\
\hline
\end{tabular}

Table 4 Regional GDP elasticities

\begin{tabular}{|l|l|}
\hline \multicolumn{2}{|l|}{$\mathrm{Y}$} \\
\hline-0.15 & USA \\
\hline-0.15 & Canada \\
\hline-0.15 & WEUR \\
\hline-0.15 & Japan \\
\hline-0.15 & Aus\&NZ \\
\hline-0.15 & FSU \\
\hline-0.20 & ACENP \\
\hline 0.05 & MidEast \\
\hline-0.20 & Africa \\
\hline-0.20 & LatAmer \\
\hline-0.20 & SEAsia \\
\hline-0.15 & EEUR \\
\hline-0.15 & Korea \\
\hline-0.20 & India \\
\hline
\end{tabular}

Table 5 Examples of projections of regional labor productivity increases and regional labor force participation rates 


\begin{tabular}{|l|l|l|l|l|l|l|l|l|l|}
\hline \multicolumn{2}{|l|}{ Labor productivity growth rate: Prod $_{1, \mathrm{~m}}$ (Equation 62) } \\
\hline Region & 1975 & 1990 & 2005 & 2020 & 2035 & 2050 & 2065 & 2080 & 2095 \\
\hline USA & 0.0170 & 0.0118 & 0.0162 & 0.0132 & 0.0114 & 0.0076 & 0.0090 & 0.0093 & 0.0116 \\
\hline Canada & 0.0170 & 0.0046 & 0.0193 & 0.0089 & 0.0241 & 0.0028 & 0.0125 & 0.0041 & 0.0110 \\
\hline WEUR & 0.0170 & 0.0127 & 0.0241 & 0.0058 & 0.0107 & 0.0052 & 0.0112 & 0.0119 & 0.0096 \\
\hline Japan & 0.0170 & 0.0103 & 0.0126 & 0.0226 & 0.0044 & 0.0091 & 0.0044 & 0.0126 & 0.0154 \\
\hline Aus\&NZ & 0.0170 & 0.0290 & 0.0121 & 0.0207 & 0.0185 & 0.0132 & 0.0068 & -0.0028 & 0.0096 \\
\hline FSU & 0.0170 & 0.0659 & -0.0344 & 0.0353 & 0.0540 & 0.0535 & 0.0242 & 0.0158 & 0.0131 \\
\hline ACENP & 0.0250 & 0.0901 & 0.0813 & 0.0718 & 0.0649 & 0.0446 & 0.0324 & 0.0184 & 0.0122 \\
\hline MidEast & 0.0250 & 0.1232 & -0.0044 & 0.0082 & 0.0211 & 0.0259 & 0.0146 & 0.0091 & 0.0012 \\
\hline Africa & 0.0250 & 0.0647 & 0.0034 & 0.0158 & 0.0385 & 0.0486 & 0.0393 & 0.0326 & 0.0221 \\
\hline LatAmer & 0.0250 & 0.0137 & 0.0108 & 0.0188 & 0.0358 & 0.0342 & 0.0231 & 0.0135 & 0.0068 \\
\hline SEAsia & 0.0250 & 0.0252 & 0.0225 & 0.0507 & 0.0446 & 0.0379 & 0.0213 & 0.0180 & 0.0152 \\
\hline EEUR & 0.0170 & 0.0500 & 0.0194 & 0.0586 & 0.0582 & 0.0490 & 0.0177 & 0.0100 & 0.0086 \\
\hline Korea & 0.0170 & 0.1290 & 0.0474 & 0.0431 & 0.0203 & 0.0135 & 0.0007 & 0.0012 & 0.0013 \\
\hline India & 0.0200 & 0.0737 & 0.0343 & 0.0604 & 0.0524 & 0.0445 & 0.0266 & 0.0223 & 0.0188 \\
\hline
\end{tabular}

Table 6 Examples of projections of regional labor force participation

\begin{tabular}{|l|l|l|l|l|l|l|l|l|l|l|}
\hline \multicolumn{2}{|l|}{ Labor force Percentage } & \multicolumn{7}{l|}{ This is the ratio of working persons over total population } \\
\hline LFPerc(L,M); UN_98 Med Pop for the B2 scenario; see Equation 62 \\
\hline REGION & 1975 & 1990 & 2005 & 2020 & 2035 & 2050 & 2065 & 2080 & 2095 \\
\hline 1 & 0.45 & 0.5 & 0.52 & 0.52 & 0.49 & 0.49 & 0.48 & 0.47 & 0.45 \\
\hline 2 & 0.44 & 0.52 & 0.49 & 0.52 & 0.41 & 0.45 & 0.43 & 0.47 & 0.47 \\
\hline 3 & 0.43 & 0.46 & 0.42 & 0.47 & 0.45 & 0.47 & 0.45 & 0.43 & 0.43 \\
\hline 4 & 0.49 & 0.52 & 0.5 & 0.42 & 0.44 & 0.44 & 0.48 & 0.47 & 0.45 \\
\hline 5 & 0.43 & 0.5 & 0.56 & 0.51 & 0.44 & 0.41 & 0.42 & 0.5 & 0.5 \\
\hline 6 & 0.51 & 0.49 & 0.54 & 0.49 & 0.47 & 0.43 & 0.47 & 0.49 & 0.49 \\
\hline 7 & 0.53 & 0.59 & 0.58 & 0.64 & 0.57 & 0.54 & 0.46 & 0.44 & 0.44 \\
\hline 8 & 0.29 & 0.3 & 0.35 & 0.38 & 0.44 & 0.46 & 0.49 & 0.49 & 0.51 \\
\hline 9 & 0.47 & 0.48 & 0.48 & 0.49 & 0.54 & 0.55 & 0.56 & 0.52 & 0.5 \\
\hline 10 & 0.34 & 0.39 & 0.45 & 0.47 & 0.48 & 0.48 & 0.48 & 0.47 & 0.47 \\
\hline 11 & 0.35 & 0.44 & 0.47 & 0.49 & 0.5 & 0.49 & 0.49 & 0.48 & 0.47 \\
\hline 12 & 0.51 & 0.49 & 0.54 & 0.49 & 0.47 & 0.43 & 0.47 & 0.49 & 0.49 \\
\hline 13 & 0.35 & 0.44 & 0.47 & 0.49 & 0.5 & 0.49 & 0.49 & 0.48 & 0.47 \\
\hline 14 & 0.35 & 0.44 & 0.47 & 0.49 & 0.5 & 0.49 & 0.49 & 0.48 & 0.47 \\
\hline
\end{tabular}

\section{Energy supply and extraction parameters}

Table 7 Minimum extraction costs by grade and fuel (1975\$/GJ)

\begin{tabular}{|l|l|l|l|l|l|}
\hline \multicolumn{2}{|l|}{ Extraction costs CIGIS(IG,IS); see Equation 5 \& 21} & \multicolumn{3}{l|}{} \\
\hline Grade & CONV OIL & CONV GAS & COAL & UNCON OIL & NUCLEAR \\
\hline
\end{tabular}




\begin{tabular}{|l|l|l|l|l|l|}
\hline 1 & 0.50 & 0.62 & 0.34 & 3.80 & 1.07 \\
\hline 2 & 0.55 & 0.68 & 0.37 & 4.10 & 2.00 \\
\hline 3 & 0.92 & 1.10 & 1.20 & 5.60 & 2.10 \\
\hline 4 & 1.30 & 1.70 & 1.70 & 6.70 & 2.50 \\
\hline 5 & 2.10 & 3.10 & 2.00 & 8.00 & 3.00 \\
\hline 6 & 2.70 & 3.70 & 2.30 & 9.00 & 4.00 \\
\hline 100 & 3.50 & 6.50 & 2.60 & 10.00 & 8.00 \\
\hline
\end{tabular}

Table 8 Energy resources by grade and region (EJ)

\begin{tabular}{|c|c|c|c|c|c|c|}
\hline \multicolumn{7}{|c|}{$\begin{array}{l}\text { Regional supply RIGISL(IG,IS,L); see Equation 7, 8, \& 9; Recent values for total fossil resources were taken from } \\
\text { Rogner (1997) }\end{array}$} \\
\hline Grade & REGION & CONV OIL & CONV GAS & COAL & UNCON OIL & NUCLEAR \\
\hline 1 & US & 247 & 207 & 284 & 4397 & 105 \\
\hline 2 & US & 312 & 778 & 6851 & 8594 & 562 \\
\hline 3 & US & 356 & 575 & 9469 & 82637 & 87084 \\
\hline 4 & US & 226 & 1431 & 13456 & 247909 & 87084 \\
\hline 5 & US & 236 & 716 & 18440 & 0 & 0 \\
\hline 6 & $\overline{U S}$ & 343 & 1339 & 18440 & 0 & 0 \\
\hline 1 & CANADA & 55 & 44 & 20 & 803 & 77 \\
\hline 2 & CANADA & 115 & 279 & 293 & 1570 & 411 \\
\hline 3 & CANADA & 199 & 119 & 293 & 15095 & 34833 \\
\hline 4 & CANADA & 208 & 279 & 415 & 45285 & 34833 \\
\hline 5 & CANADA & 216 & 478 & 569 & 0 & 0 \\
\hline 6 & CANADA & 314 & 893 & 569 & 0 & 0 \\
\hline 1 & WEUR & 121 & 78 & 117 & 1204 & 116 \\
\hline 2 & WEUR & 49 & 496 & 2633 & 2355 & 617 \\
\hline 3 & WEUR & 85 & 278 & 2632 & 22643 & 52250 \\
\hline 4 & WEUR & 89 & 647 & 3740 & 67928 & 52250 \\
\hline 5 & WEUR & 92 & 382 & 5125 & 0 & 0 \\
\hline 6 & WEUR & 134 & 714 & 5125 & 0 & 0 \\
\hline 1 & JAPAN & 0 & 1 & 2 & 146 & 10 \\
\hline 2 & JAPAN & 0 & 6 & 336 & 287 & 50 \\
\hline 3 & JAPAN & 0 & 23 & 496 & 2754 & 8708 \\
\hline 4 & JAPAN & 0 & 51 & 704 & 8263 & 8708 \\
\hline 5 & JAPAN & 0 & 239 & 965 & 0 & 0 \\
\hline 6 & JAPAN & 0 & 446 & 965 & 0 & 0 \\
\hline 1 & AUS\&NZ & 18 & 10 & 57 & 1320 & 84 \\
\hline 2 & AUS\&NZ & 5 & 67 & 1186 & 2578 & 449 \\
\hline 3 & AUS\&NZ & 6 & 46 & 1753 & 24791 & 78375 \\
\hline 4 & AUS\&NZ & 7 & 99 & 2491 & 74374 & 78375 \\
\hline 5 & AUS\&NZ & 9 & 478 & 3414 & 0 & 0 \\
\hline 6 & AUS\&NZ & 12 & 893 & 3414 & 0 & 0 \\
\hline 1 & FSU & 333 & 325 & 158 & 3874 & 205 \\
\hline 2 & FSU & 305 & 2074 & 8728 & 7575 & 1092 \\
\hline 3 & FSU & 569 & 1409 & 15404 & 72804 & 69271 \\
\hline
\end{tabular}




\begin{tabular}{|c|c|c|c|c|c|c|}
\hline 4 & FSU & 551 & 1389 & 21890 & 218412 & 69271 \\
\hline 5 & FSU & 572 & 478 & 29997 & 0 & 0 \\
\hline 6 & FSU & 556 & 893 & 29997 & 0 & 0 \\
\hline 1 & ACENP & 83 & 6 & 295 & 2012 & 123 \\
\hline 2 & ACENP & 102 & 40 & 7032 & 3933 & 657 \\
\hline 3 & ACENP & 98 & 171 & 4820 & 37820 & 87084 \\
\hline 4 & ACENP & 137 & 379 & 6849 & 113461 & 87084 \\
\hline 5 & ACENP & 136 & 239 & 9387 & 0 & 0 \\
\hline 6 & ACENP & 187 & 446 & 9387 & 0 & 0 \\
\hline 1 & MIDEAST & 501 & 41 & 0 & 503 & 2 \\
\hline 2 & MIDEAST & 657 & 810 & 2 & 983 & 12 \\
\hline 3 & MIDEAST & 485 & 735 & 2 & 9455 & 87084 \\
\hline 4 & MIDEAST & 452 & 2252 & 3 & 28366 & 87084 \\
\hline 5 & MIDEAST & 1380 & 239 & 4 & 0 & 0 \\
\hline 6 & MIDEAST & 1820 & 446 & 4 & 0 & 0 \\
\hline 1 & AFR & 188 & 30 & 56 & 6009 & 426 \\
\hline 2 & AFR & 296 & 194 & 1059 & 11745 & 2269 \\
\hline 3 & $\overline{\mathrm{AFR}}$ & 56 & 335 & 723 & 112937 & 87084 \\
\hline 4 & AFR & 397 & 739 & 1026 & 338813 & 87084 \\
\hline 5 & AFR & 393 & 716 & 1406 & 0 & 0 \\
\hline 6 & AFR & 1298 & 1339 & 1406 & 0 & 0 \\
\hline 1 & LA & 222 & 37 & 11 & 3004 & 973 \\
\hline 2 & $\overline{L A}$ & 261 & 236 & 116 & 5873 & 5188 \\
\hline 3 & LA & 119 & 372 & 144 & 56469 & 87084 \\
\hline 4 & $\overline{\mathrm{LA}}$ & 348 & 783 & 205 & 169406 & 87084 \\
\hline 5 & LA & 346 & 716 & 280 & 0 & 0 \\
\hline 6 & LA & 475 & 1339 & 280 & 0 & 0 \\
\hline 1 & SEASIA & 73 & 45 & 6 & 1509 & 20 \\
\hline 2 & SEASIA & 48 & 287 & 1018 & 2950 & 109 \\
\hline 3 & SEASIA & 110 & 301 & 434 & 28366 & 87084 \\
\hline 4 & SEASIA & 63 & 339 & 616 & 85096 & 87084 \\
\hline 5 & SEASIA & 63 & 478 & 845 & 0 & 0 \\
\hline 6 & SEASIA & 314 & 893 & 845 & 0 & 0 \\
\hline 1 & EEUR & 8 & 16 & 86 & 151 & 53 \\
\hline 2 & EEUR & 7 & 101 & 390 & 295 & 281 \\
\hline 3 & EEUR & 13 & 25 & 689 & 2837 & 17813 \\
\hline 4 & EEUR & 12 & 24 & 979 & 8510 & 17813 \\
\hline 5 & EEUR & 13 & 48 & 1341 & 0 & 0 \\
\hline 6 & EEUR & 12 & 89 & 1341 & 0 & 0 \\
\hline 1 & KOREA & 0 & 0 & 4 & 0 & 10 \\
\hline 2 & KOREA & 0 & 0 & 17 & 0 & 50 \\
\hline 3 & KOREA & 0 & 0 & 0 & 0 & 8708 \\
\hline 4 & KOREA & 0 & 0 & 0 & 0 & 8708 \\
\hline 5 & KOREA & 0 & 191 & 0 & 0 & 0 \\
\hline 6 & KOREA & 0 & 357 & 0 & 0 & 0 \\
\hline 1 & INDIA & 21 & 5 & 55 & 1509 & 20 \\
\hline
\end{tabular}




\begin{tabular}{|l|l|l|l|l|l|l|}
\hline 2 & INDIA & 48 & 32 & 1018 & 2950 & 109 \\
\hline 3 & INDIA & 110 & 301 & 434 & 28366 & 87084 \\
\hline 4 & INDIA & 63 & 339 & 616 & 85096 & 87084 \\
\hline 5 & INDIA & 63 & 382 & 845 & 0 & 0 \\
\hline 6 & INDIA & 314 & 714 & 845 & 0 & 0 \\
\hline
\end{tabular}

Table 9 Regional environmental costs $(1975 \$ / G J)$ for the B2 scenario

\begin{tabular}{|c|c|c|c|c|c|c|c|c|c|}
\hline \multicolumn{10}{|c|}{ Environmental costs VISLM(IS,L,M)); see Equation 5, 13 \& 21} \\
\hline fuel & 1975 & 1990 & 2005 & 2020 & 2035 & 2050 & 2065 & 2080 & REGION \\
\hline Oil & 0 & 0 & 0 & 0.07 & 0.12 & 0.19 & 0.24 & 0.32 & USA \\
\hline Oil & 0 & 0 & 0 & 0.07 & 0.12 & 0.19 & 0.24 & 0.32 & CANADA \\
\hline Oil & 0 & 0 & 0 & 0.07 & 0.12 & 0.19 & 0.24 & 0.32 & WEUR \\
\hline Oil & 0 & 0 & 0 & 0.07 & 0.12 & 0.19 & 0.24 & 0.32 & JAPAN \\
\hline Oil & 0 & 0 & 0 & 0.07 & 0.12 & 0.19 & 0.24 & 0.32 & AUS\&NZ \\
\hline Oil & 0 & 0 & 0 & 0.05 & 0.07 & 0.12 & 0.17 & 0.19 & FSU \\
\hline Oil & 0 & 0 & 0 & 0.05 & 0.07 & 0.12 & 0.17 & 0.19 & ACENP \\
\hline Oil & 0 & 0 & 0 & 0.02 & 0.07 & 0.1 & 0.12 & 0.17 & MIDEAST \\
\hline Oil & 0 & 0 & 0 & 0.02 & 0.05 & 0.07 & 0.07 & 0.1 & AFR \\
\hline Oil & 0 & 0 & 0 & 0.05 & 0.07 & 0.12 & 0.17 & 0.19 & LA \\
\hline Oil & 0 & 0 & 0 & 0.02 & 0.07 & 0.1 & 0.12 & 0.17 & S\&E ASIA \\
\hline Oil & 0 & 0 & 0 & 0.07 & 0.12 & 0.19 & 0.24 & 0.32 & EEUR \\
\hline Oil & 0 & 0 & 0 & 0.07 & 0.12 & 0.19 & 0.24 & 0.32 & KOR \\
\hline Oil & 0 & 0 & 0 & 0.02 & 0.07 & 0.1 & 0.12 & 0.17 & INDIA \\
\hline Gas & 0 & 0 & 0 & 0 & 0 & 0 & 0 & 0 & USA \\
\hline Gas & 0 & 0 & 0 & 0 & 0 & 0 & 0 & 0 & CANADA \\
\hline Gas & 0 & 0 & 0 & 0 & 0 & 0 & 0 & 0 & WEUR \\
\hline Gas & 0 & 0 & 0 & 0 & 0 & 0 & 0 & 0 & JAPAN \\
\hline Gas & 0 & 0 & 0 & 0 & 0 & 0 & 0 & 0 & AUS\&NZ \\
\hline Gas & 0 & 0 & 0 & 0 & 0 & 0 & 0 & 0 & FSU \\
\hline Gas & 0 & 0 & 0 & 0 & 0 & 0 & 0 & 0 & ACENP \\
\hline Gas & 0 & 0 & 0 & 0 & 0 & 0 & 0 & 0 & MIDEAST \\
\hline Gas & 0 & 0 & 0 & 0 & 0 & 0 & 0 & 0 & AFR \\
\hline Gas & 0 & 0 & 0 & 0 & 0 & 0 & 0 & 0 & LA \\
\hline Gas & 0 & 0 & 0 & 0 & 0 & 0 & 0 & 0 & S\&E ASIA \\
\hline Gas & 0 & 0 & 0 & 0 & 0 & 0 & 0 & 0 & EEUR \\
\hline Gas & 0 & 0 & 0 & 0 & 0 & 0 & 0 & 0 & KOR \\
\hline Gas & 0 & 0 & 0 & 0 & 0 & 0 & 0 & 0 & INDIA \\
\hline Coal & 0 & 0 & 0.02 & 0.15 & 0.27 & 0.39 & 0.48 & 0.6 & USA \\
\hline Coal & 0 & 0 & 0.02 & 0.15 & 0.27 & 0.39 & 0.48 & 0.6 & CANADA \\
\hline Coal & 0 & 0 & 0.02 & 0.15 & 0.27 & 0.39 & 0.48 & 0.6 & WEUR \\
\hline Coal & 0 & 0 & 0.02 & 0.15 & 0.27 & 0.39 & 0.48 & 0.6 & JAPAN \\
\hline Coal & 0 & 0 & 0.02 & 0.15 & 0.27 & 0.39 & 0.48 & 0.6 & AUS\&NZ \\
\hline Coal & 0 & 0 & 0.02 & 0.1 & 0.17 & 0.27 & 0.34 & 0.41 & FSU \\
\hline Coal & 0 & 0 & 0.02 & 0.1 & 0.17 & 0.27 & 0.34 & 0.41 & ACENP \\
\hline
\end{tabular}




\begin{tabular}{|c|c|c|c|c|c|c|c|c|c|}
\hline Coal & 0 & 0 & 0.02 & 0.1 & 0.15 & 0.22 & 0.27 & 0.34 & MIDEAST \\
\hline Coal & 0 & 0 & 0.02 & 0.07 & 0.1 & 0.15 & 0.17 & 0.22 & $\overline{\mathrm{AFR}}$ \\
\hline Coal & 0 & 0 & 0.02 & 0.1 & 0.17 & 0.27 & 0.34 & 0.41 & $\overline{\mathrm{LA}}$ \\
\hline Coal & 0 & 0 & 0.02 & 0.1 & 0.15 & 0.22 & 0.27 & 0.34 & S\&E ASIA \\
\hline Coal & 0 & 0 & 0.02 & 0.15 & 0.27 & 0.39 & 0.48 & 0.6 & EEUR \\
\hline Coal & 0 & 0 & 0.02 & 0.15 & 0.27 & 0.39 & 0.48 & 0.6 & KOR \\
\hline Coal & 0 & 0 & 0.02 & 0.1 & 0.15 & 0.22 & 0.27 & 0.34 & INDIA \\
\hline Unconventional Oil & 0 & 0.1 & 0.15 & 0.32 & 0.46 & 0.63 & 0.77 & 0.94 & $\overline{\text { USA }}$ \\
\hline Unconventional Oil & 0 & 0.1 & 0.15 & 0.32 & 0.46 & 0.63 & 0.77 & 0.94 & CANADA \\
\hline Unconventional Oil & 0 & 0.1 & 0.15 & 0.32 & 0.46 & 0.63 & 0.77 & 0.94 & $\begin{array}{l}\text { WEUR } \\
\end{array}$ \\
\hline Unconventional Oil & 0 & 0.1 & 0.15 & 0.32 & 0.46 & 0.63 & 0.77 & 0.94 & JAPAN \\
\hline Unconventional Oil & 0 & 0.1 & 0.15 & 0.32 & 0.46 & 0.63 & 0.77 & 0.94 & AUS\&NZ \\
\hline Unconventional Oil & 0 & 0.02 & 0.05 & 0.17 & 0.27 & 0.39 & 0.51 & 0.6 & FSU \\
\hline Unconventional Oil & 0 & 0.02 & 0.05 & 0.17 & 0.27 & 0.39 & 0.51 & 0.6 & ACENP \\
\hline Unconventional Oil & 0 & 0.02 & 0.05 & 0.15 & 0.22 & 0.32 & 0.41 & 0.48 & MIDEAST \\
\hline Unconventional Oil & 0 & 0.02 & 0.05 & 0.1 & 0.15 & 0.22 & 0.27 & 0.32 & AFR \\
\hline Unconventional Oil & 0 & 0.02 & 0.05 & 0.17 & 0.27 & 0.39 & 0.51 & 0.6 & $\overline{\mathrm{LA}}$ \\
\hline $\begin{array}{l}\text { Unconventional Oil } \\
\text { }\end{array}$ & 0 & 0.02 & 0.05 & 0.15 & 0.22 & 0.32 & 0.41 & 0.48 & S\&E ASIA \\
\hline Unconventional Oil & 0 & 0.02 & 0.05 & 0.22 & 0.39 & 0.58 & 0.75 & 0.92 & EEUR \\
\hline Unconventional Oil & 0 & 0.1 & 0.15 & 0.32 & 0.46 & 0.63 & 0.77 & 0.94 & KOR \\
\hline Unconventional Oil & 0 & 0.02 & 0.05 & 0.15 & 0.22 & 0.32 & 0.41 & 0.48 & INDIA \\
\hline Nuclear Fuel & 0 & 0 & 0 & 0 & 0 & 0 & 0 & 0 & USA \\
\hline Nuclear Fuel & 0 & 0 & 0 & 0 & 0 & 0 & 0 & 0 & CANADA \\
\hline Nuclear Fuel & 0 & 0 & 0 & 0 & 0 & 0 & 0 & 0 & WEUR \\
\hline Nuclear Fuel & 0 & 0 & 0 & 0 & 0 & 0 & 0 & 0 & JAPAN \\
\hline Nuclear Fuel & 0 & 0 & 0 & 0 & 0 & 0 & 0 & 0 & AUS\&NZ \\
\hline Nuclear Fuel & 0 & 0 & 0 & 0 & 0 & 0 & 0 & 0 & FSU \\
\hline Nuclear Fuel & 0 & 0 & 0 & 0 & 0 & 0 & 0 & 0 & ACENP \\
\hline Nuclear Fuel & 0 & 0 & 0 & 0 & 0 & 0 & 0 & 0 & MIDEAST \\
\hline Nuclear Fuel & 0 & 0 & 0 & 0 & 0 & 0 & 0 & 0 & AFR \\
\hline Nuclear Fuel & 0 & 0 & 0 & 0 & 0 & 0 & 0 & 0 & $\overline{\mathrm{LA}}$ \\
\hline Nuclear Fuel & 0 & 0 & 0 & 0 & 0 & 0 & 0 & 0 & S\&E ASIA \\
\hline Nuclear Fuel & 0 & 0 & 0 & 0 & 0 & 0 & 0 & 0 & EEUR \\
\hline Nuclear Fuel & 0 & 0 & 0 & 0 & 0 & 0 & 0 & 0 & KOR \\
\hline Nuclear Fuel & 0 & 0 & 0 & 0 & 0 & 0 & 0 & 0 & INDIA \\
\hline
\end{tabular}

Table 10 Technological change in generating energy supplies

\begin{tabular}{|l|l|l|l|l|l|l|}
\hline \multicolumn{2}{|l|}{ STISM(IS,M); see Equation 4} \\
\hline PERIOD & $\begin{array}{l}\text { CONV } \\
\text { OIL }\end{array}$ & CONV GAS & COAL & \multicolumn{2}{l|}{ UNCON OIL } & \multicolumn{2}{l|}{ NUCLEAR FUEL } \\
\hline 1 & 0.005 & 0.005 & 0.005 & 0.01 & 0.005 & 1975 \\
\hline 2 & 0.005 & 0.005 & 0.005 & 0.01 & 0.005 & 1990 \\
\hline 3 & 0.0075 & 0.0075 & 0.0075 & 0.01 & 0.005 & 2005 \\
\hline 4 & 0.0075 & 0.0075 & 0.0075 & 0.01 & 0.005 & 2020 \\
\hline 5 & 0.0075 & 0.0075 & 0.0075 & 0.01 & 0.005 & 2035 \\
\hline 6 & 0.0075 & 0.0075 & 0.0075 & 0.01 & 0.005 & 2050 \\
\hline
\end{tabular}




\begin{tabular}{|l|l|l|l|l|l|l|}
\hline 7 & 0.0075 & 0.0075 & 0.0075 & 0.01 & 0.005 & 2065 \\
\hline 8 & 0.0075 & 0.0075 & 0.0075 & 0.01 & 0.005 & 2080 \\
\hline 9 & 0.0075 & 0.0075 & 0.0075 & 0.01 & 0.005 & 2095 \\
\hline
\end{tabular}

Table 11 Regional initial estimates of energy supplies

\begin{tabular}{|l|l|l|l|l|l|}
\hline $\begin{array}{l}\text { ESFIL--INITIAL ESTIMATE OF ENERGY SUPPLY BY FUEL, REGION, AND PERIOD } \\
\text { (UNITS=EXAJOULES/YR): ESFIL(IS,L) - YEAR 1975; see Equation 10 }\end{array}$ \\
\hline REGION & CONV OIL & CONV GAS & COAL & UNCON OIL & NUCLEAR \\
\hline US & 19.9 & 18.5 & 12.8 & 0 & 0.62 \\
\hline CAN & 3.6 & 2.5 & 0.5 & 0 & 0.06 \\
\hline WEUR & 1.2 & 5.7 & 9 & 0 & 0.52 \\
\hline JAPAN & 0 & 0.1 & 0.5 & 0 & 0.09 \\
\hline AUS\&NZ & 0.9 & 0.2 & 1.6 & 0 & 0 \\
\hline FSU & 20.6 & 10 & 12.1 & 0 & 0.06 \\
\hline ACENP & 3.3 & 0.3 & 9.3 & 0 & 0 \\
\hline MIDEAST & 41.8 & 1.3 & 0 & 0 & 0 \\
\hline AFR & 10.4 & 0.4 & 1.5 & 0 & 0 \\
\hline LA & 9.7 & 1.5 & 0.2 & 0 & 0.01 \\
\hline SEASIA & 2.9 & 0.3 & 7.2 & 0 & 0.01 \\
\hline EEUR & 1 & 1.6 & 6.1 & 0 & 0.01 \\
\hline KOR & 0 & 0 & 0.3 & 0 & 0.09 \\
\hline INDIA & 0.4 & 0 & 1.8 & 0 & 0.01 \\
\hline
\end{tabular}

Table 12 Regional minimum production rates for fuel production

\begin{tabular}{|c|c|c|c|c|c|}
\hline \multicolumn{6}{|c|}{ BESIL(IS,L); see description of Equation 11} \\
\hline REGION & $\begin{array}{l}\text { CONV } \\
\text { OIL }\end{array}$ & CONV GAS & COAL & $\begin{array}{l}\text { UNCON } \\
\text { OIL }\end{array}$ & NUCLEAR \\
\hline USA & 9 & 9 & 22 & 5 & 0.03 \\
\hline Canada & 2 & 2 & 2 & 1 & 0.03 \\
\hline WEUR & 5 & 3 & 9 & 3 & 0.03 \\
\hline Japan & 1 & 1 & 1 & 1 & 0.03 \\
\hline Aus\&NZ & 1 & 1 & 4 & 1 & 0.03 \\
\hline FSU & 12 & 14 & 12 & 3 & 0.03 \\
\hline ACENP & 3 & 1 & 23 & 2 & 0.03 \\
\hline MidEast & 18 & 2 & 1 & 1 & 0.03 \\
\hline Africa & 7 & 2 & 4 & 1 & 0.03 \\
\hline LatAmer & 8 & 2 & 1 & 1 & 0.03 \\
\hline SEAsia & 3 & 2 & 1 & 1 & 0.03 \\
\hline EEUR & 1 & 1 & 7 & 1 & 0.03 \\
\hline Korea & 1 & 1 & 1 & 1 & 0.03 \\
\hline India & 1 & 1 & 4 & 1 & 0.03 \\
\hline
\end{tabular}


Table 13 Regional initial estimates of available biomass waste

\begin{tabular}{|l|l|}
\hline \multicolumn{2}{|l|}{ WASTE ENERGY: BIOLM(L,IM); see Equation 22} \\
\hline \multicolumn{2}{|l|}{} \\
\hline Value (EJ) & Region \\
\hline 5.48 & US \\
\hline 1 & CANADA \\
\hline 6.95 & WEUR \\
\hline 2.21 & JAPAN \\
\hline 0.5 & AUS\&NZ \\
\hline 5 & FSU \\
\hline 5 & ACENP \\
\hline 0.35 & MIDEAST \\
\hline 6 & AFRICA \\
\hline 8.21 & L AMER \\
\hline 2.5 & S\&E ASIA \\
\hline 0.55 & EEUR \\
\hline 1 & KOR \\
\hline 5 & INDIA \\
\hline
\end{tabular}

Table 14 Regional supply price elasticities

\begin{tabular}{|c|c|c|c|c|}
\hline \multirow{2}{*}{\multicolumn{5}{|c|}{$\begin{array}{l}\text { RIL--PRICE ELASTICITY OF SUPPLY, EVALUATED } \\
\text { PREVIOUS PRICE (BY SUPPLY TYPE AND REGION) } \\
\text { RIJ }\end{array}$}} \\
\hline & & & \\
\hline REGION & $\begin{array}{l}\text { CONV } \\
\text { OIL }\end{array}$ & $\begin{array}{l}\text { CONV } \\
\text { GAS }\end{array}$ & COAL & $\begin{array}{l}\text { UNCON } \\
\text { OIL }\end{array}$ \\
\hline US & 1.5 & 2 & 2 & 2 \\
\hline CANADA & 1.5 & 2 & 2 & 2 \\
\hline WEUR & 1.5 & 2 & 2 & 2 \\
\hline JAPAN & 1.5 & 2 & 2 & 2 \\
\hline AUS\&NZ & 1.5 & 2 & 2 & 2 \\
\hline$\overline{F S U}$ & 1.5 & 2 & 2 & 2 \\
\hline ACENP & 1.5 & 2 & 2 & 2 \\
\hline MIDEAST & 1.5 & 2 & 2 & 2 \\
\hline AFR & 1.5 & 2 & 2 & 2 \\
\hline $\mathrm{LA}$ & 1.5 & 2 & 2 & 2 \\
\hline SEASIA & 1.5 & 2 & 2 & 2 \\
\hline$\overline{\text { EEUR }}$ & 1.5 & 2 & 2 & 2 \\
\hline KOR & 1.5 & 2 & 2 & 2 \\
\hline INDIA & 1.5 & 2 & 2 & 2 \\
\hline
\end{tabular}

Table 15 Initial prices and base share weights for biomass supply shares BIOMASS COEFFICIENTS: 


\begin{tabular}{|l|l|}
\hline \multicolumn{2}{|l|}{ BIOPSM: Bio $_{1, \mathrm{~m}}$; Equation 22 } \\
\hline PRICE & SHARE \\
\hline 0.1 & 0 \\
\hline 0.56 & 0.3 \\
\hline 0.74 & 0.7 \\
\hline 0.93 & 1 \\
\hline 2.22 & 1.5 \\
\hline
\end{tabular}

Table 16 Aggregate income elasticity of biomass supply

\begin{tabular}{|l|}
\hline $\begin{array}{l}\text { INCOME ELASTICITY OF BIOMASS } \\
\text { SUPPLY }\end{array}$ \\
\hline RYSHT; see Equation 22 \\
\hline 0.1 \\
\hline
\end{tabular}

Table 17 Hydropower generation parameters

\begin{tabular}{|l|l|l|l|l|l|}
\hline \multicolumn{7}{|l|}{ Hydro parameters; see Equation 23 } \\
\hline REGION & HYDRO1L & HYDRO2L & HYDRO3L & HYDRO4L & HYDRO5L \\
\hline USA & 0.4080 & 0.0158 & 1.5441 & 4.03 & 0.107 \\
\hline Canada & -0.1570 & 0.0655 & 1.3281 & 4.03 & 0.616 \\
\hline WEUR & 0.2975 & 0.0274 & 2.0599 & 4.03 & 0.19 \\
\hline Japan & 1.4034 & 0.0352 & 0.3338 & 4.03 & 0.107 \\
\hline Aus\&NZ & 0.7305 & 0.0490 & 0.1485 & 4.03 & 0.213 \\
\hline FSU & -0.4164 & 0.0452 & 0.9901 & 4.03 & 0.124 \\
\hline ACENP & -2.0631 & 0.0641 & 1.9259 & 4.03 & 0.235 \\
\hline MidEast & -2.4897 & 0.0725 & 0.2207 & 4.03 & 0.063 \\
\hline Africa & -2.9014 & 0.0393 & 1.4400 & 4.03 & 0.14 \\
\hline LatAmer & -1.9800 & 0.0952 & 3.2674 & 4.03 & 0.667 \\
\hline SEAsia & -2.0491 & 0.0880 & 0.5860 & 4.03 & 0.205 \\
\hline EEUR & -0.0371 & 0.0180 & 0.2732 & 4.03 & 0.119 \\
\hline Korea & -1.2333 & 0.2357 & 0.0218 & 4.03 & 0.059 \\
\hline India & -1.6957 & 0.0663 & 0.5900 & 4.03 & 0.252 \\
\hline
\end{tabular}

Table 18 Regional energy from hydropower obtained in the base year in the B2 scenario and the fixed hydro shares for producing electricity

\begin{tabular}{|l|l|l|}
\hline & \multicolumn{2}{|l|}{$\begin{array}{l}\text { EJ of electricity } \\
\text { generated by hydropower }\end{array}$} \\
\hline & by hydro & Hydro share \\
\hline & 1990 & \\
\hline US & 1.01 & 0.107 \\
\hline CANADA & 0.92 & 0.616 \\
\hline WEUR & 1.38 & 0.19 \\
\hline JAPAN & 0.29 & 0.107 \\
\hline AUS\&NZ & 0.12 & 0.213 \\
\hline
\end{tabular}




\begin{tabular}{|l|l|l|}
\hline FSU & 0.56 & 0.124 \\
\hline ACENP & 0.48 & 0.235 \\
\hline MIDEAST & 0.04 & 0.063 \\
\hline AFR & 0.13 & 0.14 \\
\hline LA & 1.19 & 0.667 \\
\hline SEASIA & 0.19 & 0.205 \\
\hline EEUR & 0.15 & 0.119 \\
\hline KOR & 0.02 & 0.059 \\
\hline INDIA & 0.2 & 0.252 \\
\hline & 6.69 & \\
\hline
\end{tabular}

\section{Primary energy price parameters}

Table 19 Regional initial market prices for all goods

\begin{tabular}{|l|l|l|l|l|}
\hline P(in,l,1) & \multicolumn{4}{|l}{ Initial starting market prices for all goods in 1975 \$/GJ; see Equation 24 } \\
\hline region & OIL(1) & GAS(2) & COAL(3) & BIOMASS(4) \\
\hline USA & 1.8398 & 0.6256 & 0.5121 & 2.5 \\
\hline CANADA & 1.8398 & 0.6256 & 0.5121 & 2.5 \\
\hline WEUR & 1.8398 & 0.6256 & 0.5121 & 2.5 \\
\hline JAPAN & 1.8398 & 0.6256 & 0.5121 & 2.5 \\
\hline AUS\&NZ & 1.8398 & 0.6256 & 0.5121 & 2.5 \\
\hline FSU & 1.8398 & 0.6256 & 0.5121 & 2.5 \\
\hline ACENP & 1.8398 & 0.6256 & 0.5121 & 2.5 \\
\hline MIDEAST & 1.8398 & 0.6256 & 0.5121 & 2.5 \\
\hline AFR & 1.8398 & 0.6256 & 0.5121 & 2.5 \\
\hline LA & 1.8398 & 0.6256 & 0.5121 & 2.5 \\
\hline $\begin{array}{l}\text { S\&E } \\
\text { ASIA }\end{array}$ & 1.8398 & 0.6256 & 0.5121 & 2.5 \\
\hline EEUR & 1.8398 & 0.6256 & 0.5121 & 2.5 \\
\hline KOR & 1.8398 & 0.6256 & 0.5121 & 2.5 \\
\hline INDIA & 1.8398 & 0.6256 & 0.5121 & 2.5 \\
\hline
\end{tabular}

Table 20 Transportation costs for traded fuels

\begin{tabular}{|c|c|c|c|}
\hline \multicolumn{4}{|c|}{$\begin{array}{l}\text { TRI--TRANSPORTATION COSTS FOR TRADED FUELS (UNITS=1975 DOLLARS PER GJ } \\
\text { (GIGAJOULE)): Costs for coal \& gas taken from analysis of US cost figures; see Equation } 24\end{array}$} \\
\hline \multicolumn{4}{|c|}{ TRI(I) } \\
\hline OIL & GAS & COAL & BIOMASS \\
\hline 0.1397 & 0.4 & 0.25 & 0.681 \\
\hline
\end{tabular}

Table 21 Trade barrier scale factors such that fuel prices can be region specific

TXILM(I,L,M); Pxi $\mathrm{i}_{\mathrm{i}, \mathrm{l}, \mathrm{m}}$ a regional fee towards oil, gas, coal, and biomass prices; see Equation 24 


\begin{tabular}{|c|c|c|c|c|c|c|c|}
\hline REGION & 1975 & 1990 & 2005 & 2020 & 2035 & 2050 & \\
\hline USA & 1 & 1 & 1 & 1 & 1 & 1 & $\begin{array}{l}\text { OIL } \\
\end{array}$ \\
\hline CANADA & 1 & 1 & 1 & 1 & 1 & 1 & OIL \\
\hline WEUR & 1.8 & 1.5 & 1.3 & 1.1 & 1 & 1 & OIL \\
\hline JAPAN & 1 & 1 & 1 & 1 & 1 & 1 & OIL \\
\hline AUS\&NZ & 1 & 1 & 1 & 1 & 1 & 1 & OIL \\
\hline$\overline{F S U}$ & 1 & 1 & 1 & 1 & 1 & 1 & OIL \\
\hline ACENP & 1 & 1 & 1 & 1 & 1 & 1 & OIL \\
\hline MIDEAST & 1 & 1 & 1 & 1 & 1 & 1 & OIL \\
\hline AFR & 1 & 1 & 1 & 1 & 1 & 1 & OIL \\
\hline LA & 1 & 1 & 1 & 1 & 1 & 1 & OIL \\
\hline S\&E ASIA & 1 & 1 & 1 & 1 & 1 & 1 & OIL \\
\hline EEUR & 1 & 1 & 1 & 1 & 1 & 1 & OIL \\
\hline KOR & 1 & 1 & 1 & 1 & 1 & 1 & OIL \\
\hline INDIA & 1 & 1 & 1 & 1 & 1 & 1 & OIL \\
\hline USA & 1 & 1 & 1 & 1 & 1 & 1 & GAS \\
\hline CANADA & 1 & 1 & 1 & 1 & 1 & 1 & GAS \\
\hline WEUR & 1.8 & 1.5 & 1.3 & 1.1 & 1 & 1 & GAS \\
\hline JAPAN & 1 & 1 & 1 & 1 & 1 & 1 & GAS \\
\hline AUS\&NZ & 1 & 1 & 1 & 1 & 1 & 1 & GAS \\
\hline FSU & 1 & 1 & 1 & 1 & 1 & 1 & GAS \\
\hline ACENP & 1 & 1 & 1 & 1 & 1 & 1 & GAS \\
\hline MIDEAST & 1 & 1 & 1 & 1 & 1 & 1 & GAS \\
\hline AFR & 1 & 1 & 1 & 1 & 1 & 1 & GAS \\
\hline LA & 1 & 1 & 1 & 1 & 1 & 1 & GAS \\
\hline S\&E ASIA & 1 & 1 & 1 & 1 & 1 & 1 & GAS \\
\hline EEUR & 1 & 1 & 1 & 1 & 1 & 1 & GAS \\
\hline KOR & 1 & 1 & 1 & 1 & 1 & 1 & GAS \\
\hline INDIA & 1 & 1 & 1 & 1 & 1 & 1 & GAS \\
\hline USA & 1 & 1 & 1 & 1 & 1 & 1 & COAL \\
\hline CANADA & 1 & 1 & 1 & 1 & 1 & 1 & COAL \\
\hline WEUR & 1.8 & 1.5 & 1.3 & 1.1 & 1 & 1 & COAL \\
\hline JAPAN & 1 & 1 & 1 & 1 & 1 & 1 & COAL \\
\hline AUS\&NZ & 0.75 & 0.75 & 0.75 & 0.75 & 0.75 & 0.75 & COAL \\
\hline FSU & 1 & 1 & 1 & 1 & 1 & 1 & COAL \\
\hline ACENP & 0.75 & 0.75 & 0.75 & 0.75 & 0.75 & 0.75 & COAL \\
\hline MIDEAST & 1 & 1 & 1 & 1 & 1 & 1 & COAL \\
\hline AFR & 1 & 1 & 1 & 1 & 1 & 1 & COAL \\
\hline LA & 1 & 1 & 1 & 1 & 1 & 1 & COAL \\
\hline S\&E ASIA & 1 & 1 & 1 & 1 & 1 & 1 & COAL \\
\hline EEUR & 1 & 1 & 1 & 1 & 1 & 1 & COAL \\
\hline KOR & 1 & 1 & 1 & 1 & 1 & 1 & COAL \\
\hline INDIA & 1 & 1 & 1 & 1 & 1 & 1 & COAL \\
\hline USA & 1 & 1 & 1 & 1 & 1 & 1 & BIOMASS \\
\hline CANADA & 1 & 1 & 1 & 1 & 1 & 1 & BIOMASS \\
\hline WEUR & 1 & 1 & 1 & 1 & 1 & 1 & BIOMASS \\
\hline
\end{tabular}




\begin{tabular}{|l|l|l|l|l|l|l|l|}
\hline JAPAN & 1 & 1 & 1 & 1 & 1 & 1 & BIOMASS \\
\hline AUS\&NZ & 1 & 1 & 1 & 1 & 1 & 1 & BIOMASS \\
\hline FSU & 1 & 1 & 1 & 1 & 1 & 1 & BIOMASS \\
\hline ACENP & 1 & 1 & 1 & 1 & 1 & 1 & BIOMASS \\
\hline MIDEAST & 1 & 1 & 1 & 1 & 1 & 1 & BIOMASS \\
\hline AFR & 1 & 1 & 1 & 1 & 1 & 1 & BIOMASS \\
\hline LA & 1 & 1 & 1 & 1 & 1 & 1 & BIOMASS \\
\hline S\&E ASIA & 1 & 1 & 1 & 1 & 1 & 1 & BIOMASS \\
\hline EEUR & 1 & 1 & 1 & 1 & 1 & 1 & BIOMASS \\
\hline KOR & 1 & 1 & 1 & 1 & 1 & 1 & BIOMASS \\
\hline INDIA & 1 & 1 & 1 & 1 & 1 & 1 & BIOMASS \\
\hline
\end{tabular}

\section{Parameters to calculate prices of secondary fuels}

Table 22 Energy conversion factors from primary energy to secondary energy and markup costs

\begin{tabular}{|l|l|l|l|l|}
\hline See Equation 25 & OIL & GAS & COAL & BIOMASS \\
\hline $\begin{array}{l}\text { GIJ(I); see also } \\
\text { Equation 75, 109, } \\
110\end{array}$ & 1 & 1 & 1 & 1 \\
\hline HIJ(I) & 1.425 & 0.3487 & 0.14 & 0.14 \\
\hline
\end{tabular}

\section{Synfuel production parameters}

Table 23 Synfuel parameters to calculate non-energy costs of synliquid production from natural gas

\begin{tabular}{|l|l|l|l|}
\hline \multicolumn{5}{|l|}{ SYNCRUDE from Natural Gas; see Equation 26 } \\
\hline REGION & HCILT1 & HCILT2 & HCILT3 \\
\hline US & 100 & 5 & 25 \\
\hline CAN & 100 & 5 & 25 \\
\hline WEUR & 100 & 5 & 25 \\
\hline JAPAN & 100 & 5 & 25 \\
\hline AUS\&NZ & 100 & 5 & 25 \\
\hline FSU & 100 & 5 & 25 \\
\hline ACENP & 100 & 5 & 25 \\
\hline MIDEAST & 100 & 5 & 25 \\
\hline AFR & 100 & 5 & 25 \\
\hline LA & 100 & 5 & 25 \\
\hline SEASIA & 100 & 5 & 25 \\
\hline EEUR & 100 & 5 & 25 \\
\hline KOR & 100 & 5 & 25 \\
\hline
\end{tabular}




\begin{tabular}{|l|l|l|l|}
\hline INDIA & 100 & 5 & 25 \\
\hline
\end{tabular}

Table 24 Synfuel parameters to calculate non-energy costs of synfuel production from coal in 75 $\$ / G J$

\begin{tabular}{|l|l|l|l|l|l|l|}
\hline & \multicolumn{5}{|l|}{ SYNCRUDE from Coal; see Equation 26 } & \multicolumn{4}{l|}{ SYNGAS from Coal; see Equation 26 } \\
\hline REGION & HCILT1 & HCILT2 & HCILT3 & HCILT1 & HCILT2 & HCILT3 \\
\hline US & 100 & 5 & 25 & 100 & 3.63 & 25 \\
\hline CAN & 100 & 5 & 25 & 100 & 3.63 & 25 \\
\hline WEUR & 100 & 5 & 25 & 100 & 3.63 & 25 \\
\hline JAPAN & 100 & 5 & 25 & 100 & 3.63 & 25 \\
\hline AUS\&NZ & 100 & 5 & 25 & 100 & 3.63 & 25 \\
\hline FSU & 100 & 5 & 25 & 100 & 3.63 & 25 \\
\hline ACENP & 100 & 5 & 50 & 100 & 3.63 & 50 \\
\hline MIDEAST & 100 & 5 & 100 & 100 & 3.63 & 100 \\
\hline AFR & 12.54 & 5 & 25 & 100 & 3.63 & 25 \\
\hline LA & 12.54 & 5 & 25 & 100 & 3.63 & 25 \\
\hline SEASIA & 100 & 5 & 50 & 100 & 3.63 & 50 \\
\hline EEUR & 100 & 50 & 25 & 100 & 3.63 & 25 \\
\hline KOR & 100 & 5 & 25 & 100 & 3.63 & 25 \\
\hline INDIA & 100 & 5 & 50 & 100 & 3.63 & 50 \\
\hline
\end{tabular}

Table 25 Synfuel parameters to calculate non-energy costs of synfuel production from biomass

\begin{tabular}{|l|l|l|l|l|l|l|}
\hline & \multicolumn{2}{|l|}{ SYNCRUDE from Biomass; see Equation 26 } & \multicolumn{4}{l|}{ SYNGAS from Biomass; see Equation 26 } \\
\hline REGION & HCILT1 & HCILT2 & HCILT3 & HCILT1 & HCILT2 & HCILT3 \\
\hline US & 100 & 5 & 25 & 100 & 3.63 & 25 \\
\hline CAN & 100 & 5 & 25 & 100 & 3.63 & 25 \\
\hline WEUR & 100 & 5 & 25 & 100 & 3.63 & 25 \\
\hline JAPAN & 100 & 5 & 25 & 100 & 3.63 & 25 \\
\hline AUS\&NZ & 100 & 5 & 25 & 100 & 3.63 & 25 \\
\hline FSU & 100 & 5 & 25 & 100 & 3.63 & 25 \\
\hline ACENP & 100 & 5 & 50 & 100 & 3.63 & 50 \\
\hline MIDEAST & 100 & 5 & 100 & 100 & 3.63 & 100 \\
\hline AFR & 12.54 & 5 & 25 & 100 & 3.63 & 25 \\
\hline LA & 12.54 & 5 & 25 & 100 & 3.63 & 25 \\
\hline SEASIA & 100 & 5 & 50 & 100 & 3.63 & 50 \\
\hline EEUR & 100 & 5 & 25 & 100 & 3.63 & 25 \\
\hline KOR & 100 & 5 & 25 & 100 & 3.63 & 25 \\
\hline INDIA & 100 & 5 & 50 & 100 & 3.63 & 50 \\
\hline
\end{tabular}

Table 26 Synfuel efficiency coefficients

GCI; see Equation 27 \& 78 \& 91 


\begin{tabular}{|l|l|l|l|l|}
\hline SYNFUEL & N.Gas & Coal & \multicolumn{2}{|l|}{ Biomass } \\
\hline 1 & 1.5 & 1.5 & 1.5 & SYNCRUDE GCI \\
\hline 2 & 1.5 & 1.5 & 1.5 & SYNGAS GCI \\
\hline
\end{tabular}

Table 27 Non-energy costs in synfuel and electricity generation (values are the same for each region)

\begin{tabular}{|l|l|l|l|l|l|l|l|l|l|}
\hline HUILM(I,L,M); see Equation $29,47,49,50 \& 52$ & \multicolumn{1}{l|}{$\mid$} \\
\hline FuelName & 1975 & 1990 & 2005 & 2020 & 2035 & 2050 & 2065 & 2080 & 2095 \\
\hline OIL & 2.8 & 2.7 & 2.7 & 2.7 & 2.7 & 2.7 & 2.7 & 2.7 & 2.7 \\
\hline GAS & 2 & 2 & 2 & 2 & 2 & 2 & 2 & 2 & 2 \\
\hline COAL & 3.9 & 3.9 & 3.9 & 3.9 & 3.9 & 3.9 & 3.9 & 3.9 & 3.9 \\
\hline NUCLEAR & 6.3 & 6.3 & 6.3 & 6.3 & 6.3 & 6.3 & 6.3 & 6.3 & 6.3 \\
\hline SOLAR & 201.7 & 92.4 & 53.3 & 30.8 & 17.7 & 10.2 & 8 & 7.7 & 7.5 \\
\hline HYDRO & 4.03 & 4.03 & 4.03 & 4.03 & 4.03 & 4.03 & 4.03 & 4.03 & 4.03 \\
\hline BIOMASS & 3.9 & 3.9 & 3.9 & 3.9 & 3.9 & 3.9 & 3.9 & 3.9 & 3.9 \\
\hline COAL W/ CO2 CAPT & 5.193 & 5.193 & 5.193 & 5.193 & 5.099 & 5.012 & 4.932 & 4.857 & 4.788 \\
\hline OIL W/ CO2 CAPT & 3.728 & 3.595 & 3.595 & 3.595 & 3.530 & 3.470 & 3.414 & 3.363 & 3.315 \\
\hline GAS W/ CO2 CAPT & 2.915 & 2.915 & 2.915 & 2.915 & 2.849 & 2.787 & 2.730 & 2.677 & 2.628 \\
\hline H2 FUEL CELL & 4.533 & 4.533 & 4.0797 & 4.0797 & 4.0797 & 4.0797 & 4.0797 & 4.0797 & 4.0797 \\
\hline FUSION & 100 & 100 & 100 & 100 & 100 & 18.2 & 8.8 & 8.4 & 8 \\
\hline WIND & 10 & 10 & 7 & 6.1 & 5.75 & 5.65 & 5.44 & 5.24 & 5.05 \\
\hline SWSTOR & 1000 & 500 & 350 & 200 & 150 & 100 & 75 & 50 & 25 \\
\hline SatSolar & 1000 & 100 & 79 & 63 & 50 & 40 & 32 & 32 & 32 \\
\hline
\end{tabular}

Table 28 Example of carbon coefficients: carbon release by source (in Teragrams C per ExaJoule)

\begin{tabular}{|l|l|l|l|l|l|l|}
\hline \multicolumn{2}{|l|}{ See Equation 28} \\
\hline $\begin{array}{l}\text { GAS } \\
\text { BURNUP }\end{array}$ & $\begin{array}{l}\text { COAL } \\
\text { BURNUP }\end{array}$ & $\begin{array}{l}\text { COAL } \\
\text { LIQUIFICAT } \\
\text { ION }\end{array}$ & $\begin{array}{l}\text { GASIFICATI } \\
\text { ON }\end{array}$ & $\begin{array}{l}\text { OIL } \\
\text { BURNUP }\end{array}$ & $\begin{array}{l}\text { SHALE OIL } \\
\text { PRODUCTIO } \\
\text { N }\end{array}$ & BIOMASS \\
\hline 14.2 & 27.3 & 18.9 & 26.9 & 18.9 & 27.9 & 0 \\
\hline
\end{tabular}

Table 29 Example of regional carbon disposal costs

\begin{tabular}{|c|c|c|c|c|c|c|c|}
\hline \multicolumn{8}{|c|}{$\begin{array}{l}\text { Carbon Disposal Costs; see Equation } 30 \\
\text { Example where carbon sequestration is turned off by setting disposal costs } \\
\text { to a high value }\end{array}$} \\
\hline \multicolumn{8}{|c|}{ CARBDISP(L,M) } \\
\hline REGION & 2005 & 2020 & 2035 & 2050 & 2065 & 2080 & 2095 \\
\hline US & 5000 & 5000 & 5000 & 5000 & 5000 & 5000 & 5000 \\
\hline CAN & 5000 & 5000 & 5000 & 5000 & 5000 & 5000 & 5000 \\
\hline WEUR & 5000 & 5000 & 5000 & 5000 & 5000 & 5000 & 5000 \\
\hline JAPAN & 5000 & 5000 & 5000 & 5000 & 5000 & 5000 & 5000 \\
\hline AUS\&NZ & 5000 & 5000 & 5000 & 5000 & 5000 & 5000 & 5000 \\
\hline FSU & 5000 & 5000 & 5000 & 5000 & 5000 & 5000 & 5000 \\
\hline
\end{tabular}




\begin{tabular}{|l|l|l|l|l|l|l|l|}
\hline ACENP & 5000 & 5000 & 5000 & 5000 & 5000 & 5000 & 5000 \\
\hline MIDEAST & 5000 & 5000 & 5000 & 5000 & 5000 & 5000 & 5000 \\
\hline AFRICA & 5000 & 5000 & 5000 & 5000 & 5000 & 5000 & 5000 \\
\hline L AMER & 5000 & 5000 & 5000 & 5000 & 5000 & 5000 & 5000 \\
\hline $\begin{array}{l}\text { S\&E } \\
\text { ASIA }\end{array}$ & 5000 & 5000 & 5000 & 5000 & 5000 & 5000 & 5000 \\
\hline EEUR & 5000 & 5000 & 5000 & 5000 & 5000 & 5000 & 5000 \\
\hline KOR & 5000 & 5000 & 5000 & 5000 & 5000 & 5000 & 5000 \\
\hline INDIA & 5000 & 5000 & 5000 & 5000 & 5000 & 5000 & 5000 \\
\hline
\end{tabular}

Table 30 Synfuel logit share exponent

\begin{tabular}{|l|l|l|l|l|}
\hline \multicolumn{4}{|l|}{ RCI; see Equation 35} \\
\hline SYNFUEL & N.Gas & Coal & \multicolumn{3}{|l|}{ Biomass } \\
\hline 1 & -6 & -6 & -8 & SYNCRUDE RCI \\
\hline 2 & -6 & -6 & -8 & SYNGAS RCI \\
\hline
\end{tabular}

Table 31 Conversion factors to calculate carbon fees towards final consumption

\begin{tabular}{|l|l|l|l|l|l|l|l|}
\hline Pfj $_{\mathrm{j}, \mathrm{k}, \mathrm{l}, \mathrm{m}}$; see Equation 36 \\
\hline REGION & 1975 & 1990 & 2005 & 2020 & 2035 & 2050 & \\
\hline ALL & 0 & 0 & 0.896 & 0.896 & 0.896 & 0.896 & OIL \\
\hline ALL & 0 & 0 & 0.617 & 0.617 & 0.617 & 0.617 & GAS \\
\hline ALL & 0 & 0 & 1.084 & 1.084 & 1.084 & 1.084 & COAL \\
\hline ALL & 0 & 0 & 0 & 0 & 0 & 0 & ELECTRIC \\
\hline
\end{tabular}

\section{Hydrogen production B2 Scenario}

Table 32 Total System Efficiency of Hydrogen Production GHILM

\begin{tabular}{|c|c|c|c|c|c|c|c|c|c|}
\hline \multicolumn{10}{|c|}{$\begin{array}{l}\text { GHILM: see Equation } 37,38 \& 41 \& 73 \& 110 \\
\text { (efficiency improves at } 0.5 \% / y r \text { after 2005) }\end{array}$} \\
\hline FUEL & 1975 & 1990 & 2005 & 2020 & 2035 & 2050 & 2065 & 2080 & 2095 \\
\hline OIL & 10 & 10 & 1.67 & 1.547 & 1.435 & 1.333 & 1.333 & 1.333 & 1.333 \\
\hline GAS & 10 & 10 & 1.43 & 1.326 & 1.25 & 1.25 & 1.25 & 1.25 & 1.25 \\
\hline COAL & 10 & 10 & 1.61 & 1.515 & 1.515 & 1.515 & 1.515 & 1.515 & 1.515 \\
\hline BIOMASS & 10 & 10 & 1.663 & 1.543 & 1.432 & 1.329 & 1.25 & 1.25 & 1.25 \\
\hline ELECTRO & 10 & 10 & 1.15 & 1.067 & 1.064 & 1.064 & 1.064 & 1.064 & 1.064 \\
\hline OIL CO2 Cap & 10 & 10 & 2 & 1.83 & 1.68 & 1.55 & 1.53 & 1.52 & 1.5 \\
\hline GAS CO2 Cap & 10 & 10 & 1.71 & 1.57 & 1.47 & 1.45 & 1.44 & 1.42 & 1.41 \\
\hline COAL CO2 Cap & 10 & 10 & 1.94 & 1.8 & 1.78 & 1.76 & 1.74 & 1.72 & 1.71 \\
\hline Penalty & 0.2 & 0.2 & 0.2 & 0.186 & 0.172 & 0.16 & 0.148 & 0.138 & 0.128 \\
\hline
\end{tabular}


Table 33 Non-energy costs in hydrogen generation (values are the same for each region)

\begin{tabular}{|c|c|c|c|c|c|c|c|c|c|}
\hline \multicolumn{10}{|c|}{\begin{tabular}{|l|l|l} 
"HHILM" is the non-energy cost in $1975 \$$ for hydrogen production; see Equation $37,38 \& 41$ & \\
\end{tabular}} \\
\hline & & HHILM & & 0.005 & (efficis & $y$ impr & $\mathrm{s}$ at 0.5 & yr after & \\
\hline FUEL & 1975 & 1990 & 2005 & 2020 & 2035 & 2050 & 2065 & 2080 & 2095 \\
\hline OIL & 10 & 10 & 6.7 & 6.217 & 5.769 & 5.353 & 4.967 & 4.609 & 4.277 \\
\hline GAS & 10 & 10 & 1.1 & 1.021 & 0.947 & 0.879 & 0.816 & 0.757 & 0.702 \\
\hline$\overline{C O A L}$ & 10 & 10 & 3.1 & 2.877 & 2.669 & 2.477 & 2.298 & 2.133 & 1.979 \\
\hline BIOMASS & 10 & 10 & 2.5 & 2.32 & 2.153 & 1.997 & 1.853 & 1.72 & 1.596 \\
\hline ELECTRO & 10 & 10 & 2.523 & 2.341 & 2.172 & 2.016 & 1.87 & 1.736 & 1.611 \\
\hline OIL CO2 Cap & 13 & 13 & 8.71 & 7.95 & 7.26 & 6.64 & 6.07 & 5.56 & 5.1 \\
\hline GAS CO2 Cap & 13 & 13 & 1.43 & 1.3 & 1.19 & 1.09 & 1 & 0.91 & 0.84 \\
\hline COAL CO2 Cap & 13 & 13 & 4.03 & 3.68 & 3.36 & 3.07 & 2.81 & 2.57 & 2.36 \\
\hline Penalty & 0.3 & 0.3 & 0.3 & 0.278 & 0.258 & 0.24 & 0.222 & 0.206 & 0.192 \\
\hline
\end{tabular}

Table 34 Examples of carbon fractions to be removed when synfuels are produced or in coalelectric plants

\begin{tabular}{|l|l|l|}
\hline \multicolumn{4}{|l|}{$\begin{array}{l}\text { Carbon removal fraction,by mode: REMFRAC(1,L); } \\
\text { see Equation } 38\end{array}$} \\
\hline Region & 1 for synfuel & 2 for coal electric \\
\hline US & 0.9 & 0.9 \\
\hline CAN & 0.9 & 0.9 \\
\hline WEUR & 0.9 & 0.9 \\
\hline JAPAN & 0.9 & 0.9 \\
\hline AUS\&NZ & 0.9 & 0.9 \\
\hline FSU & 0.9 & 0.9 \\
\hline ACENP & 0.9 & 0.9 \\
\hline MIDEAST & 0.9 & 0.9 \\
\hline AFRICA & 0.9 & 0.9 \\
\hline L AMER & 0.9 & 0.9 \\
\hline S\&E & 0.9 & 0.9 \\
ASIA & & 0.9 \\
\hline EEUR & 0.9 & 0.9 \\
\hline KOR & 0.9 & 0.9 \\
\hline INDIA & 0.9 & \\
\hline
\end{tabular}

Table 35 Hydrogen subsector share weights

\begin{tabular}{|c|c|c|c|c|c|c|c|c|c|c|}
\hline \multicolumn{11}{|c|}{$\begin{array}{l}\text { BSSHILM(I,ISS,L,M) } \\
\text { For ISS }=1,0=\text { off } 1=\text { on ; see Equation } 39\end{array}$} \\
\hline ISS & 1975 & 1990 & 2005 & 2020 & 2035 & 2050 & 2065 & 2080 & 2095 & FUEL \\
\hline 1 & 1 & 1 & 1 & 1 & 1 & 1 & 1 & 1 & 1 & OIL \\
\hline 2 & 1 & 1 & 1 & 1 & 1 & 1 & 1 & 1 & 1 & OIL Scrub \\
\hline 1 & 1 & 1 & 1 & 1 & 1 & 1 & 1 & 1 & 1 & GAS \\
\hline 2 & 1 & 1 & 1 & 1 & 1 & 1 & 1 & 1 & 1 & GAS Scrub \\
\hline
\end{tabular}




\begin{tabular}{|l|l|l|l|l|l|l|l|l|l|l|}
\hline 1 & 1 & 1 & 1 & 1 & 1 & 1 & 1 & 1 & 1 & COAL \\
\hline 2 & 1 & 1 & 1 & 1 & 1 & 1 & 1 & 1 & 1 & Coal Scrub \\
\hline
\end{tabular}

Table 36 Hydrogen and electricity generation logit exponent

\begin{tabular}{|c|c|c|c|}
\hline \multicolumn{4}{|c|}{$\begin{array}{l}\text { RUISS is the logit exponent for the electric subsector competition; } \\
\text { see Equation } 39 \text { and } 48\end{array}$} \\
\hline NO SCRUB & SCRUB & BIOMASS & \\
\hline-6 & -6 & & Oil \\
\hline-6 & -6 & & Gas \\
\hline-6 & -6 & -6 & Coal \\
\hline
\end{tabular}

Table 37 Hydrogen production share coefficients

\begin{tabular}{|l|l|l|l|l|l|l|l|l|l|l|l|}
\hline \multicolumn{2}{|l|}{ "BSHILM" iare scale or base weigh share coefficients for hydrogen production; see Equation 43} \\
\hline \multicolumn{2}{|l|}{} & \multicolumn{1}{l|}{ Give electrolysis equal weight } \\
\hline FUEL & 1975 & 1990 & 2005 & 2020 & 2035 & 2050 & 2065 & 2080 & 2095 \\
\hline OIL & 1 & 1 & 1 & 1 & 1 & 1 & 1 & 1 & 1 \\
\hline GAS & 1 & 1 & 1 & 1 & 1 & 1 & 1 & 1 & 1 \\
\hline COAL & 1 & 1 & 1 & 1 & 1 & 1 & 1 & 1 & 1 \\
\hline BIOMASS & 1 & 1 & 1 & 1 & 1 & 1 & 1 & 1 & 1 \\
\hline ELECTRO & 1 & 1 & 1 & 1 & 1 & 1 & 1 & 1 & 1 \\
\hline
\end{tabular}

Table 38 Logit share exponent for hydrogen production

\begin{tabular}{|l|l|}
\hline \multicolumn{2}{|l|}{ "RHI" is the SHARE EXPONENT FOR } \\
PRODUCING HYDROGEN; see Equation 43 \\
\hline FUELNum & RHI \\
\hline OIL & -3 \\
\hline GAS & -3 \\
\hline COAL & -3 \\
\hline BIOMASS & -3 \\
\hline ELECTRO & -3 \\
\hline
\end{tabular}

\section{Electricity generation B2 Scenario}

Table 39 Regional electricity generation efficiency coefficients for oil-, gas-, coal-, and biomassgenerated electricity

\begin{tabular}{|l|l|l|l|l|l|l|l|l|l|l|l|}
\hline \multicolumn{2}{|l}{ GUILM(I,L,M); see Equation 44, 45, 46, 49, 50, 52 \& 74 \& 109} & Max \\
\hline REG\# & 1975 & 1990 & 2005 & 2020 & 2035 & 2050 & 2065 & 2080 & 2095 & & Efficiency \\
\hline USA & 3.277 & 3.1051 & 2.8788 & 2.6526 & 2.4263 & 2.2 & 2 & 1.91 & 1.82 & OIL & $55 \%$ \\
\hline Canada & 3.569 & 2.8964 & 2.7223 & 2.5482 & 2.3741 & 2.2 & 2 & 1.91 & 1.82 & OIL & $55 \%$ \\
\hline
\end{tabular}




\begin{tabular}{|c|c|c|c|c|c|c|c|c|c|c|c|}
\hline WEUR & 2.987 & 3.0214 & 2.8161 & 2.6107 & 2.4054 & 2.2 & 2 & 1.91 & 1.82 & OIL & $55 \%$ \\
\hline Japan & 2.738 & 2.4672 & 2.4004 & 2.3336 & 2.2668 & 2.2 & 2 & 1.91 & 1.82 & OIL & $55 \%$ \\
\hline Aus\&NZ & 3.034 & 2.8553 & 2.6915 & 2.5277 & 2.3638 & 2.2 & 2 & 1.91 & 1.82 & OIL & $55 \%$ \\
\hline FSU & 3.604 & 2.7867 & 2.64 & 2.4934 & 2.3467 & 2.2 & 2 & 1.91 & 1.82 & OIL & $55 \%$ \\
\hline ACENP & 4.394 & 4.1417 & 3.6563 & 3.1709 & 2.6854 & 2.2 & 2 & 1.91 & 1.82 & OIL & $55 \%$ \\
\hline MidEast & 3.504 & 3.5531 & 3.2148 & 2.8766 & 2.5383 & 2.2 & 2 & 1.91 & 1.82 & OIL & $55 \%$ \\
\hline Africa & 3.873 & 2.761 & 2.6958 & 2.6305 & 2.5653 & 2.5 & 2.2045 & 1.9 & 1.82 & OIL & $55 \%$ \\
\hline LatAmer & 4.143 & 3.8734 & 3.4551 & 3.0367 & 2.6184 & 2.2 & 2 & 1.91 & 1.82 & OIL & $55 \%$ \\
\hline SEAsia & 3.505 & 3.6277 & 3.3458 & 3.0639 & 2.7819 & 2.5 & 2.2045 & 1.9 & 1.82 & OIL & $55 \%$ \\
\hline EEUR & 3.207 & 3.2816 & 3.0253 & 2.769 & 2.5126 & 2.2 & 2 & 1.91 & 1.82 & OIL & $55 \%$ \\
\hline Korea & 3.564 & 3.0398 & 2.83184 & 2.62388 & 2.41592 & 2.2 & 2 & 1.91 & 1.82 & OIL & $55 \%$ \\
\hline India & 4.807 & 3.2212 & 3.0409 & 2.8606 & 2.6803 & 2.5 & 2.2045 & 1.9 & 1.82 & OIL & $55 \%$ \\
\hline & & & & & & & & & & & \\
\hline & & \multicolumn{2}{|c|}{ GUILM(I,L,M) } & & & & & & & & Max \\
\hline$\overline{\text { REG\# }}$ & 1975 & 1990 & 2005 & 2020 & 2035 & 2050 & 2065 & 2080 & 2095 & & Efficiency \\
\hline USA & 3.143 & 3.2972 & 2.9229 & 2.5486 & 2.1743 & 1.9 & 1.8 & 1.73 & 1.67 & GAS & $60 \%$ \\
\hline Canada & 3.608 & 2.2936 & 2.1702 & 2.0468 & 1.9234 & 1.9 & 1.8 & 1.73 & 1.67 & GAS & $60 \%$ \\
\hline WEUR & 2.934 & 2.9988 & 2.6991 & 2.3994 & 2.0997 & 1.9 & 1.8 & 1.73 & 1.67 & GAS & $60 \%$ \\
\hline Japan & 2.852 & 2.5173 & 2.338 & 2.1587 & 1.9793 & 1.9 & 1.8 & 1.73 & 1.67 & GAS & $60 \%$ \\
\hline Aus\&NZ & 3.234 & 2.9331 & 2.6498 & 2.3666 & 2.0833 & 1.9 & 1.8 & 1.73 & 1.67 & GAS & $60 \%$ \\
\hline FSU & 3.283 & 3.9704 & 3.4528 & 2.9352 & 2.4176 & 1.9 & 1.8 & 1.73 & 1.67 & GAS & $60 \%$ \\
\hline ACENP & 3.03 & 2.7671 & 2.5503 & 2.3336 & 2.1168 & 1.9 & 1.8 & 1.73 & 1.67 & GAS & $60 \%$ \\
\hline MidEast & 5.055 & 3.2493 & 2.912 & 2.5747 & 2.2373 & 1.9 & 1.8 & 1.73 & 1.67 & GAS & $60 \%$ \\
\hline Africa & 3.837 & 4.1246 & 3.7685 & 3.4123 & 3.0562 & 2.7 & 2.2167 & 1.73 & 1.67 & $\overline{\text { GAS }}$ & $60 \%$ \\
\hline LatAmer & 5.181 & 4.307 & 3.7053 & 3.1035 & 2.5018 & 1.9 & 1.8 & 1.73 & 1.67 & GAS & $60 \%$ \\
\hline SEAsia & 4.136 & 4.3048 & 3.8536 & 3.4024 & 2.9512 & 2.5 & 2.1167 & 1.73 & 1.67 & GAS & $60 \%$ \\
\hline EEUR & 3.571 & 3.7954 & 3.3963 & 2.9972 & 2.5982 & 1.9 & 1.8 & 1.73 & 1.67 & GAS & $60 \%$ \\
\hline Korea & 3.03 & 3.0874 & 2.82992 & 2.57244 & 2.31496 & 1.9 & 1.8 & 1.73 & 1.67 & GAS & $60 \%$ \\
\hline \multirow[t]{2}{*}{ India } & 4.136 & 5.2882 & 4.5912 & 3.8941 & 3.1971 & 2.5 & 2.1167 & 1.73 & 1.67 & GAS & $60 \%$ \\
\hline & & \multicolumn{2}{|c|}{ GUILM(I,L,M) } & & & & & & & & Max \\
\hline \begin{tabular}{|l|l} 
REG\# \\
\end{tabular} & 1975 & 1990 & 2005 & 2020 & 2035 & 2050 & 2065 & 2080 & 2095 & & Efficiency \\
\hline USA & 3.502 & 3.3131 & 2.9741 & 2.6351 & 2.296 & 2.2 & 2 & 1.9 & 1.82 & COAL & $55 \%$ \\
\hline Canada & 3.247 & 3.2359 & 2.9162 & 2.5965 & 2.2767 & 2.2 & 2 & 1.91 & 1.82 & COAL & $55 \%$ \\
\hline WEUR & 3.217 & 2.9877 & 2.73 & 2.4724 & 2.2147 & 2.2 & 2 & 1.91 & 1.82 & COAL & $55 \%$ \\
\hline Japan & 3.478 & 2.6414 & 2.4703 & 2.2992 & 2.1281 & 2.2 & 2 & 1.91 & 1.82 & COAL & $55 \%$ \\
\hline Aus\&NZ & 4.293 & 3.3252 & 2.9832 & 2.6411 & 2.2991 & 2.2 & 2 & 1.91 & 1.82 & COAL & $55 \%$ \\
\hline FSU & 3.654 & 3.5998 & 3.2499 & 2.8999 & 2.55 & 2.2 & 2 & 1.91 & 1.82 & COAL & $55 \%$ \\
\hline ACENP & 4.317 & 3.8966 & 3.4725 & 3.0483 & 2.6242 & 2.2 & 2 & 1.91 & 1.82 & COAL & $55 \%$ \\
\hline MidEast & 3.03 & 3.288 & 3.016 & 2.744 & 2.472 & 2.2 & 2 & 1.91 & 1.82 & COAL & $55 \%$ \\
\hline Africa & 3.875 & 3.2894 & 3.0921 & 2.8947 & 2.6974 & 2.5 & 2.2045 & 1.91 & 1.82 & COAL & $55 \%$ \\
\hline LatAmer & 4.877 & 3.9332 & 3.4999 & 3.0666 & 2.6333 & 2.2 & 1.791 & 1.8 & 1.82 & COAL & $55 \%$ \\
\hline SEAsia & 4.903 & 2.8471 & 2.7603 & 2.6736 & 2.5868 & 2.5 & 2.1523 & 1.8 & 1.82 & COAL & $55 \%$ \\
\hline EEUR & 3.654 & 3.7921 & 3.4337 & 3.0753 & 2.7168 & 2.2 & 2 & 1.91 & 1.82 & COAL & $55 \%$ \\
\hline Korea & 4.903 & 3.0553 & 2.84424 & 2.63318 & 2.42212 & 2.2 & 2 & 1.91 & 1.82 & COAL & $55 \%$ \\
\hline India & 4.903 & 4.7243 & 4.1682 & 3.6122 & 3.0561 & 2.5 & 2.2045 & 1.91 & 1.82 & COAL & $55 \%$ \\
\hline
\end{tabular}




\begin{tabular}{|c|c|c|c|c|c|c|c|c|c|c|c|}
\hline & & & & & & & & & & & \\
\hline & & \multicolumn{2}{|c|}{ GUILM(I,L,M) } & & & & & & & & Max \\
\hline REG\# & 1975 & 1990 & 2005 & 2020 & 2035 & 2050 & 2065 & 2080 & 2095 & & Efficiency \\
\hline$\overline{\text { USA }}$ & 3.325 & 3.325 & 2.553 & 2.336 & 2.138 & 2.2 & 2 & 1.9 & 1.82 & BIOMASS & $55 \%$ \\
\hline Canada & 3.325 & 3.325 & 2.553 & 2.336 & 2.138 & 2.2 & 2 & 1.91 & 1.82 & BIOMASS & $55 \%$ \\
\hline WEUR & 3.325 & 3.325 & 2.553 & 2.336 & 2.138 & 2.2 & 2 & 1.91 & 1.82 & BIOMASS & $55 \%$ \\
\hline Japan & 3.325 & 3.325 & 2.553 & 2.336 & 2.138 & 2.2 & 2 & 1.91 & 1.82 & BIOMASS & $55 \%$ \\
\hline Aus\&NZ & 3.325 & 3.325 & 2.553 & 2.336 & 2.138 & 2.2 & 2 & 1.91 & 1.82 & BIOMASS & $55 \%$ \\
\hline$\overline{\mathrm{FSU}}$ & 3.325 & 3.325 & 3.0438 & 2.7625 & 2.4813 & 2.2 & 2 & 1.91 & 1.82 & BIOMASS & $55 \%$ \\
\hline ACENP & 3.325 & 3.325 & 3.0438 & 2.7625 & 2.4813 & 2.2 & 2 & 1.91 & 1.82 & BIOMASS & $55 \%$ \\
\hline MidEast & 3.325 & 3.325 & 3.0438 & 2.7625 & 2.4813 & 2.2 & 2 & 1.91 & 1.82 & BIOMASS & $55 \%$ \\
\hline Africa & 3.325 & 3.325 & 3.1188 & 2.9125 & 2.7063 & 2.5 & 2.2045 & 1.91 & 1.82 & BIOMASS & $55 \%$ \\
\hline LatAmer & 3.325 & 3.325 & 3.0438 & 2.7625 & 2.4813 & 2.2 & 1.791 & 1.8 & 1.82 & BIOMASS & $55 \%$ \\
\hline SEAsia & 3.325 & 3.325 & 3.1188 & 2.9125 & 2.7063 & 2.5 & 2.1523 & 1.8 & 1.82 & BIOMASS & $55 \%$ \\
\hline EEUR & 3.325 & 3.325 & 3.06 & 2.795 & 2.53 & 2.2 & 2 & 1.91 & 1.82 & BIOMASS & $55 \%$ \\
\hline Korea & 3.325 & 3.325 & 3.06 & 2.795 & 2.53 & 2.2 & 2 & 1.91 & 1.82 & BIOMASS & $55 \%$ \\
\hline India & 3.325 & 3.325 & 3.1188 & 2.9125 & 2.7063 & 2.5 & 2.2045 & 1.91 & 1.82 & BIOMASS & $55 \%$ \\
\hline
\end{tabular}

Table 40 Regional electricity price coefficients used to account for end-sector differences and distribution costs

\begin{tabular}{|l|l|l|l|l|}
\hline \multicolumn{5}{|l|}{ PAUIL(I,L); see Equation 44, 45 \& 46 } \\
\hline REGION & OIL & GAS & COAL & BIOMASS \\
\hline US & 1 & 0.8 & 0.5 & 0.8 \\
\hline CANADA & 1 & 0.8 & 0.5 & 0.8 \\
\hline WEUR & 1 & 0.8 & 0.5 & 0.8 \\
\hline JAPAN & 1 & 0.8 & 1.5 & 0.8 \\
\hline AUS\&NZ & 1 & 0.8 & 0.5 & 0.8 \\
\hline FSU & 1 & 0.8 & 0.5 & 0.8 \\
\hline ACENP & 1 & 0.8 & 0.5 & 0.8 \\
\hline MIDEAST & 1 & 0.8 & 0.8 & 0.8 \\
\hline AFRICA & 1 & 0.8 & 0.8 & 0.8 \\
\hline L AMER & 1 & 0.8 & 0.8 & 0.8 \\
\hline S\&E ASIA & 1 & 0.8 & 0.8 & 0.8 \\
\hline EEUR & 1 & 0.8 & 0.5 & 0.8 \\
\hline KOR & 1 & 0.8 & 0.8 & 0.8 \\
\hline INDIA & 1 & 0.8 & 0.8 & 0.8 \\
\hline
\end{tabular}

Table 41 Electricity generating subsector-specific base-share weights

\begin{tabular}{|l|l|l|l|l|l|l|l|l|l|}
\hline BSSUILM: & ELECTRIC SUBSECTOR SHARE WEIGHTS, BY PERIOD, FUEL; see Equation 48 \\
\hline ISS- Fuel & 1975 & 1990 & 2005 & 2020 & 2035 & 2050 & 2065 & 2080 & 2095 \\
\hline OIL & 1 & 1 & 1 & 1 & 1 & 1 & 1 & 1 & 1 \\
\hline $\begin{array}{l}\text { OIL } \\
\text { SCRUB }\end{array}$ & 0 & 0 & 1 & 1 & 1 & 1 & 1 & 1 & 1 \\
\hline
\end{tabular}




\begin{tabular}{|l|l|l|l|l|l|l|l|l|l|}
\hline GAS & 1 & 1 & 1 & 1 & 1 & 1 & 1 & 1 & 1 \\
\hline $\begin{array}{l}\text { GAS } \\
\text { SCRUB }\end{array}$ & 0 & 0 & 1 & 1 & 1 & 1 & 1 & 1 & 1 \\
\hline COAL & 1 & 1 & 1 & 1 & 1 & 1 & 1 & 1 & 1 \\
\hline $\begin{array}{l}\text { COAL } \\
\text { SCRUB }\end{array}$ & 0 & 0 & 1 & 1 & 1 & 1 & 1 & 1 & 1 \\
\hline BIOMASS & 0 & 0 & 0.25 & 0.33 & 0.66 & 1 & 1 & 1 & 1 \\
\hline
\end{tabular}

Table 42 Logit function scale parameters for electricity

NOTE: shares between 1990 and 2050 are automatically overwritten

Most techs have equal base shares in 2050

Extrapolate between 1990 and 2050

Coal is an exception -- deviates from price-derivied shares in many regions,

so extrapolation is extended to 2065 and is non-linear

\begin{tabular}{|c|c|c|c|c|c|c|c|c|c|c|}
\hline \multicolumn{11}{|c|}{ BSUILM; see Equation 54} \\
\hline & Fuel & 1975 & 1990 & 2005 & 2020 & 2035 & 2050 & 2065 & 2080 & 2095 \\
\hline USA & OIL & 0.0915 & 0.0244 & 0.0495 & 0.0747 & 0.0998 & 0.125 & 0.125 & 0.125 & 0.125 \\
\hline Canada & OIL & 0.168 & 0.0386 & 0.0602 & 0.0818 & 0.1034 & 0.125 & 0.125 & 0.125 & 0.125 \\
\hline WEUR & OIL & 0.168 & 0.073 & 0.086 & 0.099 & 0.112 & 0.125 & 0.125 & 0.125 & 0.125 \\
\hline Japan & OIL & 0.1937 & 0.1419 & 0.1377 & 0.1335 & 0.1292 & 0.125 & 0.125 & 0.125 & 0.125 \\
\hline Aus\&NZ & OIL & 0.1937 & 0.0276 & 0.052 & 0.0763 & 0.1007 & 0.125 & 0.125 & 0.125 & 0.125 \\
\hline FSU & OIL & 0.1157 & 0.0968 & 0.1039 & 0.1109 & 0.118 & 0.125 & 0.125 & 0.125 & 0.125 \\
\hline ACENP & OIL & 0.0547 & 0.104 & 0.1092 & 0.1145 & 0.1197 & 0.125 & 0.125 & 0.125 & 0.125 \\
\hline MidEast & OIL & 0.2 & 0.5405 & 0.4366 & 0.3327 & 0.2289 & 0.125 & 0.125 & 0.125 & 0.125 \\
\hline Africa & OIL & 0.1851 & 0.1345 & 0.1321 & 0.1297 & 0.1274 & 0.125 & 0.125 & 0.125 & 0.125 \\
\hline LatAmer & OIL & 0.2 & 0.4316 & 0.355 & 0.2783 & 0.2017 & 0.125 & 0.125 & 0.125 & 0.125 \\
\hline SEAsia & OIL & 0.1158 & 0.2918 & 0.2501 & 0.2084 & 0.1667 & 0.125 & 0.125 & 0.125 & 0.125 \\
\hline EEUR & OIL & 0.1157 & 0.0444 & 0.0645 & 0.0847 & 0.1048 & 0.125 & 0.125 & 0.125 & 0.125 \\
\hline Korea & OIL & 1 & 0.0731 & 0.086 & 0.099 & 0.112 & 0.125 & 0.125 & 0.125 & 0.125 \\
\hline India & OIL & 1 & 0.0287 & 0.0528 & 0.0769 & 0.1009 & 0.125 & 0.125 & 0.125 & 0.125 \\
\hline USA & GAS & 0.0274 & 0.0551 & 0.0726 & 0.0901 & 0.1075 & 0.125 & 0.125 & 0.125 & 0.125 \\
\hline Canada & GAS & 0.0694 & 0.0157 & 0.0431 & 0.0704 & 0.0977 & 0.125 & 0.125 & 0.125 & 0.125 \\
\hline WEUR & GAS & 0.0694 & 0.0604 & 0.0766 & 0.0927 & 0.1089 & 0.125 & 0.125 & 0.125 & 0.125 \\
\hline Japan & GAS & 0.2 & 0.0776 & 0.0895 & 0.1013 & 0.1132 & 0.125 & 0.125 & 0.125 & 0.125 \\
\hline Aus\&NZ & GAS & 0.2 & 0.1319 & 0.1302 & 0.1284 & 0.1267 & 0.125 & 0.125 & 0.125 & 0.125 \\
\hline FSU & GAS & 0.0565 & 0.3678 & 0.3071 & 0.2464 & 0.1857 & 0.125 & 0.125 & 0.125 & 0.125 \\
\hline ACENP & GAS & 0.0074 & 0.0045 & 0.0347 & 0.0648 & 0.0949 & 0.125 & 0.125 & 0.125 & 0.125 \\
\hline MidEast & GAS & 0.0408 & 0.395 & 0.3275 & 0.26 & 0.1925 & 0.125 & 0.125 & 0.125 & 0.125 \\
\hline Africa & GAS & 0.0128 & 0.1341 & 0.1318 & 0.1295 & 0.1273 & 0.125 & 0.125 & 0.125 & 0.125 \\
\hline LatAmer & GAS & 0.0453 & 0.2674 & 0.2318 & 0.1962 & 0.1606 & 0.125 & 0.125 & 0.125 & 0.125 \\
\hline SEAsia & GAS & 0.0007 & 0.1764 & 0.1636 & 0.1507 & 0.1379 & 0.125 & 0.125 & 0.125 & 0.125 \\
\hline EEUR & GAS & 0.0565 & 0.0728 & 0.0859 & 0.0989 & 0.112 & 0.125 & 0.125 & 0.125 & 0.125 \\
\hline Korea & GAS & 0.5005 & 0.0343 & 0.057 & 0.0796 & 0.1023 & 0.125 & 0.125 & 0.125 & 0.125 \\
\hline India & GAS & 1 & 0.0514 & 0.0698 & 0.0882 & 0.1066 & 0.125 & 0.125 & 0.125 & 0.125 \\
\hline USA & COAL & 0.2 & 0.3967 & 0.336 & 0.2753 & 0.2147 & 0.154 & 0.125 & 0.125 & 0.125 \\
\hline Canada & COAL & 0.2 & 0.2522 & 0.2219 & 0.1916 & 0.1613 & 0.131 & 0.125 & 0.125 & 0.125 \\
\hline
\end{tabular}




\begin{tabular}{|c|c|c|c|c|c|c|c|c|c|c|}
\hline WEUR & COAL & 0.2 & 0.249 & 0.2215 & 0.194 & 0.1665 & 0.139 & 0.125 & 0.125 & 0.125 \\
\hline Japan & COAL & 0.0458 & 0.2359 & 0.2117 & 0.1875 & 0.1632 & 0.139 & 0.125 & 0.125 & 0.125 \\
\hline Aus\&NZ & COAL & 0.0458 & 0.8405 & 0.6744 & 0.5082 & 0.3421 & 0.176 & 0.125 & 0.125 & 0.125 \\
\hline FSU & COAL & 0.2 & 0.2259 & 0.2036 & 0.1814 & 0.1592 & 0.137 & 0.125 & 0.125 & 0.125 \\
\hline ACENP & COAL & 0.2 & 0.8915 & 0.7128 & 0.5342 & 0.3556 & 0.177 & 0.125 & 0.125 & 0.125 \\
\hline MidEast & COAL & 0 & 0.0645 & 0.0753 & 0.0862 & 0.0971 & 0.108 & 0.125 & 0.125 & 0.125 \\
\hline Africa & COAL & 0.2 & 0.6662 & 0.5422 & 0.4181 & 0.2941 & 0.17 & 0.125 & 0.125 & 0.125 \\
\hline LatAmer & COAL & 0.0319 & 0.1285 & 0.1246 & 0.1207 & 0.1169 & 0.113 & 0.125 & 0.125 & 0.125 \\
\hline SEAsia & $\mathrm{COAL}$ & 0.2 & 0.2723 & 0.2395 & 0.2067 & 0.1738 & 0.141 & 0.125 & 0.125 & 0.125 \\
\hline EEUR & COAL & 0.2 & 0.4743 & 0.3958 & 0.3172 & 0.2386 & 0.16 & 0.125 & 0.125 & 0.125 \\
\hline Korea & COAL & 4.0012 & 0.1156 & 0.1172 & 0.1188 & 0.1204 & 0.122 & 0.125 & 0.125 & 0.125 \\
\hline India & COAL & 4.0012 & 0.8722 & 0.6981 & 0.5241 & 0.35 & 0.176 & 0.125 & 0.125 & 0.125 \\
\hline USA & NUCLEAR & 0.0346 & 0.5238 & 0.4241 & 0.3244 & 0.2247 & 0.125 & 0.125 & 0.125 & 0.125 \\
\hline Canada & NUCLEAR & 0.0192 & 0.6935 & 0.5514 & 0.4092 & 0.2671 & 0.125 & 0.125 & 0.125 & 0.125 \\
\hline WEUR & NUCLEAR & 0.0192 & 0.6176 & 0.4944 & 0.3713 & 0.2481 & 0.125 & 0.125 & 0.125 & 0.125 \\
\hline Japan & NUCLEAR & 0.0082 & 0.5446 & 0.4397 & 0.3348 & 0.2299 & 0.125 & 0.125 & 0.125 & 0.125 \\
\hline Aus\&NZ & NUCLEAR & 0.0082 & 0 & 0.0313 & 0.0625 & 0.0938 & 0.125 & 0.125 & 0.125 & 0.125 \\
\hline$\overline{\mathrm{FSU}}$ & NUCLEAR & 0.006 & 0.3095 & 0.2634 & 0.2172 & 0.1711 & 0.125 & 0.125 & 0.125 & 0.125 \\
\hline ACENP & NUCLEAR & 0 & 0 & 0.0313 & 0.0625 & 0.0938 & 0.125 & 0.125 & 0.125 & 0.125 \\
\hline MidEast & NUCLEAR & 0.0001 & 0 & 0.0313 & 0.0625 & 0.0938 & 0.125 & 0.125 & 0.125 & 0.125 \\
\hline Africa & NUCLEAR & 0 & 0.0652 & 0.0802 & 0.0951 & 0.1101 & 0.125 & 0.125 & 0.125 & 0.125 \\
\hline LatAmer & NUCLEAR & 0.008 & 0.1726 & 0.1607 & 0.1488 & 0.1369 & 0.125 & 0.125 & 0.125 & 0.125 \\
\hline SEAsia & NUCLEAR & 0.0039 & 0.2594 & 0.2258 & 0.1922 & 0.1586 & 0.125 & 0.125 & 0.125 & 0.125 \\
\hline EEUR & NUCLEAR & 0.006 & 0.4085 & 0.3376 & 0.2668 & 0.1959 & 0.125 & 0.125 & 0.125 & 0.125 \\
\hline Korea & NUCLEAR & 31.335 & 0.777 & 0.614 & 0.451 & 0.288 & 0.125 & 0.125 & 0.125 & 0.125 \\
\hline India & NUCLEAR & 31.335 & 0.0477 & 0.067 & 0.0863 & 0.1057 & 0.125 & 0.125 & 0.125 & 0.125 \\
\hline USA & SOLAR PV & 0.0253 & 0 & 0.0313 & 0.0625 & 0.0938 & 0.125 & 0.125 & 0.125 & 0.125 \\
\hline Canada & SOLAR PV & 0.0172 & 0 & 0.0313 & 0.0625 & 0.0938 & 0.125 & 0.125 & 0.125 & 0.125 \\
\hline WEUR & SOLAR PV & 0.0172 & 0 & 0.0313 & 0.0625 & 0.0938 & 0.125 & 0.125 & 0.125 & 0.125 \\
\hline Japan & SOLAR PV & 0.0056 & 0 & 0.0313 & 0.0625 & 0.0938 & 0.125 & 0.125 & 0.125 & 0.125 \\
\hline Aus\&NZ & SOLAR PV & 0.0056 & 0 & 0.0313 & 0.0625 & 0.0938 & 0.125 & 0.125 & 0.125 & 0.125 \\
\hline$\overline{\mathrm{FSU}}$ & SOLAR PV & 0.006 & 0 & 0.0313 & 0.0625 & 0.0938 & 0.125 & 0.125 & 0.125 & 0.125 \\
\hline ACENP & SOLAR PV & 0.0011 & 0 & 0.0313 & 0.0625 & 0.0938 & 0.125 & 0.125 & 0.125 & 0.125 \\
\hline MidEast & SOLAR PV & 0 & 0 & 0.0313 & 0.0625 & 0.0938 & 0.125 & 0.125 & 0.125 & 0.125 \\
\hline Africa & SOLAR PV & 0.0009 & 0 & 0.0313 & 0.0625 & 0.0938 & 0.125 & 0.125 & 0.125 & 0.125 \\
\hline LatAmer & SOLAR PV & 0.0061 & 0 & 0.0313 & 0.0625 & 0.0938 & 0.125 & 0.125 & 0.125 & 0.125 \\
\hline SEAsia & SOLAR PV & 0.0036 & 0 & 0.0313 & 0.0625 & 0.0938 & 0.125 & 0.125 & 0.125 & 0.125 \\
\hline EEUR & SOLAR PV & 0.006 & 0 & 0.0313 & 0.0625 & 0.0938 & 0.125 & 0.125 & 0.125 & 0.125 \\
\hline Korea & SOLAR PV & 0 & 0 & 0.0313 & 0.0625 & 0.0938 & 0.125 & 0.125 & 0.125 & 0.125 \\
\hline India & SOLAR PV & 0 & 0 & 0.0313 & 0.0625 & 0.0938 & 0.125 & 0.125 & 0.125 & 0.125 \\
\hline USA & HYDRO & 0.1 & 0.1073 & 0.2957 & 0.3641 & 0.3268 & 0.2995 & 0.2065 & 0.1488 & 0.0985 \\
\hline Canada & HYDRO & 0.63 & 0.6154 & 0.9 & 0.9 & 0.9 & 0.9 & 0.9 & 0.9 & 0.8447 \\
\hline WEUR & HYDRO & 0.21 & 0.1897 & 0.426 & 0.9693 & 0.9051 & 0.8939 & 0.5987 & 0.4658 & 0.356 \\
\hline Japan & HYDRO & 0.13 & 0.1074 & 0.2435 & 0.3256 & 0.5686 & 0.5984 & 0.4748 & 0.3429 & 0.2464 \\
\hline Aus\&NZ & HYDRO & 0.23 & 0.2129 & 0.5841 & 0.5329 & 0.5373 & 0.557 & 0.4275 & 0.3957 & 0.2457 \\
\hline FSU & HYDRO & 0.14 & 0.1242 & 0.9 & 0.7756 & 0.326 & 0.1999 & 0.1947 & 0.158 & 0.0949 \\
\hline
\end{tabular}




\begin{tabular}{|c|c|c|c|c|c|c|c|c|c|c|}
\hline ACENP & HYDRO & 0.22 & 0.2362 & 0.2675 & 0.8649 & 0.2568 & 0.125 & 0.0817 & 0.0759 & 0.0411 \\
\hline MidEast & HYDRO & 0.06 & 0.0624 & 0.2764 & 0.2078 & 0.1376 & 0.1106 & 0.0727 & 0.0718 & 0.0543 \\
\hline Africa & HYDRO & 0.17 & 0.1398 & 0.554 & 0.4931 & 0.3633 & 0.3232 & 0.2028 & 0.1024 & 0.058 \\
\hline LatAmer & HYDRO & 0.63 & 0.6701 & 0.9 & 0.9 & 0.9 & 0.9 & 0.7741 & 0.5338 & 0.4229 \\
\hline SEAsia & HYDRO & 0.19 & 0.205 & 0.864 & 0.3952 & 0.3294 & 0.2019 & 0.1549 & 0.0626 & 0.038 \\
\hline EEUR & HYDRO & 0.16 & 0.119 & 0.3877 & 0.5733 & 0.3956 & 0.1711 & 0.2246 & 0.1934 & 0.1297 \\
\hline Korea & HYDRO & 0.08 & 0.0591 & 0.0285 & 0.0336 & 0.0519 & 0.0247 & 0.0184 & 0.0193 & 0.0144 \\
\hline India & HYDRO & 0.19 & 0.2523 & 0.5818 & 0.303 & 0.225 & 0.1123 & 0.0635 & 0.041 & 0.0242 \\
\hline USA & H2 FUEL CELL & 0 & 0 & 0.0313 & 0.0625 & 0.0938 & 0.125 & 0.125 & 0.125 & 0.125 \\
\hline Canada & H2 FUEL CELL & 0 & 0 & 0.0313 & 0.0625 & 0.0938 & 0.125 & 0.125 & 0.125 & 0.125 \\
\hline WEUR & H2 FUEL CELL & 0 & 0 & 0.0313 & 0.0625 & 0.0938 & 0.125 & 0.125 & 0.125 & 0.125 \\
\hline Japan & H2 FUEL CELL & 0 & 0 & 0.0313 & 0.0625 & 0.0938 & 0.125 & 0.125 & 0.125 & 0.125 \\
\hline Aus\&NZ & H2 FUEL CELL & 0 & 0 & 0.0313 & 0.0625 & 0.0938 & 0.125 & 0.125 & 0.125 & 0.125 \\
\hline FSU & H2 FUEL CELL & 0 & 0 & 0.0313 & 0.0625 & 0.0938 & 0.125 & 0.125 & 0.125 & 0.125 \\
\hline$\overline{\text { ACENP }}$ & H2 FUEL CELL & 0 & 0 & 0.0313 & 0.0625 & 0.0938 & 0.125 & 0.125 & 0.125 & 0.125 \\
\hline MidEast & H2 FUEL CELL & 0 & 0 & 0.0313 & 0.0625 & 0.0938 & 0.125 & 0.125 & 0.125 & 0.125 \\
\hline Africa & H2 FUEL CELL & 0 & 0 & 0.0313 & 0.0625 & 0.0938 & 0.125 & 0.125 & 0.125 & 0.125 \\
\hline LatAmer & H2 FUEL CELL & 0 & 0 & 0.0313 & 0.0625 & 0.0938 & 0.125 & 0.125 & 0.125 & 0.125 \\
\hline SEAsia & H2 FUEL CELL & 0 & 0 & 0.0313 & 0.0625 & 0.0938 & 0.125 & 0.125 & 0.125 & 0.125 \\
\hline EEUR & H2 FUEL CELL & 0 & 0 & 0.0313 & 0.0625 & 0.0938 & 0.125 & 0.125 & 0.125 & 0.125 \\
\hline Korea & H2 FUEL CELL & 0 & 0 & 0.0313 & 0.0625 & 0.0938 & 0.125 & 0.125 & 0.125 & 0.125 \\
\hline India & H2 FUEL CELL & 0 & 0 & 0.0313 & 0.0625 & 0.0938 & 0.125 & 0.125 & 0.125 & 0.125 \\
\hline USA & FUSION & 0 & 0 & 0 & 0 & 0 & 0 & 0 & 0 & 0 \\
\hline Canada & FUSION & 0 & 0 & 0 & 0 & 0 & 0 & 0 & 0 & 0 \\
\hline WEUR & FUSION & 0 & 0 & 0 & 0 & 0 & 0 & 0 & 0 & 0 \\
\hline Japan & FUSION & 0 & 0 & 0 & 0 & 0 & 0 & 0 & 0 & 0 \\
\hline Aus\&NZ & FUSION & 0 & 0 & 0 & 0 & 0 & 0 & 0 & 0 & 0 \\
\hline FSU & FUSION & 0 & 0 & 0 & 0 & 0 & 0 & 0 & 0 & 0 \\
\hline ACENP & FUSION & 0 & 0 & 0 & 0 & 0 & 0 & 0 & 0 & 0 \\
\hline MidEast & FUSION & 0 & 0 & 0 & 0 & 0 & 0 & 0 & 0 & 0 \\
\hline Africa & FUSION & 0 & 0 & 0 & 0 & 0 & 0 & 0 & 0 & 0 \\
\hline LatAmer & FUSION & 0 & 0 & 0 & 0 & 0 & 0 & 0 & 0 & 0 \\
\hline SEAsia & FUSION & 0 & 0 & 0 & 0 & 0 & 0 & 0 & 0 & 0 \\
\hline EEUR & FUSION & 0 & 0 & 0 & 0 & 0 & 0 & 0 & 0 & 0 \\
\hline Korea & FUSION & 0 & 0 & 0 & 0 & 0 & 0 & 0 & 0 & 0 \\
\hline India & FUSION & 0 & 0 & 0 & 0 & 0 & 0 & 0 & 0 & 0 \\
\hline USA & WIND & 0.001 & 0 & 0.0313 & 0.0625 & 0.0938 & 0.125 & 0.125 & 0.125 & 0.125 \\
\hline Canada & WIND & 0.001 & 0 & 0.0313 & 0.0625 & 0.0938 & 0.125 & 0.125 & 0.125 & 0.125 \\
\hline WEUR & WIND & 0.001 & 0 & 0.0313 & 0.0625 & 0.0938 & 0.125 & 0.125 & 0.125 & 0.125 \\
\hline Japan & WIND & 0.001 & 0 & 0.0313 & 0.0625 & 0.0938 & 0.125 & 0.125 & 0.125 & 0.125 \\
\hline Aus\&NZ & WIND & 0.001 & 0 & 0.0313 & 0.0625 & 0.0938 & 0.125 & 0.125 & 0.125 & 0.125 \\
\hline FSU & WIND & 0.001 & 0 & 0.0313 & 0.0625 & 0.0938 & 0.125 & 0.125 & 0.125 & 0.125 \\
\hline ACENP & WIND & 0.001 & 0 & 0.0313 & 0.0625 & 0.0938 & 0.125 & 0.125 & 0.125 & 0.125 \\
\hline MidEast & WIND & 0.001 & 0 & 0.0313 & 0.0625 & 0.0938 & 0.125 & 0.125 & 0.125 & 0.125 \\
\hline Africa & WIND & 0.001 & 0 & 0.0313 & 0.0625 & 0.0938 & 0.125 & 0.125 & 0.125 & 0.125 \\
\hline LatAmer & WIND & 0.001 & 0 & 0.0313 & 0.0625 & 0.0938 & 0.125 & 0.125 & 0.125 & 0.125 \\
\hline
\end{tabular}




\begin{tabular}{|l|l|l|l|l|l|l|l|l|l|l|}
\hline SEAsia & WIND & 0.001 & 0 & 0.0313 & 0.0625 & 0.0938 & 0.125 & 0.125 & 0.125 & 0.125 \\
\hline EEUR & WIND & 0.001 & 0 & 0.0313 & 0.0625 & 0.0938 & 0.125 & 0.125 & 0.125 & 0.125 \\
\hline Korea & WIND & 0.001 & 0 & 0.0313 & 0.0625 & 0.0938 & 0.125 & 0.125 & 0.125 & 0.125 \\
\hline India & WIND & 0.001 & 0 & 0.0313 & 0.0625 & 0.0938 & 0.125 & 0.125 & 0.125 & 0.125 \\
\hline
\end{tabular}

\section{Fuel sharing and energy services}

Table 43 Energy services input-output coefficients GJK

\begin{tabular}{|l|l|l|l|l|l|l|}
\hline \multicolumn{6}{|l|}{ ENERGY SERVICE INPUT-OUTPUT COEFFICIENTS } \\
\hline GJK; see Equation 5 \\
\hline SECTOR & OIL & GAS & COAL & ELECTRIC & \multicolumn{3}{|l|}{ BIOMASS } \\
\hline 1 & 1.67 & 1.54 & 2.5 & 0.86 & 2.5 & RES/COM \\
\hline 2 & 1.92 & 1.9 & 2 & 1.05 & 2 & INDUSTRY \\
\hline 3 & 3 & 3 & 3.33 & 1.05 & 3.33 & TRANSPORT \\
\hline
\end{tabular}

Table 44 Energy services non-fuel costs HJK

\begin{tabular}{|l|l|l|l|l|l|l|}
\hline \multicolumn{6}{|l|}{ NON-ENERGY Costs BY SECTOR } \\
\hline HJK; see equation 55 \\
\hline SECTOR & OIL & GAS & COAL & ELECTRIC & BIOMASS \\
\hline 1 & 4.98 & 3.24 & 2.87 & 3.41 & 2.87 & RES/COM \\
\hline 2 & 0.41 & 0.32 & 0.8 & 1.16 & 0.8 & INDUSTRY \\
\hline 3 & 98.88 & 200 & 200 & 153.17 & 200 & TRANSPORT \\
\hline
\end{tabular}

Table 45 Hydrogen energy service fuel-related efficiency coefficient (Gjk: $\mathrm{j}=$ hydrogen)

\begin{tabular}{|l|l|l|l|l|l|l|l|l|l|l|}
\hline GJ Hydrogen per generic energy service \\
\hline GJK(JSH2,K,M); see Equation 55 \& 67 \\
\hline SECTOR & 1975 & 1990 & 2005 & 2020 & 2035 & 2050 & 2065 & 2080 & 2095 \\
\hline RES/COM & 5 & 5 & 3 & 1.483 & 1.246 & 1.075 & 1.075 & 1.075 & 1.075 \\
\hline INDUSTRY & 5 & 5 & 5 & 1.727 & 1.727 & 1.727 & 1.727 & 1.727 & 1.727 \\
\hline TRANSPORT & 5 & 5 & 2.22 & 1.2 & 1.2 & 1.2 & 1.2 & 1.2 & 1.2 \\
\hline & & & & & & & & & \\
\hline
\end{tabular}

Table 46 Hydrogen energy service related non-fuel costs (Hjk: $\mathrm{j}=$ hydrogen) 


\begin{tabular}{|c|c|c|c|c|c|c|c|c|c|}
\hline \multicolumn{10}{|c|}{ ENERGY TRANSFORMATION BY SECTOR, Hydrogen fuel cells } \\
\hline \multicolumn{10}{|c|}{ \$/GJ energy service capital and O\&M for hydrogen fuel cell } \\
\hline \multicolumn{10}{|c|}{ HJK(JSH2,K,M); see Equation 55} \\
\hline SECTOR & 1975 & 1990 & 2005 & 2020 & 2035 & 2050 & 2065 & 2080 & 2095 \\
\hline $\mathrm{RES} / \mathrm{COM}$ & 5 & 5 & 5 & 5 & 5 & 5 & 5 & 5 & 5 \\
\hline INDUSTRY & 0.5 & 0.5 & 0.5 & 0.5 & 0.5 & 0.5 & 0.5 & 0.5 & 0.5 \\
\hline TRANSPORT & 120 & 120 & 120 & 120 & 120 & 120 & 120 & 120 & 120 \\
\hline & & Note & 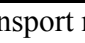 & ne & $S 1$ & y hi & tha & & \\
\hline
\end{tabular}

Table 47 Transportation sector fuel-related efficiency coefficients

\begin{tabular}{|c|c|c|c|c|c|c|c|c|c|}
\hline GJKLM & \multicolumn{2}{|c|}{ for transport sector } & & & & & & & \\
\hline \multicolumn{10}{|c|}{ GJKLM(J,K,L,M) } \\
\hline & 1975 & 1990 & 2005 & 2020 & 2035 & 2050 & 2065 & 2080 & 2095 \\
\hline OIL & 3 & 3 & 3 & 3 & 3 & 3 & 3 & 3 & 3 \\
\hline$\overline{\text { GAS }}$ & 3 & 3 & 3 & 3 & 3 & 3 & 3 & 3 & 3 \\
\hline COAL & 3.33 & 3.33 & 3.33 & 3.33 & 3.33 & 3.33 & 3.33 & 3.33 & 3.33 \\
\hline ELECTRIC & 1.05 & 1.05 & 1.05 & 1.05 & 1.05 & 1.05 & 1.05 & 1.05 & 1.05 \\
\hline BIOMASS & 3.33 & 3.33 & 3.33 & 3.33 & 3.33 & 3.33 & 3.33 & 3.33 & 3.33 \\
\hline
\end{tabular}

Table 48 Transportation sector non-energy costs

\begin{tabular}{|c|c|c|c|c|c|c|c|c|c|}
\hline \multirow[t]{3}{*}{ HJKLM } & & \multicolumn{4}{|c|}{ More detailed transportation coefficients } & & & & \\
\hline & & \multicolumn{2}{|c|}{ HJKLM(J,K,L,M) } & & & & & & \\
\hline & 1975 & 1990 & 2005 & 2020 & 2035 & 2050 & 2065 & 2080 & 2095 \\
\hline OIL & 98.88 & 98.88 & 98.88 & 98.88 & 98.88 & 98.88 & 98.88 & 98.88 & 98.88 \\
\hline GAS & 200 & 200 & 200 & 200 & 200 & 200 & 200 & 200 & 200 \\
\hline COAL & 105 & 105 & 110 & 120 & 130 & 150 & 200 & 200 & 200 \\
\hline ELECTRIC & 153.17 & 153.17 & 153.17 & 153.17 & 153.17 & 153.17 & 153.17 & 153.17 & 153.17 \\
\hline BIOMASS & 200 & 200 & 200 & 200 & 200 & 200 & 200 & 200 & 200 \\
\hline
\end{tabular}

Table 49 Aggregate price elasticity

\begin{tabular}{|l|l|}
\hline RPK & See Equation 66 \\
\hline-0.7 & AGGREGATE \\
\hline
\end{tabular}

Table 50 End-use sector-specific price elasticities for oil, gas, coal and electricity

\begin{tabular}{|l|l|l|l|l|}
\hline \multicolumn{5}{|l|}{ RPJK; see Equation 69} \\
\hline OIL & GAS & COAL & ELECTRIC & SECTOR \\
\hline-3 & -3 & -3 & -3 & RES/COM \\
\hline-3 & -3 & -3 & -3 & INDUSTRY \\
\hline-13 & -13 & -13 & -13 & TRANSPORT \\
\hline
\end{tabular}


Table 51 Transmission and Distribution Costs for Hydrogen

\begin{tabular}{|l|l|l|l|l|l|l|l|l|l|l|}
\hline \multicolumn{1}{|l|}{ PH2TDKM(K,M); see Equation 56} \\
\hline SECTOR & 1975 & 1990 & 2005 & 2020 & 2035 & 2050 & 2065 & 2080 & 2095 & SecName \\
\hline 1 & 1.5 & 1.5 & 1.2 & 0.94 & 0.75 & 0.7 & 0.65 & 0.6 & 0.56 & RES/COM \\
\hline 2 & 0.75 & 0.75 & 0.6 & 0.47 & 0.375 & 0.35 & 0.32 & 0.3 & 0.28 & INDUSTRY \\
\hline 3 & 1.5 & 1.5 & 1.2 & 0.94 & 0.75 & 0.7 & 0.65 & 0.6 & 0.56 & TRANSPORT \\
\hline
\end{tabular}

Table 52 Transmission and Distribution Cost of Electricity

\begin{tabular}{|l|l|l|l|l|l|l|l|l|l|l|}
\hline \multicolumn{2}{|l|}{ PUTDKM(K,M): 1975 \$/GJ see Equation 57 } \\
\hline SECTOR & 1975 & 1990 & 2005 & 2020 & 2035 & 2050 & 2065 & 2080 & 2095 & SecName \\
\hline 1 & 3.03 & 3.03 & 2.81 & 2.61 & 2.42 & 2.25 & 2.08 & 1.93 & 1.79 & RES/COM \\
\hline 2 & 0.75 & 0.75 & 0.7 & 0.65 & 0.6 & 0.56 & 0.52 & 0.48 & 0.44 & INDUSTRY \\
\hline 3 & 3.03 & 3.03 & 2.81 & 2.61 & 2.42 & 2.25 & 2.08 & 1.93 & 1.79 & TRANSPORT \\
\hline
\end{tabular}

Table 53 Regional weights of fuel share coefficients and initial shares of energy services consumptions

\begin{tabular}{|c|c|c|c|c|c|c|}
\hline \multicolumn{5}{|c|}{$\begin{array}{l}\text { BASE ENERGY SERVICE CONSUMPTION WEIGHTS BY FUEL BY } \\
\text { SECTOR BY REGION SJKLP(J,K,L) (UNITS=UNDIMENTIONED); see } \\
\text { Equation } 60 \& 69\end{array}$} & \multicolumn{2}{|c|}{$\begin{array}{l}\text { BASE ENERGY SERVICE } \\
\text { CONSUMPTION WEIGHTS BY } \\
\text { FUEL BY SECTOR BY REGION } \\
\text { BSKL(K,L) (UNITS=EXAJOULES); } \\
\text { see Equation } 60,61,64,65 \& 69\end{array}$} \\
\hline & OIL & GAS & COAL & ELECTRIC & SECTOR & BSKL \\
\hline USA & 0.185 & 0.683 & 0.011 & 0.379 & RES/COM & 15.238 \\
\hline$\overline{\text { USA }}$ & 0.091 & 0.345 & 0.129 & 0.145 & INDUSTRY & 9.7881 \\
\hline USA & 1.369 & 0 & 0 & 0.001 & TRANSPORT & 6.6411 \\
\hline CANADA & 0.359 & 0.122 & 0.112 & 0.372 & $\mathrm{RES} / \mathrm{COM}$ & 2.2295 \\
\hline CANADA & 0.26 & 0.065 & 0.131 & 0.212 & INDUSTRY & 1.8809 \\
\hline CANADA & 1.962 & 0 & 0.003 & 0.028 & TRANSPORT & 0.6795 \\
\hline WEUR & 0.359 & 0.122 & 0.112 & 0.372 & RES/COM & 10.256 \\
\hline WEUR & 0.26 & 0.065 & 0.131 & 0.212 & INDUSTRY & 8.6523 \\
\hline WEUR & 1.962 & 0 & 0.003 & 0.028 & TRANSPORT & 3.1256 \\
\hline JAPAN & 0.443 & 0.088 & 0.207 & 0.462 & $\mathrm{RES} / \mathrm{COM}$ & 1.6701 \\
\hline JAPAN & 0.224 & 0.032 & 0.267 & 0.263 & INDUSTRY & 3.1513 \\
\hline JAPAN & 2.672 & 0 & 0.001 & 0.05 & TRANSPORT & 0.7153 \\
\hline AUS\&NZ & 0.443 & 0.088 & 0.207 & 0.462 & RES/COM & 0.6263 \\
\hline AUS\&NZ & 0.224 & 0.032 & 0.267 & 0.263 & INDUSTRY & 1.1817 \\
\hline AUS\&NZ & 2.672 & 0 & 0.001 & 0.05 & TRANSPORT & 0.2682 \\
\hline$\overline{F S U}$ & 0.359 & 0.122 & 0.112 & 0.372 & RES/COM & 5.4703 \\
\hline$\overline{F S U}$ & 0.26 & 0.065 & 0.131 & 0.212 & INDUSTRY & 14.525 \\
\hline$\overline{F S U}$ & 1.962 & 0 & 0.003 & 0.028 & TRANSPORT & 2.1262 \\
\hline CHINA & 0.443 & 0.088 & 0.207 & 0.462 & RES/COM & 1.7254 \\
\hline CHINA & 0.224 & 0.032 & 0.267 & 0.263 & INDUSTRY & 7.0613 \\
\hline CHINA & 2.672 & 0 & 0.001 & 0.05 & TRANSPORT & 0.3344 \\
\hline MIDEAST & 0.443 & 0.088 & 0.207 & 0.462 & RES/COM & 0.5171 \\
\hline
\end{tabular}




\begin{tabular}{|l|l|l|l|l|l|l|}
\hline MIDEAST & 0.224 & 0.032 & 0.267 & 0.263 & INDUSTRY & 0.9323 \\
\hline MIDEAST & 2.672 & 0 & 0.001 & 0.05 & TRANSPORT & 0.3659 \\
\hline AFRICA & 0.443 & 0.088 & 0.207 & 0.462 & RES/COM & 0.4621 \\
\hline AFRICA & 0.224 & 0.032 & 0.267 & 0.263 & INDUSTRY & 1.4083 \\
\hline AFRICA & 2.672 & 0 & 0.001 & 0.05 & TRANSPORT & 0.413 \\
\hline L.AMERICA & 0.443 & 0.088 & 0.207 & 0.462 & RES/COM & 1.2285 \\
\hline L.AMERICA & 0.224 & 0.032 & 0.267 & 0.263 & INDUSTRY & 2.7492 \\
\hline L.AMERICA & 2.672 & 0 & 0.001 & 0.05 & TRANSPORT & 1.0636 \\
\hline S\&E ASIA & 0.443 & 0.088 & 0.207 & 0.462 & RES/COM & 0.5077 \\
\hline S\&E ASIA & 0.224 & 0.032 & 0.267 & 0.263 & INDUSTRY & 1.2696 \\
\hline S\&E ASIA & 2.672 & 0 & 0.001 & 0.05 & TRANSPORT & 0.3854 \\
\hline EEUR & 0.359 & 0.122 & 0.112 & 0.372 & RES/COM & 1.5735 \\
\hline EEUR & 0.26 & 0.065 & 0.131 & 0.212 & INDUSTRY & 4.0853 \\
\hline EEUR & 1.962 & 0 & 0.003 & 0.028 & TRANSPORT & 0.4494 \\
\hline KOR & 0.443 & 0.088 & 0.207 & 0.462 & RES/COM & 0.6953 \\
\hline KOR & 0.224 & 0.032 & 0.267 & 0.263 & INDUSTRY & 0.7109 \\
\hline KOR & 2.672 & 0 & 0.001 & 0.05 & TRANSPORT & 0.2515 \\
\hline INDIA & 0.443 & 0.088 & 0.207 & 0.462 & RES/COM & 0.5077 \\
\hline INDIA & 0.224 & 0.032 & 0.267 & 0.263 & INDUSTRY & 1.2696 \\
\hline INDIA & 2.672 & 0 & 0.001 & 0.05 & TRANSPORT & 0.31 \\
\hline
\end{tabular}

\section{Elasticities}

Note: Developing country parameters have more effect since income change is greater Increased preference away from building use of coal Increased preference for building use of electricity

Table 54 Regional income elasticities by secondary fuel (oil, gas, coal, electricity) for end-use sectors

\begin{tabular}{|c|c|c|c|c|c|c|c|c|c|c|c|}
\hline \multicolumn{12}{|c|}{ RYJKLM(J,K,L,M); see Equation 60 \& 69} \\
\hline REGION & SECTOR & FUEL & $\begin{array}{l}197 \\
5\end{array}$ & 1990 & 2005 & 2020 & 2035 & 2050 & 2065 & 2080 & 2095 \\
\hline USA & RES/COM & OIL & -0.1 & -0.1 & -0.1 & -0.1 & -0.1 & -0.1 & -0.1 & -0.1 & -0.1 \\
\hline USA & INDUSTRY & OIL & 0 & 0 & 0 & 0 & 0 & 0 & 0 & 0 & 0 \\
\hline USA & TRANSPORT & OIL & 0 & 0 & 0 & 0 & 0 & 0 & 0 & 0 & 0 \\
\hline USA & $\mathrm{RES} / \mathrm{COM}$ & GAS & 0.3 & 0.1 & 0.1 & 0.1 & 0.1 & 0.1 & 0.1 & 0.1 & 0.1 \\
\hline USA & INDUSTRY & GAS & 0.1 & 0.1 & 0.1 & 0.1 & 0.1 & 0.1 & 0.1 & 0.1 & 0.1 \\
\hline USA & TRANSPORT & GAS & 0 & 0 & 0 & 0 & 0 & 0 & 0 & 0 & 0 \\
\hline USA & RES/COM & COAL & -1 & -1 & -1 & -1 & -1 & -1 & -1 & -1 & -1 \\
\hline USA & INDUSTRY & COAL & $\begin{array}{c}-0.3 \\
\end{array}$ & -0.3 & -0.3 & $\begin{array}{c}-0.3 \\
\end{array}$ & -0.3 & -0.3 & -0.3 & $\begin{array}{c}-0.3 \\
\end{array}$ & -0.3 \\
\hline USA & TRANSPORT & COAL & 0 & 0 & 0 & 0 & 0 & 0 & 0 & 0 & 0 \\
\hline USA & RES/COM & ELECTRIC & 1 & 1 & 1 & 1 & 1 & 1 & 1 & 1 & 1 \\
\hline USA & INDUSTRY & ELECTRIC & 0.3 & 0.3 & 0.3 & 0.3 & 0.3 & 0.3 & 0.3 & 0.3 & 0.3 \\
\hline USA & TRANSPORT & ELECTRIC & 0 & 0 & 0 & 0 & 0 & 0 & 0 & 0 & 0 \\
\hline CANADA & RES/COM & OIL & -0.1 & -0.1 & -0.1 & $\begin{array}{l}-0.1 \\
\end{array}$ & -0.1 & $\begin{array}{l}-0.1 \\
\end{array}$ & -0.1 & $\begin{array}{l}-0.1 \\
\end{array}$ & -0.1 \\
\hline
\end{tabular}




\begin{tabular}{|c|c|c|c|c|c|c|c|c|c|c|c|}
\hline CANADA & INDUSTRY & OIL & 0 & 0 & 0 & 0 & 0 & 0 & 0 & 0 & 0 \\
\hline CANADA & TRANSPORT & $\overline{\text { OIL }}$ & 0 & 0 & 0 & 0 & 0 & 0 & 0 & 0 & 0 \\
\hline CANADA & RES/COM & GAS & 0.3 & 0.1 & 0.1 & 0.1 & 0.1 & 0.1 & 0.1 & 0.1 & 0.1 \\
\hline CANADA & INDUSTRY & GAS & 0.1 & 0.1 & 0.1 & 0.1 & 0.1 & 0.1 & 0.1 & 0.1 & 0.1 \\
\hline CANADA & TRANSPORT & GAS & 0 & 0 & 0 & 0 & 0 & 0 & 0 & 0 & 0 \\
\hline CANADA & $\mathrm{RES} / \mathrm{COM}$ & COAL & -1 & -1 & -1 & -1 & -1 & -1 & -1 & -1 & -1 \\
\hline CANADA & INDUSTRY & COAL & -0.3 & -0.3 & -0.3 & $\begin{array}{l}-0.3 \\
\end{array}$ & -0.3 & $\begin{array}{l}-0.3 \\
\end{array}$ & $\begin{array}{l}-0.3 \\
\end{array}$ & -0.3 & -0.3 \\
\hline CANADA & TRANSPORT & COAL & 0 & 0 & 0 & 0 & 0 & 0 & 0 & 0 & 0 \\
\hline CANADA & RES/COM & ELECTRIC & 1 & 1 & 1 & 1 & 1 & 1 & 1 & 1 & 1 \\
\hline CANADA & INDUSTRY & ELECTRIC & 0.3 & 0.3 & 0.3 & 0.3 & 0.3 & 0.3 & 0.3 & 0.3 & 0.3 \\
\hline CANADA & TRANSPORT & ELECTRIC & 0 & 0 & 0 & 0 & 0 & 0 & 0 & 0 & 0 \\
\hline WEUR & $\mathrm{RES} / \mathrm{COM}$ & $\overline{\text { OIL }}$ & -0.1 & -0.1 & -0.1 & $\begin{array}{l}-0.1 \\
\end{array}$ & $\begin{array}{l}-0.1 \\
\end{array}$ & $\begin{array}{l}-0.1 \\
\end{array}$ & $\begin{array}{l}-0.1 \\
\end{array}$ & $\begin{array}{l}-0.1 \\
\end{array}$ & -0.1 \\
\hline WEUR & INDUSTRY & OIL & 0 & 0 & 0 & 0 & 0 & 0 & 0 & 0 & 0 \\
\hline WEUR & TRANSPORT & $\overline{\text { OIL }}$ & 0 & 0 & 0 & 0 & 0 & 0 & 0 & 0 & 0 \\
\hline WEUR & $\mathrm{RES} / \mathrm{COM}$ & GAS & 0.3 & 0.1 & 0.1 & 0.1 & 0.1 & 0.1 & 0.1 & 0.1 & 0.1 \\
\hline WEUR & INDUSTRY & GAS & 0.1 & 0.1 & 0.1 & 0.1 & 0.1 & 0.1 & 0.1 & 0.1 & 0.1 \\
\hline WEUR & TRANSPORT & GAS & 0 & 0 & 0 & 0 & 0 & 0 & 0 & 0 & 0 \\
\hline WEUR & RES/COM & COAL & -1 & -1 & -1 & -1 & -1 & -1 & -1 & -1 & -1 \\
\hline WEUR & INDUSTRY & COAL & -0.3 & -0.3 & -0.3 & -0.3 & -0.3 & $\begin{array}{l}-0.3 \\
\end{array}$ & $\begin{array}{l}-0.3 \\
\end{array}$ & -0.3 & -0.3 \\
\hline WEUR & TRANSPORT & COAL & 0 & 0 & 0 & 0 & 0 & 0 & 0 & 0 & 0 \\
\hline WEUR & $\mathrm{RES} / \mathrm{COM}$ & ELECTRIC & 1 & 1 & 1 & 1 & 1 & 1 & 1 & 1 & 1 \\
\hline WEUR & INDUSTRY & ELECTRIC & 0.3 & 0.3 & 0.3 & 0.3 & 0.3 & 0.3 & 0.3 & 0.3 & 0.3 \\
\hline WEUR & TRANSPORT & ELECTRIC & 0 & 0 & 0 & 0 & 0 & 0 & 0 & 0 & 0 \\
\hline JAPAN & RES/COM & $\overline{\text { OIL }}$ & -0.1 & -0.1 & -0.1 & -0.1 & $\begin{array}{l}-0.1 \\
\end{array}$ & $\begin{array}{l}-0.1 \\
\end{array}$ & $\begin{array}{l}-0.1 \\
\end{array}$ & $\begin{array}{c}-0.1 \\
\end{array}$ & -0.1 \\
\hline JAPAN & INDUSTRY & OIL & 0 & 0 & 0 & 0 & 0 & 0 & 0 & 0 & 0 \\
\hline JAPAN & TRANSPORT & OIL & 0 & 0 & 0 & 0 & 0 & 0 & 0 & 0 & 0 \\
\hline JAPAN & $\mathrm{RES} / \mathrm{COM}$ & GAS & 0.3 & 0.1 & 0.1 & 0.1 & 0.1 & 0.1 & 0.1 & 0.1 & 0.1 \\
\hline JAPAN & INDUSTRY & GAS & 0.1 & 0.1 & 0.1 & 0.1 & 0.1 & 0.1 & 0.1 & 0.1 & 0.1 \\
\hline JAPAN & TRANSPORT & GAS & 0 & 0 & 0 & 0 & 0 & 0 & 0 & 0 & 0 \\
\hline JAPAN & RES/COM & COAL & -1 & -1 & -1 & -1 & -1 & -1 & -1 & -1 & -1 \\
\hline JAPAN & INDUSTRY & COAL & -0.3 & -0.3 & -0.3 & -0.3 & -0.3 & $\begin{array}{l}-0.3 \\
\end{array}$ & $\begin{array}{l}-0.3 \\
\end{array}$ & -0.3 & -0.3 \\
\hline JAPAN & TRANSPORT & COAL & 0 & 0 & 0 & 0 & 0 & 0 & 0 & 0 & 0 \\
\hline JAPAN & RES/COM & ELECTRIC & 1 & 1 & 1 & 1 & 1 & 1 & 1 & 1 & 1 \\
\hline JAPAN & INDUSTRY & ELECTRIC & 0.3 & 0.3 & 0.3 & 0.3 & 0.3 & 0.3 & 0.3 & 0.3 & 0.3 \\
\hline JAPAN & TRANSPORT & ELECTRIC & 0 & 0 & 0 & 0 & 0 & 0 & 0 & 0 & 0 \\
\hline AUS\&NZ & $\mathrm{RES} / \mathrm{COM}$ & $\overline{\text { OIL }}$ & -0.1 & -0.1 & -0.1 & $\begin{array}{l}-0.1 \\
\end{array}$ & $\begin{array}{l}-0.1 \\
\end{array}$ & -0.1 & -0.1 & -0.1 & -0.1 \\
\hline AUS\&NZ & INDUSTRY & OIL & 0 & 0 & 0 & 0 & 0 & 0 & 0 & 0 & 0 \\
\hline AUS\&NZ & TRANSPORT & OIL & 0 & 0 & 0 & 0 & 0 & 0 & 0 & 0 & 0 \\
\hline AUS\&NZ & RES/COM & GAS & 0.3 & 0.1 & 0.1 & 0.1 & 0.1 & 0.1 & 0.1 & 0.1 & 0.1 \\
\hline AUS\&NZ & INDUSTRY & GAS & 0.1 & 0.1 & 0.1 & 0.1 & 0.1 & 0.1 & 0.1 & 0.1 & 0.1 \\
\hline AUS\&NZ & TRANSPORT & GAS & 0 & 0 & 0 & 0 & 0 & 0 & 0 & 0 & 0 \\
\hline AUS\&NZ & RES/COM & COAL & -1 & -1 & -1 & -1 & -1 & -1 & -1 & -1 & -1 \\
\hline AUS\&NZ & INDUSTRY & COAL & -0.3 & -0.3 & -0.3 & -0.3 & -0.3 & -0.3 & -0.3 & -0.3 & -0.3 \\
\hline AUS\&NZ & TRANSPORT & COAL & 0 & 0 & 0 & 0 & 0 & 0 & 0 & 0 & 0 \\
\hline AUS\&NZ & RES/COM & ELECTRIC & 1 & 1 & 1 & 1 & 1 & 1 & 1 & 1 & 1 \\
\hline AUS\&NZ & INDUSTRY & ELECTRIC & 0.3 & 0.3 & 0.3 & 0.3 & 0.3 & 0.3 & 0.3 & 0.3 & 0.3 \\
\hline AUS\&NZ & TRANSPORT & ELECTRIC & 0 & 0 & 0 & 0 & 0 & 0 & 0 & 0 & 0 \\
\hline
\end{tabular}




\begin{tabular}{|c|c|c|c|c|c|c|c|c|c|c|c|}
\hline FSU & RES/COM & OIL & 0 & -0.1 & -0.1 & -0.1 & -0.1 & -0.1 & -0.1 & -0.1 & $\begin{array}{l}-0.1 \\
\end{array}$ \\
\hline$\overline{\text { FSU }}$ & INDUSTRY & OIL & 0 & 0 & 0 & $\overline{0}$ & 0 & 0 & 0 & 0 & 0 \\
\hline$\overline{F S U}$ & TRANSPORT & OIL & 0 & 0 & 0 & 0 & 0 & 0 & 0 & 0 & 0 \\
\hline$\overline{F S U}$ & $\mathrm{RES} / \mathrm{COM}$ & GAS & 0 & 0.1 & 0.1 & 0.1 & 0.1 & 0.1 & 0.1 & 0.1 & 0.1 \\
\hline FSU & INDUSTRY & GAS & 0 & 0.1 & 0.1 & 0.1 & 0.1 & 0.1 & 0.1 & 0.1 & 0.1 \\
\hline FSU & TRANSPORT & GAS & 0 & 0 & 0 & 0 & 0 & 0 & 0 & 0 & 0 \\
\hline FSU & RES/COM & COAL & -0.5 & -0.5 & -0.5 & -0.5 & -0.75 & -0.75 & -0.75 & -0.75 & -0.75 \\
\hline FSU & INDUSTRY & COAL & 0 & -0.3 & \begin{tabular}{c|c|}
-0.3 \\
\end{tabular} & -0.3 & -0.3 & -0.3 & \begin{tabular}{c|c|}
-0.3 \\
\end{tabular} & -0.3 & -0.3 \\
\hline$\overline{F S U}$ & TRANSPORT & COAL & 0 & 0 & 0 & 0 & 0 & 0 & 0 & 0 & 0 \\
\hline FSU & $\mathrm{RES} / \mathrm{COM}$ & ELECTRIC & 0.5 & 0.5 & 0.5 & 0.5 & 0.75 & 0.75 & 0.75 & 0.75 & 0.75 \\
\hline$\overline{\text { FSU }}$ & INDUSTRY & ELECTRIC & 0.1 & 0.3 & 0.3 & 0.3 & 0.3 & 0.3 & 0.3 & 0.3 & 0.3 \\
\hline$\overline{\text { FSU }}$ & TRANSPORT & ELECTRIC & 0 & 0 & 0 & 0 & 0 & 0 & 0 & 0 & 0 \\
\hline CHINA & $\mathrm{RES} / \mathrm{COM}$ & OIL & 0 & -0.1 & -0.1 & -0.1 & -0.1 & -0.1 & -0.1 & -0.1 & -0.1 \\
\hline CHINA & INDUSTRY & $\overline{\mathrm{OIL}}$ & 0 & 0 & 0 & 0 & 0 & 0 & 0 & 0 & 0 \\
\hline CHINA & TRANSPORT & OIL & 0 & 0 & 0 & 0 & 0 & 0 & 0 & 0 & 0 \\
\hline CHINA & RES/COM & GAS & 0 & 0.1 & 0.1 & 0.1 & 0.1 & 0.1 & 0.1 & 0.1 & 0.1 \\
\hline CHINA & INDUSTRY & GAS & 0 & 0.1 & 0.1 & 0.1 & 0.1 & 0.1 & 0.1 & 0.1 & 0.1 \\
\hline CHINA & TRANSPORT & GAS & 0 & 0 & 0 & 0 & 0 & 0 & 0 & 0 & 0 \\
\hline CHINA & RES/COM & COAL & -0.5 & -0.5 & -0.5 & -0.5 & -0.5 & -0.5 & -0.5 & -0.5 & -0.5 \\
\hline CHINA & INDUSTRY & COAL & 0 & -0.3 & -0.3 & -0.3 & -0.3 & -0.3 & -0.3 & -0.3 & -0.3 \\
\hline CHINA & TRANSPORT & COAL & 0 & 0 & 0 & 0 & 0 & 0 & 0 & 0 & 0 \\
\hline CHINA & $\mathrm{RES} / \mathrm{COM}$ & ELECTRIC & 0.5 & 0.5 & 0.5 & 0.5 & 0.5 & 0.5 & 0.5 & 0.5 & 0.5 \\
\hline CHINA & INDUSTRY & ELECTRIC & 0.1 & 0.3 & 0.3 & 0.3 & 0.3 & 0.3 & 0.3 & 0.3 & 0.3 \\
\hline CHINA & TRANSPORT & ELECTRIC & 0 & 0 & 0 & 0 & 0 & 0 & 0 & 0 & 0 \\
\hline MIDEAST & $\mathrm{RES} / \mathrm{COM}$ & OIL & 0 & -0.1 & -0.1 & -0.1 & -0.1 & -0.1 & $\begin{array}{l}-0.1 \\
\end{array}$ & $\begin{array}{l}-0.1 \\
\end{array}$ & -0.1 \\
\hline MIDEAST & INDUSTRY & OIL & 0 & 0 & 0 & 0 & 0 & 0 & 0 & 0 & 0 \\
\hline MIDEAST & TRANSPORT & OIL & 0 & 0 & 0 & 0 & 0 & 0 & 0 & 0 & 0 \\
\hline MIDEAST & RES/COM & GAS & 0 & 0.1 & 0.1 & 0.1 & 0.1 & 0.1 & 0.1 & 0.1 & 0.1 \\
\hline MIDEAST & INDUSTRY & GAS & 0 & 0.1 & 0.1 & 0.1 & 0.1 & 0.1 & 0.1 & 0.1 & 0.1 \\
\hline MIDEAST & TRANSPORT & GAS & 0 & 0 & 0 & 0 & 0 & 0 & 0 & 0 & 0 \\
\hline MIDEAST & RES/COM & $\mathrm{COAL}$ & -0.5 & -0.5 & -0.5 & -0.5 & -0.5 & -0.5 & -0.5 & -0.5 & -0.5 \\
\hline MIDEAST & INDUSTRY & $\mathrm{COAL}$ & 0 & -0.3 & $\begin{array}{c}-0.3 \\
\end{array}$ & -0.3 & -0.3 & -0.3 & $\begin{array}{c}-0.3 \\
\end{array}$ & -0.3 & $\begin{array}{c}-0.3 \\
\end{array}$ \\
\hline MIDEAST & TRANSPORT & COAL & 0 & 0 & 0 & 0 & 0 & 0 & 0 & 0 & 0 \\
\hline MIDEAST & $\mathrm{RES} / \mathrm{COM}$ & ELECTRIC & 0.5 & 0.5 & 0.5 & 0.5 & 0.5 & 0.5 & 0.5 & 0.5 & 0.5 \\
\hline MIDEAST & INDUSTRY & ELECTRIC & 0.1 & 0.3 & 0.3 & 0.3 & 0.3 & 0.3 & 0.3 & 0.3 & 0.3 \\
\hline MIDEAST & TRANSPORT & ELECTRIC & 0 & 0 & 0 & 0 & 0 & 0 & 0 & 0 & 0 \\
\hline AFRICA & $\mathrm{RES} / \mathrm{COM}$ & OIL & 0 & -0.1 & $\begin{array}{c}-0.1 \\
\end{array}$ & -0.1 & -0.1 & $\begin{array}{c}-0.1 \\
\end{array}$ & $\begin{array}{c}-0.1 \\
\end{array}$ & $\begin{array}{c}-0.1 \\
\end{array}$ & $\begin{array}{l}-0.1 \\
\end{array}$ \\
\hline AFRICA & INDUSTRY & OIL & 0 & 0 & 0 & 0 & 0 & 0 & 0 & 0 & 0 \\
\hline AFRICA & TRANSPORT & OIL & 0 & 0 & 0 & 0 & 0 & 0 & 0 & 0 & 0 \\
\hline AFRICA & RES/COM & GAS & 0 & 0.1 & 0.1 & 0.1 & 0.1 & 0.1 & 0.1 & 0.1 & 0.1 \\
\hline AFRICA & INDUSTRY & GAS & 0 & 0.1 & 0.1 & 0.1 & 0.1 & 0.1 & 0.1 & 0.1 & 0.1 \\
\hline AFRICA & TRANSPORT & GAS & 0 & 0 & 0 & 0 & 0 & 0 & 0 & 0 & 0 \\
\hline AFRICA & RES/COM & $\mathrm{COAL}$ & -0.5 & -0.5 & -0.5 & -0.5 & -0.5 & -0.5 & -0.5 & -0.5 & -0.5 \\
\hline AFRICA & INDUSTRY & COAL & 0 & -0.3 & -0.3 & -0.3 & -0.3 & -0.3 & -0.3 & -0.3 & -0.3 \\
\hline AFRICA & TRANSPORT & COAL & 0 & 0 & 0 & 0 & 0 & 0 & 0 & 0 & 0 \\
\hline AFRICA & RES/COM & ELECTRIC & 0.5 & 0.5 & 0.5 & 0.5 & 0.5 & 0.5 & 0.5 & 0.5 & 0.5 \\
\hline AFRICA & INDUSTRY & ELECTRIC & 0.1 & 0.3 & 0.3 & 0.3 & 0.3 & 0.3 & 0.3 & 0.3 & 0.3 \\
\hline
\end{tabular}




\begin{tabular}{|c|c|c|c|c|c|c|c|c|c|c|c|}
\hline AFRICA & TRANSPORT & ELECTRIC & 0 & 0 & 0 & 0 & 0 & 0 & 0 & 0 & 0 \\
\hline L.AMERICA & RES/COM & OIL & 0 & $\begin{array}{l}-0.1 \\
\end{array}$ & -0.1 & $\begin{array}{l}-0.1 \\
\end{array}$ & $\begin{array}{l}-0.1 \\
\end{array}$ & -0.1 & $\begin{array}{l}-0.1 \\
\end{array}$ & $\begin{array}{c}-0.1 \\
\end{array}$ & -0.1 \\
\hline L.AMERICA & INDUSTRY & $\overline{\text { OIL }}$ & 0 & 0 & 0 & 0 & 0 & 0 & 0 & 0 & 0 \\
\hline L.AMERICA & TRANSPORT & $\overline{\text { OIL }}$ & 0 & 0 & 0 & 0 & 0 & 0 & 0 & 0 & 0 \\
\hline L.AMERICA & $\mathrm{RES} / \mathrm{COM}$ & GAS & 0 & 0.1 & 0.1 & 0.1 & 0.1 & 0.1 & 0.1 & 0.1 & 0.1 \\
\hline L.AMERICA & INDUSTRY & GAS & 0 & 0.1 & 0.1 & 0.1 & 0.1 & 0.1 & 0.1 & 0.1 & 0.1 \\
\hline L.AMERICA & TRANSPORT & GAS & 0 & $\overline{0}$ & 0 & 0 & 0 & 0 & 0 & 0 & 0 \\
\hline L.AMERICA & RES/COM & COAL & -0.5 & -0.5 & -0.5 & -0.5 & -0.5 & -0.5 & -0.5 & -0.5 & -0.5 \\
\hline L.AMERICA & INDUSTRY & COAL & 0 & -0.3 & -0.3 & -0.3 & -0.3 & -0.3 & -0.3 & -0.3 & -0.3 \\
\hline L.AMERICA & TRANSPORT & COAL & 0 & 0 & 0 & 0 & 0 & 0 & 0 & 0 & 0 \\
\hline L.AMERICA & $\mathrm{RES} / \mathrm{COM}$ & ELECTRIC & 0.5 & 0.5 & 0.5 & 0.5 & 0.5 & 0.5 & 0.5 & 0.5 & 0.5 \\
\hline L.AMERICA & INDUSTRY & ELECTRIC & 0.1 & 0.3 & 0.3 & 0.3 & 0.3 & 0.3 & 0.3 & 0.3 & 0.3 \\
\hline L.AMERICA & TRANSPORT & ELECTRIC & 0 & 0 & 0 & 0 & 0 & 0 & 0 & 0 & 0 \\
\hline S\&E ASIA & RES/COM & $\overline{\mathrm{OIL}}$ & 0 & -0.1 & -0.1 & -0.1 & -0.1 & -0.1 & -0.1 & -0.1 & -0.1 \\
\hline S\&E ASIA & INDUSTRY & OIL & 0 & 0 & 0 & 0 & 0 & 0 & 0 & 0 & 0 \\
\hline S\&E ASIA & TRANSPORT & OIL & 0 & 0 & 0 & 0 & 0 & 0 & 0 & 0 & 0 \\
\hline S\&E ASIA & RES/COM & GAS & 0 & 0.1 & 0.1 & 0.1 & 0.1 & 0.1 & 0.1 & 0.1 & 0.1 \\
\hline S\&E ASIA & INDUSTRY & GAS & 0 & 0.1 & 0.1 & 0.1 & 0.1 & 0.1 & 0.1 & 0.1 & 0.1 \\
\hline S\&E ASIA & TRANSPORT & GAS & 0 & 0 & 0 & 0 & 0 & 0 & 0 & 0 & 0 \\
\hline S\&E ASIA & RES/COM & COAL & -0.5 & -0.5 & -0.5 & -0.5 & -0.5 & -0.5 & -0.5 & -0.5 & -0.5 \\
\hline S\&E ASIA & INDUSTRY & COAL & 0 & -0.3 & -0.3 & -0.3 & -0.3 & -0.3 & -0.3 & -0.3 & -0.3 \\
\hline S\&E ASIA & TRANSPORT & COAL & 0 & 0 & 0 & 0 & 0 & 0 & 0 & 0 & 0 \\
\hline S\&E ASIA & RES/COM & ELECTRIC & 0.5 & 0.5 & 0.5 & 0.5 & 0.5 & 0.5 & 0.5 & 0.5 & 0.5 \\
\hline S\&E ASIA & INDUSTRY & ELECTRIC & 0.1 & 0.3 & 0.3 & 0.3 & 0.3 & 0.3 & 0.3 & 0.3 & 0.3 \\
\hline S\&E ASIA & TRANSPORT & ELECTRIC & 0 & 0 & 0 & 0 & 0 & 0 & 0 & 0 & 0 \\
\hline EEUR & $\mathrm{RES} / \mathrm{COM}$ & $\overline{\text { OIL }}$ & 0 & -0.1 & -0.1 & -0.1 & $\begin{array}{l}-0.1 \\
\end{array}$ & -0.1 & -0.1 & -0.1 & -0.1 \\
\hline EEUR & INDUSTRY & OIL & 0 & 0 & 0 & 0 & 0 & 0 & 0 & 0 & 0 \\
\hline EEUR & TRANSPORT & OIL & 0 & 0 & 0 & 0 & 0 & 0 & 0 & 0 & 0 \\
\hline EEUR & RES/COM & GAS & 0 & 0.1 & 0.1 & 0.1 & 0.1 & 0.1 & 0.1 & 0.1 & 0.1 \\
\hline$\overline{\text { EEUR }}$ & INDUSTRY & GAS & 0 & 0.1 & 0.1 & 0.1 & 0.1 & 0.1 & 0.1 & 0.1 & 0.1 \\
\hline$\overline{\text { EEUR }}$ & TRANSPORT & GAS & 0 & 0 & 0 & 0 & 0 & 0 & 0 & 0 & 0 \\
\hline$\overline{\text { EEUR }}$ & RES/COM & COAL & -0.5 & -0.5 & -0.5 & -0.5 & -0.5 & -0.5 & -0.5 & -0.5 & -0.5 \\
\hline$\overline{\text { EEUR }}$ & INDUSTRY & COAL & 0 & $\begin{array}{l}-0.3 \\
\end{array}$ & -0.3 & -0.3 & -0.3 & $\begin{array}{l}-0.3 \\
\end{array}$ & $\begin{array}{l}-0.3 \\
\end{array}$ & $\begin{array}{l}-0.3 \\
\end{array}$ & -0.3 \\
\hline EEUR & TRANSPORT & COAL & 0 & 0 & 0 & 0 & 0 & 0 & 0 & 0 & 0 \\
\hline EEUR & RES/COM & ELECTRIC & 0.5 & 0.5 & 0.5 & 0.5 & 0.5 & 0.5 & 0.5 & 0.5 & 0.5 \\
\hline EEUR & INDUSTRY & ELECTRIC & 0.1 & 0.3 & 0.3 & 0.3 & 0.3 & 0.3 & 0.3 & 0.3 & 0.3 \\
\hline$\overline{\text { EEUR }}$ & TRANSPORT & ELECTRIC & 0 & 0 & 0 & 0 & 0 & 0 & 0 & 0 & 0 \\
\hline KOR & RES/COM & $\overline{\mathrm{OIL}}$ & 0 & -0.1 & $\begin{array}{l}-0.1 \\
\end{array}$ & $\begin{array}{l}-0.1 \\
\end{array}$ & $\begin{array}{l}-0.1 \\
\end{array}$ & $\begin{array}{l}-0.1 \\
\end{array}$ & $\begin{array}{c}-0.1 \\
\end{array}$ & -0.1 & -0.1 \\
\hline KOR & INDUSTRY & OIL & 0 & 0 & 0 & 0 & 0 & 0 & 0 & 0 & 0 \\
\hline KOR & TRANSPORT & OIL & 0 & 0 & 0 & 0 & 0 & 0 & 0 & 0 & 0 \\
\hline KOR & $\mathrm{RES} / \mathrm{COM}$ & GAS & 0 & 0.1 & 0.1 & 0.1 & 0.1 & 0.1 & 0.1 & 0.1 & 0.1 \\
\hline KOR & INDUSTRY & GAS & 0 & 0.1 & 0.1 & 0.1 & 0.1 & 0.1 & 0.1 & 0.1 & 0.1 \\
\hline KOR & TRANSPORT & GAS & 0 & 0 & 0 & 0 & 0 & 0 & 0 & 0 & 0 \\
\hline KOR & RES/COM & COAL & -0.5 & -0.5 & -0.5 & -0.5 & -0.5 & -0.5 & -0.5 & -0.5 & -0.5 \\
\hline KOR & INDUSTRY & COAL & 0 & -0.3 & -0.3 & $\begin{array}{l}-0.3 \\
\end{array}$ & $\begin{array}{l}-0.3 \\
\end{array}$ & $\begin{array}{l}-0.3 \\
\end{array}$ & -0.3 & -0.3 & -0.3 \\
\hline KOR & TRANSPORT & COAL & 0 & 0 & 0 & 0 & 0 & 0 & 0 & 0 & 0 \\
\hline KOR & $\mathrm{RES} / \mathrm{COM}$ & ELECTRIC & 0.5 & 0.5 & 0.5 & 0.5 & 0.5 & 0.5 & 0.5 & 0.5 & 0.5 \\
\hline
\end{tabular}




\begin{tabular}{|c|c|c|c|c|c|c|c|c|c|c|c|}
\hline KOR & INDUSTRY & ELECTRIC & 0.1 & 0.3 & 0.3 & 0.3 & 0.3 & 0.3 & 0.3 & 0.3 & 0.3 \\
\hline KOR & TRANSPORT & ELECTRIC & 0 & 0 & 0 & 0 & 0 & 0 & 0 & 0 & 0 \\
\hline INDIA & RES/COM & OIL & 0 & -0.1 & -0.1 & -0.1 & -0.1 & -0.1 & -0.1 & -0.1 & -0.1 \\
\hline INDIA & INDUSTRY & OIL & 0 & 0 & 0 & 0 & 0 & 0 & 0 & 0 & 0 \\
\hline INDIA & TRANSPORT & OIL & 0 & 0 & 0 & 0 & 0 & 0 & 0 & 0 & 0 \\
\hline INDIA & RES/COM & GAS & 0 & 0.1 & 0.1 & 0.1 & 0.1 & 0.1 & 0.1 & 0.1 & 0.1 \\
\hline INDIA & INDUSTRY & GAS & 0 & 0.1 & 0.1 & 0.1 & 0.1 & 0.1 & 0.1 & 0.1 & 0.1 \\
\hline INDIA & TRANSPORT & GAS & 0 & 0 & 0 & 0 & 0 & 0 & 0 & 0 & 0 \\
\hline INDIA & RES/COM & COAL & -0.5 & -0.5 & -0.5 & -0.5 & -0.5 & -0.5 & -0.5 & -0.5 & -0.5 \\
\hline INDIA & INDUSTRY & $\mathrm{COAL}$ & 0 & -0.3 & -0.3 & -0.3 & -0.3 & -0.3 & -0.3 & -0.3 & -0.3 \\
\hline INDIA & TRANSPORT & $\mathrm{COAL}$ & 0 & 0 & 0 & 0 & 0 & 0 & 0 & 0 & 0 \\
\hline INDIA & RES/COM & ELECTRIC & 0.5 & 0.5 & 0.5 & 0.5 & 0.5 & 0.5 & 0.5 & 0.5 & 0.5 \\
\hline INDIA & INDUSTRY & ELECTRIC & 0.1 & 0.3 & 0.3 & 0.3 & 0.3 & 0.3 & 0.3 & 0.3 & 0.3 \\
\hline INDIA & TRANSPORT & ELECTRIC & 0 & 0 & 0 & 0 & 0 & 0 & 0 & 0 & 0 \\
\hline
\end{tabular}

Table 55 Regional income elasticities for end-use sectors

\begin{tabular}{|c|c|c|c|c|c|c|c|c|c|c|}
\hline \multicolumn{11}{|c|}{ RYKLM(K,L,M); see Equation 64 \& 65} \\
\hline SECTOR & 1975 & 1990 & 2005 & 2020 & 2035 & 2050 & 2065 & 2080 & 2095 & REGION \\
\hline RES/COM & 1 & 1 & 1 & 1 & 1 & 1 & 1 & 1 & 1 & USA \\
\hline INDUSTRY & 1 & 1.1 & 1 & 1 & 1 & 1 & 1 & 1 & 1 & $\overline{\text { USA }}$ \\
\hline TRANSPORT & 1 & 1 & 1 & 1 & 1 & 1 & 1 & 1 & 1 & USA \\
\hline $\mathrm{RES} / \mathrm{COM}$ & 1 & 1 & 1 & 1 & 1 & 1 & 1 & 1 & 1 & CANADA \\
\hline INDUSTRY & 1 & 1 & 1 & 1 & 1 & 1 & 1 & 1 & 1 & CANADA \\
\hline TRANSPORT & 1 & 1 & 1 & 1 & 1 & 1 & 1 & 1 & 1 & CANADA \\
\hline $\mathrm{RES} / \mathrm{COM}$ & 1 & 1 & 1 & 1 & 1 & 1 & 1 & 1 & 1 & WEUR \\
\hline INDUSTRY & 1 & 1 & 1 & 1 & 1 & 1 & 1 & 1 & 1 & WEUR \\
\hline TRANSPORT & 1 & 1 & 1 & 1 & 1 & 1 & 1 & 1 & 1 & WEUR \\
\hline RES/COM & 1 & 1 & 1 & 1 & 1 & 1 & 1 & 1 & 1 & JAPAN \\
\hline $\begin{array}{l}\text { INDUSTRY } \\
\end{array}$ & 1 & $\overline{1}$ & 1 & 1 & 1 & 1 & 1 & 1 & 1 & JAPAN \\
\hline TRANSPORT & 1 & 1 & 1 & 1 & 1 & 1 & 1 & 1 & 1 & JAPAN \\
\hline RES/COM & 1 & 1 & 1 & 1 & 1 & 1 & 1 & 1 & 1 & AUS\&NZ \\
\hline INDUSTRY & 1 & 1 & 1 & 1 & 1 & 1 & 1 & 1 & 1 & AUS\&NZ \\
\hline TRANSPORT & 1 & 1 & 1 & 1 & 1 & 1 & 1 & 1 & 1 & AUS\&NZ \\
\hline $\mathrm{RES} / \mathrm{COM}$ & 1.25 & 1.209 & 1.169 & 1.131 & 1.11 & 1.05 & 1.05 & 1.05 & 1 & FSU \\
\hline INDUSTRY & 1.25 & 1.209 & 1.169 & 1.131 & 1.11 & 1.05 & 1.05 & 1.05 & 1 & FSU \\
\hline TRANSPORT & 1.25 & 1.209 & 1.169 & 1.131 & 1.11 & 1.05 & 1.05 & 1.05 & 1 & FSU \\
\hline RES/COM & 1.4 & 1.331 & 1.265 & 1.203 & 1.144 & 1.087 & 1.087 & 1.0653 & 1.0435 & CHINA \\
\hline INDUSTRY & 1.4 & 1.331 & 1.265 & 1.203 & 1.144 & 1.087 & 1.087 & 1.0653 & 1.0435 & CHINA \\
\hline TRANSPORT & 1.4 & 1.331 & 1.265 & 1.203 & 1.144 & 1.087 & 1.087 & 1.0653 & 1.0435 & CHINA \\
\hline RES/COM & 1.4 & 1.331 & 1.265 & 1.203 & 1.144 & 1.087 & 1.087 & 1.0653 & 1.0435 & MIDEAST \\
\hline INDUSTRY & 1.4 & 1.331 & 1.265 & 1.203 & 1.144 & 1.087 & 1.087 & 1.0653 & 1.0435 & MIDEAST \\
\hline TRANSPORT & 1.4 & 1.331 & 1.265 & 1.203 & 1.144 & 1.087 & 1.087 & 1.0653 & 1.0435 & MIDEAST \\
\hline RES/COM & 1.4 & 1.331 & 1.265 & 1.203 & 1.144 & 1.087 & 1.087 & 1.0653 & 1.0435 & AFRICA \\
\hline INDUSTRY & 1.4 & 1.331 & 1.265 & 1.203 & 1.144 & 1.087 & 1.087 & 1.0653 & 1.0435 & AFRICA \\
\hline TRANSPORT & 1.4 & 1.331 & 1.265 & 1.203 & 1.144 & 1.087 & 1.087 & 1.0653 & 1.0435 & AFRICA \\
\hline
\end{tabular}




\begin{tabular}{|l|l|l|l|l|l|l|l|l|l|l|}
\hline RES/COM & 1.4 & 1.331 & 1.265 & 1.203 & 1.144 & 1.087 & 1.087 & 1.0653 & 1.0435 & L.AMERICA \\
\hline INDUSTRY & 1.4 & 1.331 & 1.265 & 1.203 & 1.144 & 1.087 & 1.087 & 1.0653 & 1.0435 & L.AMERICA \\
\hline TRANSPORT & 1.4 & 1.331 & 1.265 & 1.203 & 1.144 & 1.087 & 1.087 & 1.0653 & 1.0435 & L.AMERICA \\
\hline RES/COM & 1.4 & 1.331 & 1.265 & 1.203 & 1.144 & 1.087 & 1.087 & 1.0816 & 1.0761 & S\&E ASIA \\
\hline INDUSTRY & 1.4 & 1.331 & 1.265 & 1.203 & 1.144 & 1.087 & 1.087 & 1.0816 & 1.0761 & S\&E ASIA \\
\hline TRANSPORT & 1.4 & 1.331 & 1.265 & 1.203 & 1.144 & 1.087 & 1.087 & 1.0816 & 1.0761 & S\&E ASIA \\
\hline RES/COM & 1.25 & 1.209 & 1.169 & 1.25 & 1.09 & 1.02 & 1 & 1 & 1 & EEUR \\
\hline INDUSTRY & 1.25 & 1.209 & 1.169 & 1.25 & 1.09 & 1.02 & 1 & 1 & 1 & EEUR \\
\hline TRANSPORT & 1.25 & 1.209 & 1.169 & 1.25 & 1.09 & 1.02 & 1 & 1 & 1 & EEUR \\
\hline RES/COM & 1.35 & 1.205 & 1.265 & 1.2 & 1.1 & 1 & 1 & 1 & 1 & KOR \\
\hline INDUSTRY & 1.35 & 1.205 & 1.265 & 1.2 & 1.1 & 1 & 1 & 1 & 1 & KOR \\
\hline TRANSPORT & 1.35 & 1.205 & 1.265 & 1.2 & 1.1 & 1 & 1 & 1 & 1 & KOR \\
\hline RES/COM & 1.4 & 1.331 & 1.265 & 1.203 & 1.144 & 1.087 & 1.087 & 1.0816 & 1.0761 & INDIA \\
\hline INDUSTRY & 1.4 & 1.331 & 1.265 & 1.203 & 1.144 & 1.087 & 1.087 & 1.0816 & 1.0761 & INDIA \\
\hline TRANSPORT & 1.4 & 1.331 & 1.265 & 1.203 & 1.144 & 1.087 & 1.087 & 1.0816 & 1.0761 & INDIA \\
\hline
\end{tabular}

Table 56 End-use sector-specific price elasticities

\begin{tabular}{|l|l|l|}
\hline \multicolumn{4}{|l|}{ RPKK(K); see Equation 64, 65 \& 66} \\
\hline AGG & SECTOR & \\
\hline-0.5 & RES/COM & RPKK,JK,K=1 \\
\hline-0.8 & INDUSTRY & RPKK,JK,K $=2$ \\
\hline-0.07 & TRANSPORT & RPKK,JK,K $=3$ \\
\hline
\end{tabular}

Table 57 Regional end-use sector efficiency coefficients for 1990

\begin{tabular}{|l|l|l|l|}
\hline \multicolumn{4}{|l|}{ TKLM- see Equation 68} \\
\hline Region & Buildings & Industry & Transport \\
\hline US & 0.019565 & -0.00056 & 0.013115 \\
\hline CAN & 0.039315 & 0.033156 & 0.021391 \\
\hline WEUR & 0.025902 & 0.007587 & -0.01245 \\
\hline Japan & 0.020001 & 0.029208 & 0.010587 \\
\hline AUS\&NZ & 0.074481 & 0.082479 & 0.022877 \\
\hline FSU & -0.00492 & 0.00876 & 0.006304 \\
\hline ACENP & 0.002941 & 0.014158 & -0.02308 \\
\hline MIDEAST & 0.027642 & -0.01459 & -0.00216 \\
\hline AFRICA & 0.003204 & 0.018172 & 0.010918 \\
\hline L AMER & -0.01118 & 0.002468 & -0.01948 \\
\hline S\&E ASIA & -0.0148 & -0.00167 & -0.02505 \\
\hline EEUR & -0.00492 & 0.00876 & 0.006304 \\
\hline KOR & 0.066001 & 0.040868 & 0.071239 \\
\hline INDIA & -0.0148 & -0.00167 & -0.02505 \\
\hline
\end{tabular}

Table 58 End-use sector efficiency improvement coefficients for 2005 through 2095 


\begin{tabular}{|l|l|l|l|l|l|l|l|}
\hline TKLM(K,L,M); see Equation 68 \\
\hline Region & 2005 & 2020 & 2035 & 2050 & 2065 & 2080 & 2095 \\
\hline US & 0.005 & 0.005 & 0.005 & 0.005 & 0.005 & 0.005 & 0.005 \\
\hline CAN & 0.005 & 0.005 & 0.005 & 0.005 & 0.005 & 0.005 & 0.005 \\
\hline WEUR & 0.015 & 0.005 & 0.005 & 0.005 & 0.005 & 0.005 & 0.005 \\
\hline Japan & 0.025 & 0.005 & 0.005 & 0.005 & 0.005 & 0.005 & 0.005 \\
\hline AUS\&NZ & 0.005 & 0.005 & 0.005 & 0.005 & 0.005 & 0.005 & 0.005 \\
\hline FSU & 0.02 & 0.025 & 0.02 & 0.015 & 0.0075 & 0.0075 & 0.005 \\
\hline ACENP & 0.05 & 0.035 & 0.025 & 0.015 & 0.01 & 0.005 & 0.005 \\
\hline MIDEAST & 0.005 & 0.005 & 0.015 & 0.015 & 0.02 & 0.01 & 0.01 \\
\hline AFRICA & 0.015 & 0.015 & 0.01 & 0.01 & 0.02 & 0.02 & 0.015 \\
\hline L AMER & 0.01 & 0.01 & 0.01 & 0.02 & 0.02 & 0.02 & 0.01 \\
\hline S\&E ASIA & 0.015 & 0.02 & 0.01 & 0.01 & 0.01 & 0.01 & 0.01 \\
\hline EEUR & 0.02 & 0.025 & 0.02 & 0.015 & 0.0075 & 0.0075 & 0.005 \\
\hline KOR & 0.025 & 0.02 & 0.01 & 0.01 & 0.01 & 0.01 & 0.01 \\
\hline INDIA & 0.015 & 0.02 & 0.01 & 0.01 & 0.01 & 0.01 & 0.01 \\
\hline
\end{tabular}

\section{Input data for calibration}

The next 4 tables are 1990 input data for calibration for the US

Data from IEA database

Units: EJ Net energy (HHV)

Non-fossil electricity inputs evaluated at average fossil generation efficiency for that region

*** Oil consumption figures for industry INCLUDE non-energy use

Table 59 Fuel demand (EJ) Industry sector

\begin{tabular}{|l|l|l|l|l|l|l|l|}
\hline & & & & \multicolumn{2}{|l|}{ fdemand(L,K,J) } & & \\
\hline Region\# & sec\# & IndOil & IndGas & IndCoal & IndElec & IndBio & IndTotal \\
\hline USA & 2 & 7.356 & 7.0887 & 2.7183 & 3.1207 & 1.1701 & 21.5 \\
\hline
\end{tabular}

Table 60 Fuel demand, Transportation sector

\begin{tabular}{|c|c|c|c|c|c|c|c|}
\hline \multicolumn{8}{|c|}{ fdemand(L,K,J) } \\
\hline Region\# & sec\# & TranOil & TranGas & TranCoal & TranElec & TranBio & TranTotal \\
\hline USA & 3 & 22.5011 & 0.7371 & 0 & 0.0149 & 0 & 23.3 \\
\hline
\end{tabular}

Table 61 Fuel demand, Buildings

fdemand -- Fuel demand, Buildings sector 


\begin{tabular}{|l|l|l|l|l|l|l|l|}
\hline \multicolumn{1}{|l|}{ fdemand(L,K,J) } \\
\hline Region\# & sec\# & BldgOil & BldgGas & BldgCoal & BldgElec & BldgBio & BldgTotal \\
\hline USA & 1 & 2.0986 & 7.836 & 0.1725 & 6.3488 & 0.6209 & 17.1 \\
\hline
\end{tabular}

Table 62 Fuel demand, Electricity generation sector

\begin{tabular}{|c|c|c|c|c|c|c|c|c|c|}
\hline \multicolumn{10}{|c|}{ fdemand -- Fuel demand, Electric Gen sector } \\
\hline \multicolumn{10}{|c|}{ fdemand(L,K,J) } \\
\hline Region\# & sec\# & ElecOil & ElecGas & ElecCoal & ElecNuc & ElecSol & $\begin{array}{l}\text { ElecHydr } \\
\text { o }\end{array}$ & ElecBio & ElecTot \\
\hline$\overline{\text { USA }}$ & 4 & 1.1414 & 2.7354 & 16.2322 & 7.0663 & 0 & 3.341 & 0.6209 & 31.1 \\
\hline
\end{tabular}

\section{Resulting, for example, for the USA for the B2 scenario in Final Energy Demand:}

Table 63 Final energy demand, for example, for the USA for the B2 scenario (MiniCAM output)

\begin{tabular}{|l|l|l|l|l|l|l|l|}
\hline \multicolumn{2}{|l|}{ Final Energy Total-By Fuel } & & & & & \\
\hline & EJ/yr & & & & & & \\
\hline & Oil & Gas & Coal & Elec & Biom & H2 & Total \\
\hline 1990 & 31.95551 & 15.66202 & 2.89031 & 9.48416 & 1.79046 & 0 & 61.78246 \\
\hline 2005 & 37.76573 & 24.58468 & 2.66865 & 10.98545 & 1.41134 & 0 & 77.41586 \\
\hline 2020 & 39.77497 & 32.67494 & 2.22209 & 11.0709 & 1.19786 & 0 & 86.94076 \\
\hline 2035 & 42.12493 & 39.07377 & 2.41247 & 11.02969 & 1.25828 & 0 & 95.89915 \\
\hline 2050 & 46.10209 & 40.7299 & 2.87739 & 10.80512 & 1.44334 & 0 & 101.9579 \\
\hline 2065 & 51.43048 & 37.19612 & 3.89162 & 13.47239 & 1.49725 & 0 & 107.4879 \\
\hline 2080 & 53.06372 & 35.71502 & 4.9359 & 17.97672 & 1.61982 & 0 & 113.3112 \\
\hline 2095 & 56.9303 & 32.48741 & 6.07086 & 22.79717 & 1.7928 & 0 & 120.0785 \\
\hline
\end{tabular}

\section{Resulting, for example, for the USA for the B2 scenario in electricty generation:}

Table 64 Results, for example, for the USA for the B2 scenario in Electric Power Generation by Technologies

\begin{tabular}{|l|l|l|l|l|l|l|l|l|l|l|l|l|l|}
\hline \multicolumn{2}{|l}{ Electric Power Generation } & & & & & & & & & & & & \\
\hline & EJ/yr & & & & & & & & & & & & \\
\hline & Oil & Gas & Coal & Nuclear & Solar & Hydro & Biomass & H2Fcell & Fusion & Wind & SWStor & SatSolar & Tota \\
\hline 1990 & 0.3696 & 0.8341 & 4.926 & 2.1541 & 0 & 1.0128 & 0.1877 & 0 & 0 & 0 & 0 & 0 & 9.48 \\
\hline 2005 & 0.6707 & 1.4479 & 5.0687 & 2.1362 & 0.0004 & 1.0922 & 0.3522 & 0.0416 & 0 & 0.1766 & 0 & 0.0001 & 10.9 \\
\hline 2020 & 0.7513 & 2.1479 & 4.1 & 1.7371 & 0.0043 & 1.1644 & 0.4734 & 0.1375 & 0 & 0.5583 & $1 \mathrm{E}-05$ & 0.0005 & 11.0 \\
\hline 2035 & 0.7342 & 2.7299 & 3.2278 & 1.2523 & 0.0351 & 1.2285 & 0.5253 & 0.2794 & 0 & 1.0228 & $5 \mathrm{E}-05$ & 0.0016 & 11.0 \\
\hline 2050 & 0.9367 & 3.0457 & 2.4818 & 0.7853 & 0.2709 & 1.2846 & 0.4499 & 0.465 & 0 & 1.0919 & 0.0002 & 0.0045 & 10.8 \\
\hline 2065 & 1.4595 & 3.5024 & 2.784 & 1.0825 & 0.7651 & 1.3324 & 0.5731 & 0.6135 & 0 & 1.3649 & 0.0007 & 0.012 & 13.4 \\
\hline 2080 & 1.0266 & 4.4432 & 4.4743 & 1.723 & 1.3612 & 1.3732 & 0.8283 & 0.9268 & 0 & 1.8315 & 0.0036 & 0.019 & 18.0 \\
\hline
\end{tabular}




\begin{tabular}{|c|c|c|c|c|c|c|c|c|c|c|c|c|}
\hline 2095 & 1.0364 & 5.0218 & 6.2393 & 2.349 & 2.0284 & 1.4073 & 1.1117 & 1.2677 & 0 & 2.3341 & 0.0298 & 0.0261 \\
\hline
\end{tabular}

\section{Parameters for emission calculations}

Table 65 An example of a cost curve

\begin{tabular}{|l|l|l|l|l|l|l|l|l|l|l|}
\hline 1 & \multicolumn{9}{l|}{} & \multicolumn{6}{l|}{ from US METHANE REPORT } \\
\hline Region & NumPts & Pt1 & Pt2 & Pt3 & Pt4 & Pt5 & Pt6 & Pt7 & Pt8 & Pt9 \\
\hline 1 & 9 & 0 & 1 & 5 & 10 & 30.6 & 57.1 & 79.4 & 108 & 160.8 \\
\hline 1 & & 0 & 0.0662 & 0.1325 & 0.1656 & 0.2318 & 0.3113 & 0.3689 & 0.4258 & 0.4536 \\
\hline
\end{tabular}

(and so on for all regions, for each cost curve)

Table 66 Global carbon emissions from oil, natural gas and coal combustion to calibrate against for 1990

\begin{tabular}{|l|l|l|}
\hline \multicolumn{2}{|l|}{1990 Carbon Emissions } \\
\hline CO2Calib(I) \\
\hline Source & & \\
\hline 1 & 2372 & Oil \\
\hline 2 & 1005 & Nat Gas \\
\hline 3 & 2495 & Coal \\
\hline
\end{tabular}

Table 67 Global Warming Potential, Atmospheric Half-Lives and Climate Forcing Information of Non- $\mathrm{CO}_{2}$ Greenhouse Gases

\begin{tabular}{|c|c|c|c|}
\hline Greenhouse Gas & GWP & $\begin{array}{l}\text { Approximate removal times } \\
\text { that is half-lives in the } \\
\text { atmosphere }\end{array}$ & $\begin{array}{l}\text { Climate forcing }(\mathrm{W} / \mathrm{m} 2) \text { up to } \\
\text { the year } 2000\end{array}$ \\
\hline Carbon dioxide $\left(\mathrm{CO}_{2}\right)$ & 1 & $>100$ years & 1.3 to 1.5 \\
\hline Methane $\left(\mathrm{CH}_{4}\right)$ & 23 & 10 years & 0.5 to 0.7 \\
\hline Nitrous oxide $\left(\mathrm{N}_{2} \mathrm{O}\right)$ & 296 & 100 years & 0.1 to 0.2 \\
\hline HFC-23 & 12,000 & & \\
\hline HFC-125 & 3,400 & & \\
\hline HFC-134a & 1,300 & & \\
\hline HFC-143a & 4,300 & & \\
\hline HFC-152a & 120 & & \\
\hline HFC-227ea & 3,500 & & \\
\hline HFC-236fa & 9,400 & & \\
\hline $\begin{array}{l}\text { Perfluoromethane } \\
\text { (CF4) }\end{array}$ & 5,700 & $>1000$ years & approximately 0.01 \\
\hline $\begin{array}{l}\text { Perfluoroethane } \\
\text { (C2F6) }\end{array}$ & 11,900 & & \\
\hline $\begin{array}{l}\text { Sulfur Hexafluoride } \\
\text { (SF6) }\end{array}$ & 22,200 & & \\
\hline Tropospheric Ozone & & 10-100 days & 0.25 to 0.75 \\
\hline Fine aerosols & & & \\
\hline
\end{tabular}




\begin{tabular}{|l|l|l|l|l|}
\hline Sulfate & & & 10 days & minus 0.3 to -1.0 \\
\hline Black carbon & & & 10 days & 0.1 to 0.8 \\
\hline
\end{tabular}

Table 68 Gas flare, flared gas burn, and shale burn parameters

"FLRL1" IS THE FLARING RATE IN 1975, "FLRL2" IS THE ULTIMATE

FLARING RATE, AND "FLRL3" IS THE NUMBER OF YEARS TO REACH "FLRL2."

THE MODEL EXPONENTIALLY INTERPOLATES BETWEEN THE RATES; See Equation 93

\begin{tabular}{|l|l|l|l|l|l|l|l|l|l|l|}
\hline $\begin{array}{l}\text { See Equation } \\
92 \text { \& 93 }\end{array}$ & Region & FLRL1 & FLRL2 & FLRL3 & SBRL1 & SBRL2 & SBRL3 & $\begin{array}{l}\text { SHAL } \\
\text { E1 }\end{array}$ & $\begin{array}{l}\text { SHAL } \\
\text { E2 }\end{array}$ & $\begin{array}{l}\text { SHAL } \\
\text { E3 }\end{array}$ \\
\hline US & 1 & 0.08 & 0.025 & 25 & 0.11 & 0.20 & 25 & 0.01 & 0.99 & 70 \\
\hline CANADA & 2 & 0.07 & 0.025 & 25 & 0.25 & 0.20 & 25 & 0.01 & 0.45 & 70 \\
\hline WEUR & 3 & 0.07 & 0.025 & 25 & 0.25 & 0.20 & 25 & 0.01 & 0.45 & 70 \\
\hline JAPAN & 4 & 0.03 & 0.025 & 25 & 0.80 & 0.20 & 25 & 0.01 & 0.99 & 70 \\
\hline AUS\&NZ & 5 & 0.03 & 0.025 & 25 & 0.80 & 0.20 & 25 & 0.01 & 0.99 & 70 \\
\hline FSU & 6 & 0.02 & 0.015 & 25 & 0.80 & 0.28 & 25 & 0.01 & 0.9 & 70 \\
\hline ACENP & 7 & 0.107 & 0.035 & 50 & 0.80 & 0.59 & 50 & 0.01 & 0.25 & 70 \\
\hline MIDEAST & 8 & 0.687 & 0.023 & 50 & 0.75 & 0.44 & 50 & 0.01 & 0.25 & 70 \\
\hline AFRICA & 9 & 0.753 & 0.08 & 50 & 0.60 & 0.28 & 50 & 0.01 & 0.25 & 70 \\
\hline L AMER & 10 & 0.499 & 0.08 & 50 & 0.29 & 0.28 & 50 & 0.01 & 0.25 & 70 \\
\hline S\&E ASIA & 11 & 0.38 & 0.045 & 50 & 0.71 & 0.47 & 50 & 0.01 & 0.25 & 70 \\
\hline EEUR & 12 & 0.02 & 0.015 & 50 & 0.80 & 0.20 & 25 & 0.01 & 0.9 & 70 \\
\hline KOREA & 13 & 0.0001 & 0.0001 & 50 & 0.80 & 0.20 & 25 & 0.01 & 0.9 & 70 \\
\hline INDIA & 14 & 0.38 & 0.045 & 50 & 0.71 & 0.47 & 50 & 0.01 & 0.25 & 70 \\
\hline
\end{tabular}

Table 69 Regional non-feedstock use of oil, gas, and coal (Sfedl)

\begin{tabular}{|l|l|l|l|}
\hline \multicolumn{4}{|l}{ FEEDSTOCK USES OF FOSSIL FUELS (SFEDIL) -- } \\
\multicolumn{3}{l}{ SHARE OF EACH FOSSIL FUEL USED AS A } \\
FEEDSTOCK; equation 97, 98, 99 , 105, 106 \\
\hline OIL & GAS & COAL & Region \\
\hline 0.078 & 0.029 & 0.007 & US \\
\hline 0.06 & 0.029 & 0.007 & CANADA \\
\hline 0.05 & 0.029 & 0.007 & WEUR \\
\hline 0.045 & 0.029 & 0.007 & JAPAN \\
\hline 0.074 & 0.029 & 0.007 & AUS\&NZ \\
\hline 0.097 & 0.029 & 0.007 & FSU \\
\hline 0.069 & 0.029 & 0.007 & ACENP \\
\hline 0.042 & 0.029 & 0.007 & MIDEAST \\
\hline 0.041 & 0.029 & 0.007 & AFRICA \\
\hline 0.043 & 0.029 & 0.007 & L AMER \\
\hline 0.025 & 0.029 & 0.007 & S\&E ASIA \\
\hline 0.093 & 0.029 & 0.007 & EEUR \\
\hline 0.018 & 0.029 & 0.007 & KOR \\
\hline 0.063 & 0.029 & 0.007 & INDIA \\
\hline
\end{tabular}




\section{Non-CO2 emissions}

Table 70 Overview of variables and considerations of non-CO2 emission calculations

\begin{tabular}{|c|c|c|c|c|c|}
\hline Source & Index & Driver Activity & Base Year Data & $\begin{array}{l}\text { \% of } \\
\text { Total } \\
\text { (base } \\
\text { year) }\end{array}$ & $\begin{array}{l}\text { Cost Curve } \\
(\max )\end{array}$ \\
\hline \multicolumn{6}{|l|}{ Methane (Gas 1) } \\
\hline Industrial Sources & 1 & GDP (exponent set to 0.25 ) & $\begin{array}{l}\text { EDGAR I10:Metals + } \\
\text { I30:Chemicals }\end{array}$ & $0.3 \%$ & \\
\hline $\begin{array}{l}\text { Transportation } \\
\text { (Mobile Sources) }\end{array}$ & 2 & Oil for transportation & $\begin{array}{l}\text { Fuel Stat \& Mobile } \\
\text { (split using ICF/EPA } \\
\text { models } 2 / 03 \text { ) }\end{array}$ & $0.4 \%$ & \\
\hline Coal Mining & 3 & $\begin{array}{l}\text { Average of coal production and } \\
\text { consumption (to smooth for } \\
\text { regional swings in coal } \\
\text { production) }\end{array}$ & Coal & $10.0 \%$ & $\begin{array}{l}\text { Coal } \\
(20-98 \%)\end{array}$ \\
\hline $\begin{array}{l}\text { Elec Utilities } \\
\text { (Stationary) }\end{array}$ & 4 & $\begin{array}{l}\text { Tier 1 Coefficients on } \\
\text { stationary fossil use (except } \\
\text { buildings biomass which is in } \\
\text { source 9) }\end{array}$ & $\begin{array}{l}\text { Fuel Stat \& Mobile } \\
\text { (split) }\end{array}$ & $0.7 \%$ & \\
\hline $\begin{array}{l}\text { Natural Gas } \\
\text { Systems }\end{array}$ & 5 & $\begin{array}{l}0.66 * \text { gas consumption }+ \\
0.33 * \text { gas production }\end{array}$ & Natural Gas & $15.6 \%$ & $\begin{array}{l}\text { Natural Gas } \\
(35-45 \%)\end{array}$ \\
\hline Petroleum Systems & 6 & Oil production & Oil & $1.0 \%$ & $\begin{array}{l}\text { Oil } \\
(0-40 \%)\end{array}$ \\
\hline Landfills & 7 & $\begin{array}{l}\text { Population with an exponential } \\
\text { logistic to approximate waste } \\
\text { per capita based on income }\end{array}$ & Solid Waste & $13.1 \%$ & $\begin{array}{l}\text { Solid Waste } \\
(60-90 \%)\end{array}$ \\
\hline $\begin{array}{l}\text { Wastewater } \\
\text { Treatment }\end{array}$ & 8 & Population & Wastewater & $8.6 \%$ & \\
\hline $\begin{array}{l}\text { Biofuel } \\
\text { Combustion }\end{array}$ & 9 & Biomass in buildings sector & Biofuel Combustion & $3.3 \%$ & \\
\hline Land Use/Burning & 10 & $\begin{array}{l}\text { Land use emissions (restricted } \\
\text { to positive values) }\end{array}$ & $\begin{array}{l}\text { EDGAR: LU Change } \\
\text { and Burning }\end{array}$ & $4.1 \%$ & \\
\hline $\begin{array}{l}\text { Enteric } \\
\text { Fermentation }\end{array}$ & 11 & Beef/mutton production & Enteric Fermentation & $28.0 \%$ & \\
\hline $\begin{array}{l}\text { Manure } \\
\text { Management }\end{array}$ & 12 & $\begin{array}{l}\text { Managed beef (fraction beef } \\
\text { grain-fed), plus } 5 \times \text { pork and } 5 \\
\text { x poultry production }\end{array}$ & Manure & $3.4 \%$ & $\begin{array}{l}\text { Manure } \\
\text { Management } \\
(0-20 \%)\end{array}$ \\
\hline
\end{tabular}




\begin{tabular}{|c|c|c|c|c|c|}
\hline Rice Cultivation & 13 & $\begin{array}{l}\text { Food grain production / cumul. } \\
\text { technological change in food } \\
\text { grain production }\end{array}$ & Rice & $10.6 \%$ & \\
\hline $\begin{array}{l}\text { Agricultural } \\
\text { Residue Burning }\end{array}$ & 14 & Total crop area & EDGAR Ag Residue & $0.3 \%$ & \\
\hline $\begin{array}{l}\text { Temperate Forest } \\
\text { Fires }\end{array}$ & 15 & Forest land & EDGAR forest fires & $0.4 \%$ & \\
\hline \multicolumn{6}{|l|}{ N2O (Gas 2) } \\
\hline $\begin{array}{l}\text { Elec Utilities } \\
\text { (Stationary) }\end{array}$ & 1 & $\begin{array}{l}\text { IPCC Tier } 1 \text { coefs for Coal } \\
\text { (end-use) and Fuel Oil } \\
\text { (stationary oil) }\end{array}$ & $\begin{array}{l}\text { Fossil Fuel (Split using } \\
\text { spreadsheet models 2- } \\
\text { 03) }\end{array}$ & $6.8 \%$ & \\
\hline $\begin{array}{l}\text { Transportation } \\
\text { (Mobile) }\end{array}$ & 2 & Oil for transportation & $\begin{array}{l}\text { Fossil Fuel (Split using } \\
\text { spreadsheet models 2- } \\
03 \text { ) }\end{array}$ & $1.0 \%$ & \\
\hline Human Sewage & 3 & $\begin{array}{l}\text { Population * percap calories } \\
\text { from meat (protein proxy) }\end{array}$ & HumanSewage & $2.6 \%$ & \\
\hline Adipic Acid & 4 & GDP (exponent set to 0.25 ) & $\begin{array}{l}\text { ICF/EPA 2-03 } \\
\text { Spreadsheet model }\end{array}$ & $2.7 \%$ & $\begin{array}{l}\text { Adipic Acid } \\
(96 \%)\end{array}$ \\
\hline Nitric Acid & 5 & GDP (exponent set to 0.25 ) & $\begin{array}{l}\text { ICF/EPA 2-03 } \\
\text { Spreadsheet model }\end{array}$ & $5.1 \%$ & $\begin{array}{l}\text { Nitric Acid } \\
(89 \%)\end{array}$ \\
\hline Agricultural Soils & 6 & $\begin{array}{l}\text { Oil crops and part of misc. } \\
\text { crops (proxy for } \mathrm{N} \text { fixing } \\
\text { crops), and total crops (proxy } \\
\text { for fert use) weighted by } \\
\text { estimated emissions factors }\end{array}$ & $\begin{array}{l}\text { Ag Soil Values (split } \\
\text { using EDGAR) }\end{array}$ & $41.0 \%$ & \\
\hline $\begin{array}{l}\text { Manure } \\
\text { Management }\end{array}$ & 7 & $\begin{array}{l}\text { Managed beef (fraction beef } \\
\text { grain-fed), plus pork and } \\
\text { poultry production }\end{array}$ & Manure & $7.4 \%$ & \\
\hline $\begin{array}{l}\text { Biomass } \\
\text { Combustion }\end{array}$ & 8 & $\begin{array}{l}\text { Biomass (total energy } \\
\text { consumption) }\end{array}$ & Biomass Fuel & $1.2 \%$ & \\
\hline $\begin{array}{l}\text { Agricultural } \\
\text { Residue Burning }\end{array}$ & 9 & Total crop area & $\begin{array}{l}\text { EDGAR Ag Residue } \\
\text { Burning }\end{array}$ & $0.3 \%$ & \\
\hline Land Use/Burning & 10 & $\begin{array}{l}\text { Same as methane from land use } \\
\text { / burning }\end{array}$ & $\begin{array}{l}\text { EDGAR: LU change } \\
\text { and burning }\end{array}$ & $5.5 \%$ & \\
\hline $\begin{array}{l}\text { Unmanaged } \\
\text { Manure }\end{array}$ & 11 & $\begin{array}{l}\text { Beef production from pasture } \\
\text { land }\end{array}$ & $\begin{array}{l}\text { Ag Soil Values (split } \\
\text { using EDGAR) }\end{array}$ & $26.3 \%$ & \\
\hline $\begin{array}{l}\text { Temperate Forest } \\
\text { Fires }\end{array}$ & 12 & Forest land & EDGAR Forest fires & $0.1 \%$ & \\
\hline
\end{tabular}




\section{Sulfur emissions}

Table 71 Regional end-use sector specific ash retention parameters for coal

\begin{tabular}{|l|l|l|l|l|}
\hline Ash Retention percentage for Coal & & \\
\hline SO2ASHR & $($ KL $)$ & & & \\
\hline Reg & RESCOM & INDUSTRY & TRANSPORT & E Power G \\
\hline USA & 10 & 7.3 & 5 & 5 \\
\hline CANADA & 18 & 7.3 & 5 & 20 \\
\hline WEUR & 15 & 11.3 & 5 & 13.3 \\
\hline JAPAN & 10 & 58.1 & 5 & 5 \\
\hline AUSNZ & 10 & 5 & 5 & 13.3 \\
\hline FSUEE & 30 & 30 & 30 & 30 \\
\hline ACENP & 29.7 & 19.5 & 30 & 8 \\
\hline MIDEAST & 10 & 5 & 5 & 5 \\
\hline AFR & 10 & 5 & 5 & 5 \\
\hline LA & 10 & 10 & 5 & 13.3 \\
\hline SEASIA & 11 & 10.3 & 5 & 8.5 \\
\hline EEuro & 15 & 30 & 15 & 5 \\
\hline Korea & 10 & 5 & 5 & 5 \\
\hline India & 10 & 5 & 5 & 5.5 \\
\hline
\end{tabular}

Table 72 Sulfur content (percentage by weight)

For emissions in TgS, use: (Fuel Use in EJ) / (GJ/Tonne) * (S \%/100) * $1000 *(1$ - f_control\%)

Biomass has fixed emission coefficient

For nat gas, the factor below is really the emissions rate, not $\mathrm{S} \%$

Generally identical for coal (adjusted in some instances to match sectoral inventories)

SO2SCT Sulfur content (percentage by weight)

Note that in dev countries, the $\mathrm{S} \%$ of pet products

is the $\mathrm{S} \%$ before controls (which include, reducing $\mathrm{S} \%$ !)

\begin{tabular}{|c|c|c|c|c|c|}
\hline \multicolumn{6}{|c|}{ SO2SCT Sulfur content (percentage by weight) } \\
\hline Reg & FuelName & RESCOM & INDUSTRY & TRANSPORT & $\begin{array}{l}\text { E Power } \\
\text { G }\end{array}$ \\
\hline USA & OIL & 0.67 & 0.26 & 0.17 & 1.34 \\
\hline CANADA & OIL & 0.28 & 0.57 & 0.17 & 1 \\
\hline WEUR & OIL & 0.3 & 0.32 & 0.19 & 0.5 \\
\hline JAPAN & OIL & 0.43 & 0.33 & 0.49 & 1.2 \\
\hline AUSNZ & OIL & 0.4 & 1 & 0.2 & 1.4 \\
\hline$\overline{F S U}$ & OIL & 0.4 & 1.3 & 0.4 & 1.3 \\
\hline ACENP & OIL & 0.23 & 0.45 & 0.21 & 0.56 \\
\hline MIDEAST & OIL & 0.2 & 1 & 0.25 & 1.4 \\
\hline AFR & OIL & 0.32 & 1.05 & 0.27 & 1.75 \\
\hline
\end{tabular}




\begin{tabular}{|c|c|c|c|c|c|}
\hline LA & OIL & 0.4 & 2.43 & 0.55 & 2.7 \\
\hline SEASIA & OIL & 0.3 & 1.73 & 0.54 & 1.66 \\
\hline EEuro & OIL & 0.3 & 0.75 & 0.55 & 0.9 \\
\hline Korea & OIL & 0.78 & 1.74 & 0.45 & 2.85 \\
\hline India & OIL & 0.5 & 3.17 & 0.56 & 1.6 \\
\hline USA & GAS & 0.0063 & 0.4389 & 0.0063 & 0.0063 \\
\hline CANADA & GAS & 0.0063 & 1.254 & 0.0063 & 0.0063 \\
\hline WEUR & GAS & 0.0063 & 0.1568 & 0.0063 & 0.0063 \\
\hline JAPAN & GAS & 0.0063 & 0.1568 & 0.0063 & 0.0063 \\
\hline AUSNZ & GAS & 0.0063 & 0.1568 & 0.0063 & 0.0063 \\
\hline FSU & GAS & 0.0063 & 0.35 & 0.0063 & 0.0627 \\
\hline ACENP & GAS & 0.0063 & 0.5 & 0.0063 & 0.0063 \\
\hline MIDEAST & GAS & 0.0063 & 0.5 & 0.0063 & 0.0063 \\
\hline AFR & GAS & 0.0063 & 0.5 & 0.0063 & 0.0063 \\
\hline LA & GAS & 0.0063 & 0.5 & 0.0063 & 0.0063 \\
\hline SEASIA & GAS & 0.0063 & 0.5 & 0.0063 & 0.0063 \\
\hline EEuro & GAS & 0.0063 & 0.5 & 0.0063 & 0.0627 \\
\hline Korea & GAS & 0.0063 & 0.5 & 0.0063 & 0.0063 \\
\hline India & GAS & 0.0063 & 0.5 & 0.0063 & 0.0063 \\
\hline USA & COAL & 1.84 & 1.18 & 1.38 & 1.38 \\
\hline CANADA & COAL & 1.05 & 1.05 & 1.05 & 1.05 \\
\hline WEUR & COAL & 1.14 & 1.23 & 1.23 & 1.23 \\
\hline JAPAN & COAL & 0.55 & 0.75 & 0.55 & 0.55 \\
\hline AUSNZ & COAL & 0.34 & 0.34 & 0.34 & 0.34 \\
\hline FSU & COAL & 1.04 & 1.15 & 1.04 & 1.04 \\
\hline ACENP & COAL & 1.25 & 1.25 & 1.25 & 1.25 \\
\hline MIDEAST & COAL & 1.25 & 1.25 & 1.25 & 1.25 \\
\hline AFR & COAL & 0.59 & 0.59 & 0.59 & 0.59 \\
\hline LA & COAL & 1.23 & 1.23 & 1.23 & 1.23 \\
\hline SEASIA & COAL & 1.23 & 1.23 & 1.23 & 1.23 \\
\hline EEuro & COAL & 1.07 & 1.33 & 1.33 & 1.4 \\
\hline Korea & COAL & 0.99 & 0.99 & 0.99 & 0.99 \\
\hline India & COAL & 0.55 & 0.55 & 0.55 & 0.55 \\
\hline
\end{tabular}

Table 73 Regional end-use specific and fuel-specific heat content values

\begin{tabular}{|l|l|l|l|l|l|}
\hline Heat Content (GJTonne) & & & \\
\hline SO2ENDN & $(\mathrm{JKL})$ & & & & \\
\hline Reg & FuelName & RESCOM & INDUSTRY & TRANSPORT & $\begin{array}{l}\text { E Power } \\
\text { G }\end{array}$ \\
\hline USA & OIL & 42.98 & 42 & 44.68 & 42 \\
\hline CANADA & OIL & 42.98 & 42 & 44.68 & 42 \\
\hline WEUR & OIL & 42.98 & 42 & 44.68 & 42 \\
\hline JAPAN & OIL & 42.87 & 42.91 & 43.87 & 42.02 \\
\hline
\end{tabular}




\begin{tabular}{|c|c|c|c|c|c|}
\hline AUSNZ & OIL & 42.01 & 42.56 & 44.46 & 43.03 \\
\hline FSUEE & OIL & 42.98 & 42 & 44.68 & 42 \\
\hline ACENP & OIL & 40.49 & 39.41 & 40.61 & 39.41 \\
\hline MIDEAST & OIL & 41.17 & 43.13 & 44.61 & 42.49 \\
\hline AFR & OIL & 42.4 & 42.72 & 44.48 & 42.35 \\
\hline LA & OIL & 40.86 & 42.89 & 40.86 & 42.17 \\
\hline SEASIA & OIL & 43.28 & 40.1 & 41.89 & 39.58 \\
\hline EEuro & OIL & 42.98 & 42 & 44.68 & 42 \\
\hline Korea & OIL & 41.17 & 39.87 & 41.42 & 38.36 \\
\hline India & OIL & 41.52 & 40.01 & 40.96 & 39.83 \\
\hline USA & GAS & 100 & 100 & 100 & 100 \\
\hline CANADA & GAS & 100 & 100 & 100 & 100 \\
\hline WEUR & GAS & 100 & 100 & 100 & 100 \\
\hline JAPAN & GAS & 100 & 100 & 100 & 100 \\
\hline AUSNZ & GAS & 100 & 100 & 100 & 100 \\
\hline$\overline{F S U}$ & GAS & 100 & 100 & 100 & 100 \\
\hline ACENP & GAS & 100 & 100 & 100 & 100 \\
\hline MIDEAST & GAS & 100 & 100 & 100 & 100 \\
\hline AFR & GAS & 100 & 100 & 100 & 100 \\
\hline LA & GAS & 100 & 100 & 100 & 100 \\
\hline SEASIA & GAS & 100 & 100 & 100 & 100 \\
\hline EEuro & GAS & 100 & 100 & 100 & 100 \\
\hline Korea & GAS & 100 & 100 & 100 & 100 \\
\hline India & GAS & 100 & 100 & 100 & 100 \\
\hline USA & $\overline{\mathrm{COAL}}$ & 23.53 & 23.53 & 23.53 & 23.53 \\
\hline CANADA & COAL & 20.56 & 20.56 & 20.56 & 20.56 \\
\hline WEUR & COAL & 15.34 & 15.34 & 15.34 & 15.34 \\
\hline JAPAN & COAL & 27.34 & 27.34 & 27.34 & 27.34 \\
\hline AUSNZ & COAL & 15.46 & 15.46 & 15.46 & 15.46 \\
\hline FSU & COAL & 18.54 & 18.54 & 18.54 & 18.54 \\
\hline ACENP & COAL & 20.97 & 20.97 & 20.97 & 20.97 \\
\hline MIDEAST & $\overline{\mathrm{COAL}}$ & 26.53 & 26.53 & 26.53 & 26.53 \\
\hline AFR & COAL & 22.71 & 22.71 & 22.71 & 22.71 \\
\hline$\overline{\mathrm{LA}}$ & COAL & 25.86 & 25.86 & 25.86 & 25.86 \\
\hline SEASIA & COAL & 21.46 & 21.46 & 21.46 & 21.46 \\
\hline EEuro & COAL & 13.99 & 13.99 & 13.99 & 13.99 \\
\hline Korea & COAL & 26.79 & 26.79 & 26.79 & 26.79 \\
\hline India & COAL & 20.22 & 20.22 & 20.22 & 20.22 \\
\hline
\end{tabular}

Table 74 An example of the non-climate sulfur control fraction

\begin{tabular}{|l|l|l|l|l|l|l|l|l|}
\hline \multicolumn{2}{|l}{ Oth Emiss SO2 Cntl Frac } \\
\hline & $\%$ & & & & & & & \\
\hline & Bld Oil & Bld Gas & Bld Coal & Bld Biom & Ind Oil & Ind Gas & Ind Coal & Ind Biom \\
\hline 1990 & 0.23181 & 0.12261 & 0.12261 & 0 & 0.06288 & 0.2722 & 0.2207 & 0.11035 \\
\hline 2005 & 0.51286 & 0.27128 & 0.27128 & 0 & 0.13912 & 0.60223 & 0.4883 & 0.24415 \\
\hline
\end{tabular}




\begin{tabular}{|l|l|l|l|l|l|l|l|l|}
\hline 2020 & 0.71749 & 0.37951 & 0.37951 & 0 & 0.19462 & 0.84252 & 0.68312 & 0.34156 \\
\hline 2035 & 0.78565 & 0.41557 & 0.41557 & 0 & 0.21311 & 0.92256 & 0.74802 & 0.37401 \\
\hline 2050 & 0.82357 & 0.43562 & 0.43562 & 0 & 0.2234 & 0.96708 & 0.78412 & 0.39206 \\
\hline 2065 & 0.84087 & 0.44478 & 0.44478 & 0 & 0.22809 & 0.9874 & 0.8006 & 0.4003 \\
\hline 2080 & 0.84757 & 0.44832 & 0.44832 & 0 & 0.22991 & 0.99526 & 0.80697 & 0.40349 \\
\hline 2095 & 0.85001 & 0.44961 & 0.44961 & 0 & 0.23057 & 0.99813 & 0.8093 & 0.40465 \\
\hline
\end{tabular}

Table 75 Additional sulfur emission control factors

\begin{tabular}{|l|l|l|l|l|l|l|l|l|}
\hline Oth Emiss SO2 Cntl Frac & & & & & \\
\hline & $\%$ & & & & & & \\
\hline & Tran Oil & Tran Gas & Tran Coal & $\begin{array}{l}\text { Tran } \\
\text { Biom }\end{array}$ & Elec Oil & Elec Gas & Elec Coal & Elec Biom \\
\hline 1990 & 0.19233 & 0.12261 & 0.2207 & 0.2207 & 0.1708 & 0.24523 & 0.24523 & 0.12261 \\
\hline 2005 & 0.42553 & 0.27128 & 0.4883 & 0.4883 & 0.3779 & 0.54255 & 0.54255 & 0.27128 \\
\hline 2020 & 0.59531 & 0.37951 & 0.68312 & 0.68312 & 0.52867 & 0.75902 & 0.75902 & 0.37951 \\
\hline 2035 & 0.65187 & 0.41557 & 0.74802 & 0.74802 & 0.5789 & 0.83114 & 0.83114 & 0.41557 \\
\hline 2050 & 0.68333 & 0.43562 & 0.78412 & 0.78412 & 0.60684 & 0.87125 & 0.87125 & 0.43562 \\
\hline 2065 & 0.69769 & 0.44478 & 0.8006 & 0.8006 & 0.61959 & 0.88955 & 0.88955 & 0.44478 \\
\hline 2080 & 0.70324 & 0.44832 & 0.80697 & 0.80697 & 0.62452 & 0.89663 & 0.89663 & 0.44832 \\
\hline 2095 & 0.70527 & 0.44961 & 0.8093 & 0.8093 & 0.62632 & 0.89922 & 0.89922 & 0.44961 \\
\hline
\end{tabular}

Table 76 Sulfur Emissions Control Mid-point GDP_0 (PPP-based GDPcap) S Emissions Control "timescale" Tau (PPP-based GDPcap)

\begin{tabular}{|l|l|}
\hline \multicolumn{2}{|l|}{\begin{tabular}{l} 
Sulfur Emissions Control Mid-point \\
GDP_0 (ppp-based GDPcap) \\
\hline SO2GDP0 \\
\hline Reg
\end{tabular} Value } \\
\hline USA & 27.2 \\
\hline CANADA & 32.3 \\
\hline WEUR & 16.8 \\
\hline JAPAN & 8 \\
\hline AUSNZ & 16.9 \\
\hline FSUEE & 12 \\
\hline ACENP & 8 \\
\hline MIDEAST & 8 \\
\hline AFR & 8 \\
\hline LA & 8 \\
\hline SEASIA & 8 \\
\hline EEuro & 10.3 \\
\hline Korea & 8 \\
\hline India & 8 \\
\hline
\end{tabular}

Table 77 Regional end-use and fuel-specific maximum control values 


\begin{tabular}{|c|c|c|c|c|c|}
\hline \multicolumn{2}{|c|}{ SO2MAXCTRL } & \multirow{2}{*}{$\begin{array}{l}\text { (JKL) } \\
\text { RESCOM }\end{array}$} & \multicolumn{3}{|c|}{$\begin{array}{l}\text { For oil, can use alternative formulation based on } \\
\mathrm{S} \% \text { below }\end{array}$} \\
\hline Reg & FuelName & & INDUSTRY & TRANSPORT & E Power G \\
\hline USA & OIL & 45 & 81 & 45 & 81 \\
\hline CANADA & OIL & 45 & 81 & 45 & 81 \\
\hline WEUR & OIL & 45 & 81 & 45 & 81 \\
\hline JAPAN & OIL & 45 & 81 & 45 & 81 \\
\hline AUSNZ & OIL & 45 & 81 & 45 & 81 \\
\hline FSUEE & OIL & 45 & 81 & 45 & 81 \\
\hline ACENP & OIL & 90 & 81 & 72 & 90 \\
\hline MIDEAST & OIL & 90 & 81 & 72 & 90 \\
\hline AFR & OIL & 90 & 81 & 72 & 90 \\
\hline LA & OIL & 90 & 81 & 72 & 90 \\
\hline SEASIA & OIL & 90 & 81 & 79.2 & 90 \\
\hline EEuro & OIL & 45 & 81 & 45 & 81 \\
\hline Korea & OIL & 90 & 81 & 79.2 & 90 \\
\hline India & OIL & 90 & 81 & 79.2 & 90 \\
\hline USA & GAS & 45 & 99.9 & 45 & 90 \\
\hline CANADA & GAS & 45 & 99.9 & 45 & 90 \\
\hline WEUR & GAS & 45 & 99.9 & 45 & 90 \\
\hline JAPAN & GAS & 45 & 99.9 & 45 & 90 \\
\hline AUSNZ & GAS & 45 & 99.9 & 45 & 90 \\
\hline FSU & GAS & 45 & 99.9 & 45 & 90 \\
\hline ACENP & GAS & 45 & 99.9 & 45 & 90 \\
\hline MIDEAST & GAS & 45 & 99.9 & 45 & 90 \\
\hline AFR & GAS & 45 & 99.9 & 45 & 90 \\
\hline LA & GAS & 45 & 99.9 & 45 & 90 \\
\hline SEASIA & GAS & 45 & 99.9 & 45 & 90 \\
\hline EEuro & GAS & 45 & 99.9 & 45 & 90 \\
\hline Korea & GAS & 45 & 99.9 & 45 & 90 \\
\hline India & GAS & 45 & 99.9 & 45 & 90 \\
\hline USA & COAL & 45 & 81 & 81 & 90 \\
\hline CANADA & COAL & 45 & 81 & 81 & 90 \\
\hline WEUR & COAL & 45 & 81 & 81 & 90 \\
\hline JAPAN & COAL & 45 & 81 & 81 & 90 \\
\hline AUSNZ & COAL & 45 & 81 & 81 & 90 \\
\hline FSU & COAL & 45 & 81 & 81 & 90 \\
\hline ACENP & COAL & 45 & 81 & 81 & 90 \\
\hline MIDEAST & COAL & 45 & 81 & 81 & 90 \\
\hline AFR & COAL & 45 & 81 & 81 & 90 \\
\hline LA & COAL & 45 & 81 & 81 & 90 \\
\hline SEASIA & COAL & 45 & 81 & 81 & 90 \\
\hline EEuro & COAL & 45 & 81 & 81 & 90 \\
\hline Korea & COAL & 45 & 81 & 81 & 90 \\
\hline India & COAL & 45 & 81 & 81 & 90 \\
\hline
\end{tabular}


Table 78 Regional maximum percentages of non-energy related industrial sulfur emissions

\begin{tabular}{|l|l|}
\hline \multicolumn{2}{|l|}{ Max Reduction \% for Industrial (non- } \\
Energy) Emissions \\
\hline SO2IPMR & \\
\hline Reg & Value \\
\hline USA & 45 \\
\hline CANADA & 45 \\
\hline WEUR & 45 \\
\hline JAPAN & 45 \\
\hline AUSNZ & 45 \\
\hline FSUEE & 80 \\
\hline ACENP & 90 \\
\hline MIDEAST & 90 \\
\hline AFR & 90 \\
\hline LA & 90 \\
\hline SEASIA & 90 \\
\hline EEuro & 45 \\
\hline Korea & 90 \\
\hline India & 90 \\
\hline
\end{tabular}

Table 79 Regional coefficients determining changes in industrial sulfur emissions over time

\begin{tabular}{|l|l|}
\hline \multicolumn{2}{|l|}{$\begin{array}{l}\text { Power-law growth in industrial } \\
\text { emissions (as yr } \wedge \text { r) }\end{array}$} \\
\hline SO2PLG & \\
\hline Region & Value \\
\hline USA & 0 \\
\hline CANADA & 0 \\
\hline WEUR & 0 \\
\hline JAPAN & 0 \\
\hline AUSNZ & 0 \\
\hline FSUEE & 0 \\
\hline ACENP & 0.25 \\
\hline MIDEAST & 0.25 \\
\hline AFR & 0.25 \\
\hline LA & 0.25 \\
\hline SEASIA & 0.25 \\
\hline EEuro & 0 \\
\hline Korea & 0.25 \\
\hline India & 0.25 \\
\hline
\end{tabular}

\section{Parameters related to the AgLU module}

Table 80 Example of historical land use data collected 


\begin{tabular}{|l|l|l|l|l|l|l|l|l|l|l|l|}
\hline \multicolumn{2}{|l|}{ Historical Land Use (000ha) } & & \multicolumn{1}{|l|}{} & & & & & & \\
\hline Based on FAO numbers and converted to AgLU land allocation methodology & & & & \\
\hline HistLand & 1961 (due to lack of FAO data for 1960) & & 1975 & & & & \\
\hline Region & CropLand & Pasture & Forest & Unmgd & Other & CropLand & Pasture & Forest & Unmgd & Other \\
\hline USA & 90582 & 276067 & 200025 & 165410 & 183828 & 93416 & 252044 & 195019 & 191605 & 183828 \\
\hline Canada & 21158 & 22041 & 59430 & 425252 & 394217 & 21599 & 27159 & 59430 & 419693 & 394217 \\
\hline $\begin{array}{l}\text { OECD90 } \\
\text { Europe }\end{array}$ & 81520 & 89259 & 112775 & 52173 & 100505 & 78110 & 85775 & 121645 & 50207 & 100505 \\
\hline Japan & 4849 & 254 & 11310 & 14797 & 6443 & 4182 & 1119 & 11076 & 14832 & 6443 \\
\hline Aus \& NZ & 9475 & 34436 & 12022 & 608228 & 130868 & 12846 & 35521 & 12022 & 603772 & 130868 \\
\hline FSU & 133332 & 309929 & 140509 & 954933 & 651367 & 129218 & 326184 & 140509 & 942791 & 651367 \\
\hline China/CPA & 173712 & 341012 & 142086 & 211950 & 305855 & 166364 & 398302 & 130977 & 173117 & 305855 \\
\hline MiddleEast & 16462 & 20487 & 3437 & 201205 & 272611 & 17357 & 20484 & 3433 & 200316 & 272611 \\
\hline Africa & 84711 & 51247 & 188865 & 1460883 & 1148280 & 93777 & 50956 & 187652 & 1453237 & 1148280 \\
\hline $\begin{array}{l}\text { Latin } \\
\text { America }\end{array}$ & 46595 & 125369 & 146625 & 1424004 & 263752 & 57721 & 138624 & 139124 & 1407138 & 263752 \\
\hline S\&E Asia & 49821 & 50291 & 176468 & 151149 & 162703 & 56011 & 50735 & 166079 & 154884 & 162703 \\
\hline EEU & 35245 & 24205 & 26551 & 17110 & 11523 & 34071 & 24119 & 27425 & 17481 & 11523 \\
\hline Korea & 2598 & 41 & 1239 & 5231 & 764 & 2778 & 73 & 1227 & 5031 & 764 \\
\hline India & 153229 & 21173 & 51601 & 37023 & 34294 & 159914 & 19541 & 59648 & 23922 & 34294 \\
\hline
\end{tabular}

Table 81 Regional land areas in 1990

\begin{tabular}{|l|l|l|l|l|l|l|}
\hline \multicolumn{2}{|l|}{ Land Area (1990 data in 000 ha) } & & & & \\
\hline Region & ArableLand & Pasture & Forest & Other & TotalLand & NonWild \\
\hline USA & 139099 & 249161 & 295990 & 183828 & 915912 & 732084 \\
\hline Canada & 32150 & 33731 & 453300 & 394217 & 922097 & 527880 \\
\hline OECD90 Europe & 96320 & 81749 & 142822 & 100505 & 436214 & 335709 \\
\hline Japan & 4611 & 1493 & 25105 & 6443 & 37652 & 31209 \\
\hline Aus \& NZ & 47649 & 33342 & 153280 & 130868 & 795029 & 664161 \\
\hline FSU & 195820 & 335893 & 941530 & 651367 & 2190070 & 1538703 \\
\hline China/CPA & 160243 & 421777 & 181791 & 305855 & 1174615 & 868760 \\
\hline MiddleEast & 26572 & 24905 & 16187 & 272611 & 514201 & 241590 \\
\hline Africa & 144177 & 51523 & 715388 & 1148280 & 2934225 & 1785945 \\
\hline Latin America & 106132 & 147691 & 1011154 & 263752 & 2005002 & 1741250 \\
\hline S\&E Asia & 106717 & 52245 & 257910 & 162703 & 590410 & 427707 \\
\hline EEU & 39219 & 24605 & 35158 & 11523 & 114581 & 103058 \\
\hline Korea & 2415 & 200 & 6476 & 764 & 9873 & 9109 \\
\hline India & 175297 & 17646 & 67762 & 34294 & 297319 & 263025 \\
\hline
\end{tabular}

Table 82 Land Carbon Density Parameters, by Region (TgC/000ha)

\begin{tabular}{|l|l|l|l|l|l|l|l|l|l|l|}
\hline CDensity & \multicolumn{4}{|l|}{ Vegetation C Density (TgC/000ha) } & \multicolumn{4}{l|}{ Soil C Density (TgC/000ha) } \\
\hline Region & crops & biomass & pasture & trees & UnMan & crops & biomass & pasture & trees & UnMan \\
\hline USA & 0.0050 & 0.0300 & 0.0070 & 0.0920 & 0.0920 & 0.1420 & 0.1890 & 0.1890 & 0.1392 & 0.1392 \\
\hline
\end{tabular}




\begin{tabular}{|l|l|l|l|l|l|l|l|l|l|l|}
\hline Canada & 0.0050 & 0.0300 & 0.0070 & 0.0920 & 0.0920 & 0.1420 & 0.1890 & 0.1890 & 0.1392 & 0.1392 \\
\hline $\begin{array}{l}\text { OECD90 } \\
\text { Europe }\end{array}$ & 0.0050 & 0.0300 & 0.0070 & 0.1388 & 0.1388 & 0.1420 & 0.1890 & 0.1890 & 0.1465 & 0.1465 \\
\hline Japan & 0.0050 & 0.0300 & 0.0070 & 0.1161 & 0.1161 & 0.1420 & 0.1890 & 0.1890 & 0.0947 & 0.0947 \\
\hline Aus \& NZ & 0.0050 & 0.0300 & 0.0070 & 0.1161 & 0.1161 & 0.1420 & 0.1890 & 0.1890 & 0.0947 & 0.0947 \\
\hline FSU & 0.0050 & 0.0300 & 0.0100 & 0.0936 & 0.0936 & 0.1510 & 0.1890 & 0.1890 & 0.2002 & 0.2002 \\
\hline China/CPA & 0.0050 & 0.0300 & 0.0070 & 0.1565 & 0.1565 & 0.1420 & 0.1890 & 0.1890 & 0.1332 & 0.1332 \\
\hline MiddleEast & 0.0050 & 0.0300 & 0.0032 & 0.1800 & 0.0032 & 0.0972 & 0.0649 & 0.0649 & 0.1309 & 0.0649 \\
\hline Africa & 0.0150 & 0.0300 & 0.0150 & 0.1191 & 0.1191 & 0.0736 & 0.0736 & 0.0736 & 0.0920 & 0.0920 \\
\hline $\begin{array}{l}\text { Latin } \\
\text { America }\end{array}$ & 0.0050 & 0.0300 & 0.0100 & 0.1543 & 0.1543 & 0.0801 & 0.0420 & 0.0420 & 0.1066 & 0.1066 \\
\hline S\&E Asia & 0.0050 & 0.0300 & 0.0600 & 0.2159 & 0.2159 & 0.0644 & 0.0500 & 0.0500 & 0.0915 & 0.0915 \\
\hline EEU & 0.0050 & 0.0300 & 0.0070 & 0.1388 & 0.1388 & 0.1420 & 0.1890 & 0.1890 & 0.1465 & 0.1465 \\
\hline Korea & 0.0050 & 0.0300 & 0.0070 & 0.1161 & 0.1161 & 0.1420 & 0.1890 & 0.1890 & 0.0947 & 0.0947 \\
\hline India & 0.0050 & 0.0300 & 0.0600 & 0.2159 & 0.2159 & 0.0644 & 0.0500 & 0.0500 & 0.0915 & 0.0915 \\
\hline
\end{tabular}

Table 83 Harvested (1990 data in 000 ha)

\begin{tabular}{|l|l|l|l|l|l|l|}
\hline \multicolumn{4}{|l|}{ Area Harvested (1990 data in 000 ha) } & & & \\
\hline USA & FoodGr & CoarseGr & OilCrops & OthCrops & Biomass & Hay/Grass \\
\hline Canada & 29107.40 & 36530.60 & 29337.76 & 4059.20 & 0 & 31274.53 \\
\hline OECD90 Europe & 14097.50 & 7480.80 & 4002.10 & 621.71 & 0 & 5903.90 \\
\hline Japan & 27360.19 & 26644.81 & 12647.97 & 16729.04 & 0 & 10224.03 \\
\hline Aus \& NZ & 2334.40 & 137.09 & 165.78 & 1127.62 & 0 & 846.20 \\
\hline FSU & 9361.14 & 4242.61 & 468.79 & 1781.48 & 0 & 30998.49 \\
\hline China/CPA & 48792.00 & 55114.80 & 10329.00 & 16435.84 & 0 & 56000.00 \\
\hline MiddleEast & 73964.20 & 30837.77 & 24949.28 & 28512.02 & 0 & 1979.84 \\
\hline Africa & 10448.00 & 8499.65 & 1283.80 & 4124.17 & 0 & 1169.37 \\
\hline Latin America & 14575.58 & 64823.14 & 19352.34 & 37077.16 & 0 & 4438.26 \\
\hline S\&E Asia & 16923.29 & 30559.93 & 27621.39 & 20717.49 & 0 & 5098.87 \\
\hline EEU & 53814.89 & 12632.93 & 18539.89 & 14892.62 & 0 & 340.93 \\
\hline Korea & 9926.81 & 16050.49 & 2717.42 & 6757.19 & 0 & 3644.94 \\
\hline India & 1244.64 & 196.35 & 263.73 & 579.79 & 0 & 130.00 \\
\hline 14 & 66188.51 & 36347.39 & 32330.60 & 32066.87 & 0 & 8364.00 \\
\hline
\end{tabular}

Table 84 Example of regional technical improvements in food production in two time periods

\begin{tabular}{|l|l|l|l|l|l|l|l|l|l|l|}
\hline \multicolumn{2}{|l|}{ Annual percent technical improvement (start) } \\
\hline KJIMP(J,L,M) & UnMgd & $\begin{array}{l}\text { MgdFore } \\
\text { st }\end{array}$ & Pasture & AnimPrds & Biomass & FoodGr & CoarseGr & OilCrops \\
\hline period & region & 0 & 0.005 & 0 & 0 & 0.01 & 0.01 & 0.01 & 0.01 \\
\hline 3 & USA & 0 & 0.005 & 0 & 0 & 0.01 & 0.01 & 0.01 & 0.01 \\
\hline 3 & Canada & 0 & 0.005 & 0 & 0 & 0.01 & 0.01 & 0.01 & 0.01 \\
\hline 3 & $\begin{array}{l}\text { OECD90 } \\
\text { Europe }\end{array}$ & 0 & 0 & 0.005 & 0 & 0 & 0.01 & 0.01 & 0.01 & 0.01 \\
\hline 3 & Japan & Aus \& NZ & 0 & 0.005 & 0 & 0 & 0.01 & 0.01 & 0.01 & 0.01 \\
\hline 3
\end{tabular}




\begin{tabular}{|c|c|c|c|c|c|c|c|c|c|}
\hline 3 & FSU & 0 & 0.005 & 0 & 0 & 0.01 & 0.01 & 0.01 & 0.01 \\
\hline 3 & China/CPA & 0 & 0.005 & 0 & 0 & 0.01 & 0.01 & 0.01 & 0.01 \\
\hline 3 & MiddleEast & 0 & 0.005 & 0 & 0 & 0.01 & 0.01 & 0.01 & 0.01 \\
\hline 3 & Africa & 0 & 0.005 & 0 & 0 & 0.01 & 0.01 & 0.01 & 0.01 \\
\hline 3 & $\begin{array}{l}\text { Latin } \\
\text { America }\end{array}$ & 0 & 0.005 & 0 & 0 & 0.01 & 0.01 & 0.01 & 0.01 \\
\hline 3 & S\&E Asia & 0 & 0.005 & 0 & 0 & 0.01 & 0.01 & 0.01 & 0.01 \\
\hline 3 & EEU & 0 & 0.005 & 0 & 0 & 0.01 & 0.01 & 0.01 & 0.01 \\
\hline 3 & Korea & 0 & 0.005 & 0 & 0 & 0.01 & 0.01 & 0.01 & 0.01 \\
\hline 3 & India & 0 & 0.005 & 0 & 0 & 0.01 & 0.01 & 0.01 & 0.01 \\
\hline \multicolumn{10}{|c|}{ Annual percent technical improvement (for later period) } \\
\hline \multicolumn{10}{|c|}{ KJIMP(J,L,M) } \\
\hline period & region & UnMgd & $\begin{array}{l}\text { MgdFore } \\
\text { st }\end{array}$ & Pasture & AnimPrds & Biomass & FoodGr & CoarseGr & OilCrops \\
\hline 6 & USA & 0 & 0.005 & 0 & 0 & 0.005 & 0.005 & 0.005 & 0.005 \\
\hline 6 & Canada & 0 & 0.005 & 0 & 0 & 0.005 & 0.005 & 0.005 & 0.005 \\
\hline 6 & $\begin{array}{l}\text { OECD90 } \\
\text { Europe }\end{array}$ & 0 & 0.005 & 0 & 0 & 0.005 & 0.005 & 0.005 & 0.005 \\
\hline 6 & Japan & 0 & 0.005 & 0 & 0 & 0.005 & 0.005 & 0.005 & 0.005 \\
\hline 6 & Aus \& NZ & 0 & 0.005 & 0 & 0 & 0.005 & 0.005 & 0.005 & 0.005 \\
\hline 6 & FSU & 0 & 0.005 & 0 & 0 & 0.005 & 0.005 & 0.005 & 0.005 \\
\hline 6 & China/CPA & 0 & 0.005 & 0 & 0 & 0.005 & 0.005 & 0.005 & 0.005 \\
\hline 6 & MiddleEast & 0 & 0.005 & 0 & 0 & 0.005 & 0.005 & 0.005 & 0.005 \\
\hline 6 & Africa & 0 & 0.005 & 0 & 0 & 0.005 & 0.005 & 0.005 & 0.005 \\
\hline 6 & $\begin{array}{l}\text { Latin } \\
\text { America }\end{array}$ & 0 & 0.005 & 0 & 0 & 0.005 & 0.005 & 0.005 & 0.005 \\
\hline 6 & S\&E Asia & 0 & 0.005 & 0 & 0 & 0.005 & 0.005 & 0.005 & 0.005 \\
\hline 6 & EEU & 0 & 0.005 & 0 & 0 & 0.005 & 0.005 & 0.005 & 0.005 \\
\hline 6 & Korea & 0 & 0.005 & 0 & 0 & 0.005 & 0.005 & 0.005 & 0.005 \\
\hline 6 & India & 0 & 0.005 & 0 & 0 & 0.005 & 0.005 & 0.005 & 0.005 \\
\hline
\end{tabular}

Table 85 Example of regional food demand data

\begin{tabular}{|c|c|c|c|c|c|c|c|c|c|c|}
\hline \multicolumn{3}{|c|}{ Base year demand for food } & & \multirow{3}{*}{ MiscCrop } & \multirow{3}{*}{ ProcCrop } & \multirow{3}{*}{ BeefPrds } & \multirow{3}{*}{ PorkPrds } & \multirow{3}{*}{ Poultry } & \multirow{3}{*}{ AnimFats } & \multirow{3}{*}{ Fish } \\
\hline kcal1(L,J,2) & \multicolumn{3}{|c|}{ Units are kcal per day per person } & & & & & & & \\
\hline Region & FoodGr & CoarseGr & OilCrops & & & & & & & \\
\hline USA & 675.20 & 147.78 & 54.03 & 318.54 & 1339.64 & 554.00 & 128.21 & 212.01 & 97.66 & 29.09 \\
\hline Canada & 590.40 & 41.89 & 74.37 & 303.10 & 907.98 & 476.39 & 116.26 & 142.23 & 276.99 & 31.10 \\
\hline $\begin{array}{l}\text { OECD90 } \\
\text { Europe }\end{array}$ & 864.77 & 107.55 & 44.91 & 394.66 & 978.81 & 537.30 & 165.08 & 120.72 & 240.45 & 31.60 \\
\hline Japan & 971.52 & 167.08 & 105.05 & 198.46 & 669.89 & 131.27 & 64.45 & 120.01 & 43.94 & 92.04 \\
\hline Aus \& NZ & 553.80 & 63.93 & 53.32 & 290.33 & 971.04 & 711.39 & 74.06 & 125.39 & 171.14 & 24.80 \\
\hline FSU & 1103.11 & 120.13 & 20.43 & 279.18 & 761.96 & 533.89 & 104.18 & 107.94 & 280.48 & 33.21 \\
\hline China/CPA & 1651.55 & 249.13 & 57.93 & 207.84 & 221.77 & 20.15 & 89.10 & 37.30 & 23.21 & 16.71 \\
\hline MiddleEast & 1352.73 & 80.29 & 31.83 & 295.44 & 557.13 & 196.32 & 0.56 & 68.53 & 38.89 & 6.25 \\
\hline Africa & 476.48 & 585.77 & 46.21 & 345.37 & 350.50 & 93.97 & 4.13 & 24.26 & 17.64 & 11.45 \\
\hline $\begin{array}{l}\text { Latin } \\
\text { America }\end{array}$ & 635.40 & 349.16 & 31.70 & 296.10 & 755.59 & 217.66 & 29.36 & 73.21 & 53.64 & 12.69 \\
\hline
\end{tabular}




\begin{tabular}{|c|c|c|c|c|c|c|c|c|c|c|}
\hline S\&E Asia & 1462.46 & 116.31 & 168.16 & 157.54 & 332.66 & 73.52 & 15.18 & 25.04 & 19.87 & 19.22 \\
\hline EEU & 1034.51 & 217.80 & 7.83 & 282.91 & 747.39 & 415.97 & 197.72 & 102.13 & 309.43 & 9.09 \\
\hline Korea & 1461.07 & 191.62 & 137.38 & 208.22 & 600.41 & 66.00 & 55.13 & 56.58 & 35.32 & 63.65 \\
\hline India & 1159.75 & 278.30 & 73.34 & 228.05 & 359.65 & 111.41 & 2.16 & 6.55 & 23.19 & 5.14 \\
\hline & & & & & & & & & & \\
\hline & & & & & & & & & & \\
\hline \multicolumn{11}{|c|}{ End-year demand for food } \\
\hline kcal1(L,J,9) & \multicolumn{3}{|c|}{ Units are kcal per day per person } & & & & & & & \\
\hline Region & FoodGr & CoarseGr & OilCrops & MiscCrop & ProcCrop & BeefPrds & PorkPrds & Poultry & AnimFats & Fish \\
\hline USA & 675.20 & 147.78 & 54.03 & 318.54 & 1339.64 & 554.00 & 128.21 & 212.01 & 97.66 & 29.09 \\
\hline Canada & 590.40 & 41.89 & 74.37 & 303.10 & 907.98 & 476.39 & 116.26 & 142.23 & 276.99 & 31.10 \\
\hline $\begin{array}{l}\text { OECD90 } \\
\text { Europe }\end{array}$ & 864.77 & 107.55 & 44.91 & 394.66 & 978.81 & 537.30 & 165.08 & 120.72 & 240.45 & 31.60 \\
\hline Japan & 971.52 & 167.08 & 105.05 & 198.46 & 669.89 & 131.27 & 64.45 & 120.01 & 43.94 & 92.04 \\
\hline Aus \& NZ & 553.80 & 63.93 & 53.32 & 290.33 & 971.04 & 711.39 & 74.06 & 125.39 & 171.14 & 24.80 \\
\hline FSU & 1103.11 & 120.13 & 20.43 & 279.18 & 761.96 & 533.89 & 104.18 & 107.94 & 280.48 & 33.21 \\
\hline China/CPA & 1651.55 & 249.13 & 57.93 & 207.84 & 221.77 & 20.15 & 89.10 & 37.30 & 23.21 & 16.71 \\
\hline MiddleEast & 1352.73 & 80.29 & 31.83 & 295.44 & 557.13 & 196.32 & 0.56 & 68.53 & 38.89 & 6.25 \\
\hline Africa & 476.48 & 585.77 & 46.21 & 345.37 & 350.50 & 93.97 & 4.13 & 24.26 & 17.64 & 11.45 \\
\hline $\begin{array}{l}\text { Latin } \\
\text { America }\end{array}$ & 635.40 & 349.16 & 31.70 & 296.10 & 755.59 & 217.66 & 29.36 & 73.21 & 53.64 & 12.69 \\
\hline S\&E Asia & 1462.46 & 116.31 & 168.16 & 157.54 & 332.66 & 73.52 & 15.18 & 25.04 & 19.87 & 19.22 \\
\hline EEU & 1034.51 & 217.80 & 7.83 & 282.91 & 747.39 & 415.97 & 197.72 & 102.13 & 309.43 & 9.09 \\
\hline Korea & 1461.07 & 191.62 & 137.38 & 208.22 & 600.41 & 66.00 & 55.13 & 56.58 & 35.32 & 63.65 \\
\hline India & 1159.75 & 278.30 & 73.34 & 228.05 & 359.65 & 111.41 & 2.16 & 6.55 & 23.19 & 5.14 \\
\hline & & & & & & & & & & \\
\hline \multicolumn{11}{|c|}{ Base year demand - other uses of food products } \\
\hline kcal2(L,J) & \multicolumn{3}{|c|}{ Units are kcal per person per day } & & & & & & & \\
\hline Region & FoodGr & CoarseGr & OilCrops & MiscCrop & ProcCrop & BeefPrds & PorkPrds & Poultry & AnimFats & Fish \\
\hline USA & 6.1414 & 153.0042 & 2.9264 & 9.1475 & 219.4345 & 22.2849 & 0.9099 & 1.2802 & 133.3342 & 0.0445 \\
\hline Canada & 44.2317 & 47.9629 & 22.3945 & 0.7130 & 173.7042 & 50.6715 & 0.0000 & 0.0000 & 20.4128 & 2.5020 \\
\hline $\begin{array}{l}\text { OECD90 } \\
\text { Europe }\end{array}$ & 54.4028 & 67.0509 & 4.1315 & 20.2397 & 252.2770 & 16.7601 & 0.5859 & 0.2032 & 99.4131 & 1.5630 \\
\hline Japan & 0.0328 & 5.1103 & 0.2425 & 0.8880 & 145.9263 & 6.0484 & 0.0000 & 0.0000 & 79.8360 & 0.0458 \\
\hline Aus \& NZ & 179.2458 & 4.0296 & 0.2252 & 2.7263 & 177.5072 & 110.3789 & 0.0000 & 0.0000 & 139.9965 & 1.1543 \\
\hline FSU & 10.9669 & 207.9060 & 11.7750 & 9.4401 & 109.8181 & 8.0609 & 0.0000 & 0.0000 & 141.1541 & 0.0000 \\
\hline China/CPA & 2.0549 & 6.8088 & 8.6101 & 1.9255 & 30.0525 & 0.0143 & 0.0078 & 0.4006 & 6.8217 & 1.0940 \\
\hline MiddleEast & 19.4974 & 20.5331 & 8.4541 & 6.9333 & 81.1233 & 6.0253 & 0.0000 & 2.1661 & 17.1720 & 0.4904 \\
\hline Africa & 3.4359 & 3.1369 & 6.4576 & 1.8920 & 40.0746 & 0.9458 & 0.0020 & 0.0557 & 11.8259 & 0.1675 \\
\hline $\begin{array}{l}\text { Latin } \\
\text { America }\end{array}$ & 3.4860 & 13.9732 & 5.3332 & 15.7309 & 125.0216 & 1.1377 & 0.0359 & 0.0900 & 55.8780 & 0.0122 \\
\hline S\&E Asia & 1.6782 & 14.1605 & 7.5486 & 3.9164 & 40.5451 & 0.1872 & 0.0692 & 0.1579 & 5.4917 & 0.2849 \\
\hline EEU & 51.9228 & 75.1785 & 2.9829 & 16.3179 & 107.5803 & 10.2540 & 2.5745 & 4.3775 & 50.0716 & 0.0464 \\
\hline Korea & 0.2090 & 11.1464 & 0.0000 & 0.3538 & 111.1167 & 1.7294 & 1.7070 & 0.0000 & 35.3954 & 1.9608 \\
\hline India & 0.3235 & 0.6388 & 0.0314 & 0.0000 & 18.3877 & 0.0000 & 0.0000 & 0.0000 & 3.2986 & 0.1005 \\
\hline
\end{tabular}


Table 86 Although not directly used, an example of data collected for the AgLU module

\begin{tabular}{|l|l|}
\hline \multicolumn{2}{|l|}{ 1990 Land Use Carbon Emissions (TgC) } \\
\hline \multicolumn{2}{|l|}{ Based on numbers from: R. Houghton, ORNL } \\
\hline Region & \\
\hline USA & 7.45 \\
\hline Canada & 4.97 \\
\hline OECD90 Europe & -9.04 \\
\hline Japan & 1.96 \\
\hline Aus \& NZ & 1.96 \\
\hline FSU & 20.11 \\
\hline China/CPA & 48.69 \\
\hline MiddleEast & 16.27 \\
\hline Africa & 348.47 \\
\hline Latin America & 577.16 \\
\hline S\&E Asia & 766.07 \\
\hline EEU & -9.04 \\
\hline Korea & 0.00 \\
\hline India & 328.32 \\
\hline
\end{tabular}

Table 871990 Base Year CH4 and N2O emissions (in TgCH4 or TgN)

\begin{tabular}{|l|l|l|l|l|l|l|}
\hline Region & $\begin{array}{l}\mathrm{CH} 4 \\
\text { enteric }\end{array}$ & CH4 manure & CH4 other/rice & $\begin{array}{l}\text { N2O } \\
\text { soils }\end{array}$ & N2O managed manure & $\begin{array}{l}\text { N2O } \\
\text { empty }\end{array}$ \\
\hline USA & 6.1700 & 1.2600 & 0.4400 & 0.5524 & 0.0328 & 0 \\
\hline Canada & 0.7620 & 0.2190 & 0.0000 & 0.0738 & 0.0089 & 0 \\
\hline OECD90 Europe & 8.1841 & 2.4560 & 0.1342 & 0.4039 & 0.0654 & 0 \\
\hline Japan & 0.3460 & 0.1190 & 0.3780 & 0.0024 & 0.0031 & 0 \\
\hline Aus \& NZ & 4.5400 & 0.0927 & 0.2780 & 0.0534 & 0.0006 & 0 \\
\hline FSU & 8.7896 & 1.0420 & 0.1152 & 0.1577 & 0.0848 & 0 \\
\hline China/CPA & 5.3891 & 0.8208 & 17.1679 & 0.7557 & 0.1093 & 0 \\
\hline MiddleEast & 1.1060 & 0.1088 & 0.2374 & 0.0521 & 0.0007 & 0 \\
\hline Africa & 8.6117 & 0.5301 & 1.2381 & 0.1365 & 0.0086 & 0 \\
\hline Latin America & 17.4797 & 0.6455 & 1.0386 & 0.2898 & 0.0176 & 0 \\
\hline S\&E Asia & 5.0582 & 0.6026 & 15.8724 & 0.1801 & 0.0338 & 0 \\
\hline EEU & 2.3557 & 0.4654 & 0.0431 & 0.1037 & 0.0266 & 0 \\
\hline Korea & 0.1440 & 0.0400 & 0.4777 & 0.0196 & 0.0016 & 0 \\
\hline India & 7.5630 & 0.9050 & 14.4735 & 0.1990 & 0.0106 & 0 \\
\hline
\end{tabular}




\section{Appendix 7: List of equations}

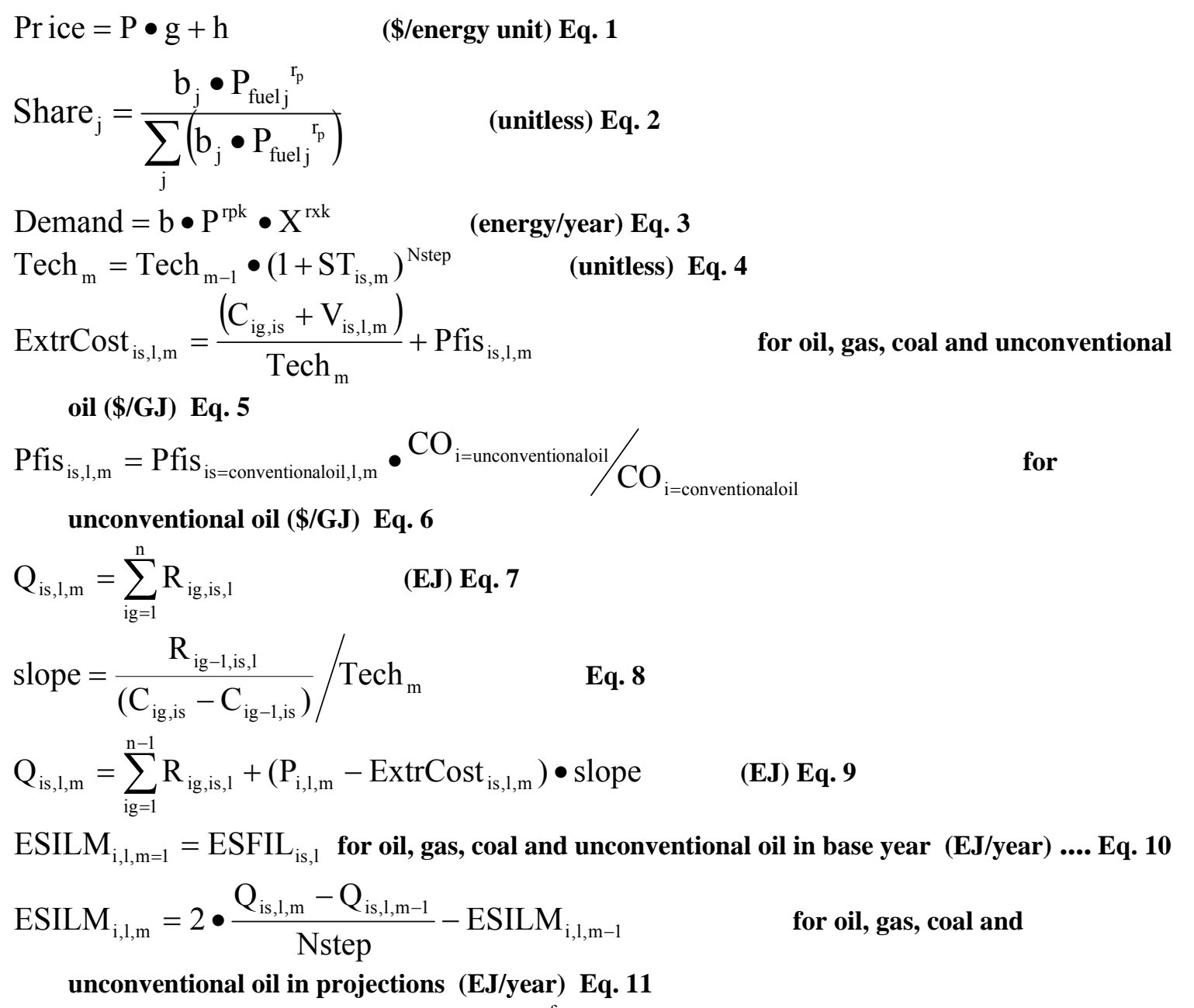

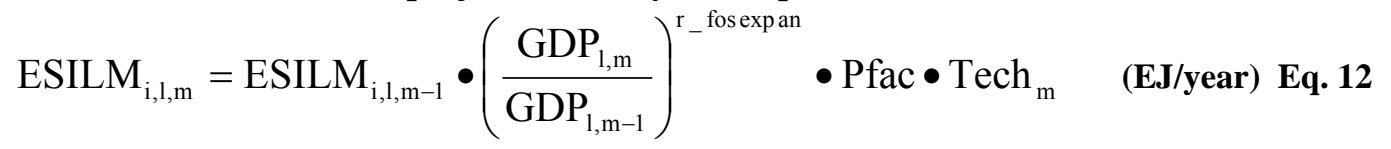

Pfac $=\left(\frac{P_{\mathrm{i}, 1, \mathrm{~m}}-\mathrm{V}_{\mathrm{is}, 1, \mathrm{~m}} / \text { Tech }_{\mathrm{m}}}{\mathrm{P}_{\mathrm{i}, 1, \mathrm{~m}-1}-\mathrm{V}_{\mathrm{is}, 1, \mathrm{~m}-1} \bullet \operatorname{Tech}_{\mathrm{m}-1} / \operatorname{Tech}_{\mathrm{m}}}\right)^{\mathrm{r}_{\mathrm{i}, \mathrm{l}}} \quad$ (unitless) Eq. 13

$\mathrm{FLR}_{1, \mathrm{~m}}=\mathrm{Flr}_{1} \frac{\left.(1-(\mathrm{m}-1))^{*} \mathrm{~N} s t e \mathrm{p}\right)}{\mathrm{Fl}_{3}} \bullet \mathrm{Flr}_{2} \frac{(\mathrm{m}-1)^{*} \mathrm{~N} \text { step }}{\mathrm{Fl}_{\mathrm{r}_{3}}} \quad$ (unitless) Eq. 14

ESILM $_{\mathrm{i}=\text { gas, }, \mathrm{m}, \mathrm{m}}=\mathrm{ESILM}_{\mathrm{i}=\mathrm{gas}, 1, \mathrm{~m}} \bullet\left(1-\mathrm{FLR}_{1, \mathrm{~m}}\right) \quad$ (EJ/year) Eq. 15

$\mathrm{Q}_{\mathrm{is}, 1, \mathrm{~m}}=\mathrm{Q}_{\mathrm{is}, 1, \mathrm{~m}-1}+\mathrm{Nstep}_{\bullet} \frac{\text { ESILM }_{\mathrm{i}, 1, \mathrm{~m}}+\text { ESILM }_{\mathrm{i}, 1, \mathrm{~m}-1}}{2} \quad$ (EJ/year) Eq. 16

$\mathrm{Q}_{\mathrm{is}=\mathrm{nuclear}, 1, \mathrm{~m}}=\mathrm{Q}_{\mathrm{is}, 1, \mathrm{~m}-1}+$ Nstep $\bullet \mathrm{ESU}_{\mathrm{ui}, 1, \mathrm{~m}-1} \quad$ (EJ/year) Eq. 17 


$$
\begin{aligned}
& \mathrm{Q}=\sum_{\mathrm{l}=1}^{\mathrm{nreg}} \mathrm{Q}_{\mathrm{is}, 1, \mathrm{~m}} \\
& \mathrm{~W}=\sum_{\mathrm{ig}=1}^{\mathrm{n}}\left(\sum_{\mathrm{l}=1}^{\text {nreg }} \mathrm{R}_{\mathrm{ig}, \mathrm{is}, \mathrm{l}}\right)
\end{aligned}
$$

(EJ/year) Eq. 19

Extr $\cos \mathrm{t}_{\mathrm{is}=\text { uranium }, 1, \mathrm{~m}}=\frac{(\mathrm{R}-\mathrm{Q})}{\mathrm{W}} \bullet \mathrm{C}_{\mathrm{ig}, \mathrm{is}}+\left(1-\frac{(\mathrm{R}-\mathrm{Q})}{\mathrm{W}}\right) \bullet \mathrm{C}_{\mathrm{ig}-1, \mathrm{is}} \quad$ (\$/GJ) Eq. 20

$\mathrm{P}_{\mathrm{i}=\text { uranium }, 1, \mathrm{~m}}=\frac{\mathrm{C}_{\mathrm{ig}, \mathrm{is}}+\mathrm{V}_{\mathrm{is}, 1, \mathrm{~m}}}{\text { Tech }_{\mathrm{m}}} \quad$ (\$/GJ) Eq. 21

ESILM $_{\mathrm{i}, 1, \mathrm{~m}}=\mathrm{BIO}_{1, \mathrm{~m}=1990} \bullet\left(\frac{\mathrm{GDP}_{1, \mathrm{~m}}}{\mathrm{GDP}_{1, \mathrm{~m}=1990}}\right)^{\text {rysht }} \quad$ (EJ/year) Eq. 22

ESILM $_{\mathrm{i}=\mathrm{hydro}, 1, \mathrm{~m}}=\mathrm{HydrO}_{3} \bullet \frac{\mathrm{e}^{\mathrm{Hydro}_{1}+\mathrm{Hydro}_{2} \bullet \mathrm{m} \bullet \mathrm{Nstep}}}{1+\mathrm{e}^{\mathrm{Hydro}+\mathrm{Hydro}_{2} \bullet \mathrm{m} \bullet \mathrm{Nstep}}} \quad$ (EJ/year) Eq. 23

$\mathrm{P}_{\mathrm{i}, 1, \mathrm{~m}}=\left(\mathrm{P}_{\mathrm{i}, 1, \mathrm{~m}}+\mathrm{Tr}_{\mathrm{i}}\right) \bullet \mathrm{Pfi}_{\mathrm{i}, 1, \mathrm{~m}} \quad$ (\$/GJ) Eq. 24

$\mathrm{Pj}_{\mathrm{j}, 1, \mathrm{~m}}=\mathrm{P}_{\mathrm{i}, 1, \mathrm{~m}} \bullet \mathrm{gij}_{\mathrm{i}}+\mathrm{hij}_{\mathrm{i}} \quad$ for oil, gas, coal, and biomass/waste (\$/GJ) Eq. 25

$\mathrm{hc}_{\mathrm{j}, \mathrm{i}}=\mathrm{HCILT}_{1} \frac{(1-(\mathrm{m}-1) \bullet \mathrm{Nstep})}{\mathrm{HCIL}_{3}} \bullet \mathrm{HCLT}_{2}^{\frac{(\mathrm{m}-1) \bullet \text { Nstep }}{\mathrm{HCLT}_{3}}}$

(\$/GJ) Eq. 26

$\mathrm{PC}_{\mathrm{j}, \mathrm{i}, 1, \mathrm{~m}}=\left(\mathrm{P}_{\mathrm{i}, \mathrm{l}, \mathrm{m}}+\right.$ syn costs $) \bullet \mathrm{gc}_{\mathrm{j}, \mathrm{i}}+\mathrm{hc}_{\mathrm{j}, \mathrm{i}}$ synliquid from coal, gas, or biomass; syngas from coal or biomass (\$/GJ) Eq. 27

SeqFractMax $=\frac{\mathrm{CO}_{\mathrm{i}=\text { coal }}-\mathrm{CO}_{\mathrm{i}=\mathrm{oil}}}{\mathrm{CO}_{\mathrm{i}=\text { coal }}} \quad$ (fraction) Eq. 28

Cpenalty $_{\mathrm{j}}=\frac{\left(\mathrm{hu}_{\mathrm{ui}, \mathrm{l}, \mathrm{m}, \mathrm{scrubbed}}-\mathrm{hu}_{\mathrm{ui}, 1, \mathrm{~m}, \text { non-scrubbed }}\right)}{\mathrm{gu}_{\mathrm{ui}, 1, \mathrm{~m}}} \bullet \mathrm{gc}_{\mathrm{j}, \mathrm{i}} \bullet \frac{1}{\mathrm{CO}_{\mathrm{i}=\text { coal }}} \quad$ (\$/ton C) Eq. 29

$\mathrm{Cst}_{\text {disp }}=\operatorname{Pf0}_{\text {ui, }, \mathrm{m}, \mathrm{m}} \bullet\left(\right.$ Carbdisp $_{1, \mathrm{~m}} \bullet$ SeqFractMax + Cpenalty $\left._{\mathrm{j}}\right) \quad$ (\$/GJ) Eq. 30

$\mathrm{C}_{\text {seq }}=\mathrm{Cst}_{\mathrm{disp}}+\mathrm{Pfu}_{\mathrm{ui}, 1, \mathrm{~m}} \bullet(1-$ SeqFractMax $)+0.0001 \quad$ (\$/GJ) Eq. 31

$\mathrm{S}_{\mathrm{no}-\mathrm{scrub}}=\frac{\mathrm{Pfu}_{\mathrm{ui}, 1, \mathrm{~m}}^{-4}}{\mathrm{Pfu}_{\mathrm{ui}, 1, \mathrm{~m}}^{-4}+\mathrm{C}_{\mathrm{seq}}^{-4}} \quad$ (unitless) Eq. 32

$\mathrm{S}_{\mathrm{scrub}}=\frac{\mathrm{C}_{\mathrm{seq}}^{-4}}{\mathrm{Pfu}_{\mathrm{ui}, 1, \mathrm{~m}}^{-4}+\mathrm{C}_{\mathrm{seq}}^{-4}} \quad$ (unitless) Eq. 33

hc $_{\mathrm{j}, \mathrm{i}=\mathrm{coal}+\text { scrubbed }}=\mathrm{hc}_{\mathrm{j}, \mathrm{i}}+\mathrm{S}_{\mathrm{scrub}} \bullet \mathrm{Cst}_{\mathrm{disp}} \quad$ (\$/GJ) Eq. 34 
SynShare $_{\mathrm{j}, \mathrm{i}, \mathrm{l}, \mathrm{m}}=\frac{\left(\frac{\mathrm{PC}_{\mathrm{j}, \mathrm{i}, \mathrm{l}, \mathrm{m}}}{\mathrm{Pj}_{\mathrm{j}, \mathrm{l}, \mathrm{m}-\text { for-oil,or,gas }}+\mathrm{Pfu}_{\mathrm{ui}, \mathrm{l}, \mathrm{m}}}\right)^{R \mathrm{II}_{\mathrm{ji}}}}{\sum_{\mathrm{ns}}\left(\frac{\mathrm{PC}_{\mathrm{j}, \mathrm{i}, \mathrm{l}, \mathrm{m}}}{\mathrm{Pj}_{\mathrm{j}, \mathrm{l}, \mathrm{m}-\text { for-oil,or,gas }}+\mathrm{Pfu}_{\mathrm{ui}, \mathrm{l}, \mathrm{m}}}\right)^{R \mathrm{I}_{\mathrm{ji}}}}$

for each of the technologies

(unitless) Eq. 35

$\mathrm{Pj}_{\mathrm{j}=\text { liquids-or-gas, }, \mathrm{m}}=\sum_{\mathrm{ns}}$ SynShare $_{\mathrm{j}, \mathrm{i}, \mathrm{l}, \mathrm{m}} \bullet \mathrm{PC}_{\mathrm{j}, \mathrm{i}, \mathrm{l}, \mathrm{m}}+\operatorname{SynShare}_{\mathrm{j}, \mathrm{i}, \mathrm{l}, \mathrm{m}} \bullet\left(\mathrm{Pj}_{\mathrm{j}=\text { liquids-or-gas, }, \mathrm{m}}+\mathrm{Pfj}_{\mathrm{j}, \mathrm{k}, \mathrm{l}, \mathrm{m}}\right)$

(\$/GJ) Eq. 36

$\operatorname{Pssh}_{\text {ssh }}=\left(\mathrm{P}_{\mathrm{i}, 1, \mathrm{~m}}+\mathrm{Pfu}_{\mathrm{ui}, 1, \mathrm{~m}}\right) \bullet \mathrm{gh}_{\mathrm{hi}, 1, \mathrm{~m}}+\mathrm{hh}_{\mathrm{hi}, 1, \mathrm{~m}} \quad$ (\$/GJ) Eq. 37

$\operatorname{Pssh}_{\mathrm{ssh}}=\left(\mathrm{P}_{\mathrm{i}, \mathrm{l}, \mathrm{m}}+\mathrm{Pfu}_{\mathrm{ui}, \mathrm{l}, \mathrm{m}} \bullet\left(1-\operatorname{RemFrac}_{\mathrm{i}, \mathrm{l}}\right)+\mathrm{PfO}_{\mathrm{ui}, \mathrm{l}, \mathrm{m}} \bullet \operatorname{Carbdisp}_{\mathrm{lm}}\right) \bullet \mathrm{gh}_{\mathrm{hi}, \mathrm{l}, \mathrm{m}}+\mathrm{hh}_{\mathrm{hi}, 1, \mathrm{~m}} \ldots$

(\$/GJ) Eq. 38

$\operatorname{Ssh}_{\mathrm{hi}, 1}=\frac{\operatorname{bssh}_{\mathrm{hi}, 1, \mathrm{~m}} \bullet \operatorname{Pssh}_{\mathrm{ssh}^{\text {ruiss }}}}{\sum_{\mathrm{nc}}\left(\mathrm{bssh}_{\mathrm{hi}, 1, \mathrm{~m}} \bullet \operatorname{Pssh}_{\mathrm{ssh}}^{\text {ruiss }}\right)}$

(unitless) Eq. 39

$\mathrm{PH}_{\mathrm{hi}, 1, \mathrm{~m}}=\sum_{\mathrm{nc}}\left(\mathrm{Ssh}_{\mathrm{hi}, 1} \bullet \mathrm{Pssh}_{\mathrm{ssh}}\right) \quad$ generated from oil, gas, or solids (\$/GJ) Eq. 40

$\mathrm{PH}_{\mathrm{hi}, 1, \mathrm{~m}}=\mathrm{P}_{\mathrm{i}, 1, \mathrm{~m}} \bullet \mathrm{gh}_{\mathrm{hi}, 1, \mathrm{~m}}+\mathrm{hh}_{\mathrm{hi}, 1, \mathrm{~m}} \quad$ generated from biomass (\$/GJ) Eq. 41

$\mathrm{Pj}_{\mathrm{j}=\text { hydrogen }, 1, \mathrm{~m}}=\sum_{\text {nhprices }} \mathrm{Sh}_{\mathrm{hi}, 1} \bullet \mathrm{PH}_{\mathrm{hi}, 1, \mathrm{~m}} \quad$ (\$/GJ) Eq. 42

$\mathrm{Sh}_{\mathrm{hi}, \mathrm{l}}=\frac{\mathrm{bsh}_{\mathrm{hi}, \mathrm{l}, \mathrm{m}} \bullet \mathrm{PH}_{\mathrm{hi}, \mathrm{l}, \mathrm{m}}{ }^{\text {rhi }}}{\sum_{\text {nhprices }}\left(\mathrm{bsh}_{\mathrm{hi}, 1, \mathrm{~m}} \bullet \mathrm{PH}_{\mathrm{hi}, \mathrm{l}, \mathrm{m}}{ }^{\text {rhi }}\right)} \quad$ (unitless) Eq. 43

$\mathrm{Pssu}_{\mathrm{ssu}}=\left(\mathrm{P}_{\mathrm{i}, 1, \mathrm{~m}} \bullet \mathrm{pa}_{\mathrm{ui}, \mathrm{l}}+\mathrm{Pfu}_{\mathrm{ui}, 1, \mathrm{~m}}\right) \bullet \mathrm{gu}_{\mathrm{ui}, 1, \mathrm{~m}}+\mathrm{hu}_{\mathrm{ui}, \mathrm{l}, \mathrm{m}} \quad$ from oil, gas, and solids (\$/GJ) Eq. 44

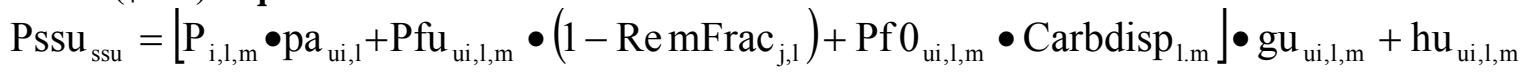

$\mathrm{Pssu}_{\mathrm{ssu}}=\left(\mathrm{P}_{\mathrm{i}, 1, \mathrm{~m}}+\mathrm{Pfu}_{\mathrm{ui}, 1, \mathrm{~m}}\right) \bullet \mathrm{pa}_{\mathrm{ui}, 1} \bullet \mathrm{gu}_{\mathrm{ui}, 1, \mathrm{~m}}+\mathrm{hu}_{\mathrm{ui}, 1, \mathrm{~m}} \quad \begin{aligned} & \text { from oil, gas, or solids (\$/G } \\ & \text { for biomass (\$/GJ) Eq. } 46\end{aligned}$

$\mathrm{PU}_{\text {ui }, 1, \mathrm{~m}}=\sum_{\mathrm{nc}} \mathrm{Ssu}_{\text {ui }, 1} \bullet \mathrm{Pssu}_{\text {ssu }} \quad$ (\$/GJ) Eq. 47

$\mathrm{Ssu}_{\mathrm{ui}, \mathrm{l}}=\frac{\mathrm{bssu}_{\mathrm{ui}, 1, \mathrm{~m}} \bullet \mathrm{Pssu}_{\mathrm{uus}^{\text {ruiss }}}}{\sum_{\mathrm{nc}}\left(\mathrm{bssu}_{\mathrm{ui}, 1, \mathrm{~m}} \bullet \mathrm{Pssu}_{\text {uus }}^{\text {ruiss }}\right)} \quad$ (unitless) Eq. 48

$\mathrm{PU}_{\mathrm{ui}, \mathrm{l}, \mathrm{m}}=\left(\mathrm{P}_{\mathrm{i}=\mathrm{uranium}, \mathrm{l}, \mathrm{m}}+\mathrm{Pfu}_{\mathrm{ui}, \mathrm{l}, \mathrm{m}}\right) \bullet \mathrm{gu}_{\mathrm{ui}, \mathrm{l}, \mathrm{m}}+\mathrm{hu}_{\mathrm{ui}, \mathrm{l}, \mathrm{m}} \quad$ from nuclear energy (\$/GJ) Eq. 49

$\mathrm{PU}_{\mathrm{ui}, 1, \mathrm{~m}}=\left(0+\mathrm{Pfu}_{\mathrm{ui}, 1, \mathrm{~m}}\right) \bullet \mathrm{gu}_{\mathrm{ui}, 1, \mathrm{~m}}+\mathrm{hu}_{\mathrm{ui}, 1, \mathrm{~m}} \quad$ from solar PV or wind (\$/GJ) Eq. 50 


$$
\mathrm{PU}_{\text {ui,l,m }}=h u_{\text {ui, }, \mathrm{l}, \mathrm{m}}+\mathrm{P}_{\text {wind }} \bullet \frac{\mathrm{P}_{\text {uus,wind }}^{-3}}{\mathrm{P}_{\text {uus, wind }}^{-3}+\mathrm{P}_{\text {uus,solar }}^{-3}}+\mathrm{P}_{\text {solar }} \bullet \frac{\mathrm{P}_{\text {uus,solar }}^{-3}}{\mathrm{P}_{\text {uus, wind }}^{-3}+\mathrm{P}_{\text {uus,solar }}^{-3}} \quad \text { from }
$$
wind-solar storage (\$/GJ) Eq. 51

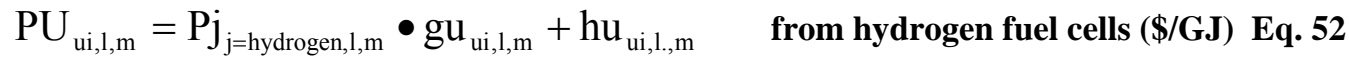

$\mathrm{Pj}_{\mathrm{j}=\text { electricity, }, \mathrm{l}, \mathrm{m}}=\sum_{\text {neprices }} \mathrm{SU}_{\text {ui,l }} \bullet \mathrm{PU}_{\text {ui, }, \mathrm{m}, \mathrm{m}} \quad$ (\$/GJ) Eq. 53

$\mathrm{SU}_{\text {ui }, 1}=\frac{\mathrm{bsu}_{\text {ui,l,m }} \bullet \mathrm{PU}_{\text {ui,l,m }}^{\text {rui }}}{\sum_{\text {neprices }}\left(\mathrm{bsu}_{\mathrm{ui}, 1, \mathrm{~m}} \bullet \mathrm{PU}_{\text {ui, }, \mathrm{m}, \mathrm{rui}}\right)} \quad$ (unitless) Eq. 54

$\mathrm{Pjk}_{\mathrm{j}, \mathrm{k}, 1, \mathrm{~m}}=\left(\mathrm{Pj}_{\mathrm{j}, 1, \mathrm{~m}} \bullet \mathrm{gjk}_{\mathrm{j}, \mathrm{k}}+\mathrm{hjk}_{\mathrm{j}, \mathrm{k}}\right) \quad$ (\$/energy service) $\mathbf{E q .} 55$

$\mathrm{Pj}_{\mathrm{j}=\text { coal }, 1, \mathrm{~m}}=\mathrm{Pj}_{\mathrm{j}=\text { coal }, 1, \mathrm{~m}}+\mathrm{Pfj}_{\mathrm{j}, \mathrm{k}, 1, \mathrm{~m}} \quad$ (\$/GJ) Eq. 56

$\mathbf{P j}_{\mathrm{j}=\text { electricity,l,m }}=\mathrm{Pj}_{\mathrm{j}=\text { electicity, }, \mathrm{l}, \mathrm{m}}+\mathrm{PUTD}_{\mathrm{k}, \mathrm{m}} \quad$ (\$/GJ) Eq. $\mathbf{5 7}$

$\mathrm{Pj}_{\mathrm{j}=\text { hydrogen, }, \mathrm{m}, \mathrm{m}}=\mathrm{Pj}_{\mathrm{j}=\text { hydrogen, }, \mathrm{l}, \mathrm{m}}+\mathrm{PH} 2 \mathrm{TD}_{\mathrm{k}, \mathrm{m}} \quad$ (\$/GJ) Eq. 58

$\mathrm{Pk}_{\mathrm{k}, 1, \mathrm{~m}}=\sum_{\mathrm{j}}\left(\mathrm{SPj}_{\mathrm{j}, \mathrm{k}, \mathrm{l}} \bullet \mathrm{Pjk}_{\mathrm{j}, \mathrm{k}, 1, \mathrm{~m}}\right) \quad$ (\$/energy service) Eq. 59

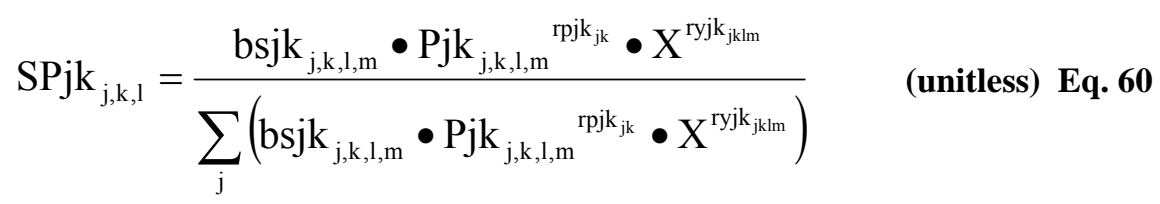

$\mathrm{PS}_{\text {ratio }}=\frac{\sum_{\mathrm{k}} \mathrm{bsk}_{\mathrm{k}, 1} \mathrm{Pk}_{\mathrm{k}, \mathrm{l}, \mathrm{m}}}{\sum_{\mathrm{k}} \mathrm{bsk}_{\mathrm{k}, 1, \mathrm{~m}-1} \mathrm{Pk}_{\mathrm{k}, 1, \mathrm{~m}-1}} \quad$ (unitless ratio) Eq. 61

GDPindex $_{1, \mathrm{~m}}=$ GDPindex $_{1, \mathrm{~m}-1} \bullet\left(1+\operatorname{Pr}_{1, \mathrm{~m}}\right)^{\text {Nstep }} \bullet \operatorname{LBFindex}_{1, \mathrm{~m}} \quad$ (unitless) Eq. 62

GDPindex $_{1, \mathrm{~m}}=$ GDPindex $_{1, \mathrm{~m}} \bullet \mathrm{PS}_{\mathrm{ratio}}{ }_{\mathrm{rGDP}}{ }_{\mathrm{adj}} \quad$ (unitless) Eq. 63

$\mathrm{Fk}_{\mathrm{k}=\text { transportation-or-buildings,1,m }}=\mathrm{bsk}_{\mathrm{k}, 1} \bullet\left(\frac{\mathrm{Pk}_{\mathrm{k}, 1, \mathrm{~m}}}{\mathrm{Pk}_{\mathrm{k}, 1, \mathrm{~m}=2}}\right)^{\mathrm{rpk}_{\mathrm{k}, \mathrm{l}}} \bullet \mathrm{X}^{\mathrm{ryk}_{\mathrm{k}, \mathrm{l}, \mathrm{m}}} \bullet \mathrm{Pop}_{\text {index }} \quad$ (EJ/year) Eq. 64

$\mathrm{Fk}_{\mathrm{k}=\text { industry, }, \mathrm{m}, \mathrm{m}}=\mathrm{bsk}_{\mathrm{k}, 1} \bullet\left(\frac{\mathrm{Pk}_{\mathrm{k}, 1, \mathrm{~m}}}{\mathrm{Pk}_{\mathrm{k}, 1, \mathrm{~m}=2}}\right)^{\mathrm{rpk}_{\mathrm{k}, \mathrm{l}}} \bullet \mathrm{Y}^{\mathrm{ryk} \mathrm{k}_{\mathrm{k}, \mathrm{m}}} \quad$ (EJ/year) Eq. 65

$\mathrm{rpk}_{\mathrm{k}, \mathrm{l}}=\mathrm{Rpk}_{\mathrm{k}} \bullet \frac{\mathrm{Pk}_{\mathrm{k}, 1, \mathrm{~m}}}{\mathrm{Pfk}_{\mathrm{k}, 1, \mathrm{~m}}} \quad$ (unitless) Eq. 66

$\mathrm{Fjk}_{\mathrm{j}, \mathrm{k}, 1, \mathrm{~m}}=\mathrm{gjk}_{\mathrm{j}, \mathrm{k}} \bullet \mathrm{Sjk}_{\mathrm{j}, \mathrm{k}, \mathrm{l}} \bullet \frac{\mathrm{Fk}_{\mathrm{k}, \mathrm{l}, \mathrm{m}}}{\mathrm{Tech}_{\mathrm{jk}}} \quad$ (EJ/year) Eq. 67

$\operatorname{Tech}_{\mathrm{j}, \mathrm{k}, \mathrm{m}}=\operatorname{Tech}_{\mathrm{j}, \mathrm{k}, \mathrm{m}-1} *\left(1+\mathrm{T}_{\mathrm{k}, 1, \mathrm{~m}}\right)^{\mathrm{Nstep}} \quad$ (unitless) Eq. 68 


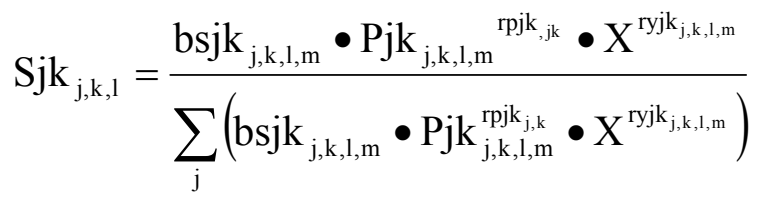

$$
\begin{aligned}
& \mathrm{Fj}_{\mathrm{j}, 1, \mathrm{~m}}=\sum_{\mathrm{k}} \mathrm{Fjk}_{\mathrm{j}, \mathrm{k}, \mathrm{l,m}} \quad \text { (EJ/year) Eq. } 70 \\
& \mathrm{Fj}_{\mathrm{j}=\text { hydrogen,l,m }}=\frac{\mathrm{Fj}_{\mathrm{j}=\text { hydrogen, }, \mathrm{m}, \mathrm{F}}+\mathrm{Fj}_{\mathrm{j}=\text { electricity, }, \mathrm{m}} \bullet \mathrm{e}_{\text {coeff }}}{1-\mathrm{e}_{\text {coeff }} * \mathrm{~h}_{\text {coeff }}} \quad \text { (EJ/year) Eq. 71 } \\
& \mathrm{Fj}_{\mathrm{j}=\text { electricty, }, \mathrm{m}, \mathrm{m}}=\frac{\mathrm{Fj}_{\mathrm{j}=\text { electricity }, 1, \mathrm{~m}}+\mathrm{Fj}_{\mathrm{j}=\text { hydrogen }, 1, \mathrm{~m}} \bullet \mathrm{h}_{\text {coeff }}}{1-\mathrm{e}_{\text {coeff }} * \mathrm{~h}_{\text {coeff }}} \quad \text { (EJ/year) Eq. } 72 \\
& \mathrm{~h}_{\text {coeff }}=\mathrm{Sh}_{\mathrm{hi}, 1} \bullet \mathrm{gh}_{\text {hi, }, 1, \mathrm{~m}} \quad \text { (unitless) Eq. } 73 \\
& \mathrm{e}_{\text {coeff }}=\mathrm{Su}_{\mathrm{ui}, 1} \bullet \mathrm{gu}_{\mathrm{ui}, 1, \mathrm{~m}} \quad \text { (unitless) Eq. } 74 \\
& \text { EDRIKL }_{\mathrm{i}, \mathrm{k}, \mathrm{l}}=\mathrm{Fjk}_{\mathrm{j}, \mathrm{k}, 1, \mathrm{~m}} \bullet \operatorname{gij}_{\mathrm{i}} \quad \mathrm{i}=\text { oil, gas, coal or biomass (EJ/year) Eq. } 75 \\
& \text { EDRIL }_{\mathrm{i}, 1, \mathrm{~m}}=\sum_{\mathrm{k}} \mathrm{EDRIKL}_{\mathrm{i}, \mathrm{k}, 1} \quad \mathbf{i}=\text { oil, gas, coal or biomass (EJ/year) Eq. } 76
\end{aligned}
$$$$
\text { SFuel }_{\mathrm{j}, \mathrm{i}, 1, \mathrm{~m}}=\sum_{\mathrm{k}} \text { EDRIKL }_{\mathrm{i}, \mathrm{k}, 1} \bullet \text { SynShare }_{\mathrm{j}, \mathrm{i}, 1, \mathrm{~m}} \quad \text { (EJ/year) Eq. } 77
$$

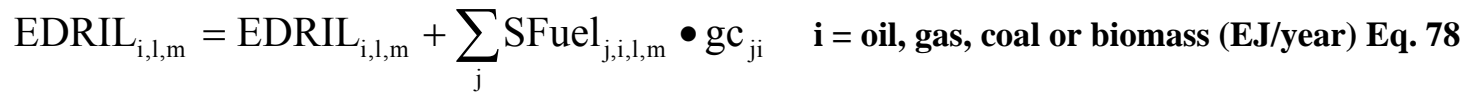$$
\mathrm{EDRIL}_{\mathrm{i}, 1, \mathrm{~m}}=\mathrm{EDRIL}_{\mathrm{i}, 1, \mathrm{~m}}+\mathrm{Fj}_{\mathrm{j}=\text { hydrogen, }, \mathrm{m}, \mathrm{m}} \bullet \mathrm{Sh}_{\mathrm{hii}, \mathrm{l}} \bullet \mathrm{gh}_{\mathrm{hi}, 1, \mathrm{~m}} \bullet \mathrm{gij}_{\mathrm{i}} \quad \mathbf{i}=\mathbf{o i l} \text {, gas, coal }
$$
or biomass (EJ/year) Eq. 79

EDRIL $_{\mathrm{i}, 1, \mathrm{~m}}=\mathrm{EDRIL}_{\mathrm{i}, 1, \mathrm{~m}}+\mathrm{Fj}_{\mathrm{j}=\text { electricity, }, \mathrm{m}, \mathrm{Su}} \bullet \mathrm{Su}_{\mathrm{ui}, 1} \bullet$ gui $_{\mathrm{ui}, 1, \mathrm{~m}} \bullet$ gij $_{\mathrm{i}} \quad$ i=oil, gas, coal or biomass (EJ/year) Eq. 80

$\mathrm{EDRI}_{\mathrm{i}, \mathrm{m}}=\sum_{1} \mathrm{EDRIL}_{\mathrm{i}, \mathrm{l}, \mathrm{m}} \quad$ for oil, gas, coal, and biomass (EJ/year) Eq. 81

ESRILM $_{\mathrm{i}, 1, \mathrm{~m}}=\mathrm{ESILM}_{\mathrm{i}, 1, \mathrm{~m}}+\sum_{\mathrm{i}}$ Sfuel $_{\mathrm{j}, \mathrm{i}, \mathrm{l}, \mathrm{m}} \quad$ for oil and gas (EJ/year) Eq. 82

$$
\begin{array}{ll}
\text { ESRI }_{i, m}=\sum_{1} \text { ESRILM }_{i, 1, m} & \text { oil, gas, coal, and biomass (EJ/year) Eq. } 83 \\
\text { MrkPRD }_{m k}=\text { ESRI }_{i, m} & \text { oil, gas, coal Eq. } 84
\end{array}
$$$$
\operatorname{MrkDEM}_{\mathrm{mk}}=\mathrm{EDRI}_{\mathrm{i}, \mathrm{m}} \quad \text { oil, gas, coal Eq. } 85
$$$$
\operatorname{MrkPRD}_{\mathrm{mk}=5}=\text { CemTot }_{\text {Eq. } 86}
$$$$
\text { MrkDEM }_{\mathrm{mk}=5}=\text { Emiss }_{1, \mathrm{~m}} \quad \text { Eq. } 87
$$$$
\operatorname{MrkPRD}_{\mathrm{mk}=6: 12}=\sum_{1=1}^{\mathrm{nr}} \operatorname{AgSup}_{\mathrm{i}, 1} \quad \text { Eq. } 88
$$ 
$\begin{array}{lc}\operatorname{MrkDEM}_{\mathrm{mk}=6: 12}=\sum_{\mathrm{l}=1}^{\mathrm{nr}} \operatorname{AgDem}_{\mathrm{i}, 1} & \text { Eq. 89 } \\ \text { ExDem }_{\mathrm{mk}}=\operatorname{MrkDEM}_{\mathrm{mk}}-\operatorname{MrkPRD}_{\mathrm{mk}} & \text { Eq. 90 } \\ \text { SynInput }_{\mathrm{i}, 1, \mathrm{~m}}=\sum_{\mathrm{j}} \text { SFuel }_{\mathrm{j}, \mathrm{i}, \mathrm{l}, \mathrm{m}} \bullet \mathrm{gc}_{\mathrm{ji}} & \text { (EJ/year) Eq. 91 }\end{array}$

$\mathrm{FLR}_{1, \mathrm{~m}}=\mathrm{Flr}_{1} \frac{(1-(\mathrm{m}-1) \bullet \mathrm{Nstep})}{\mathrm{Fl} l_{3}} \bullet \mathrm{Flr}_{2} \frac{(\mathrm{m}-1) \bullet \mathrm{Nstep}}{\mathrm{Fl} l_{3}} \quad$ (unitless) Eq. 92

Cemissions $_{\mathrm{i}=\text { gasflare, }}=\mathrm{CO}_{\mathrm{i}=\mathrm{gas}} \bullet \mathrm{SB}_{1, \mathrm{~m}} \bullet \frac{\mathrm{FLR}_{1, \mathrm{~m}}}{\left(1-\mathrm{FLR}_{1, \mathrm{~m}}\right)} \bullet \mathrm{ESILM}_{\mathrm{i}=\mathrm{gas}, \mathrm{l}, \mathrm{m}} \quad$ (MMTC) Eq. 93

$\mathrm{ESU}_{\mathrm{ui}, 1, \mathrm{~m}}=\mathrm{Su}_{\mathrm{ui}, 1} \bullet \mathrm{Ssu}_{\mathrm{ui}, 1} \bullet \mathrm{Fj}_{\mathrm{j}, 1, \mathrm{~m}} \quad$ (EJ/year) Eq. 94

$\mathrm{ESH}_{\mathrm{hi}, 1, \mathrm{~m}}=\mathrm{Sh}_{\mathrm{hi}, 1} \bullet \mathrm{Ssh}_{\mathrm{hi}, 1} \bullet \mathrm{Fj}_{\mathrm{j}, 1, \mathrm{~m}} \quad$ (EJ/year) Eq. 95

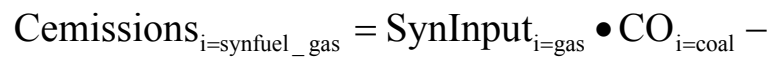

SFuel $_{\text {i=gas,j=liq, }, \text { m }} \bullet\left(1-\operatorname{SedFil}_{\mathrm{i}=\mathrm{oil}, 1}\right) \bullet \mathrm{CO}_{\mathrm{i}=\text { coal }}$

(MMTC) Eq. 96

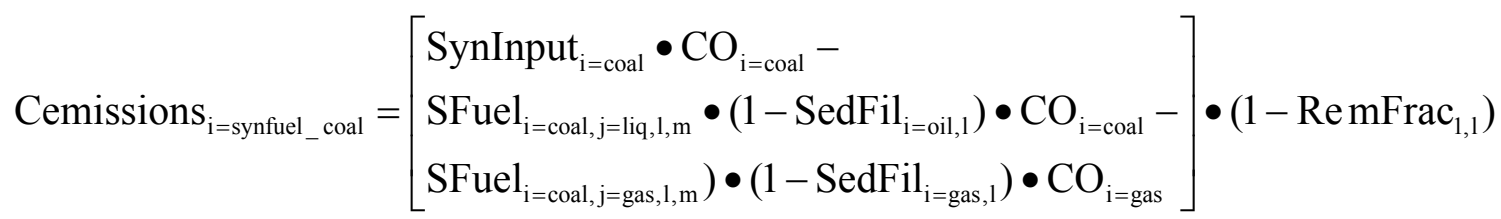
(MMTC) .

Cemissions $_{\mathrm{i}=\text { synfuel_b }}=\left(\right.$ SynInput $_{\mathrm{i}=\text { biomass }} \bullet \mathrm{CO}_{\mathrm{i}=\text { biomass }}-$

SFuel $_{\mathrm{i}=\text { biomass, } \mathrm{j}=\text { liquid }, 1, \mathrm{~m}} \bullet\left(1-\mathrm{SedFil}_{\mathrm{i}=\mathrm{oil}, 1}\right) \bullet \mathrm{CO}_{\mathrm{i}=\text { biomass }}-\quad$ (MMTC) Eq. 98

SFuel $\left.\left._{\mathrm{i}=\text { biomass }, \mathrm{j}=\text { gas }, 1, \mathrm{~m}}\right) \bullet\left(1-\mathrm{SedFil}_{\mathrm{i}=\text { gas }, 1}\right) \bullet \mathrm{CO}_{\mathrm{i}=\text { gas }}\right)$

Cemissions $_{1}=\mathrm{CO}_{\mathrm{i}} \bullet\left[\begin{array}{l}{\text { FFcons } \bullet\left(1-\operatorname{SedFil}_{\mathrm{i}, 1}\right)-}_{\operatorname{RemFrac}_{2,1} \bullet\left(\mathrm{ESU}_{\mathrm{ui}, 1, \mathrm{~m}} \bullet \mathrm{gu}_{\mathrm{ui}, 1, \mathrm{~m}} \bullet \mathrm{gij}_{\mathrm{i}}\right.}+ \\ \left.\mathrm{ESH}_{\mathrm{hi}, 1, \mathrm{~m}} \bullet \mathrm{gh}_{\mathrm{hi}, \mathrm{m}} \bullet \mathrm{gij}_{\mathrm{i}}\right)\end{array}\right]$

(MMTC) Eq. 99

FFcons $_{\mathrm{i}=\text { oil }, 1}=$ EDRIL $_{\mathrm{i}=o \mathrm{il}, 1}+\mathrm{ESIL}_{\mathrm{i}=\text { unconventionaloil }}$

FFcons $_{\mathrm{i}=\text { gas }, 1}=$ EDRIL $_{\mathrm{i}, 1}-$ SynInput $_{\mathrm{i}=\text { gas }, 1, \mathrm{~m}} \quad$ (EJ/year) Eq. 101

FFcons $_{\mathrm{i}=\text { coal }, 1}=$ EDRIL $_{\mathrm{i}, 1}-$ SynInput $_{\mathrm{i}=\text { coal }, 1, \mathrm{~m}} \quad$ (EJ/year) Eq. 102

FFcons $_{\mathrm{i}=\text { biomass, },}=$ EDRIL $_{\mathrm{i}, 1}-$ SynInput $_{\mathrm{i}=\text { biomass, }, \mathrm{m}, \mathrm{m}} \quad$ (EJ/year) Eq. 103

Cemissions $_{\mathrm{i}=\text { shaleoil }}=\mathrm{CO}_{\mathrm{i}} \bullet \mathrm{ESILM}_{\mathrm{i}, \mathrm{l}, \mathrm{m}} \bullet \mathrm{SHAL}_{1, \mathrm{~m}}+\mathrm{CO}_{\mathrm{i}} \bullet\left(1-\operatorname{SedFil}_{\mathrm{i}, 1}\right) \quad$ (MMTC) Eq. 104 $\mathrm{CO} 2_{\mathrm{k}}=\sum_{\mathrm{j}} \mathrm{CO}_{\mathrm{j}} \bullet \mathrm{Fjk}_{\mathrm{j}, \mathrm{k}, \mathrm{l}, \mathrm{m}} \bullet\left(1-\mathrm{SedFil}_{\mathrm{j}, 1}\right) \quad$ (MMTC) Eq. 105 $\mathrm{CO} 2_{\text {hydrogen }}=\sum_{\mathrm{j}} \mathrm{CO}_{\mathrm{j}} \bullet \mathrm{EDRIKL}_{\mathrm{j}, 1, \mathrm{~m}} \bullet\left(1-\mathrm{SedFil}_{\mathrm{j}, 1}\right)-\mathrm{C}_{\text {scrub }_{-} \text {hydrogen }} \quad$ (MMTC) Eq. 106 $\mathrm{CO} 2_{\text {electricty }}=\sum_{\mathrm{j}} \mathrm{CO}_{\mathrm{j}} \bullet \mathrm{EDRIKL}_{\mathrm{j}, 1, \mathrm{~m}} \bullet\left(1-\mathrm{SedFi1}_{\mathrm{j}, 1}\right)-\mathrm{C}_{\text {scrub_electricty }} \quad$ (MMTC) Eq. 107 


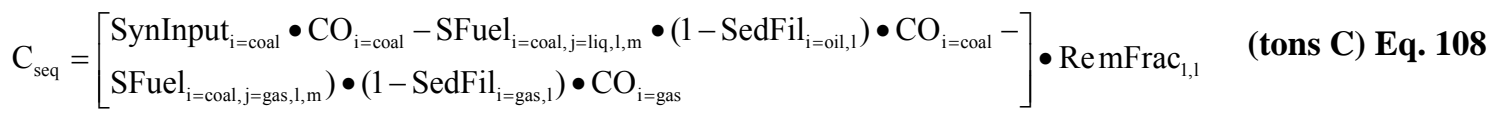

$\mathrm{C}_{\mathrm{scrub}}=\mathrm{CO}_{\mathrm{i}} \bullet \mathrm{ESU}_{\mathrm{ui}, 1, \mathrm{~m}} \bullet \mathrm{gu}_{\mathrm{ui}, 1, \mathrm{~m}} \bullet \mathrm{gij}_{\mathrm{i}} \bullet \mathrm{RemFrac}_{2,1} \quad$ (tons C) Eq. 109

$\mathrm{C}_{\text {scrub }}=\mathrm{CO}_{\mathrm{i}} \bullet \mathrm{ESH}_{\mathrm{hi}, 1, \mathrm{~m}} \bullet \mathrm{gh}_{\mathrm{hi}_{1,1, \mathrm{~m}}} \bullet \mathrm{gij}_{\mathrm{i}} \bullet \mathrm{Re} \mathrm{mFrac}_{2,1} \quad$ (tons C) Eq. 110

$\mathrm{Em}_{\mathrm{t}}=\mathrm{Em} \_$factor $\bullet \operatorname{Driver} \bullet\left(1-\operatorname{Control}\left(\mathrm{GDP}_{\mathrm{C}} \mathrm{Cap}_{\mathrm{t}}\right)\right) \bullet\left(1-\mathrm{USER}_{\mathrm{t}}\right) \bullet\left(1-\operatorname{MAC}\left(\mathrm{C}_{-} \text {Price }\right)_{\mathrm{t}}\right)$..

(variable units) Eq. 111

$\mathrm{EmLC}_{\mathrm{i}, 1, \mathrm{~m}}=\sum_{\mathrm{l}=1}^{\mathrm{nr}}\left(\right.$ CLdens $\left._{1, \mathrm{i}} \bullet \frac{\text { Landuse }_{\mathrm{i}, 1, \mathrm{~m}}-\text { Landuse }_{\mathrm{i}, 1, \mathrm{~m}-1}}{\text { Nstep }}\right) \quad$ (MMTC) Eq. 112

$\mathrm{EmSC}_{\mathrm{i}, \mathrm{m}}=\sum_{\mathrm{l}=1}^{\mathrm{nr}}\left[\sum_{\mathrm{m}=\mathrm{m}-2}^{\mathrm{m}}\left(\right.\right.$ CSdens $_{1, \mathrm{i}} \bullet$ PercDecay $\left.\left._{\mathrm{m}} \bullet \frac{\text { Landuse }_{\mathrm{m}}-\text { Landuse }_{\mathrm{m}-1}}{\text { Nstep }}\right)\right]$

(MMTC) Eq. 113

CemTot $=\sum_{\mathrm{i}=\text { oil,gas, coal }}^{4}$ Cemissions $_{\mathrm{i}} \quad$ from oil, gas, and oil (MMTC) Eq. 114

EmSulfur $_{\mathrm{t}}=\frac{\text { FuelUse }}{\text { EnergyContent }} \bullet$ SulfurContent $\bullet\left(1-\mathrm{f}_{\text {ash }}\right) \bullet\left(1-\mathrm{f}_{\text {control }}\right) \quad$ (TgS) Eq. 115

fcontrol is determined as follows fcontrol $=\frac{\mathrm{f}_{\text {max }}}{\left(1+\mathrm{e}^{\frac{-c\left(\mathrm{GDPpercap}_{\mathrm{t}} / \mathrm{GDPpercap}_{\text {midpo int }}\right)}{\tau}}\right)}$ Eq. 116

$\mathrm{P}_{\text {biofuelfromoil }}=\mathrm{P}_{\text {oil }}+$ OilTranCost $+\mathrm{P}_{\text {carbon }} \bullet$ OilCarb $\quad$ (\$/GJ) Eq. 117

$\mathrm{P}_{\text {biofuelfrombiomass }}=\frac{\mathrm{P}_{\text {biomass }}}{\text { EtoBio }}+$ BioTranCost $\quad$ (\$/GJ) Eq. 118

$\mathrm{P}_{\text {biomass }}=$ EtoBio $\bullet\left(\mathrm{P}_{\text {oil }}+\mathrm{P}_{\text {carbon }} \bullet\right.$ OilCarb + OilTranCost - BioTranCost $)$

$\left(\$ / \mathrm{m}^{3} \mathrm{C}\right)$ Eq. 119

$\mathrm{CDR}_{\mathrm{i}, 1, \mathrm{~m}}=\mathrm{A}_{\mathrm{i}, \mathrm{l}} \bullet\left(\frac{\mathrm{P}_{\mathrm{i}, 1, \mathrm{~m}}}{\mathrm{P}_{\mathrm{i}, 1, \mathrm{~m}=\text { baseyear }}}\right)^{\alpha_{\mathrm{jl}}} \bullet \mathrm{Y}_{\mathrm{i}, 1, \mathrm{~m}}^{\beta_{\mathrm{jl}}} \bullet \mathrm{N}_{1, \mathrm{~m}} \bullet \mathrm{C}_{\mathrm{i}, 1, \mathrm{~m}}$

(total calories

demanded per year) Eq. 120

$\mathrm{WDR}_{\mathrm{i}, 1, \mathrm{~m}}=\mathrm{A}_{\mathrm{i}, \mathrm{l}} \bullet\left(\frac{\mathrm{P}_{\mathrm{i}, 1, \mathrm{~m}}}{\mathrm{P}_{\mathrm{i}, 1, \mathrm{~m}=\text { baseyear }}}\right)^{\alpha_{\mathrm{jl}}} \bullet \mathrm{Y}_{\mathrm{i}, 1, \mathrm{~m}}^{\beta_{\mathrm{jl}}} \bullet \mathrm{N}_{1, \mathrm{~m}} \quad$ (total $\mathbf{m}^{3}$ wood

demanded per year) Eq. 121

$\pi r_{i, 1, m, p}=y_{i, 1, m, p} \bullet\left(P_{i, 1, m}-G_{i, 1, m}\right) \quad i=$ crops, biomass, pasture (annual \$/ha) Eq. 122

$\pi r_{i, 1, m, p}=\frac{r}{(1+r)^{45}-1} \bullet y_{i, 1, m, p} \bullet\left(\widetilde{P}_{i, 1, m}-G_{i, 1, m}\right) \quad i=$ forests (annual \$/ha) Eq. 123

$\mathrm{S}_{\mathrm{i}, 1, \mathrm{~m}}=\frac{\bar{\pi} \mathrm{r}_{\mathrm{i}, 1, \mathrm{~m}}^{1 / \lambda}}{\sum_{\mathrm{p}} \bar{\pi} \mathrm{r}_{\mathrm{i}, 1, \mathrm{~m}, \mathrm{p}}^{1 / \lambda}} \quad$ (unitless) Eq. 124

Landuse $_{\mathrm{i}, 1, \mathrm{~m}}=\mathrm{S}_{\mathrm{i}, 1, \mathrm{~m}} \bullet$ Totalland $_{1} \quad$ Eq. 125 


$$
\begin{aligned}
& \mathrm{P}_{\mathrm{i}=\text { animal }, 1, \mathrm{~m}}=\mathrm{P}_{\mathrm{i}=\text { crops }, 1, \mathrm{~m}} \bullet \text { FeedOut }+\mathrm{P}_{\mathrm{i}=\text { pasture }, \mathrm{l}, \mathrm{m}} \bullet \text { PastOut }+\mathrm{G}_{\mathrm{i}=\text { animal }, 1, \mathrm{~m}} \quad \text { (\$/cal) Eq. } 126 \\
& \hat{\pi} r_{i, 1, m}=\left[\sum_{p} \bar{\pi} r_{i, p, 1, m}^{1 / \lambda}\right]^{\lambda} \quad \text { (\$/cal or \$/m3) Eq. } 127 \\
& \hat{\pi} r_{i}=\hat{\pi} r \quad i=\text { crops, biomass, pasture, forest (\$/cal or \$/m3) Eq. } 128 \\
& \hat{y}_{i}=\frac{\hat{\pi}_{i}}{P_{i, l, m}-G_{i, l, m}} \quad i=\text { crops, biomass, pasture (\$/cal) Eq. } 129 \\
& \operatorname{Tech}_{\mathrm{i}, \mathrm{m}}=\operatorname{Tech}_{\mathrm{i}, \mathrm{m}-1}\left(1+\mathrm{S}_{\mathrm{i}, \mathrm{m}}\right)^{\mathrm{Nstep}} \quad \text { (unitless) Eq. } 130 \\
& \frac{\mathrm{s}_{\text {crops }}}{\mathrm{s}_{\text {crops }}+\mathrm{s}_{\text {biomass }}}=\frac{\bar{\pi} \mathrm{r}_{\text {crops }}^{1 / \lambda_{2}}}{\bar{\pi} \mathrm{r}_{\text {crops }}^{1 / \lambda_{2}}+\bar{\pi} \mathrm{r}_{\text {biomass }}^{1 / \lambda_{2}}} \quad \text { (unitless) Eq. 131 } \\
& \bar{\pi} \mathrm{r}_{\text {crops } / \text { biomass }}=\left[\bar{\pi} \mathrm{r}_{\text {crops }}^{1 / \lambda_{2}}+\bar{\pi} \mathrm{r}_{\text {biomass }}^{1 / \lambda_{2}}\right]^{\lambda_{2}} \quad \text { (\$/cal) Eq. } 132
\end{aligned}
$$$$
\frac{\mathrm{d} \Delta \mathrm{C}}{\mathrm{dt}}=\mathrm{E}+\mathrm{D}_{\mathrm{n}}-\mathrm{F}_{\text {ocean }}-\mathrm{F}_{\text {fert }} \quad \text { Eq. } 133
$$$$
\frac{\mathrm{d} \Delta \mathrm{C}}{\mathrm{dt}}=\frac{\mathrm{E}}{\beta}-\frac{\mathrm{C}}{\tau}
$$$$
\frac{\mathrm{dT}}{\mathrm{dt}} \propto \mathrm{S}-\mathrm{F}-\mathrm{H}
$$$$
\frac{\mathrm{dT}_{\mathrm{a}}}{\mathrm{dt}}=\frac{\mathrm{T}_{\mathrm{eq}}-\mathrm{Ta}}{\tau_{\mathrm{a}}}-\left(\frac{\tau_{\mathrm{m}}}{\tau_{\mathrm{a}}}\right) \bullet\left[\frac{\mathrm{dT}_{\mathrm{m}}}{\mathrm{dt}}+\left(\frac{\mathrm{h}_{\mathrm{d}}}{\mathrm{h}_{\mathrm{m}}}\right) \bullet \frac{\mathrm{d} \bar{\theta}_{\mathrm{d}}}{\mathrm{dt}}\right] \quad \text { Eq. } 136
$$$$
\frac{\mathrm{dz}}{\mathrm{dt}}=\frac{-\mathrm{z}+\left(\mathrm{z}_{0}-\mathrm{z}\right) \bullet \beta \bullet \Delta \mathrm{T}}{\tau} \quad \text { Eq. } 137
$$ 